\title{
POULTRY KEEPING
}

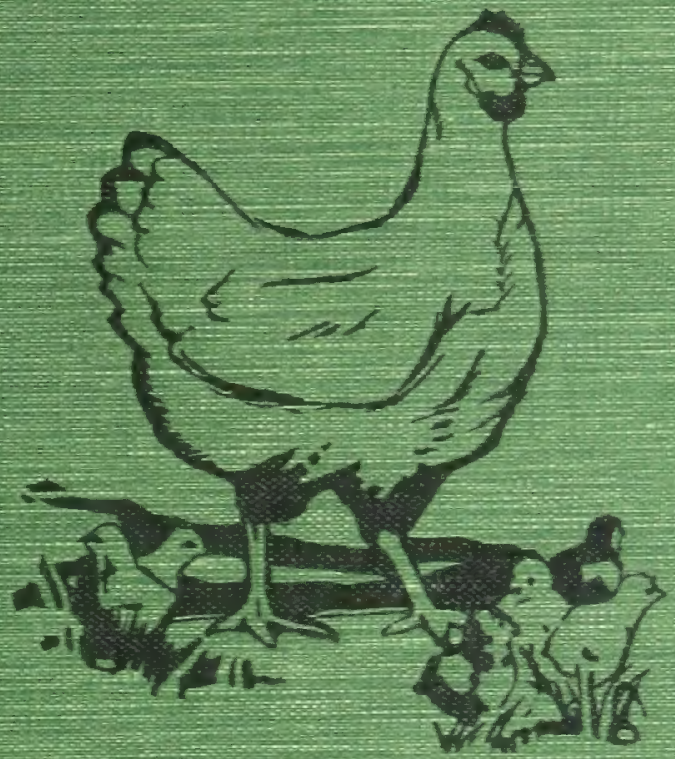

HARRY R.LEWIS 


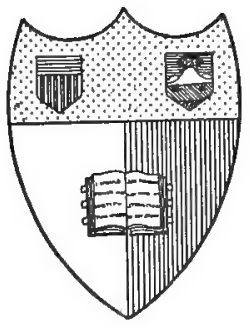

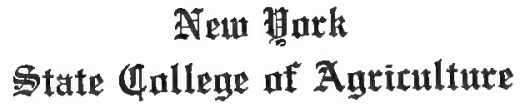

At Gுanell Hnituergity

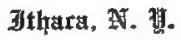

\section{Gilbraxy}


SF 487 Cornell University Library

Poultry keeping; an elementary treatise d

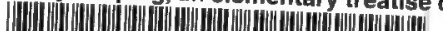

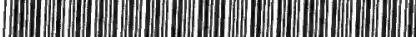

31924003040544 


\section{Cornell University Library}

The original of this book is in the Cornell University Library.

There are no known copyright restrictions in the United States on the use of the text. 


\section{POULTRY KEEPING}

AN ELEMENTARY TREATISE DEALING WITH THE SUC-

CESSFUL MANAGEMENT OF POULTRY 




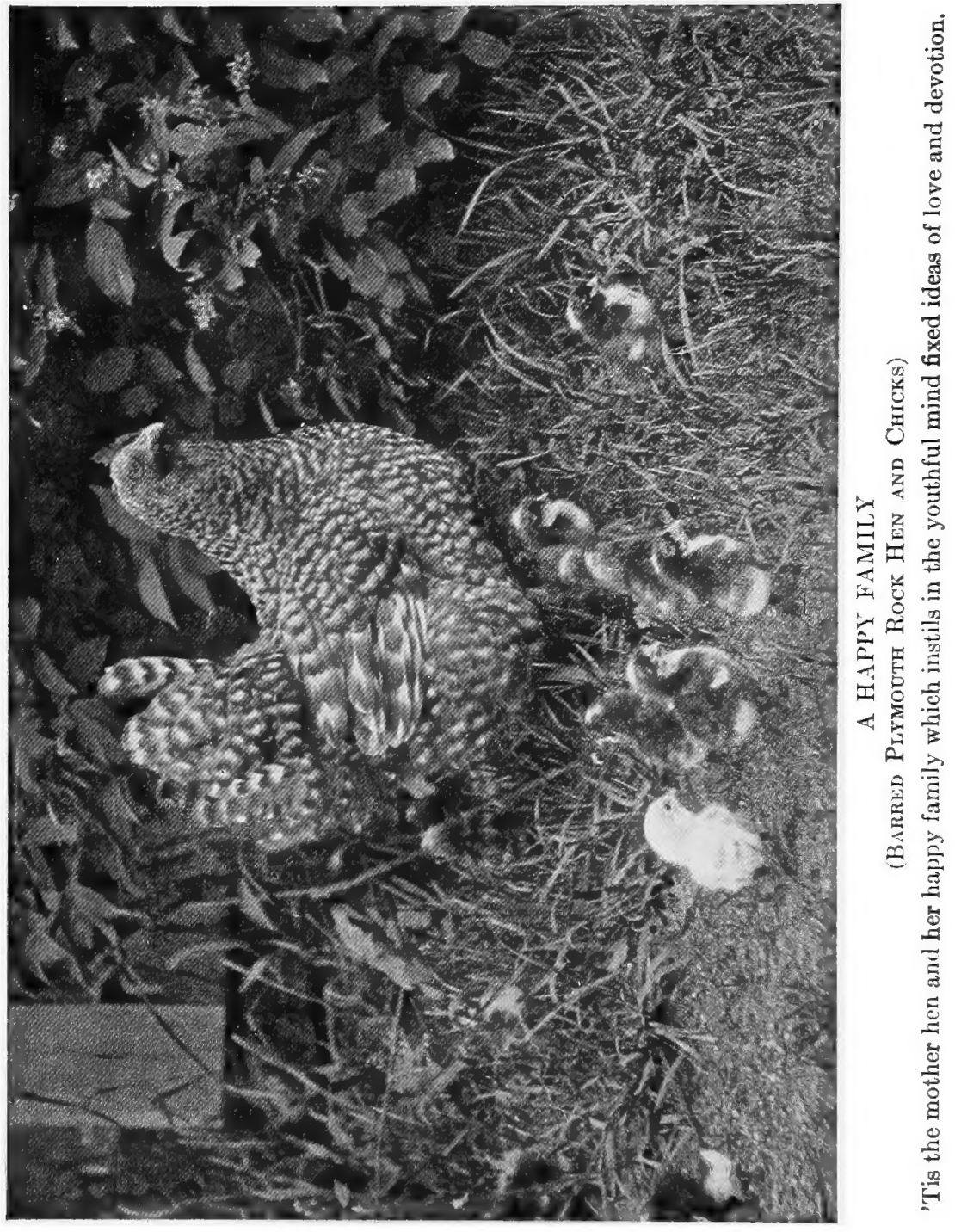




\title{
POULTRY KEEPING
}

AN ELEMENTARY TREATISE DEALING WITH THE SUCCESSFUL MANAGEMENT OF POULTRY

\author{
BY \\ HARRY R. LEWIS, B.S.
}

POULTRY HUSBANDMAN OF THE NEW JERSEY AGRICULTURAL EXPERIMENT STATION; ASSISTANT PROFESSOR OF POULTRY HUSBANDRY, NEW JERSEY STATE COLLEGE OF AGRICULTURE (RUTGERS); FORMERLY PROFESSOR OF AGRICULTURE OF THE BARON DE HIRSCH AGRICULTURAL SCHOOL; MEMBER INTERNATIONAL ASSOCIATION OF INSTRUCTORS AND INVESTI-

GATORS IN POULTRY HUSBANDRY; LIFE MEMBER OF THE AMERICAN POULTRY ASSOCIATION 


\section{(2) \\ $5 F 487$ \\ $160 k$}

COPYRIGHT, I9I 5, BY J. B. LIPPINCOTT COMPANY (a) 25456

PRINTED BY J. B, LIPPINCOTI COMPANY

THE WASHINGTON SQUARE PRESS PHILADELPHIA 
TO THE BOYS AND GIRLS OF OUR LAND

IS THIS VOLUME DEDICATED

MAY ITS TEACHINGS INSPIRE A GREATER LOVE AND RESPECT FOR OUR DOMESTIC BIRDS AND A BETTER KNOWLEDGE OF SUCCESSFUL POULTRY KEEPING 



\section{PREFACE}

The purpose in preparing this elementary treatise on Poultry Keeping has been to provide a text suitable for use in rural schools and in graded schools. It is especially adapted for use in the seventh and eighth grades but with slight adaptation can be profitably used for high school work. The need and demand for such a book is becoming more and more apparent. Each year sees a greater interest and development in the teaching of Agriculture in elementary schools. Poultry keeping offers one of the best opportunities in this line. Pupils are especially interested in things animate. A small flock of birds may be owned and kept on the school premises at a very small cost. Poultry is kept to a greater or less extent on nearly every American farm. The children especially take an active interest in this branch of the farm work. An idea of this growing popularity can be appreciated by noting the increased interest which is created by the growth of Boys' and Girls' Poultry Clubs and Poultry Raising Contests. These contests are becoming more and more a part of many school activities. In some cases these contests are but local; in others whole counties have organized and conducted Poultry Raising and Egg Laying Contests for the young folks. Such activities in the poultry field have been of great advantage to the whole agricultural population within the district. As the boys and girls are interested in poultry keeping when young, so their interest is bound to be greater and greater in this branch of agriculture in later years.

The idea in arranging the text material has been to keep it as elementary as possible, yet cover in a concise, simple way the essentials in the management of the poultry Hlock. 
All of the practices recommended are planned and described especially for the small flock. In many cases, suggestions or references have been made covering the application of these same principles to large flock management. An effort has been made to keep the material general in nature so that it will apply to all sections of the United States and Canada. Following each chapter laboratory exercises have been introduced. If these are followed out in the home or school flock or through trips of inspection to nearby poultry flocks as recommended, they will help materially to fix in mind the lessons of the text and will enthuse interest in the course. Thought questions have been placed at the end of each chapter to aid in reviewing the text material. They also emphasize and call special attention to the leading and more important points covered. A list of reference bulletins have been placed at the end of most chapters. These pubiications are known as Farmers' Bulletins, and can be secured by addressing the Secretary of Agriculture, Washington, D. C. The school library should contain a complete list of these bulletins, and the pupil should be induced to secure them for his home library. The study of these references in connection with the text will aid in giving a much broader and more detailed conception of many of the problems.

Special acknowledgment is due a number of persons for help in the preparation of parts of the text. Mrs. Harry R. Lewis has materially aided in the completion of the work by correcting manuscript and proof. And to others, including poultrymen, teachers and farmers, whose names do not appear, the author wishes to express his appreciation and indebtedness for encouragement and help given. Photographs have been secured from a number of poultrymen and farmers and from a number of Experiment Stations; credit is given where they appear. All photographs not especially credited have been taken by the author. L. P. Graham is here given credit for a number of photographs 
besides those on which his name appears, the removal of the artist's name having been necessary for uniformity of engraving.

The text embodies the modern teachings and practices prevailing at our leading Experiment Stations and on successful poultry farms. These facts have been specially condensed and made to apply to small flock management. Incorporated in the text are the results of findings from recent investigations in poultry management at our Agricultural Experiment Stations. The poultry departments of Cornell University, of the New Jersey Agricultural College, of the Connecticut Agricultural College, of Perdue University and of the Massachusetts Agricultural College have published valuable data from experimental findings, facts from which have been used in the text.

It is hoped that the text will meet the needs of rural and graded schools and that the pupils will find in it the information necessary to successfully manage the home flock and that the amateur poultry keeper will find in it elementary information pertaining to poultry keeping which is fundamental to success.

The author will be pleased to receive suggestions and corrections.

HARRY R. LEWIS.

New Brunswick, N. J., January, 1915. 



\section{CONTENTS}

\section{INTRODUCTION}

Instruction in Podutry Husbandry................. 1 Boys' and Girls' Podltry Cludbs................... 8

The School a Community Center.................... 11 The Foundation for Success in Poultry Keeping........ 12

CHAPTER

PART I-THE BIRDS

1. Brrds and Bird Lire................... 15

II. The Domestic Fowl..................... 34

III. The Egg Breeds....................... 48

IV. The Meat Breeds................... 58

V. General Utility Breeds................ 68

VI. Miscellaneots Breeds.................. 77

VII. Bremeding and Mating.................. 84

PART II-HATCHING AND REARING

VIII. The EgG........................... 94

IX. The Hatching Egg.................... 103

X. The Mother Hen....................... 112

XI. Artificial Hatching. . . . . . . . . . . . . . . . 122

XII. Brooding............................. 133

XIII. Rearing the Young Birds................ 142

\section{PART III-HOUSING}

XIV. Location of the Houses and Yards.......... 151

XV. Essfentials of a Podltry House............ 162

- XVI. Remodelling Old Podltry Houses. ........... 170

XVII. Building a Poultrey House............... 177

XVIII. The Interion of the Poultry House........... 188

XIX. Best Types of Poultry Houses............. 198

\section{PART IV-FEEDING}

XX. Elements of the Bird's Body and Composition OF ITS FEED........................ 211

XXI. Digestion, Assimilation, and Nutrition........ 218 
XXII. Common Poultry Feeds. . . . . . . . . . . . . . . . 224

XXIII. Home-Grown Podltry Feeds ................ 234

XXIV. Feeding for Growth................... 242

XXV. Feeding for EgG Production. . . . . . . . . . . 251

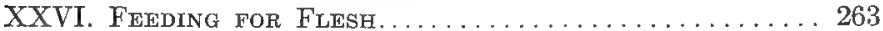

PART V-POULTRY PRODUCTS

XXVII. VArtetty of Products . . . . . . . . . . . . . . . . 272

XXVIII. Preparation of Poultry Products............ 283

XXIX. Distribution of Poultry Products.............. 294

PART VI-HEALTH, DISEASE AND ENEMIES

XXX. Sanitation. . . . . . . . . . . . . . . . . . . . . . . . 301

XXXI. Common Poultry Diseases................ 308

XXXII. Parasites and Enemies of Poultry............ 317

PART VII-MANAGEMENT

XXXIII. The Poultry Industry... . . . . . . . . . . . . . . . . . 324

XXXIV. The Business of Poultry Farming............ 332

PART VIII-APPENDIX

REFERENCE Books........................... 340

Location of Collegge........................ 342

Plan and Rules for Boys' and Girls' Poultry Contests. . . . 343

Score Cards............................... 349

Glossary of Parts of a Bird .................... 353

The Composition and Digestibility of Common Feed Stuffes 355 Feeding Standards for Podltry.................. 356

Weight and Volume of Common Fegding Stuffe......... 357 Facts a Poultry Keeper Should hnow............ 358 


\section{ILLUSTR ATIONS}

FIG.

A Happy Family

Frontispiece

1. The Farm Lad and the Farm Flock ................. 2

2. Systematic Instruction in Poultry, Shown by Chart....... 4

3. A Boys' and Girls' Poultry Show ................. 9

4. A Young Man and His Prize-winning Bird ........... 10

5. Plan for Poultry Yards and Gardens in Connection with a Rural School.............................

6. The Foundation to Poultry Keeping and Its Relation to Success............................... 14

7. The Skeleton of a Bird ..................... 16

8. Details of a Feather .................... 18

9. Royal Terns at Their Island Nesting Ground........... 20

10. Brown Pelicans at Their Nesting Site............... 21

11. (A) Young Black-crowned Night Heron. (B) Young Green

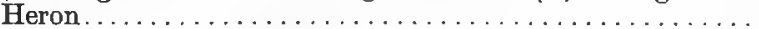

12. Green Heron's Nest and Eggs.......................

13. Bobwhite's Nest and Eggs......................... 23

14. (A) Bronze Turkey Male. (B) A Flock of White Holland Turkeys.

15. Song Sparrow's Nest and Eggs.

16. Ruby-throated Humming Bird's Nest and Eggs ............ 25

17. Baltimore Oriole's Nest ........................ 25

18. Wood Thrush's Nest and Eggs. . . . . . . . . . . . . 25

19. Flicker's Nest and Eggs. . . . . . . . . . . . . . . . . . . 26

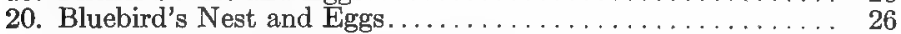

21. Barn Swallow's Nest......................... 26

22. Tree Swallow at Nesting Hole in Stump............. 26

23. (A) Rose-breasted Grosbeak at Nest. (B) Nest and Eggs of Rose-breasted Grosbeak.

24. (A) Hooded Warbler's Nest and Eggs. (B) Hooded Warbler on Nest.

25. Red-shouldered Hawk and Family ................. 28

26. White-breasted Nuthatch on Hand ............... 28

27. Simple Bird Houses Which Can Be Made at Home....... 29

28. Bluebird at Nesting Box .................... 30

29. House Wren at Nest Box.................... 30

30. (A) Slate-colored Junco on Feed Shelf, (B) Purple Finches on Feeding Shelf .......................... 31

31. A Pair of Jungle Fowls .................... 35

32. A Pair of Malay or Aseel Fowls ................. 35

33. (A) Single Comb White Leghorn Male. (B) Light Brahma Male. (C) Barred Plymouth Rock Male.

34. (A) A White Leghorn Hen. (B) A Basket of White Eggs which Accounts for the Popularity of the Leghorn.....

35. The Body Shape of the Leghorn Resembles that of an Egg. .

36. A Pair of Single Comb White Leghorns.................

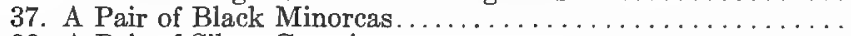

38. A Pair of Silver Campines. 
39. A Roaster Dressed for Market ....................... . 59

40. The Body Shape of the Meat Breeds Is Very Blocky ........ 60

41. A Typical Light Brahma Pair...................... 63

42. A Black Langshan Pair....................... 65

43. A Pair of Thick-feathered Cochins ................ 65

44. A Cornish Game Pair............................ 66

45. Eggs of the General Purpose Breeds Have a Brown Shell ... 69

46. General Purpose Breeds Bring in a Revenue from Meat as well as Eggs. . . . . . . . . . . . . . . . . . . . . . . . . . . 69

47. A Flock of Barred Plymouth Rocks.... ............. 70

48. The Body Shape of the General Purpose Breeds Resembles an Inverted Derby Hat.

49. Pair of Rhode Island Reds.

50. A Pair of Full-breasted White Wyandottes ............ 75

51. A Buff Orpington Pair...................... 75

52. A White Polish Male........................ 78

53. A Columbian Wyandotte Hen ................... 79

54. Black-tailed Japanese Bantams . . . . . . . . . . . . . . . 80

55. Barred Plymouth Rock Hen ................... 81

56. A Tailless Leghorn, Commonly Called a Sport........... 87

57. Barred Plymouth Rock Chicks, Showing Different Amounts of Vigor...

58. A Rhode Island Red Hen with a Large Egg Record ........

59. The Cross-section of an Egg Showing the Location of the

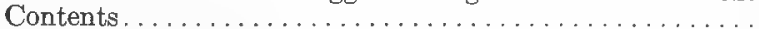

60. The Ovary and Oviduct...................... 98

61. Carefully Collecting the Hatching Eggs. ............. 105

62. Normal and Abnormal Eggs for Hatching. . . . . . . . . . . 107

63. A Mother Hen and Her Newly Hatched Chicks. . . . . . . . . . 112

64. A Barrel and a Box Nest........................... 115

65. (A) The Stolen Nest in the Long Grass. (B) The Proud Mother and Her Newly Hatched Youngsters ............ 116

66. A Slatted Coop Made to Protect the Young Chicks . . . . . . . 118

67. On the Farm the Chicks Can Be Reared in the Pasture..... 119

68. An Individual Incubator ...................... 123

69. Sketch of the Parts of a Self-regulating Device for an Incubator 12,3

70. A Class Studying Different Makes of Incubators............ 126

71. Three Types of Brooders Showing How They Furnish the Proper Requirements....................... 134

72. A Small Out-door Brooder for Fifty Chicks. . . . . . . . . . 135

73. A Gasolene Brooder House ...................... 136

74. (A) A Coal-burning Brooder Stove (B) The House in

Which the Stove was Operated............... 137

75. A Modern, Commercial, Long-pipe Brooder House ........ 137

76. An Out-door Dry Mash Hopper for Growing Chicks . . . . . . 139

77. Leghorn Pullets Being Reared on Frce Range............. 143

78. An Ideal Corner of a Pasture for the Growing Birds . . . . . . . 145

79. A Cheap, Fresh Air Shelter for Growing Poultry ............. 147

80. An Excellent Ifouse for Growing Chicks During the Summer 147

81. Working Plans for Arlaptable Summer Colony Itouse....... 147

82. Sloping Ground Showing the Proper Location of the Poultry House.

83. $\Lambda$ Desirable Plan for a Small Poultry Plant on a Farm... 
84. Single and Double Yard

85. A Poultry House with a Double Yard ............... 157

86. An Ideal Fence for Poultry. . . . . . . . . . . . . . . 158

87. A Neat, Well-built Gate for a Poultry Fence.......... 159

88. An Open, Fresh Air Poultry House ................... 162

89. A Closed, Poorly Ventilated, Old Type of Poultry House. . 163

90. Building a Concrete Floor to the Poultry House........... 164

91. Four Ways of Ventilating the Poultry House........... 165

92. Sketch Showing the Ideal Arrangement in a Poultry House. . 168

93. An Old Grist Mill Remodelled Into a Poultry House. . . . . . 170

94. An Old Tool Shed Remodelled Into a Poultry House..... . . 174

95. The Completed Small-flock Poultry House ............... 178

96. Working Plans for Small-flock, Portable Poultry House ... 180

97. Detail Drawing of Runners........................ 181

98. Detail Drawing of Floor Joist..................... 181

99. The Runners and Floor Rafters in Place and Braced....... 182

100. The Posts Erected and Braced..................... 183

101. Detail Drawing of Roof Rafter..................... 184

102. Boarding up the Walls........................ 185

103. Sketch Showing the Best Location of the Dropping Board. . 189

104. The Best Form and Place for the Perches.............. 190

105. Two of the Best Types of Poultry Nests. ..... . . . . . . . . 191

106. An Egg Crate Makes an Fxcellent Nest............... 192

107. Nests Located Under the Dropping Platform.............. 192

108. An Efficient Homemade Hopper for Dry Mash............. 194

109. White Leghorn Pullets Feeding from a Dry Mash Hopper... 194

110. A Dust Box Built Into the Corner of a Laying Pen . . . . . . 195

111. A Commercial Poultry House in Excellent Condition for the Layers. . . . . . . . . . . . . . . . . . . . . . . . . . . . . . . 196

112. Three Types of Poultry House Roofs................ 199

113. A Poultry House Built of Hollow Tile and Stucco......... 200

114. A Colony Laying House Which Will Hold Forty Hens...... 200

115. A Double Section Multiple Unit Laying House... . . . . . . . . 202

116. Working Plans of a Multiple Unit Laying House......... 203

117. A Long Laying House Containing Twelve Pens.......... 205

118. A Group of Small-flock Laying Houses . . . . . . . . . . . 207

119. A Double-pen Scratching Shed House.............. 208

120. A Gable Roof or Even Span Poultry House............ 209

121. Composition of the Bird's Body................. 212

122. The Amount of Nitrogen in Protein................ 214

123. Corn Can be Raised on Every Farm .............. 215

124. The Digestive System of the Fowl.............. 220

125. The Characteristic Growth of the Corn Plant........... 227

126. The Characteristic Growth of the Wheat Plant........... 228

127. The Characteristic Growth of the Oat Plant............ 229

128. The Characteristic Growth of the Barley Plant........... 229

129. A Well Grown Sunflower Plant................... 230

130. A Small Patch of Corn Can be Grown on Every Farm...... 235

131. Mangel Beets Make the Best Winter Succulence........... 238

132. Leghorn Pullets Feeding on Heavy Alfalfa Pasture...... . 239

133. Soy Beans Can be Used for Both Shade and Green Feed. . . . 240

134. The Maturing Pullet............................ 242

135. Leghorn Pullets on Range..................... 246 
136. An Excellent Source of Fresh Clean Water............ 247

137. A Young Man Feeding His Cockerels Their Grain Ration. 249

138. A Full Egg Pail is the Object in Feeding for Egg Production 251

139. The Story of Belle of Jersey. (A) Belle of Jersey as a Yearling. (B) The Feed She Consumed the First Year. (C) The Eggs She Laid the First Year............... 253

140. A Son of Belle of Jersey....................... 254

141. A Small Brook Supplies Fresh Drinking Water ......... 255

142. Sprouted Oats Make One of the Best Kinds of Green Feed. . 256

143. A Small Dry Mash Hopper for Out of Doors............ 256

144. Feeding the Morning Ration to His Buff Orpingtons....... . 259

145. Feeding the Night Ration to His Barred Plymouth Rocks... 260

146. Two Pairs of Broilers......................... 264

147. A Flock of Roasting Chickens Ready for Market........ 264

148. Broilers Being Finished on a Commercial Scale.......... 267

149. Cockerels Being Fattened in a Homemade Crate.......... 268

150. Table Eggs of Good Quality Packed in Cartons........... 273

151. White Leghorn Broilers Plucked and Ready for shipment. . 275

152. Six Small Roasters Weighing Four Pounds Each......... 277

153. A Plymouth Rock Cockerel and Capon.............. 278

154. An Ideal Bird To Be Used for Breeding. . . . . . . . . . . . 280

155. Poultry Manure a Valuable By-product............... 281

156. Undesirable Types of Eggs for Market.............. 284

157. A Crate Used in the Shipping of Live Poultry to Market... 285

158. A Crate Used to Ship Exhibition or Breeding Birds........ 25.5

159. Beheading a Chicken ........................ 287

160. Sticking and Dry Picking a Bird. (A) The Bird Suspended by the Feet. (B) The Operator Severing the Artery in the Mouth. (C) Plucking the Feathers Quickly but Carefully.

(D) The Bird Picked and Ready for Chilling .

161. The Plucked Carcass Being Chilled in Cold Water........ 290

162. Hatching Eggs Packed for Shipment by Parcels Post..... . . 291

163. A Neat Trade Mark for a Young Poultryman ............. 292

164. Delivering His Eggs and Poultry to a Retail Trade....... 295

165. Standard, Thirty-dozen Egg Case................... 297

166. A Special Shipping Case for the Retail Trade ........... 299

167. Removing the Droppings from His House ....... . . . . . 303

168. (A) Barrels Used for the Storing of Manure. (B) A Sipecially Constructed House for the Keeping of Poultry Manure. . 304

169. Carrying Fresh, Clean Litter to the Poultry House. . . . . . 305

170. Spraying the Interior of the House ........... . . . 305

171. An Isolation Coop or Fresh Air Hospital .............. 309

172. Sketch Showing the Effect of Freezing the Comb ......... 314

173. The Round Worm of Poultry ................... 317

174. An Enlarged Body Louse. .................. . . . 319

175. An Enlarged Red Mite...................... 319

176. Map of the United States Showing Distribution of Poultry. 325

177. The Women Often Care for the Farm Flocks ........... 326

178. A Typical Danish Poultry House and Flock ............ 328

179. The Location of Poultry Associations in New Jersey . . . . . 330

180. An Egg Record Form for Six Months............... 333

181. A Small, Neat Sign for Advertising Purposes............ 337 Sketch Showing Parts of a Bird . . . . . . . . . . . . . . 353 


\section{LABORATORY EXERCISES}

EXERCISE No.

PAGE

1. A Study of Representative Bird Types................ 31

2. The Structure and Parts of a Feather ................ 31

3. Protection of Wild Birds' Nests................... 32

4. Simple Homemade Bird Houses .................. 32

5. A Comparison of the Egg, Meat and General Purpose Type of Fowl............................. 46

6. A Study of Breed and Variety Characteristics.............. 46

7. The Differences Between Mongrels, Cross-breeds and Standard Breeds............................ 46

8. Good and Poor Types of Birds.................. 46

9. Comparison Studies with the Egg Breeds........... 56

10. Comparison Studies with the Meat Breeds............ 67

11. Comparison Studies with the General Purpose Breeds..... 76

12. Comparison Studies with the Miscellaneous Breeds........ 82

13. Practice in Selecting Breeding Birds ................. 92

14. Construction and Operation of Trap Nests............. 92

15. The Composition of the Hen's Egg................. 100

16. The Internal Structure of a Hen .................... 101

17. The Cooking of Eggs for Human Food............... 101

18. The Development of the Chick or Embryo in the Shell..... 110

19. The Care of Sitting Hens..................... 120

20. The Construction of an Artificial Incubator............ 131

21. Operating a Small Incubator.................... 131

22. The Moisture Requirements of Artificial Incubation........ 131

23. Testing Eggs During Incubation................. 132

24. Loss of Weight of Eggs During Incubation............. 132

25. Brooder Types and Their Construction.............. 141

26. Operating a Small Brooder...................... 141

27. Constructing a Small Colony House................ 149

28. Growing Crops to Give Green Feed to Poultry . . . . . . . . . 149

29. Types of Soil Best for Poultry ..................... 160

30. Construction of Poultry Fences.................... 160

31. Planning the Lay-Out of a Poultry Plant ............. 160

32. The Effect of Dampness in the Poultry House........... 168

33. Muslin Ventilation for the Poultry House............... 169

34. Remodelling an Old Poultry House................ 174

35. Ways of Improving Poultry Houses ............... 175

36. Laying a Concrete Floor in the Poultry House.......... 175

37. Constructing the Runners for a Portable House............ 181

38. Cutting the Floor Rafters..................... 181

39. Leveling the Runners and Squaring the Corners . . . . . . . . 182

40. Laying the First Rough Floor ................... 182

41. Erecting the Posts ... . . . . . . . . . . . . . . . . . 182

42. Erecting the Plates . . . . . . . . . . . . . . . . 183

43. Erecting the Roof Rafters. . . . . . . . . . . . . . . 183

44. Erecting the Studding. ........................ 184 
45. Building the Walls......................... 184

46. Laying the Roofing Boards....................... 185

47. Laying the Finished or Top Floor ................. 185

48. Miscellaneous Construction to Finish the House . . . . . . . 186

49. Amount and Value of Poultry Manure . . . . . . . . . . . 196

50. The Proper Perch Room for Birds. . . . . . . . . . . . . 196

51. Types of Dry Mash Hoppers..................... 197

52. A Good Dust Bath............................ 197

53. A Study of Poultry Houses . . . . . . . . . . . . . . . . 209

54. Drawing Poultry Appliances. . . . . . . . . . . . . . . . . . 209

55. Materials for Poultry Houses...... . . . . . . . . . . . 210

56. Composition of a Bird's Body ................... 216

57. Composition of Poultry Feeds.................... 216

58. Diffusion a Process of Assimilation.................. 222

59. A Study of the Digestive Tract.................. 222

60. Identifying Poultry Feeds .................... 232

61. A Study of Seeds and Growing Plants............... 240

62. The Unabsorbed Yolk in the Young Chick . . . . . . . . . . 249

63. Mixing Chick Rations ......................... 250

64. Feeding Young Chicks . . . . . . . . . . . . . . . . . 250

65. Mixing Laying Rations . . . . . . . . . . . . . . . . . . . 261

66. Feeding Laying Hens ........................ 261

67. A Comparison of Flock and Crate Fattening.......... 270

68. Fresh and Held Eggs, A Comparison ............... 281

69. Weight of Eggs........................... 281

70. Weight of Broilers........... . . . . . . . . . . 282

71. Curing Feathers for Marketing. .................. 282

72. Grading and Packing Market Eggs .................. 292

73. Sticking and Dry Picking Poultry .................. 292

74. Packages for Shipping Poultry Products .............. 293

75. A Study of Markets and Prices................... 300

76. Marketing Trips.......................... 300

77. Cleaning the Poultry House .................... 306

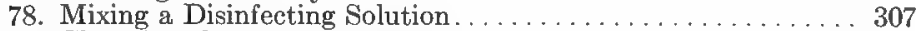

79. Cleansing the Poultry Yard .................. 307

80. Chicken Pox, Roup and Canker.................... 315

81. Potassium Permanganate Solution . . . . . . . . . . . . . 315

82. Diagnosis of Diseases .......................... 316

83. A Study of Body Lice. . . . . . . . . . . . . . . . . . . . 322

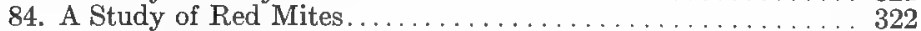

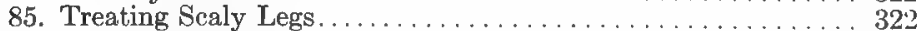

86. Combating Enemies of Poultry ..................... 323

87. Locating Centers of Poultry Production in the United States. . 329

88. Making Poultry Records ....................... 3.js

89. A Simple Account Sheet......................... . 338

90. Writing an Advertisement. .................... 338 349-352.

Note.-Score Cards for Judging all Classes of Poultry on Pages 


\section{POULTRY KEEPING}

\section{INTRODUCTION}

\section{INSTRUCTION IN POULTRY HUSBANDRY}

Demand for Instruction in Poultry Culture.-The past five years have witnessed an immense advance in the popularity of poultry raising. This growing popularity is commercial as well as educational, and has been manifested by an increased attendance at Agricultural Colleges and by the larger number of, and greater interest in, poultry organizations for educational purposes. Within the last year this growing interest has been especially evident in the demand for poultry instruction in grammar and high schools.

Various causes create this demand, but one of the leading factors is a growing revival of interest in the problems of life, a "back to nature" movement, as it were, which is becoming quite general, and is more and more evident among young people. The present high cost of living is in part responsible for some of the popularity of poultry keeping. A small flock in the back yard or on the farm will materially decrease expenditure for certain foods since poultry and eggs can be used largely in place of meat (Fig. 1). Products for the table can be more easily secured with poultry than any other kind of animal. Another decided advantage in poultry keeping, which accounts for its growing popularity, is the fact that a small plant can be readily equipped and run by the investment of a little money, which is an important consideration for the average small farmer or back yard poultryman. A variety of products can be secured from a small flock. In addition to supplying food for the home table, commercial poultry products, such as eggs and meat, can be sold to neighbors or stores, and bring in a considera- 
ble revenue. Beginning in a small way, one can develop quite an extensive business and arouse a keen interest in agricultural problems.

Present Status of Poultry Instruction.-Poultry instruction in colleges has advanced rapidly in the last ten years, but it is only within the last two or three years that elementary instruction has been seriously considered. The success of endeavors in this line and the increasing interest of the pupils, insure progress in the future, and this popularity will result

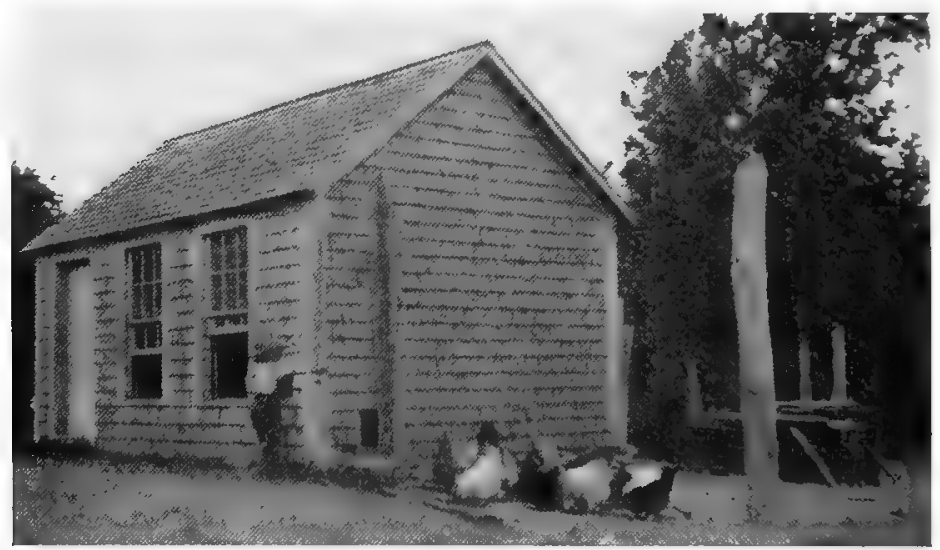

Fro. 1.-The farm lad and the farm flock. The country boy takes naturally to the care of poultry. This interest is increased and developed by suitable instruction and guidance in school.

in the general acceptance of poultry husbandry as one of the prominent branches of agriculture to be taught in our elementary schools.

In certain sections of the United States remarkable enthusiasm has been aroused in poultry farming, and larger profits secured from the birds through the work in the lower grades of the schools.

Instruction Should Be Systematic and Progressive.-In order to make the teaching of poultry keeping of any value, and to hold the student's interest year after year, the work 
of the poultry classes must be steadily progressive, and should begin in the kindergarten, where, by the use of eggs and feathers, the students may become acquainted with things that pertain to animal life. This type of instruction in the primary grades will foster in the student a craving for and a deeper interest in poultry husbandry when he takes it up as a definite study. Such general instruction might be termed elementary; it should deal only with color, shape, form, etc. Next should come secondary instruction, so outlined as to cover in an elementary way the simple operations necessary for the care and management of a small flock of birds. It should give to boys and girls of grammar and high school age enough of management and business methods to make them wish for more, and to prepare them for the more detailed, scientific work which will follow. This is the class of students which this book is designed to reach. Next should come collegiate instruction, comprising a short, two-year, and a regular four-year course, leading to the B.S. degree. Here should be reviewed the elementary instruction received in the lower grades. The course should also embrace in minute detail all of the scientific problems involved. Collegiate instruction should prepare a student to better manage a commercial farm or go into the actual work of experimenting in and teaching poultry husbandry. It is becoming more and more popular every year. The results of the next type of instruction, called extension work, are far reaching. This is primarily demonstrative in its nature. It is designed to teach farmers of all ages and varying degrees of education, the procedures necessary to the successful operation of their plants. It should demonstrate all of the new methods and facts, as they are from time to time discovered, and the instruction should be practical, and applicable to their particular line of work (Fig. 2).

The Poultry Schedule.-In outlining an elementary course in poultry husbandry, the aim should be to introduce it 
gradually into the curriculum, without materially reducing the time allotted to other subjects. In arranging such a schedule, it is a good plan to devote three recitation hours

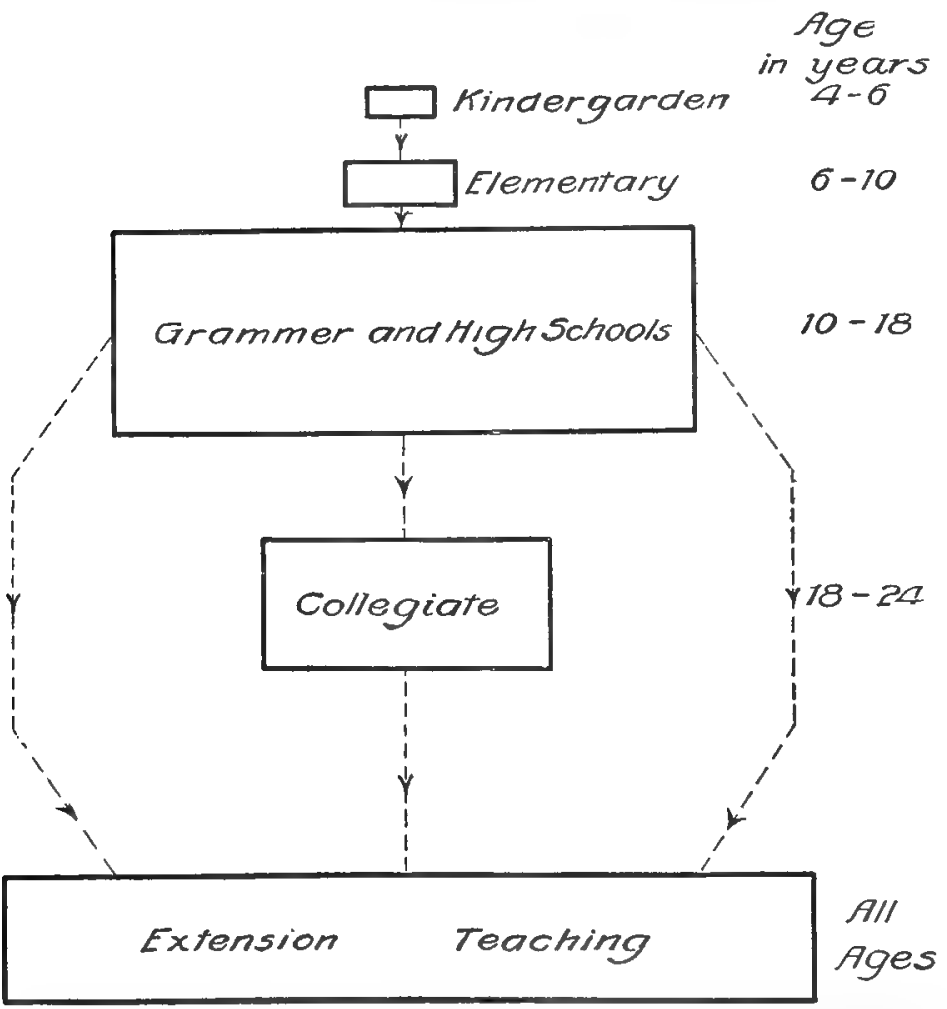

FIG. 2, - Systematic instruction in poultry is necessary. The great mass of pupils will receive what poultry instruction they will ever obtain betwecn the ages of ten and eighteen years or during their years in grammar and high seliool. With this elementary training they go directly into practical work where henceforth they can get additional information only through extension teaching. I very small proportion of young men and women ever have the opportunity of a collegiate training in poultry keeping.

a week to the subject, preferably on alternate dilys; for example, Monday, Wednesday, and Friday. If laboratory work is to be combined with recitation work, one afternoon 
a week can be profitably spent in this way. Often the actual work of caring for the birds on the school grounds and of building equipment creates so keen an interest that the students will do considerable good work before and after school hours. When the subject is being taught in high schools, at least one, and preferably two, laboratory hours should be on the schedule. Another procedure that has been very successful is to combine two or three of the upper classes. Nature study and poultry can be grouped as one class. This materially decreases the labor of teaching and stimulates interest, because all of the students are brought together on the same plane, studying a subject that is of mutual interest. In arranging the schedule, it may be possible to include some other agricultural subject, such as horticulture or school gardening, allowing three hours a week for poultry, and three or four, as the case may be, to the correlated subject.

General Advice to the Teachers.-The instructor in agricultural subjects, especially in poultry keeping, is often poorly trained and inexperienced in poultry husbandry, and therefore should not set himself or herself up as an authority on the subject, but rather study with the student and be a pupil with him. This brings them into closer relation and inspires a more personal interest on the part of the student. It is wise to begin with local conditions, and attempt gradually to improve these, rather than to make radical suggestions or departures from the methods prevailing in the district. Any radical step of this kind on the part of the teacher is apt to arouse the antagonism of the parents, and thus lessen the interest of the student. Work can be confined to local problems; for example, if the district happens to be one where egg production predominates this phase of the work should be given special consideration. In some sections market poultry in the form of broilers and roasters had better be taken up, because the parent, hence also the student, is interested in this phase. Often it may 
be well to start with the common breeds characteristic of the community, even though they be mongrels. By comparing them with some pure breed of birds, the student himself will soon appreciate the good points and advantages of the latter type, and if he detects this difference himself, it will be more permanently fixed in his mind. Starting with the prevailing type, improvement can gradually be brought about, not only in the school flocks, but the home flocks as well.

The teacher should encourage the student to begin with a very few birds, and then to expand the work as the success of his efforts may warrant. Home practice is the best, especially for the grammar grades. The student should secure the consent of his parents to have a small flock of birds at home, which he may call his own, and with which he can make a trial of the methods learned in his text-book. These home flocks, if given the careful attention of the student and frequent inspection by the teacher, will serve as object lessons in the community and keep the parents interested. Where there is high school instruction, it is advisable to rear a small flock of birds on or near the high school grounds. The teacher should point out the problems involved, without going into scientific explanations, and in all operations should endeavor to maintain the dignity of the profession. Careful study of the current literature and modern text-books on the subject will better qualify the average teacher to conduct the work satisfactorily, and will keep him in touch with fresh developments. An effort should be made to correlate poultry instruction with general school work, thus stimulating interest and broadening the opportunities from a purely educational standpoint. The writing of short essays on the subject will also materially strengthen the interest of the student in his work in English. Mathematics, chemistry, physiology, geography and zoölogy should all be correlated as far us possible with poultry studies. 
The attitude of the teacher towards the subject, and the inclusion of these branches, will do much towards insuring the success of the work in the curriculum.

Methods of Instruction. - Instruction in poultry husbandry should be divided into two groups: first, school work; second, home work. Schoolroom work should consist of the study of a complete elementary text-book, frequently supplemented by lectures, the number and nature of the lectures depending on the experience of the teacher. The instructor should begin to collect a library of poultry literature, text-books and bulletins for reference. Readings should be assigned from time to time, so that the student may acquire additional information not contained in his text-book. Reference reading enables the pupil to become acquainted with the current publications, and teaches him how to find material when he wants it. A.certain portion of each recitation can profitably be spent in a general discussion of the results obtained in the home work, as well as a review of the conditions found on poultry farms that have been visited. These will be found to materially increase the interest in the work, and will call the pupil's attention to the practical side of the study.

Home work should be encouraged, and the student should be requested to confer with the teacher as to the planning, equipment, and development of his home plant. In ideal home work each student should have a small pen of birds, the care of which should entirely devolve upon himself. He should be allowed to build a small poultry house and yard, and to equip these in a thoroughly up-to-date manner. If he has more than one pen, it may stimulate his interest to let him do a little experimental work. This may consist in a trial comparison between different birds, different methods of housing, or any other project which will cultivate his powers of observation. He should make practical application of the instruction received in class, in so far as his 
equipment will permit. He should submit monthly written reports of the work accomplished, feed consumed, chicks hatched, etc. Interest can best be obtained by offering small prizes each month to the pupil who makes the best showing. The teacher should visit the homes of the pupils, and discuss their work. Sometimes the whole class can make an inspection trip, visiting a few of the nearby and best managed poultry plants.

Trips of Inspection.-In correlating classroom and home work, the pupils should be encouraged to become acquainted with the poultry industry, as carried on in their vicinity, and this is best accomplished by frequent visits to successful poultry farms. This type of poultry culture should be studied and the student taught to observe the difference between the large specialized poultry plant and the farm flock, the latter of which is usually being run as a side line to some other branch of agriculture. The pupil should carefully note the methods followed, and question the proprietor as to details. These notes will form a valuable supplement to the text-books in classroom work. After such inspection trips, reports should be required, presenting in outline the student's observations and information acquired. This will not only make the work more interesting, but will impress the facts on his mind. In addition, it will train him in the work of writing essays.

\section{BOYS' AND GIRLS' POULTRY CLUBS}

Teaching Through Organization.-As with all other lines of effort, whether educational or commercial, organized effort is necessary to produce large results. This is especially true in poultry instruction, and the success of student organizations is proven by the present development and popularity of boys' and girls' poultry clubs (Fig. 3). Get the students themselves to organize and choose their own officers and they will take a more lively interest in the study; furthermore, the co-operation of the parent is secured, and this is absolutely 
necessary if home work is to be conducted successfully. The organization of boys and girls makes the parents enthusiastic, and arouses such an interest in the community that it of ten leads to the organization of poultry associations for adults, both for educational and show purposes. If the pupils can be led to believe that they are themselves operating the organization and conducting the study, their zeal will be more spontaneous than though they are driven to it.

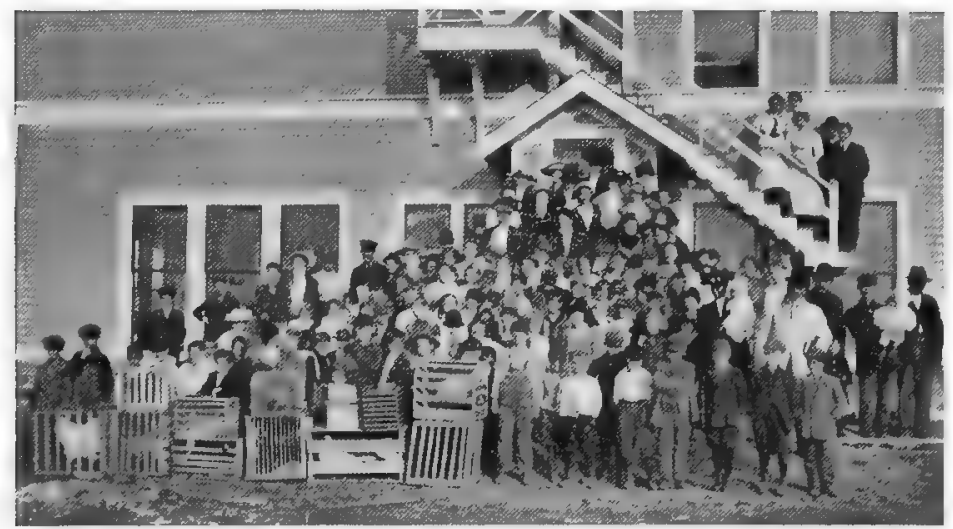

Frg. 3.-Poultry show at the consolidated school at Meadowlands, St. Louis Co., Minn. The animated expression on the faces of the young folks shows their deep interest in this form of instruction. (Photo by N. E. Chapman.)

Present Development.-The poultry club movement, especially as applied to boys and girls, has been fostered in the past year by the Federal Government (see Farmers' Bulletin No. 562 on this subject). Many states have taken up the work, notably Massachusetts and New Jersey. Other states, especially in the Middle West, are perfecting plans to begin immediately. The organization of such clubs is very simple. The students assemble and elect their officers, consisting of a President, Vice President, Secretary and Treasurer. They usually elect the teacher in charge as adviser. Meetings are held once a week after school hours. 
In addition to the regular business, a part of the time is devoted to discussion of the work of the different students. A good plan is to secure some successful poultryman in the vicinity to address the meeting for from ten to fifteen minutes, on some simple phase of the management of poultry. It is wonderful what enthusiasm boys and girls from ten to sixteen years of age will develop in a study of this kind, if they are approached in the right manner, and are allowed to share largely in the responsibility of the work.

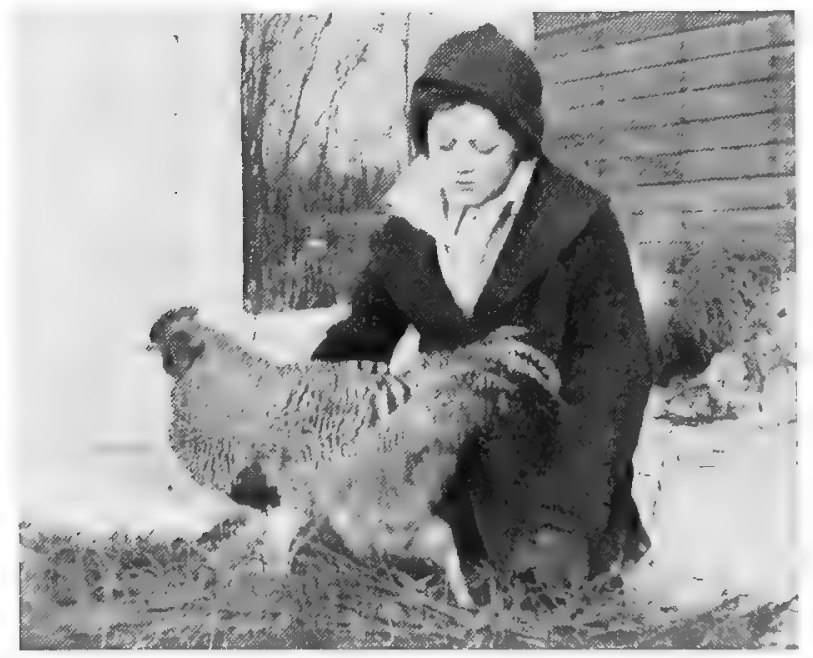

Frg. 4.-This young man bred and raised this prize-winning Plymouth Rock. It is needless to say that his interest in poultry raising is unbounded. (Photo by N. E. Chapman.)

The primary object of the poultry club is threefold. First, to awaken greater interest by allowing the student personal oversight. Second, to arouse the interest of the community. Third, to have some official organization through which Poultry Raising and Egg Laying Contests can be conducted (Fig. 4). The method which has been followed in New Jersey, and has been very successful, is to organize two contests, one elementary and one advanced. The elementary 
is known as the Poultry Raising Contest; the pupil who competes sets 25 eggs under each of two hens, hatches the chicks and rears them to maturity, keeping a record of all the work performed. The advanced contest consists in the management of a certain number of layers for egg production, usually during a period of one year. As a rule these contests are conducted as county or township affairs, prize money being divided accordingly. After the district prizes are awarded, the winners in each district are carefully gone over, and the best poultryman for the county chosen. From one hundred to five hundred dollars prize money is usually divided in the county. This is generally donated by banks, newspapers, and by public spirited citizens. ${ }^{\mathrm{I}}$

The Poultry Departments of the different State Colleges issue primers for the use of the pupils engaging in these contests, which, measured by the interest attached to them and the educational value resulting from them, are well worth the trouble. The immediate future is sure to see a rapid development and enlargement of this work.

\section{THE SCHOOL A COMMUNITY CENTER}

The teaching of poultry husbandry in grammar and high schools, the development of student associations, and the awakening of community interest are bound to make of the school a true community center, socially, educationally and commercially. Around such centers, if poultry keeping is a prominent industry in the community, should grow up poultry show associations, also egg and dressed poultry shows. Parent organizations for co-operative buying and selling will be a natural outcome. Leagues for community uplift and improvement associations are also possible. The success of the whole enterprise depends upon the teacher's zeal in getting the work started (Fig. 5). contest.

${ }^{1}$ See page 347 for circulars and blanks used in conducting such a 


\section{THE FOUNDATION FOR SUCCESS IN POULTRY KEEPING}

Poultry keeping is an occupation which necessitates attention to small details. Success can be assured only by close application, as is true of other occupations based upon natural sciences. Success demands, first of all, a substantial foundation upon which to develop.

The Four Corner Stones.-While many associated factors are necessary for success in poultry keeping, four requisites stand out pre-eminently and are often called the four corner

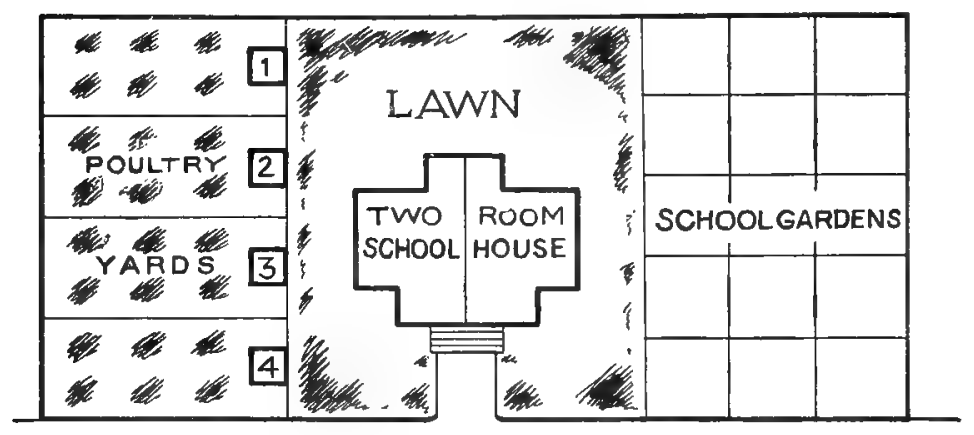

\section{HIGHWAY}

FIG. 5.-Plan for poultry yards and gardens in connection with the rural school - total arew one-half acre.

Nowe. - If the area is deep with a narrow frontage on the highway, the yards and gardens can be placed in the rear of the school building.

stones upon which may be built a successful business. These are: The poultry keeper himself; the birds; their surroundings; their feed.

The poultry keeper, whether he be pupil or commercial poultryman, must have a natural love for the birds and be a student of nature. If he makes a study of birds' habits, he will give the birds better care and more quickly note any unfavorable conditions, whether in the health of the flock or in the details of management. He should he indus- 
trious, prompt and regular in his work, and early develop a definite system. In doing the chores he must exercise good judgment and common sense. In the daily routine many problems arise for which he has no precedent, and these must be solved intelligently and immediately; therefore, a love of birds and the work of caring for them is fundamental.

The Birds.-The poultryman must think of his birds as machines, which consume raw material, and turn out a finished product, in the form of eggs and market poultry. As with all other manufacturing enterprises, good machines should be adapted to the purpose secured, whether it be meat production or egg production. The birds selected should be healthy, strong, and vigorous, of good size, carefully bred and well mated.

Surroundings.-The surroundings of the poultry flock constitute their environment, and two factors are especially important; these are the houses and yards in which the birds run. The house may be economically built, but should be exceedingly dry, well ventilated and sunny. It should afford plenty of space for the number of chicks kept. The yards should be extensive, with dry, well-drained, and rather sandy soil, covered with growing grass, and plenty of shade from trees or growing plants.

Cleanliness is essential to proper environment, and this means the frequent removal of the droppings. The litter should be coarse and abundant, and the poultry house and all the fixtures should be thoroughly cleaned at least twice a year.

Feed.-The feed must be considered as the raw material or fuel, which keeps the birds in healthy producing condition. The eggs and the meat are the finished product resulting from the combustion of this fuel. Digestion is neither more nor less than a process of burning or combustion. In choosing feed, the definite relation between the character of the feed and the composition of the product 
must be borne in mind. Egg production requires one type of feed, while flesh growth, or meat production, calls for a different type. Successful feeding means that the rations given should be abundant in amount, of a suitable character, and in a form relished by the birds. The feed must be pala-

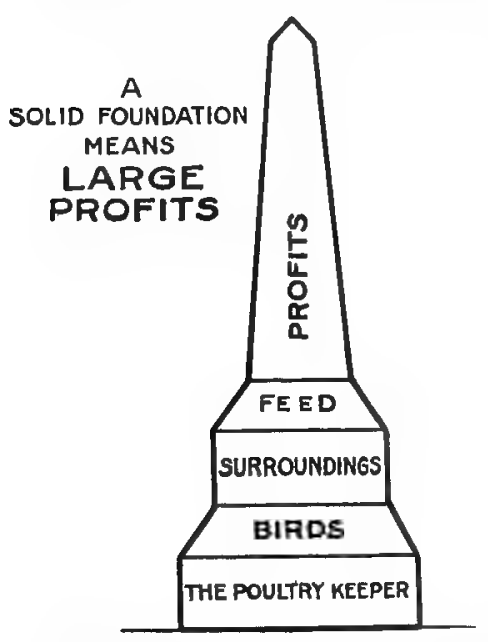

Fra. 6.-The foundation to poultry keeping and its relation to success. The stronger the foundations the greater the profits will be. table, wholesome and clean, and easily digested and the mode of feeding must be conducive to health. Exercise is largely determined by the method of feeding, but plenty of exercise is necessary for health (Fig. 6).

\section{Production as Affected} by the Four Corner Stones.-It can be truly said that these four corner stones are the controlling factors in poultry management, and that the product is limited by minimum efficiency, even as the strength of a chain is no greater than its weakest link. Hence the combination of these factors is necessary. Capable poultrymen with good houses and good feed, but with poor birds, are doomed to failure. The same is true of good birds with suitable houses and feed, if they are not properly cared for; and if the poultryman is not interested in his work, his business will never succeed.

References.-United States Farmers' Bulletins: 134, Tree Planting on Rural School Grounds; 185, Beautifying the Home Grounds; 218, The School Garden; 562, The Organization of Boys' and Girls' Poultry Clubs; 586, Collection and Preservation of Plant Material for use in the Study of Agriculture; 606, Collection and Preservation of Insects and Other Material for use in the Study of Agriculture. 


\section{PART I \\ THE BIRDS}

\section{CHAPTÉR I \\ BIRDS AND BIRD LIFE}

The term "birds" is used to define a group of animals which are feathered, and warm blooded, and produce eggs. This class includes all kinds of feathered animals, whether they live on land, water or trees. Throughout the world are hundreds of different kinds of birds, representing numerous distinct types, and many of these are useful to man.

Birds and Their Relation to Animal Life.-All animals existing on the earth are classified under the general term, "Animal Kingdom." This great kingdom is divided and subdivided until we come to a class or group known as aves or birds. Animals which belong to this class are known as true birds. They are all feathered and have four clearly defined limbs. The hind pair are the legs, which are used for walking on the ground, or for swimming in the water. The front pair of limbs are usually called wings, and are designed for flight. Birds have no teeth. They have a heart similar to other animals, and the blood circulates the same as in man. Their lungs are very highly developed. The class aves or birds is subdivided into three groups, which will later be described. Birds are one of the most highly specialized classes of the animal kingdom. They differ from other common animals in their ability to fly and in the fact that they are covered with feathers.

Aves or Birds. - The class aves or birds includes a great variety of types; among them are the eagle, the ostrich, the humming bird, and the duck. They not only differ in size, but vary greatly in habit and mode of life. In structure, birds closely resemble snakes and reptiles. Since birds are 
constructed primarily for flight, they are provided with a light skeleton, combined with very powerful muscles. The skeleton is very compact, and contains a relatively small number of bones (Fig. 7). The neck is long, and quite movable. The most characteristic external features of the bird are the fluffy feathers which cover the whole body, the well developed wings, and clearly defined tail. The wings propel the birds when in flight, and the tail is used to steer them in flight. The mouth of the bird is guarded by a beak in the case of Iand birds, and by a bill in the case of water birds. The

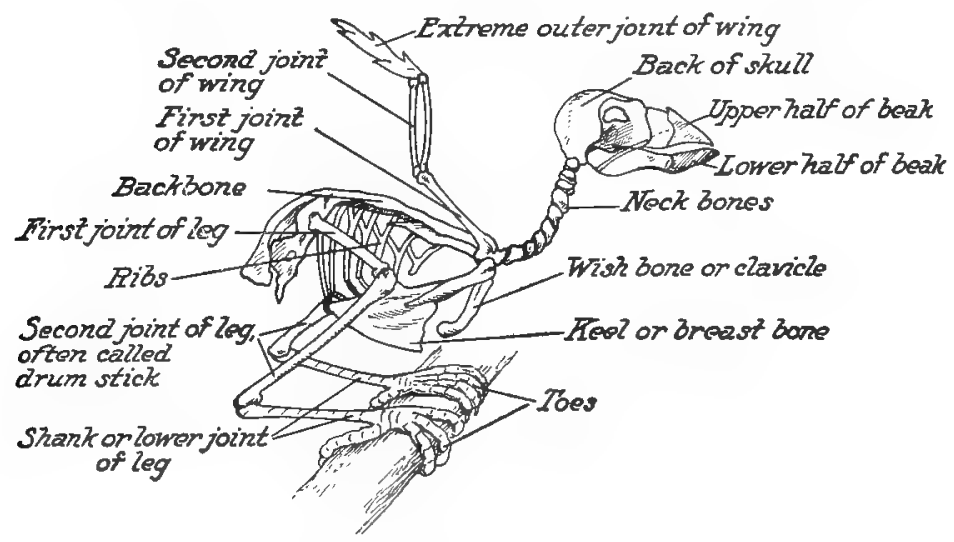

Frg. 7.-The skeleton is made up of small bones which are covered with porerful muscles, giving strength and lightness.

nostrils are located just above the base of the beak. The ears lie just below the back of the eye, and are covered by a protective growth of feathers. The breast of the bird is rather sharp and pointed, acting as a cutter with which to cleave the air when the bird is in flight. The legs are usually short and thick, except in the heron and other marsh birds, in which case they are very long and slender. The feet usually have four toes; in land and aërial birds they are round, gently curved, and fitted with claws. Aquatic birds have a thick web or membrane between the toes, which assists 
them to swim. The wings consist of three distinct parts, the inner portion being a part of the body proper, and the other two portions being outside of the body. The wings correspond to the forearm of man. When not used for flight they are usually folded close to the body. On the extremity of the wings are the flight feathers, commonly called the primaries. To the next joint of the wing are attached the secondary flight feathers. When the wing is folded, the secondaries are visible, the primaries being concealed under them. In full flight these heavy wing feathers are widely spread, and form the propelling power.

Feathers.-The feathers on the body of a bird are an outgrowth from the skin. They consist of an elongated hollow quill, and a lateral or side growth, called a vein or web (Fig. 8). The lower part of the quill is rather heavy and is filled with a pithy material; this portion is often called the staff. Each individual hair which makes the web is called a barb. On the end of the small barbs are little hooks, or curved hairs, which serve to hold the barbs together. These barbs or small hooks can be detected only by a magnifying glass. Barbed feathers which have no hooks are called down. Feathers do not cover the entire body of the bird, but are found in certain areas or tracts, being separated from each other by featherless spaces. When the bird has its full plumage, these tracts are not apparent, as the feathers grow in such a way as entirely to conceal the spaces.

Plumage color varies greatly in different species, that of the male bird being usually more vivid and brilliant than that of the female. Once, and sometimes twice, a year the birds change their plumage; in our domestic breeds this is called the molt. In some birds this change of feathers is quick, in others slow and gradual. With domestic birds a complete molt is made during the month of August. With wild birds it usually occurs after the mating season. 
Main fail or wing feather

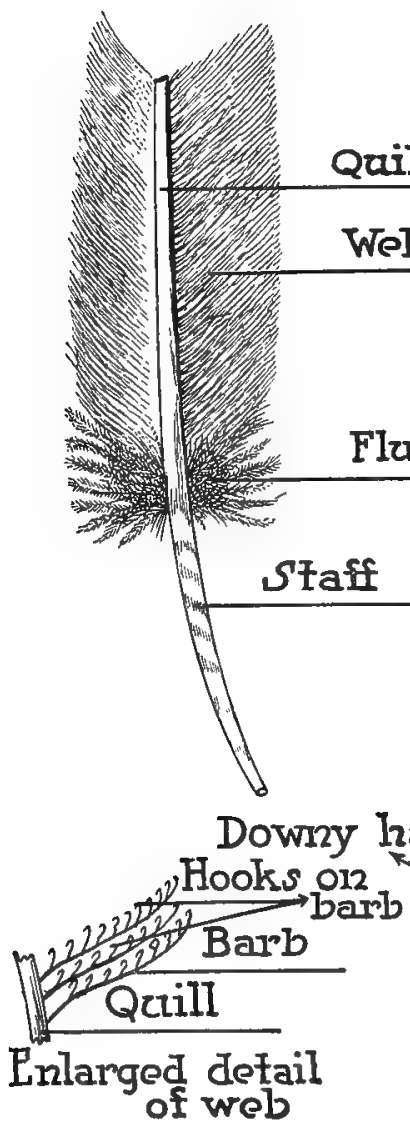

\section{Soft body feafher}

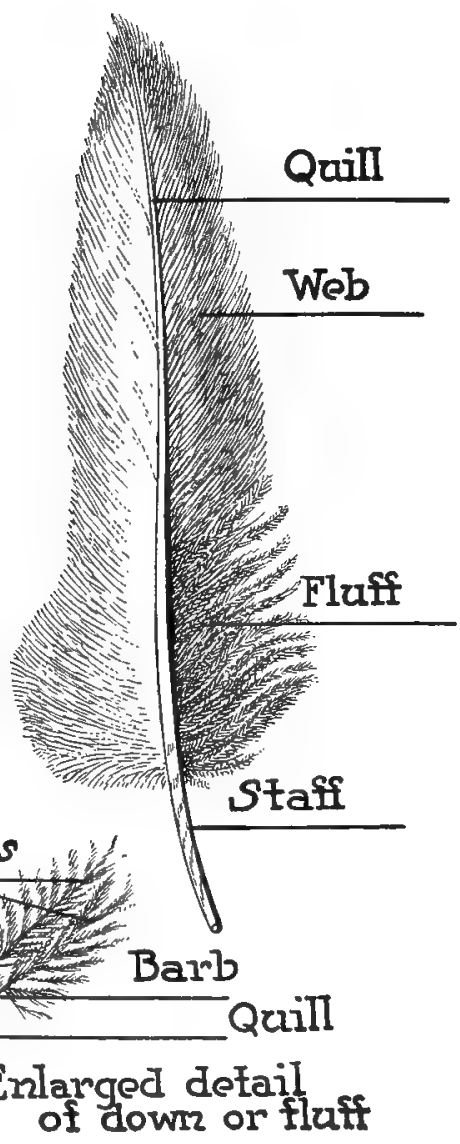

FIG. 8.-Details of a feather. 
Reproduction.-Birds reproduce by means of eggs. The egg not only contains the germ which develops into the young bird, but contains the nourishment for the germ during its development. The shell is a protective envelope which guards the embryo, or young chick, during its development. The bird's eggs are laid in nests, and are hatched out by the application of heat from the bird's body. Birds vary greatly in their nesting habits; some build nests in trees and bushes, and others burrow in the ground. Some of our wild birds build hanging nests. Many birds build their nests directly on the ground. Others bore holes in dead stumps and trees. It is a most interesting study to watch the nesting of wild birds. The student can locate the nest, watch its building, and the rearing of the young. Neither the nest nor the young should ever be disturbed.

Classification of Birds. - Birds are divided into three groups, according to their habits of life. The first group is called aquatic birds, and comprises those birds which spend a great part of their time on or near the water. Common domestic examples are ducks and geese. The pelican is one of the wild species. The second group into which birds are divided is the terrestrial, so called because these birds spend a great part of their time on land. Common examples of this type are the domestic fowl, quail, pheasant, etc. The third group is commonly called aërial. These birds derive this name from the fact that they perch largely in trees and elevated places, and spend considerable of their time in flying. Common examples of this type are the sparrow, crow, and the swallow.

Aquatic Birds.-All aquatic birds are primarily built for swimming. The body is shallow and wide, with a flattened keel, and is covered with close, compact feathers and down. Birds of this group have very short legs, and are usually provided with a web between the toes. The wings are, as a rule, very powerful. The duck is a common example of 
the aquatic bird. The duck has a web between its front toes, and the hind toe is elevated, thus making it hard for the bird to perch. It has a strongly marked bill, or flat, spoon-shaped mouth. Much of the feed of the duck is gotten from the mud in the bottom of streams or ponds, and its mouth is especially designed for extracting feed from such deep places. The gull is a common wild member of this group. It is characterized by pointed wings and a

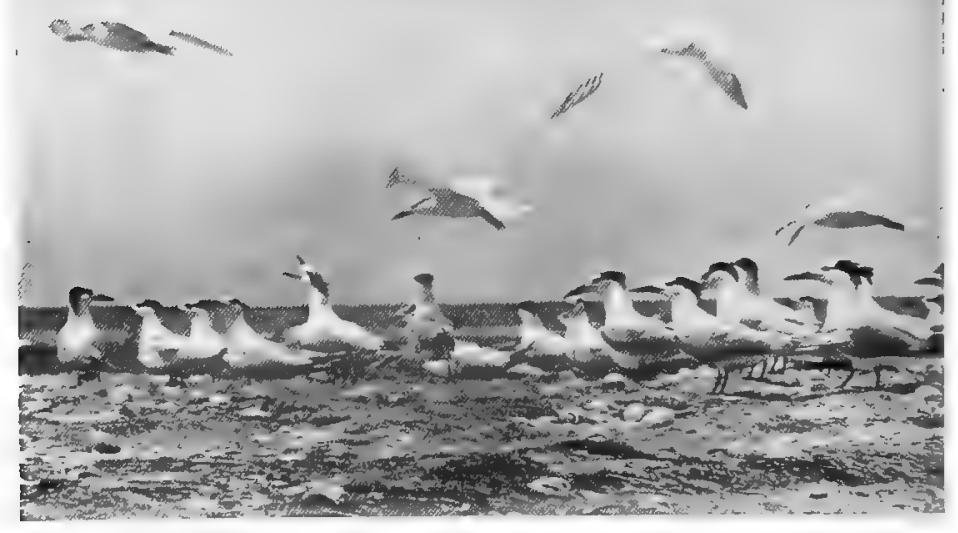

Fig. 9.-Royal Terns at their island nesting ground. Gulls and Terns are scavengers, clearing the surface of the water and the beaches of refuse, the decay of which might otherwise cause discase. (Photo by B. S. Bowdish, Secretary, New Jersey Audubon Society.)

very long tail. Geese and swans are two common domestic types of this group. Geese and swans, however, live more upon vegetable than animal feed. Aquatic birds differ greatly in their powers of flight. The wild geese migrate each year from North to South. Their powers of flight are highly developed, and they are capable of remarkable speed through the air. They fly in flocks, each year taking a well defined and similar route. In water fowls, particularly our domestic spericin, the nesting habit is but poorly devel- 
oped (Fig. 9). The duck, for example, lays but few eggs in a year, usually only from ten to twenty-five, the nests being generally made in low, wet, swampy places. The cry of the water bird varies with different types. The characteristic quack, quack of the duck should be familiar to every boy and girl. Eggs of the water breeds require a longer time for hatching than those of either the land or air birds.

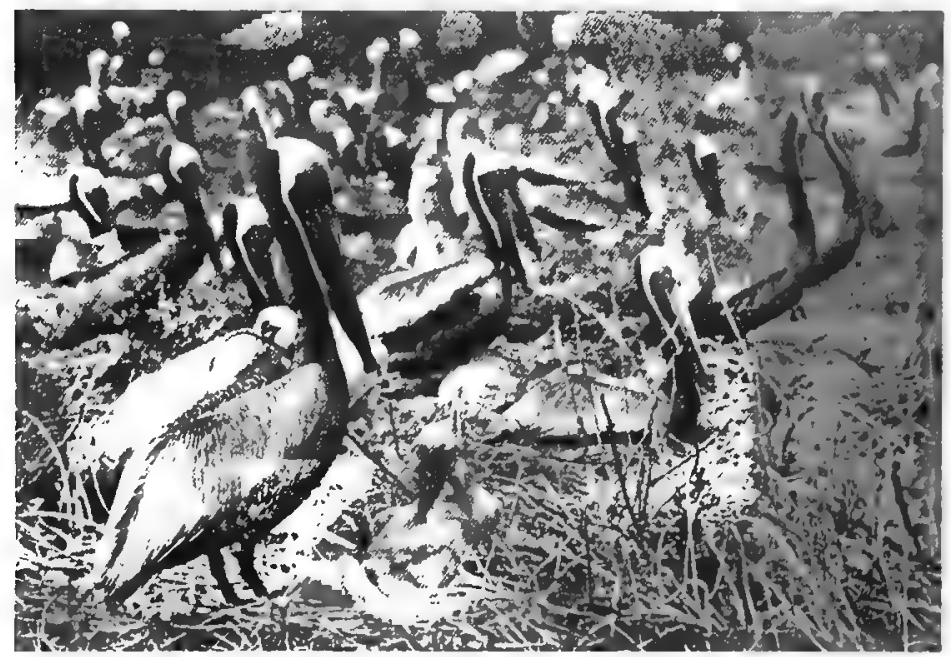

Fra. 10.-Brown Pelicans at their nesting site. One of the most picturesque eights of the southern cousts is afforded by these birds as they fup over the waves, or rest lightly on the water. The fish on which they mainly live are not of species used as food by man. (Photo by B. S. Bowdish, Secretary of New Jersey Audubon Society.)

With the common duck the period of incubation is about twenty-eight days. Some of the wild aquatic birds may be mentioned. Among them is the pelican (Fig. 10), which is a large bird, of peculiar shape, especially adapted to the eating of fish. It catches a number of fish, stores them in a pouch below its bill, and eats them when it wishes. The gull lives both in the air and in the water. It has highly developed wings, and is capable of extended flight. 
Terrestrial Birds.-This group embraces a great variety of birds, most of which live wholly on land, and rarely, if ever, go into the water. Their legs are usually long, the shanks and thighs being entirely outside of the body. In this group are found three distinct orders of birds. First, wading birds, of which the heron is an example, these having very long legs (Figs. 11 and 12). They frequent the banks of rivers, and feed on small insects and vegetable growth. The second order comprises the so-called scratching

A

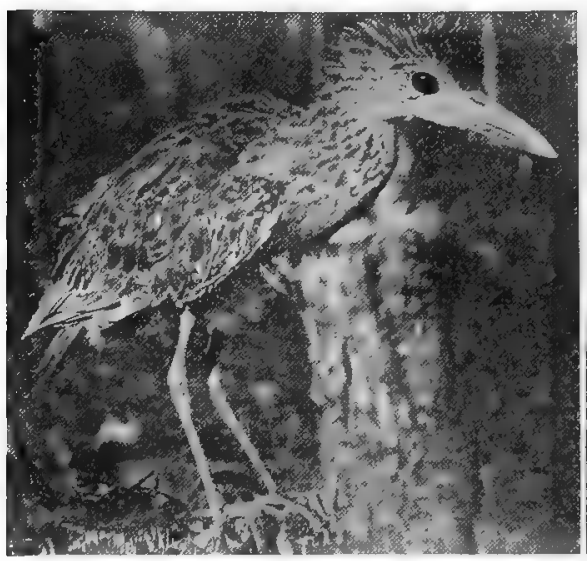

B

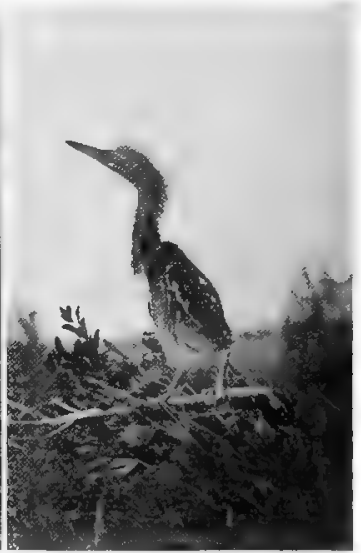

Fig. 11.-A, Young Black-crowned Night Heron. Herons eat some frogs, lizards, and other useful creatures, but offset this by destroying many insects. B, Young Green Heron. (Photos by B. S. Bowdish, New Jersey Audubon Society.)

birds, among which is the clomestic hen. Other common members of this group are the domestic turkey, the pheasant, etc. (Fig. 14). Pigeons represent a third order of bird very closely related to the aërial type. They have extended powers of flight, but also spend considerable of their time on the ground. The quail and grouse are two common wild species of the terrestrial group (Fig. 13). Their feet are adapted to scratching, the toes being webbed slightly at the base. As with our domestic birds the bill is short, thick 
and curved. A general description of our domestic fowl will be given later.

Aërial Birds. - This is by far the largest group of birds, including more orders than all of the other groups combined. Members of this group have toes especially fitted for grasping or perching, the fourth toe being level with the other three. The wings are designed for rapid flight. They hop along on the ground rather than walk. They usually build their nests

Fig. 12.

Fig. 13.

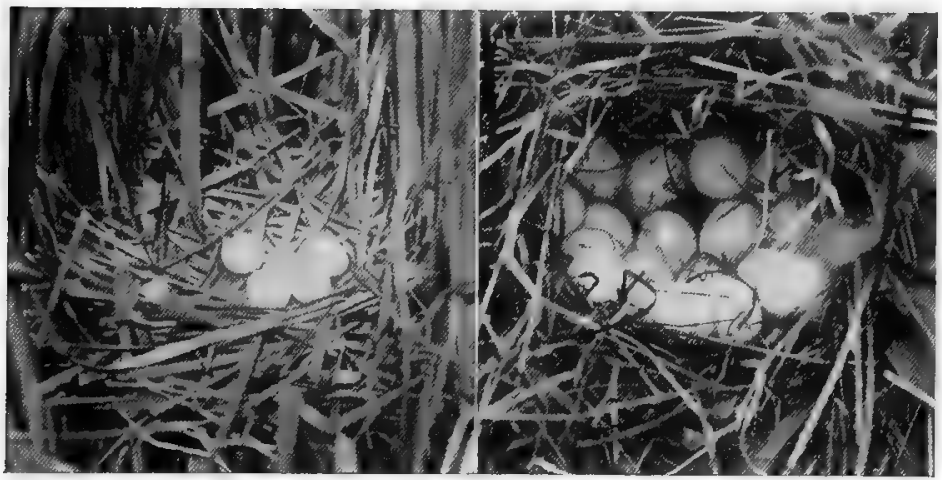

Frg. 12.-Green Heron's nest and eggs. The nest is built of coarse reeds and elevated above the ground.

FIG. 13.-Bobwhite's nest and eggs. The Bobwhite, often called "Quail," is ranked as a game bird of a high order, but to the farmer it is vastly more valuable as a destroyer of weed seed and insects than it is as garne or food for the huntsman. One thousand two hundred and eighty-six rose slugs were devoured in a single day by an immature Bobwhite; from 75 to over 100 potato beetles have been found in single stomachs. (Photos by B.S. Bowdish, Secretary, New Jersey Audubon Society.)

in trees, bushes or elevated places (Figs. 15, 16, 17, 18, 19,20, 21 and 22). Many of them have beautiful voices, and are called song birds. As a rule, they live in pairs, but rarely more than four to six eggs are laid in the nest (Figs. 23 and 24). It generally takes from fourteen to twenty-one days to hatch their eggs. At hatching time the young are helpless, and must be fed by the parent. Some common examples of this group are the humming bird, the woodpecker, the thrush, etc. The eagle is one of the largest and most power- 
ful of all birds, and is called a bird of prey, as it hunts and devours small animals. The hawk is another common example of powerful aërial birds (Fig. 25). Birds of aërial type are of little use to man, from a domestic standpoint.

A
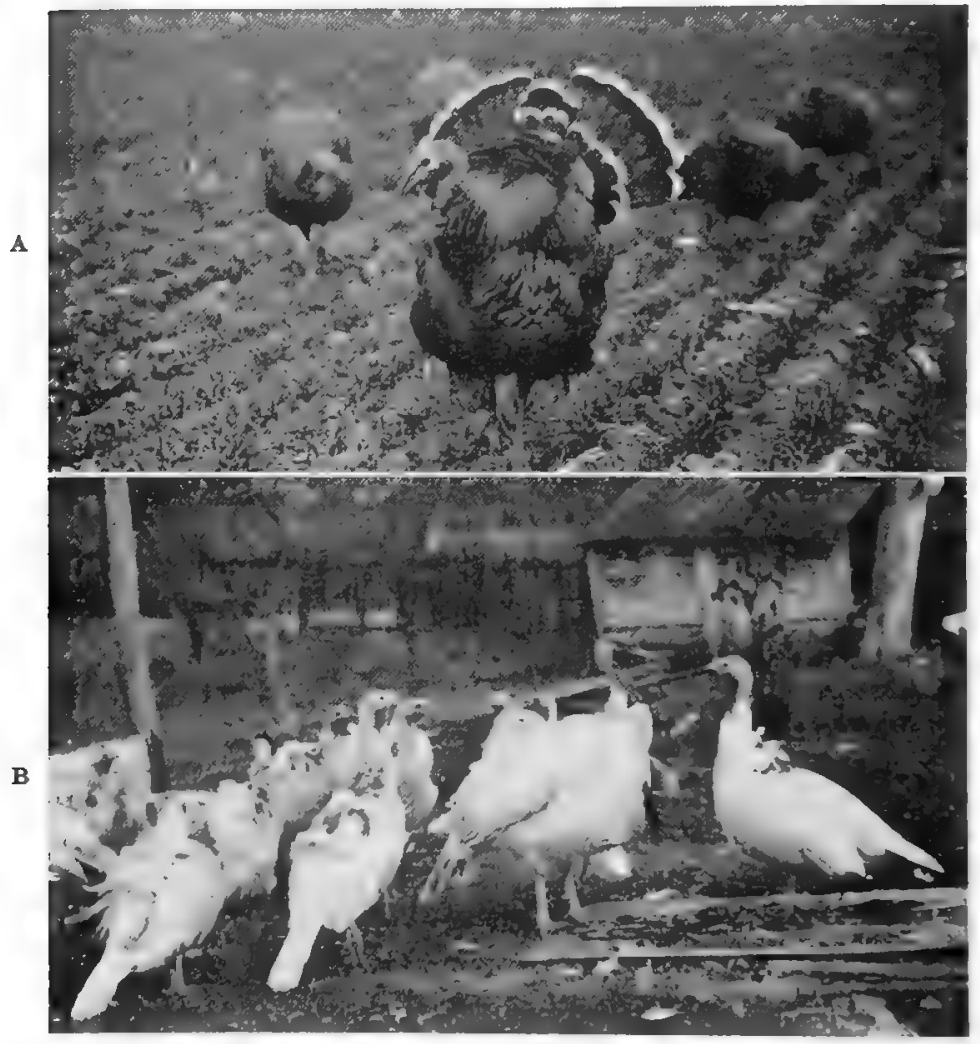

Frg. 14.-The turkey is one of America's most popular birds. A, Bronzo Turkey, male. B, A tlork of White Holland Turkeys. If allowed to roam turkeys get much of their food from waste products and natural vegetation.

They do, however, render him great service by destroying the insects and worms which prey upon crops and the foliage of trees. 
Fig. 15.

FIG. 16.

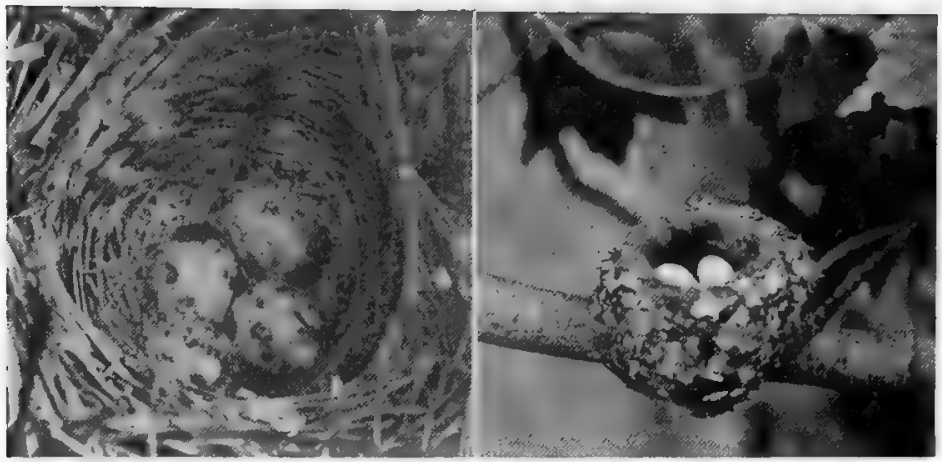

FIg. 15.-Song Sparrow's nest and eggs. The Song Sparrow sometimes nests on the ground and sometimes in bushes. The early nests are usually built on the ground, before the foliage is out on the bushes. This bird represents the great Sparrow family, valuable alike for their destruction of weed seed and insects.

Frg. 16.- Ruby-throated Humming Bird's nest and eggs. The Humming Bird's nest, built of the softest, cottony plant down, bound together with spider and worm webs, and covered with lichens from the trees, is both beautiful and difficult to detect. Contrary to the popular belief, these tiny birds do not confine their feeding to honey, but devour many tiny, but injurious, insects. (Photos by B. S. Bowdish, Secretary, New Jersey Audubon Society.)

FIG. 17.

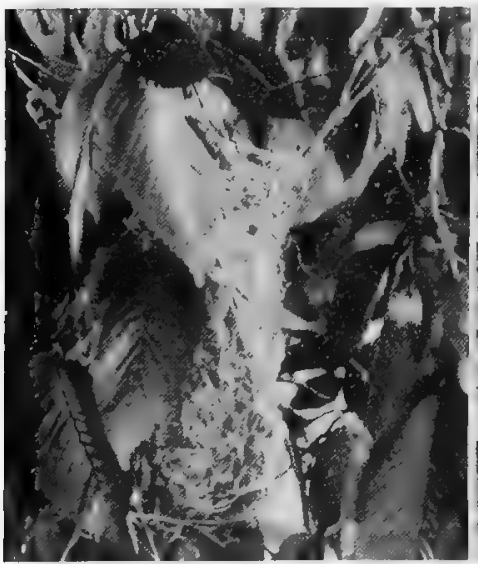

Frg. 18.

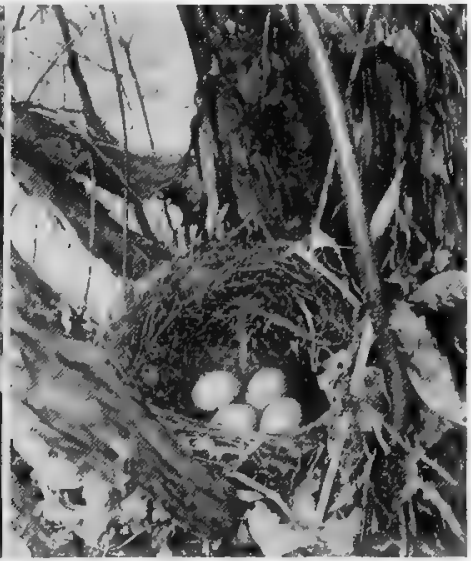

Frg. 17.-Baltimore Oriole's nest. One of the most beautiful examples of bird architecture. The orioles rank next to the cuckoos as destroyers of hairy caterpillars.

FIG. 18.-Wood Thrush's nest and eggs. The Wood Thrush is not only ranked by many as our finest northern singer, but is a very useful insect destroyer. (Photos by B. S. Bowdish, Secretary, New Jersey Audubon Society.) 
FIg. 19.

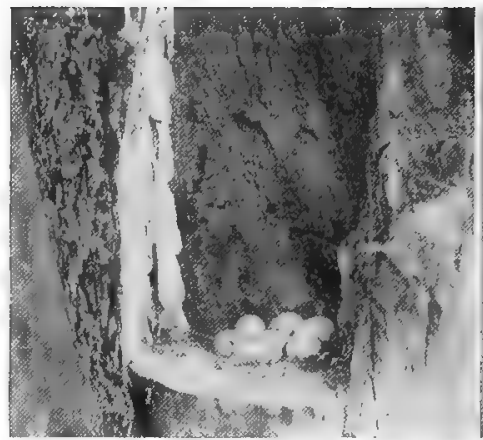

Fig. 19.-Flicker's nest and eggs. This is one of the most common of the Woodpecker family, the carpenters of the bird world, excavating their nesting holes in the dead branches and trunks of the trees and ridding the trees of wood borers and other injurious insects. Over 100 local names have been given to this species, of which $\mathrm{High}$-hole, High-holder and Golden-winged Woodpecker are the most common.

FIG 20.-Bluebird's nest and eggs. Before the advent of man, the Bluebirds and some others were forced to find nesting sites in deserted woodpecker nest holes and natural cavities in the trees and stumps. Now many occupy the boxes put up for them and pay a high rate of rent in insects killed and fed to their families. (Photos by B. S. Bowdish, Secretary, New Jersey Audubon Society.)

Fic. 21.

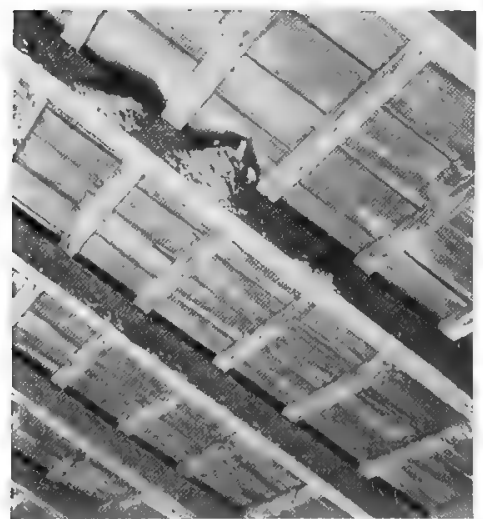

FIG. 22.

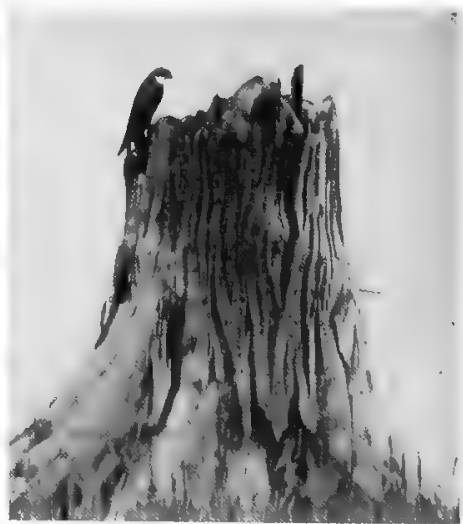

Fra, 21.-Barn Swallows' nests. The Barn Swallow is a mason, building its home prineipally of mud, with straws to strengthen it. In the North the swallows live largely on flies, gnats, mosquitoes and other annoying winged inseots; in the South they help to kcep down the scourge of the cotton boll weevil.

FIG. 22. - Tree Swallow at nesting hole in stump. (Photos by B. S. Bowdish, Secretary, New Jersey Audubon Society.) 
A

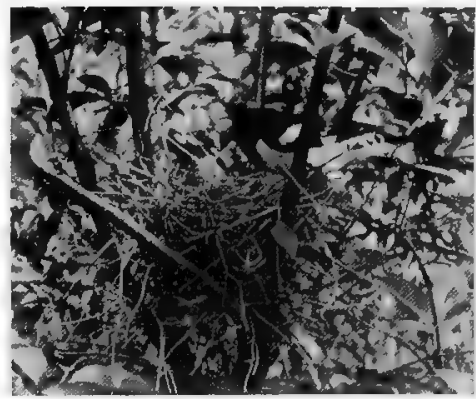

$\mathbf{B}$

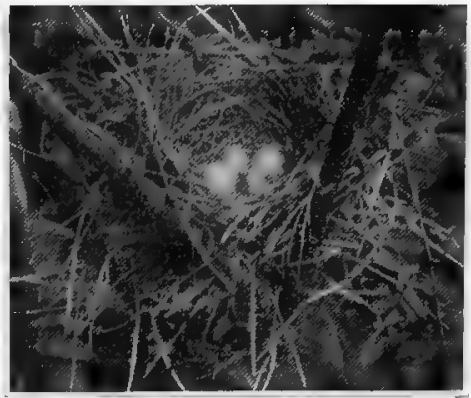

Frg. 23.-A, Rose-breasted Grosbeak at nest. A single pair of these birds, with their young, have been known to keep an entire potato patch free from beetles. They are beautiful of color and charming in song. B, Nest and eggs of Rose-breasted Grosbeak. One in the few birds the male of which performs his full share of the work of incubating the eggs. (Photos by B. S. Bowdish, Secretary, New Jersey Audubon Society.)

A

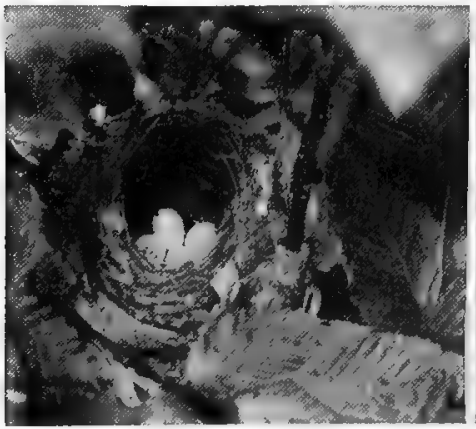

B

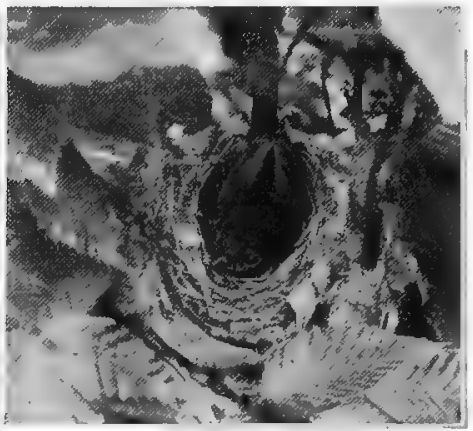

Fig. 24.-A, Hooded Warbler's nest and eggs. B, Hooded Warbler on nest. A naturalist watching a Hooded Warbler found that it caught on an average of two insects a minute, or 120 an hour. (Photos by B. S. Bowdish, Secretary, New Jersey Audubon Society.)

Protection of Our Wild Birds.-The domestic fowl is useful to man because it produces eggs and meat for food. Most of the common wild species are even more valuable because they destroy the natural enemies of crops and trees. Examination of the stomach of a bird shows that it lives largely on flies, grub worms, beetles and other insects. The common 


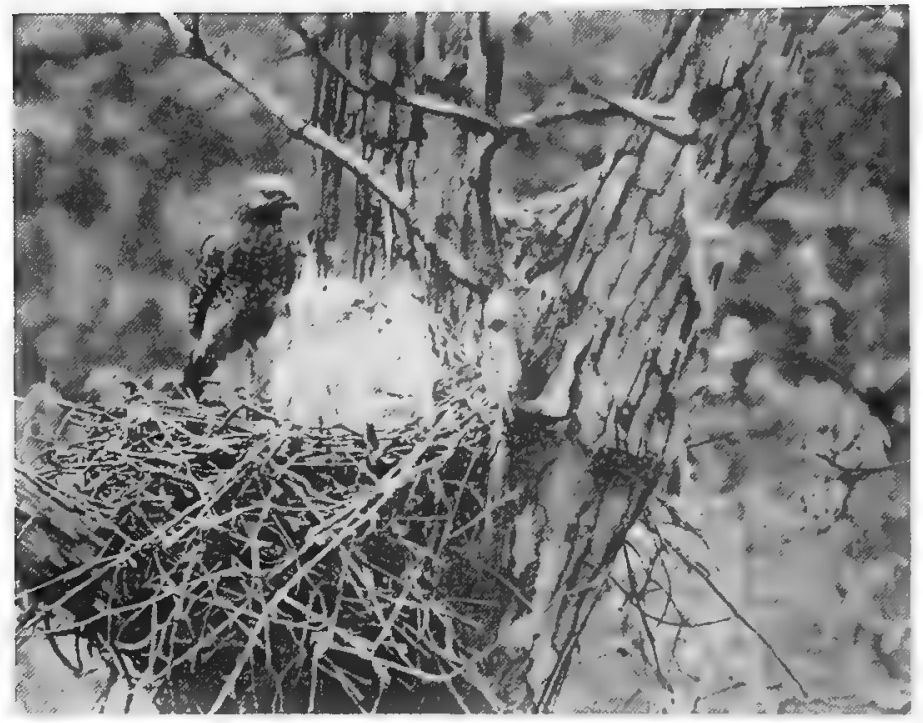

FIg. 25.-Red-shouldered Hawk and family. This is one of our large hawks, commonly styled "Hen Hawk," but unjustly so, as the bulk of its feed is rats, mice and other injurious rodents. (Photo by B. S. Bowdish, Secretary, New Jersey Audubon Society.)

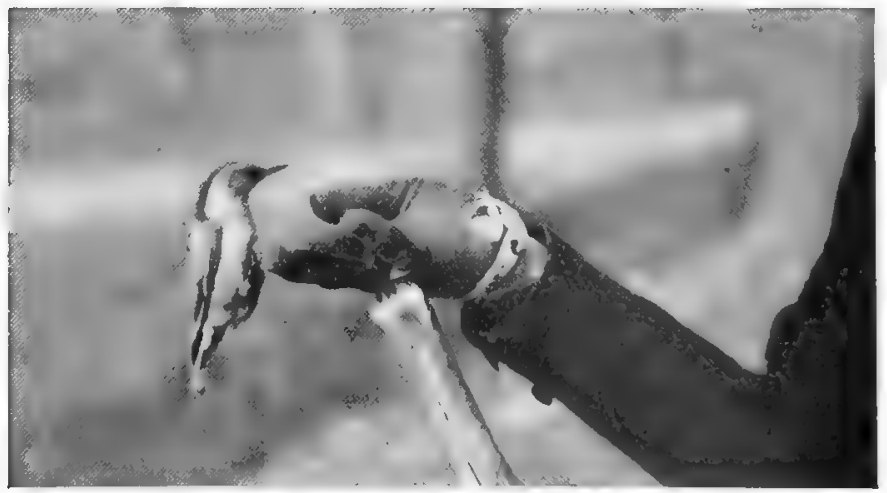

Fig, 26.-White-breasted Nutbatch on hand. Showing how kindness and feeding can tame a wild bird and make of one of our most valuable tree guards an intimate bird neighbor. (Photo by 13. S. Bowdish, Secretary, New Jersey Audubon Society.) 
caterpillar, the coddling moth larva, beetles, army worms, and spiders of all kinds are but a few of the many common enemies which our birds destroy.
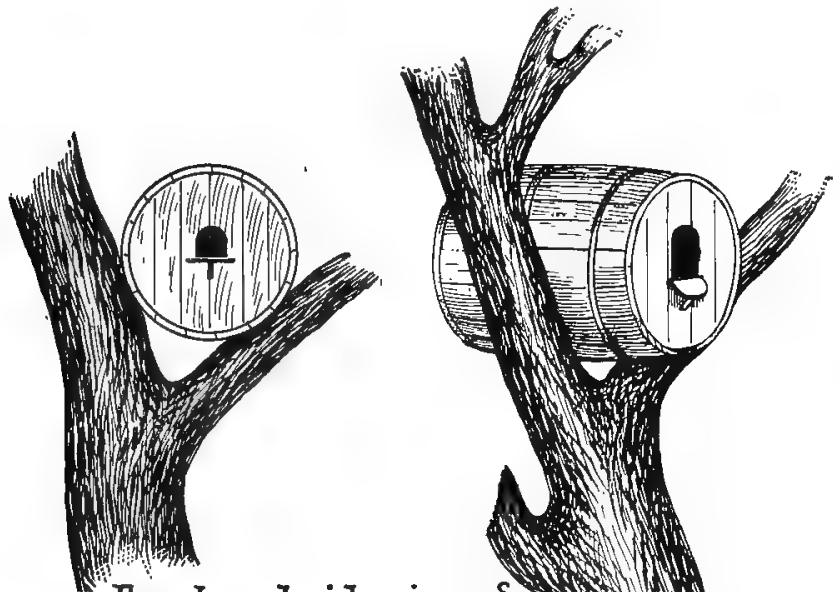

Fronzt and side view of

a bird's nest made from a nail

keg and placed in the crofclin of

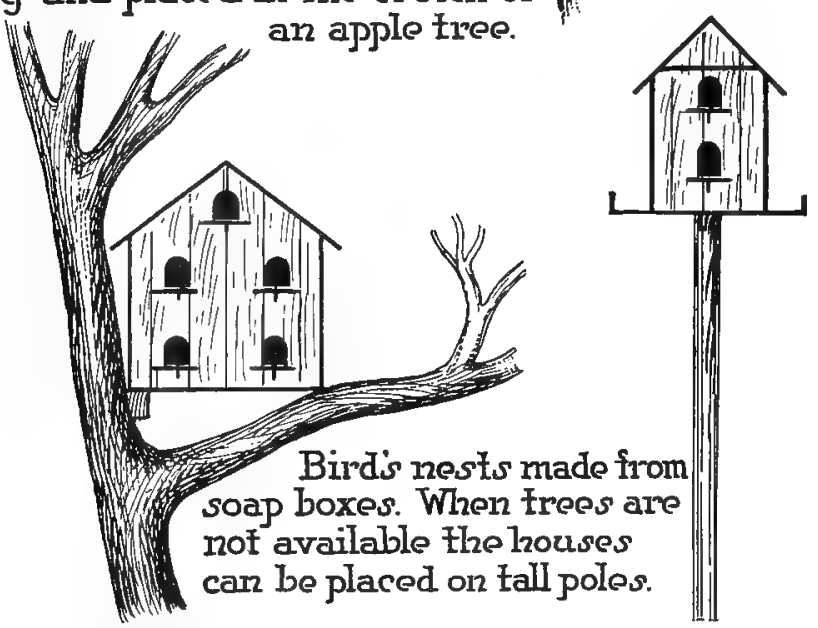

Fra. 27.-Simple and efficient bird houses can be made at home. 
In view of their economic value we should endeavor in every possible way to protect the birds (Fig. 26). Two ways of doing this are easy. First, we can provide about our homes bird houses (Fig. 27), either homemade or purchased, of such a type that certain kinds of birds can build in them, and be safe from all their enemies (Figs. 28 and 29). By feeding the birds and providing nesting places, boys and girls have a fine opportunity to study their little feath-

FIG. 28.

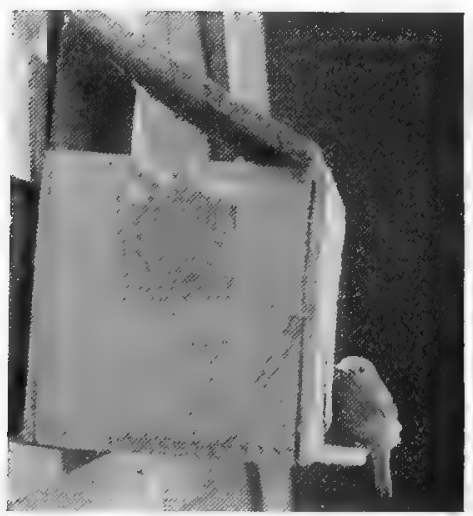

Fig. 28.-A Bluebird at nesting box. Bluebirds, too, are not over particular as to their nesting sites and will often occupy such boxes as are acceptable to wrens. They are attractive and desirable bird neighbors.

Fig. 29.-House Wren at nest box. Though tiny, the wrens are atoms of concentrated energy, both as to incessant, bubbling song, and the catching and eating of myriads of insects of many kinds. (Photos by B. S. Bowdish, Secretary, New Jersey Audubon Society.)

cred friends. Another admirable way in which to protect our birds is to feed them during the cold, snowy weather in the winter, when their natural feed is buried or covered with ice, and without the help of man many are sure to starve. Suet, meat, fine grain, and bread crumbs are easily given and will be relished. By having a board outside of the window to which the birds may come to eat, they can be studied and made friends with while pecking at the food (Fig. 30). 


\section{LABORATORY EXERCISES}

Exercise No. 1.-Secure and have in the classroom a common representative of each of the three classes of birds, as follows, - a domestic fowl to represent land birds, a duck to represent water birds, a house canary, sparrow or other wild bird to represent birds which fly in the air. Let different members of the class point out different characteristics of these three specimens, showing points in which they are

A

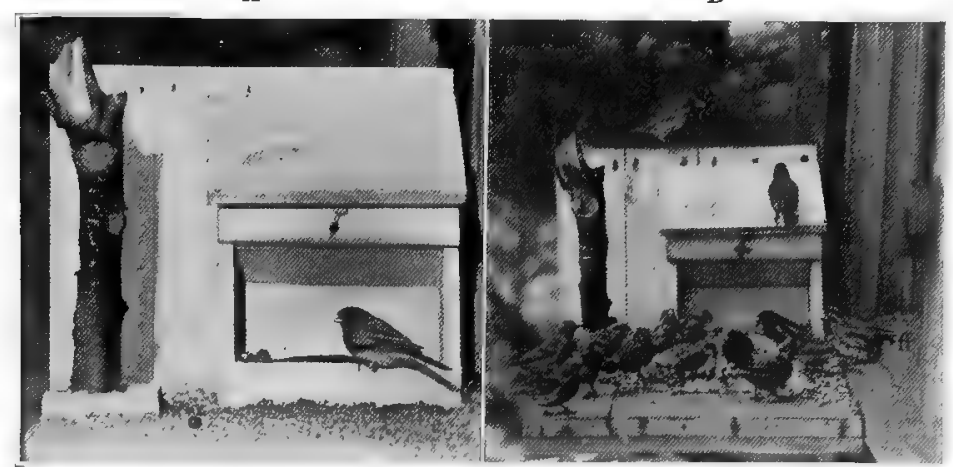

FIG. 30.-A, Slate-colored Junco or "Black Snowbird" on feed shelf. Such a shelf is easily constructed, with a hopper similar to a poultry feed hopper, for holding the mixed bird seed, bread crumbs and meat scrap which form an acceptable addition to their winter menu of weed seed. B, Purple Finches on feeding shelf. (Photos by B. S. Bowdish, Secretary, New Jersey Audubon Society.)

similar and parts which are unlike. The special points of difference, as mentioned in the text, should be shown to the class.

Exercise No. 2.-Let each student collect three or four feathers. The feathers selected for study should be from different parts of the body, from the tail, wings, back, and body fluff will be sufficient. With the aid of a small hand lens study the structure of each feather. Point out and be sure that the class is familiar with the different parts mentioned in the text. Study the difference in structure 
between the main tail feather and the fluff feathers. Note the absence of barbs on the fluff, thus allowing the web to fluff out.

Exercise No. 3.-Describe to the class the different types of bird nests. Plan a trip through the woods where the nesting habits of birds may be studied. Encourage the study and protection of wild bird life. Discourage the tearing down of birds' nests. A small prize may be offered for the pupil finding and describing the greatest number of nests of different birds.

Exercise No. 4. - Set aside a period when each member of the class.may construct a small and simple bird house. If the school is equipped with tools for carpentry work this will be an easy exercise to work out. If not, the tools will have to be brought from home. A soap box or nail keg can, with little effort, be reconstructed into an attractive and cozy bird house. The pupils should be allowed as much freedom as possible in working out the design. After the houses are built, they should be taken home by the one building them and placed in a tree or on a pole in the yard. The birds which inhabit the house can be studied. A few bird houses should be built and placed about the school yard.

\section{THOUGHT QUESTIONS}

1. What is meant by the term "bird"?

2. What comprises the animal kingdom?

3. Mention some of the peculiar characteristics of the class aves or birds.

4. How do birds differ from other animals?

5. Mention different examples of the various types of birds.

6. Describe a bird's skeleton.

7. What are the functions of the wings and tail?

8. How do the feet of land and water birds differ?

9. Describe the parts of a feather and their functions.

10. What is meant by the term "moult"?

11. How do birds reproduce their kind?

12. Describe the nesting habits of birds.

13. Into what three groups are all birds diviuled?

14. Give examples of each of the above groups. 
15. Describe the general characteristics of water or aquatic birds.

16. Enumerate peculiar features of the "pelican" and "gull."

17. What are the distinguishing features of land or terrestrial birds?

18. To what group do the quail and grouse belong?

19. Name the characteristics which are peculiar to the aërial or air birds.

20. To what group do the humming bird and woodpecker belong?

21. Of what use are the aërial birds to man?

22. Why should wild birds be protected?

23. Name two ways in which boys and girls can help protect our bird friends.

24. Describe a home for birds which you have seen or have built.

References.-United States Farmers' Bulletins: 54, Some Common Birds; 64, Ducks and Geese; 197, Importation of Game Birds and Eggs for Propagation; 200, Turkeys; 234, The Guinea Fowl; 390, Pheasant Raising in the United States; 456, Our Grosbeaks and their value to Agriculture; 493, The English Sparrow as a Pest; 497, Some Common Game, Aquatic, and Rapacious Birds in Relation to Man. 


\section{CHAPTER II}

\section{THE DOMESTIC FOWL}

Origin of Domestic Birds.-The domestic fowl is a term commonly applied to those birds which are reared for domestic uses. They belong to the large and mixed group of scratching birds. The following are the more common species: the domestic hen, the turkey, the guinea fowl, the partridge, and the pheasant. Scientists tell us that there were two original species which entered into the early history and development of our domestic hen. One of these ancestors was the jungle fowl (Gallus Bankiva), and this species is quite common in the wilds of central Asia and the jungles of India. It is a small bird, less than one half the size of our American breeds of to-day. It has a single comb and wattles; its ear lobes are similar to those of our domestic fowls. Its shanks are slender, relatively short, and greenish in color. The female is much smaller than the male, this being characteristic of a great many wild birds (Fig. 31).

Owing to the fact that these fowls have lived in a wild state for many years, they are capable of extended flight. In mode of life they resemble the quail and pheasant. In order properly to develop the life history of our present breeds we are compelled to assume that another species besides the Gallus must have been present in the early ages. This ancestor must have been of heavier build, with an abundance of feathers, especially on the shanks. It is supposed to have been the Malay or Aseel fowl, which is now only rarely found. The Malay is probably one of the earliest species of the domestic fowl. Records and legends of antiquity mention them as being raised in Asia nearly four thousand years ago. The Malay fowl has the characteristics which are common in our heavier fowls, but are not apparent 
in the Gallus. These are a heavy, meaty body, heavy, yellow shanks (feathered), and a pea comb. In disposition this bird is quiet and docile, a characteristic also of the Brahma and other Asiatic breeds of to-day (Fig. 32). It is doubtless

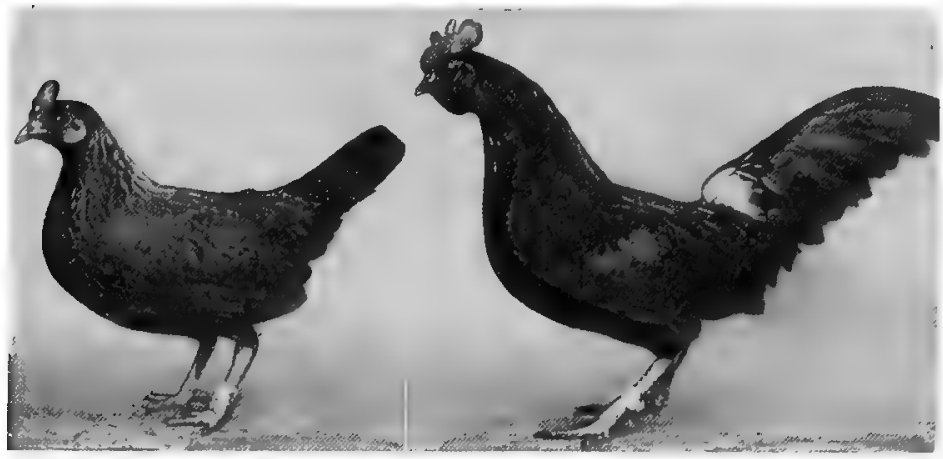

FIG. 31.-A pair of jungle fowls, supposed to be one of the ancestors of our common breeds of to-day. They resemble in many ways the egg breeds. (Photo by Station of Experimental Evolution, Cold Spring Harbor, L. I.)

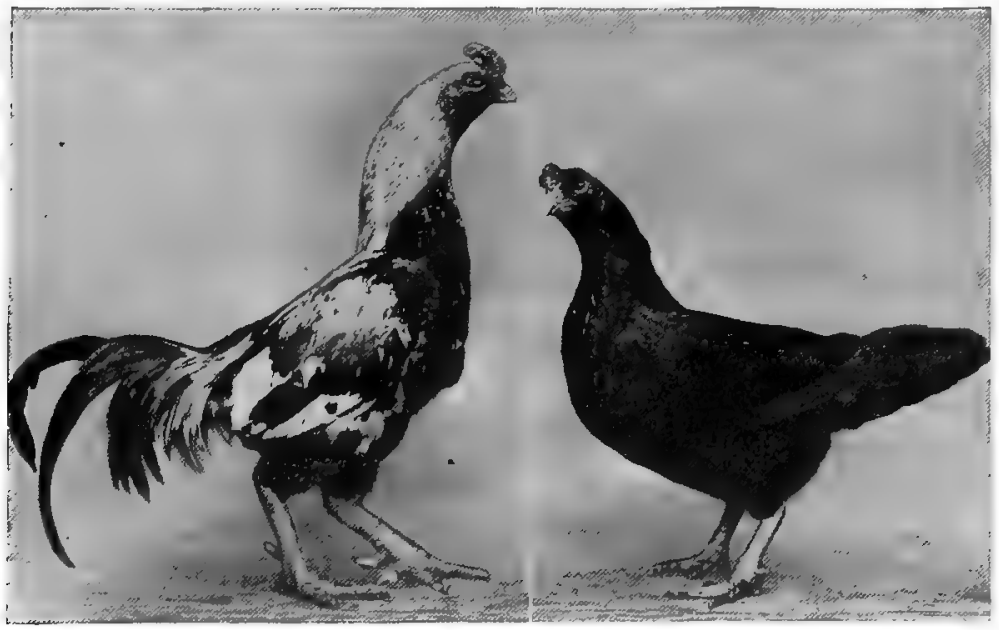

FIG. 32,-A pair of Malay or Aseel fowls which has given to our meat breeds of to-day their size and great weight. (Photos by Station of Experimental Evolution, Cold Spring Harbor, L. I.) 
true that nature and artificial selection through generations have resulted in the development of our present breeds from these two original ancestors.

The Term "Poultry" Defined.-The term "poultry" is applied in a general way to many different types of birds, either land fowl or water fowl. Strictly speaking, it means only those fowls which are kept in confinement or in a state of domestication. The American Poultry Association in its "Standard of Perfection" gives the following definition: "The above applies directly to the commercial value which poultry possesses. Poultry are domestic fowls reared for exhibition and the table, for eggs and for feathers."

Development of Our Breeds and Varieties.-Since prehistoric times, birds have doubtless been reared by man for food. In the early ages, man went forth in search of food, and killed the birds with arrows or other weapons. There are records as to the keeping of poultry which date back to 1000 B.C., and these show that birds were not only kept for food, but were also trained for the sport of cock fighting. Mediæval history contains many references to poultry and birds, and it is doubtless true that their development and improvement have followed the course of civilization across Europe and into Africa, as both of the original ancestors were Asiatic in origin. History tells us, too, that both were found in America in the early period of its development, but the last century witnessed a marked increase of interest and enthusiasm in the improvement of poultry. It is, indeed, only in recent years that they have been carefully and logically divided into breeds, and again subdivided into varieties. To-day there are listed more than 109 standard varieties which are as yet not recognized as official. This recent improvement and development are largely the outcome of efforts to enhance the commercial value of the birds.

Classifications. - Our common domestic breeds of poultry to-day are divided into four groups, which are designated 
as follows: type, class, breed, and variety. We have three different commercial types; namely, eggs, meat, and general utility.

The birds are classified according to their ability to yield a commercial product, as designated by the class name. This term is also used to describe their natural conformation, function, and growth. The term "class" is also used to differentiate the breeds according to their place of origin, as the American class, the English class, the Mediterranean class, the Asiatic class, etc. Each of the groups contains breeds which originated at the points designated.

The term "breed" applies to those of one body shape and form; for example, Leghorns, Plymouth Rocks, Rhode Island Reds, etc. Each breed has its distinctive body shape. Different characteristics are common to different birds, and usually result in a tendency towards some general commercial purpose.

The term "variety" indicates a subdivision of the breed. It is largely determined by the color of the plumage and by variation in the characteristics of the comb. For example, we have barred, white, and buff Plymouth Rocks, all three of which have the same shape, hence belong to the same breed. We have also the rose and single comb White Leghorn, both of which have the same shape and color, and differ in comb characteristics. The determining factor in classifying according to type is the natural ability of the birds to yield a general type of product, as eggs or meat, or both. The determining factor in classifying according to breed is the body shape, and in classifying according to variety within the breed is primarily the plumage. The determining factor in classifying according to class is historical development in regard to place of origin. 


\section{THREE CLASSIFICATIONS OF POULTRY}

\section{STANDARD}

Largely Based on Origin

1. American Class. Plymouth Rock.

Wyandotte.

Java.

Dominique.

Rhode Island Red.

Buckeye.

2. Asiatic Class.

Brahma.

Cochin.

Langshan.

3. Mediterranean Class.

Leghorn.

Minorca.

Spanish.

Blue Andalusian.

Ancona.

4. English Class.

Dorking.

Red Cap.

Orpington.

5. Polish Class.

Polish.

6. Hamburg Class.

Hamburg.
7. French Class.

Houdan.

Crevecoeur.

La Fleche.

8. Game and Game Bantam Class.

Game.

Game Bantam.

9. Oriental Class.

Cornish.

Sumatra.

Malay.

Malay Bantam.

10. Ornamental Bantam Class.

Sebright.

Rose Comb.

Booted.

Brahma.

Cochin.

Japanese.

Polish.

11. Miscellaneous Class.

Silkie.

Sultan.

Frizzle.

UTILITY

Based on Usefulness to Man

1. EgG Breeds.

Leghorn.

Minorca.

Ancona.

Campine.

Houdan.

2. Meat Breeds.

Brahma.

Langshan.

Cochin.

Cornish Game.
3. General Purpuse Breeds. Plymouth Rock. Rhode Island Red.

Wyandotite.

Orpington.

Dorking.

4. Miscellaneous Breeds.

Polish.

Hamburg.

Blue Andalusian.

Bantam.

Frizzle.

Silkie. 


\section{THE DOMESTIC FOWL}

\section{FARM}

Based on the Purity of Breeding.

1. Mongrel or Mrxed Breeds. Has no definite blood lines, but possesses a great variety of the blood lines of the standard breeds. ally not practised commercially for more than one year without going back to the original standard-bred bird.
2. Cross Breeds.

Consist of standard-bred birds bred together. Usu-
3. Standard Bred.

Standard breeds as recognized by the first two classifications.

Standard Classifications.-As was previously mentioned the standard of classification is the one adopted by the American Poultry Association, which groups domestic fowls into fourteen classes, one distinguishing factor being the point of origin. It is impossible to give here a detailed description of every breed and variety, but the above table gives a skeleton outline of these brceds. For a more detailed description the student is referred to the "American Standard of Perfection," published by the American Poultry Association. This book should have a place in every poultryman's library. The preceding table gives eleven of the standard classes.

Utility Classification.-Utility classification is so termed because it is based on the type and the value of the commercial products yielded. The common breeds of domestic fowls fall into one of four utility classes: Egg breeds, meat breeds, general purpose breeds, and miscellaneous breeds (Fig. 33).

Examples of egg breeds are the Leghorns, Minorcas, and the Anconas. These birds are distinguished by an active, nervous temperament, possess great powers of flight, and are hard to confine. As a class they mature comparatively early; Leghorns often grow their main tail and wing feathers at from three to six weeks. They are relatively poor sitters, being too nervous and restless to stick closely to the nest for three weeks, but are excellent foragers, roaming a long 


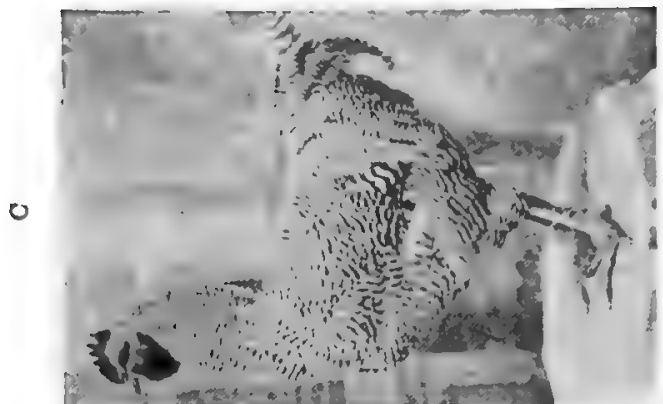

올

造是 $2 \mathrm{~g}$ 步是 $=$

. 듬용 두을 a 点目 몰 HE 承. 录递

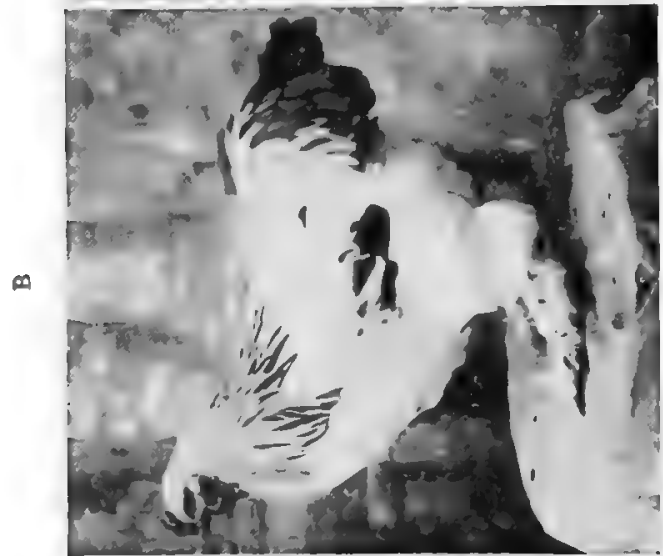
5 를 0 0 을 온

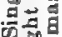
근 <‥ 들 i. 5 है एक्ष = 串 是要

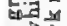
$>0$ ํํㄴ 承要 0.0

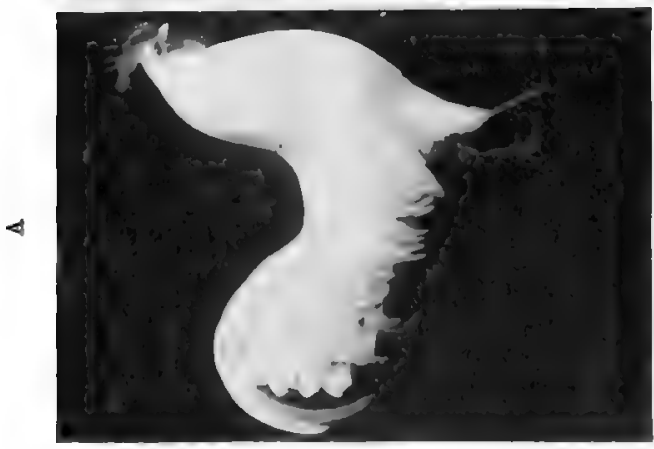

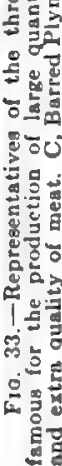


distance in search of feed. They are easily affected by exposure to cold weather, owing to their large head parts and close feathers. The Leghorn is one of the most popular egg breeds in America.

The flesh type is represented by the heavy Asiatic breeds, the Brahmas, Langshans, and Cochins being the leaders in the order named. They mature late, but are large, heavy, fleshy birds, full feathered, slow of movement, and quiet, lazy and docile in disposition. They are rangy and awkward in their early growth. They make persistent sitters, but owing to their large size and full feathered shanks, are apt to crush the eggs. On the other hand, their quiet, lazy disposition makes them poor foragers, and they will roam no great distance in search of feed. Their full feathers and heavy covering of flesh enable them to bear extremely cold weather, but this excessive development of flesh makes them poor layers.

The general purpose class includes such breeds as Plymouth Rock, Wyandotte, Rhode Island Red, and the Orpington, which are medium in size, moderately feathered, and lay a fair number of eggs. In general they combine the characteristics of both the egg and meat breeds. In disposition they are gentle, bearing confinement well. They mature moderately early, and make excellent sitters and mothers. As a class, they are much better foragers than the heavier breeds, and are extremely hardy. The Plymouth Rock takes the lead in this class, with the Rhode Island Red a close second. These are called general utility breeds, because they are especially adapted to the average farm or home poultry flock, where the object of the poultryman is to keep a small number of birds to provide eggs and meat for the home table. In sections where there is a demand for roasters and capons, a large meat breed will be superior, whereas if commercial egg production is the prominent issue, the Leghorns or members of the egg class are best. 
Under the term "miscellaneous" come the fancy breeds. This class includes numerous types which are especially distinguished by plumage of fancy or peculiar color; for example, the Polish, the Hamburg, the Sultan, and the Bantam. These birds are not raised for their commercial value, but chiefly as pets, and in some cases for show purposes.

Of all the birds named in the utility classification the Leghorn ranks first as a producer of white market eggs. The Plymouth Rock, Rhode Island Red, and Wyandotte rank preëminent when both eggs and meat are desired, or when a chicken for dual purposes is the object. The Brahmas and Langshans are leaders when a bird of extremely heavy weight, with a full round body, is demanded.

Common Farm Types.-The average domestic fowl, as it is found on poultry and general farms, is represented by one of the following types: Mixed or mongrel birds, cross bred birds, and pure or standard birds. The mixed or mongrel is the type prevailing on farms. These have been crossed or mixed in their breeding, for many generations. They vary greatly both in plumage pattern and body shape, and also in their ability to produce eggs, but they are essentially mongrel or impure, as their name implies. Mongrel birds possess no superiority, in fact they are inferior to pure bred birds for any object.

Cross bred birds are the result of mating two pure bred birds; for example, the Barred Plymouth Rock female and the Rhode Island Red male, the offspring being called cross bred. Cross bred birds are often produced for some definite purpose. Where roasters and capons are in demand, cross breeding is profitable commercially. Pure bred fowls are used each year to secure the new cross. The first generation after the cross will run quite uniformly, but cross bred birds should not be used for breeding, as the offspring is apt to become more and more impure and less uniform. 
Pure bred birds are those which have been bred for a number of generations until a particular type has been fixed. A large percentage of the progeny from pure bred birds will resemble the parents.

Standard bred birds are those which have been recognized by the American Standard of Perfection, and of which a standard description has been published, and it is to this standard that all breeders should attempt to conform.

There are many breeds that have not as yet been admitted to the American Standard of Perfection.

Value of Pure Bred Birds.-For any purpose pure bred birds are more valuable than mongrels. In the first place, there is greater certainty in breeding. The progeny in greater numbers will show the characteristics of their parents. Pure bred birds are also more efficient. For instance, the egg breeds are bred and grown for egg production slone. They, therefore, are much better producers of eggs than the meat breeds. On the other hand, the Brahmas and the heavier breeds, from the fact that they have been bred for generations for meat production, are quiet in disposition, and their feed tends to promote flesh growth. Pure bred birds yield a greater uniformity in production. This applies to shape, color, and size of egg, also to quality and amount of flesh production. A uniform flock of pure bred birds will show the same body form and color. They are much more attractive and interesting to work with than mongrels, while the cost of securing them is not materially higher, nor that of feeding and caring for them any greater. The demand for pure bred birds is large, and far in excess of any call for birds of mixed breeding. The young poultryman starting out with pure bred birds can reap a considerable revenue by selling eggs for hatching, in addition to that from the sale of adult birds.

Getting Started.-As with all other lines of business the road to success for the poultry keeper is to start in a small 
way. He should invest but little in buildings and stock. The plant must be developed slowly. A more staple and successful business can be built up by making a small beginning than by a costly one. The few failures which occur in the poultry business can be traced directly to a too heavy investment at the start, and to lack of experience. But experience is certain as the work progresses.

Securing the First Birds.-When starting out to keep a small flock of birds, there are three ways by which the poultryman can secure his first flock. One is by purchasing eggs for hatching. Another is to buy adult birds, and by mating these he can produce his own eggs. The third method is to buy day-old chicks. Of the three modes, that of purchasing and hatching eggs is the least expensive, and the buying of day-old chicks is the next. But, in all probability, the most satisfactory way is to buy a small brooding pen of hens and mate them with a male bird of good breeding and high vitality. During the hatching season the eggs from this pen should be saved. Thus the poultryman will know the characteristics of his stock, and can give the birds proper care previous to incubation. Eggs for hatching should be purchased from a reliable breeder, and if they prove to be poor or infertile, the person selling them should make the sale good.

Care in Buying Foundation Stock.-In buying the first breeding pen of hens, select with great care. The first requirement is absolute health, combined with plenty of vitality and vigor. Never buy birds which are, or ever have been, subjected to the common poultry diseases, such as roup, chicken-pox, and canker. The external signs of a strong constitution are to be found in the size of the body, the carriage, the prominence of the eye, the width of the body, etc., and a strong constitution is cssential if the birds are to make good breeders and egg producers. Two important requirements are size and weight. The practice is too com- 
mon of breeding from small birds, which in turn lay small eggs, which hatch small chicks. In selecting birds of any definite breed, choose those as near standard weight as possible, or, if anything, a little heavier. The large hen lays the large egg, which hatches the large, fluffy chick. Breeding birds should be at least one year old before their eggs are saved for hatching. It is quite the custom to purchase yearling hens, and mate them to a good, vigorous cockerel during the breeding season. Pullets should not be used for breeding, as their continued use will result in progeny of small size as well as decreased vitality. Old birds are not desirable for breeding, as they are likely to be very fat, and brooding hens which are fat are apt to lay infertile eggs. The next points to be considered are those of body shape and color of plumage. These two factors determine variety and breed. The principal considerations in choosing stock should be health, vitality, weight and age. Unless the birds possess these first four qualities, their shape and color, no matter what, might fail to appear in their progeny. Desirable coloring should be as nearly as possible like that specified in the American Standard of Perfection, and the body shape should conform as nearly as possible to the approved type for the breed selected.

Select the Breed Suited to Local Conditions.-In choosing the breed, consider local conditions, such as market requirements and demand, and try to select a breed of a type which will best meet these conditions. Three types to be considered are, the egg group, the meat group, and the general utility group. If market egg production is the primary object, select one of the egg breeds; if meat production is desired, one of the meat breeds. If both egg and meat production are the aim, then the general utility breeds are best. The following chapters deal with these classifications, and should be carefully studied, as the discussion will bring out in detail the characteristics of the different types and breeds. 


\section{LABORATORY EXERCISES}

Exercise No. 5.-Siccure for study a representative of the egg, meat, and general purpose type of fowl; go over each individual slowly, pointing out the characteristics which are peculiar to each type as described in the text.

Exercise No. 6.-Have present in the classroom as many varieties of one breed as it is possible to secure. Call attention to the similarity in body shape and form. Emphasize the distinguishing variety feature of color or comb character.

EXercise No. 7.- If possible, allow the pupil to study at close range the differences in color and type existing between three birds; one a mongrel or barn yard chicken, another a cross bred bird, and the other a well bred bird of some standard breed. Note the uniformity of color and form in the standard bred bird. Explain to the class what could be expected from the chicks hatched from eggs laid by each of these three types.

ExerCise No. 8.-Secure a number of hens representing good and poor birds. These may be placed in one large coop or pen. The pupils can then look them over carefully and designate the healthy, vigorous birds from the inferior ones. This exercise should be conducted with the idea of choosing birds which are to be used for foundation stock from which the chicks for next year are to be raised. When making the above selection the factors of health, vigor, weight, and age should be given special attention.

\section{THOUGHT QUESTIONS}

1. Define the term "domestic fowl."

2. Give examples of the common species of domestic fowl.

3. Describe the habits and haunts of "Gallus Bankiva."

4. What was the Mialay or Aseel fowl?

5. Describe briefly the probable origin of our common domestic fowl.

6. Define the term "poultry."

7. Give the definition of the term which is given by the American Poultry Association. 
8. Trace the development of poultry from the earliest time up to their condition as found to-day.

9. Name the different classifications into which poultry may be divided.

10. Define the meaning of the term "types."

11. What is meant by the terms "class," "breed," and "variety?"

12. What is meant by the standard classification?

13. Enumerate the different classes of this grouping.

14. How is the utility classification of use to the poultryman?

15. Name a few of the prominent features of the egg breeds.

16. What is the predominant character of the meat breeds?

17. Why are the general purpose breeds so popular?

18. What is meant by the mongrel bird?

19. Define the term "cross bred bird."

20. Tell what is meant by a pure bred bird.

21. Name some of the reasons why pure bred birds are far superior to mongrels or birds of mixed breeding.

22. What is the best way to start keeping poultry?

23. Name three methods which can be used to secure the first birds.

24. Describe the best and safest method of securing the foundation stock.

25. Enumerate facts to be especially considered when buying or selecting foundation stock.

26. How will local conditions and demands determine the breed selected?

References.- United States Farmers' Bulletins: Standard Varieties of Chickens; Consult "American Standard of Perfection." 


\section{CHAPTER III}

\section{THE EGG BREEDS}

THE group of birds which come under the general title of egg breeds are a widely distributed and popular group, and are found in great numbers near the large centers of population. They seem to be more popular along both the Atlantic and Pacific coasts than in the central part of our country. The term "egg breed" is used because their chief characteristic is their ability to produce at a profit a great number of eggs. In addition to the number of eggs produced it is necessary that they be produced at the season of high prices, that is, during the winter months. In the Spring, the natural egg production from the farm flocks greatly increases the market supply and lowers the selling price. The object of commercial egg farms, where egg breeds predominate, is to produce eggs out of the natural laying season. These egg breeds are usually kept in large flocks, ranging from one hundred to one thousand birds to a plant. The care and management necessitates but a minimum amount of labor, owing to the fact that they can be herded together. Their bodies are small, hence they consume a relatively small amount of feed in proportion to the yield of eggs. The Petaluma District on the Pacific coast and the Vineland District in New Jersey are two centers where the White Leghorn of this type is kept in large numbers and throughout extensive areas, and these districts have attained a world-wide reputation (Fig. 34).

\section{CHARACTERISTICS OF THE EGG BREEDS}

Size and External Appearance.-The egg breeds, as a group, are small and of light weight, an adult bird weighing from three to five and one-half pounds, three and one-half 
to four pounds being the average. They are very close feathered, in this differing materially from the heavier breeds. They usually have very clean shanks, which are entirely free from heavy feathers, and rarely show stubs or small feathers. They are neat in appearance, and their carriage and attitude are trim and sprightly. As a group, they have rather long legs. The bones are small, the flesh hard. The head and body are always held erect, which gives them rather a tall appearance.

$A$

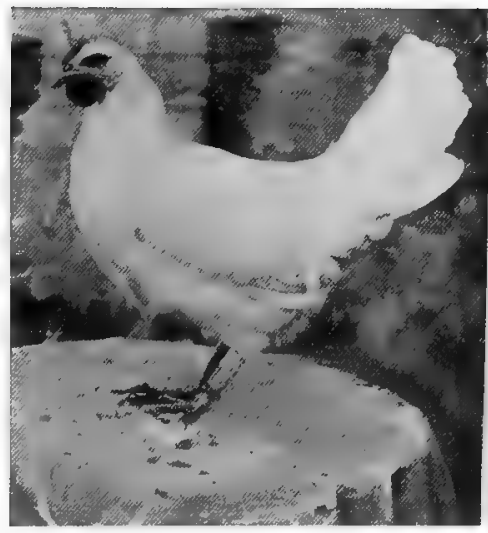

B

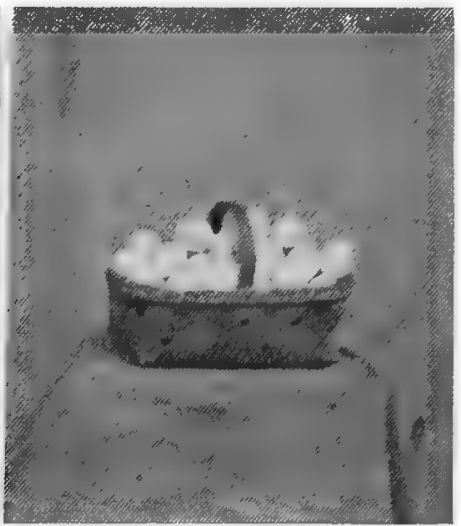

FIG. 34.-The White Leghorn is the most popular of all egg breeds. A, A Leghorn hen showing great vigor and excellent utility form. B, The popularity of the Leghorn is due to the large production of beautiful, white-shelled eggs.

Disposition.-In disposition the egg breeds are very active, both in the house, when scratching, and while ranging in search of feed, when they will go long distances. They have extensive powers of flight, being light of body and strong of wing, which fact, combined with a nervous temperament, makes them rather hard to confine. In temperament they are just opposites of the heavier breeds, being rather irritable, nervous and easily frightened. These characteristics, however, can be overcome by proper handling. 
The poultry keeper should always be calm and gentle when attending to the birds, and if they learn while young not to be afraid of the attendant they will usually be more gentle and quiet at maturity. Temperament is largely due to habit and training. Owing to their active, energetic disposition, birds of this group will stand intensive housing and confinement in large numbers, much better than flocks of heavier breeds.

Maturity.-The egg breeds make a rapid early growth and mature early, four to five months elapsing between hatching time and laying. The feather growth of the young chicks is rapid also, and they get their adult plumage at an early age. The sex characteristics, such as comb and wattles, and wing and tail feathers, also appear early. Among White Leghorns it is easy to distinguish the cockerels when four or five weeks of age.

Broodiness. - The egg breeds are poor sitters, only a few of them developing the broody habit. In individual cases some may appear to be good mothers, but, owing to their fickleness and tendency to leave the nest, it is not safe to depend upon them. They often start in on the broody period showing a decided broody tendency, but, after sitting a week, they lose the desire and leave the nest, hence they should never be used for natural incubation.

Hardiness.- Owing to their very close feathering, the egg breeds do not bear an extremely low temperature. There is less down and fluff than is common with the heavier breeds and the feathers are more sparse over the entire body. The head parts, such as comb and wattles, are usually large, hence easily frostbitten in cold, damp weather. Being light and sparsely feathered, and lacking surplus heat and energy in the form of fat, a large amount of corn is commonly given them in the winter rations. The egg breeds require more care in housing and better protection from sudden changes in temperature than do the heavier, fuller-feathered types of birds. 
Feeding.-On account of their small size, birds of this type will subsist on a smaller amount of feed than heavier birds, but owing to their greater activity more feed in proportion is required for energy and heat. On the whole, however, they eat less during the year and produce more eggs than large birds. They are heavy foragers, traversing large areas on the range in search of grubs and insects. While ranging, they get such an abundance of green grass, weed seeds, and other feed material as to permit the cutting down of the grain rations very extensively during the summer. Allowing the egg breeds to range is economical because of the decreased amount of feed required.

Production.- The eggs laid by this group of birds have white shells, are rather long in shape, and of good size. The number produced in a year, on an average, is greater than with other types. A fair egg production is about twelve dozen, but some birds lay 200 or more, and there are records which exceed 250. The meat production of this group is poor, owing to their small size, and is also limited by their activity. The quality, too, is poor, as the flesh is largely lean meat with very little fat, and contains a large amount of connective tissue, which makes it stringy and tough when cooked. But the quick maturity and plumpness of these birds when young makes them ideal small broilers. They are even better in this respect than the heavier breeds, but when they grow older the quality of the meat is poor and the amount deficient.

\section{THE EGG BREEDS}

Among the more common breeds classed as egg types are the Leghorns, Minorcas, Campines, and Houdans. The student should study specimens of these four breeds, and become familiar with their general characteristics. The following brief discussion will call attention to their chief characteristics.

Leghorns.-The Leghorns belong to the Mediterranean class, hence had their origin on the shores of the Mediter- 
ranean Sea, in Europe. It is said that they were originally found at Leghorn, Italy. In appearance Leghorns are the neatest of all birds. They are small and very compact in form, carry the tail rather low, and have a small head with

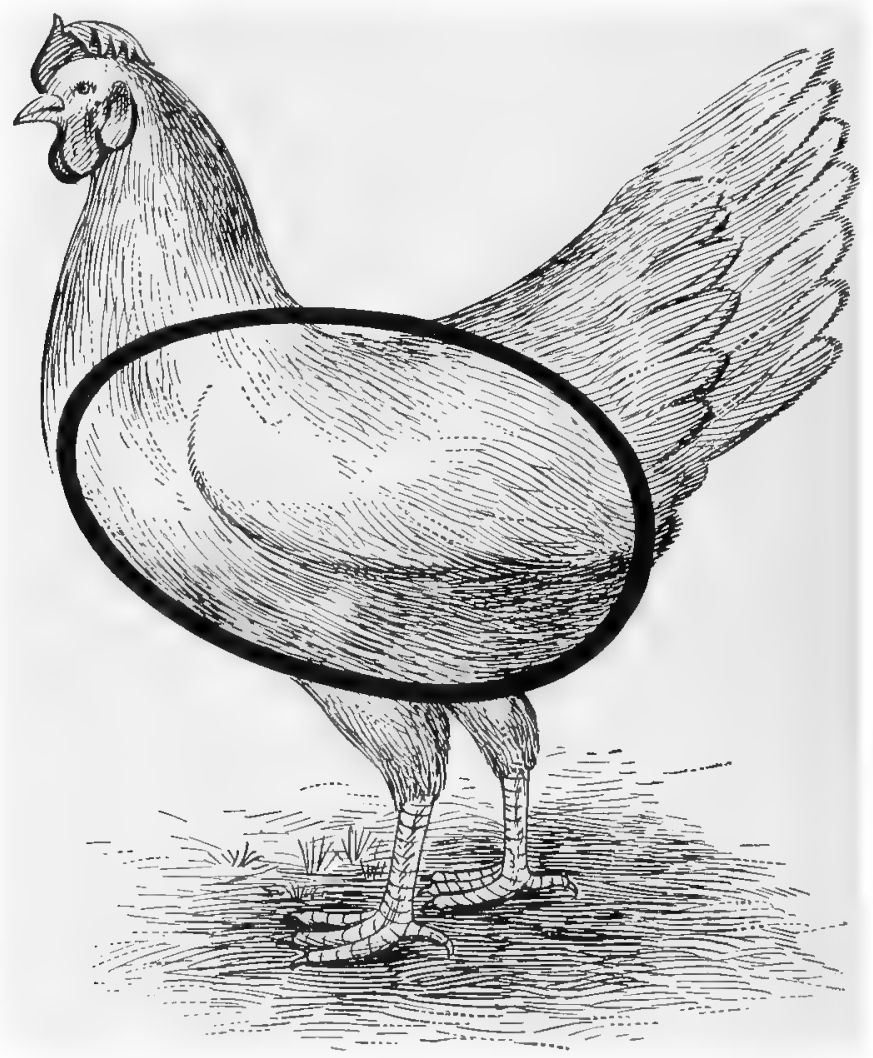

FIG. 35.-The body shape of the Leghorn resembles that of an egg.

rather dainty comb and wattles. The body shape of the Leghorn may be likened to that of an egg, the large end of the egg corresponding to the hinder part of the chicken (Fig. 35). Common varieties of Leghorns are the white, buff, 
and brown. In the last few years the popularity of the white variety has immensely increased. The brown variety was very popular in the early development of the breed, and now the buff variety is gaining rapidly. As a breed, the Leghorns are widely distributed throughout the United States, being found in New England and along the whole Atlantic coast, and also west of the Rocky Mountains. As they produce chiefly market eggs, one expects to find them in the vicinity of large centers of egg consumption.

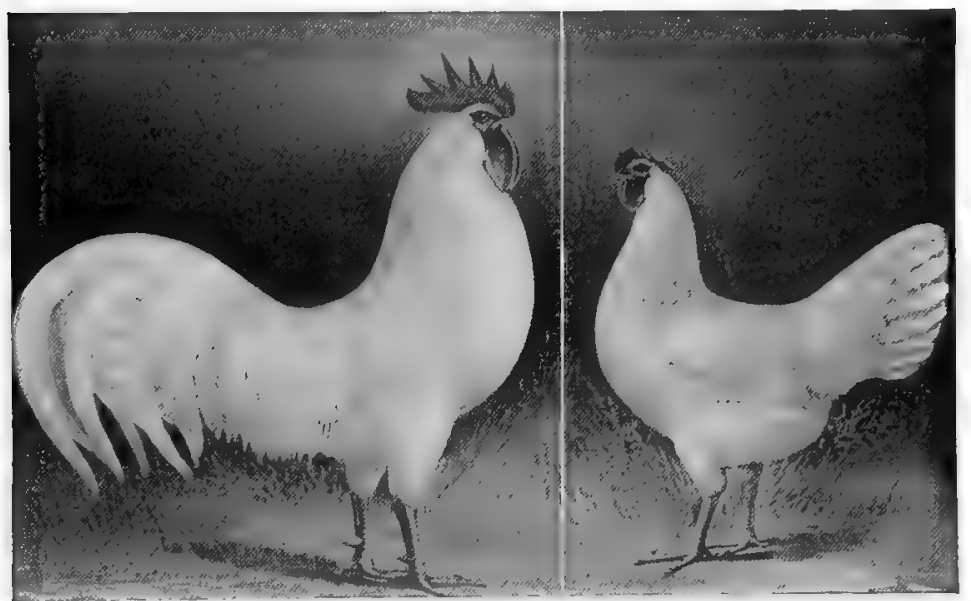

Fra. 36.-The Single Comb White Leghorns are kept more than any other breed for commercial egg production. They produce an egg with a pure white shell. (Photos by International Correspondence Schools.)

The Leghorn is used almost entirely on the commercial egg farms of the country, the white-shelled egg which they produce bringing a premium in most markets (Fig. 36).

Minorcas.-The Minorcas are probably the second most popular breed of this type. They are said to have originated on the Island of Minorca, off the coast of Spain. They are a very old breed, but not exceptionally popular, most likely because of the dark skin and shanks, which are considered undesirable in America. Externally the Minorcas 
are larger and fuller breasted than the Leghorn. The head and body are held very high, which gives them a more or less tilted appearance. In outline the body resembles a rectangle, the back being flat and forming the upper side of the rectangle. A distinctive mark of the Minorca is the very large comb and wattles. Long legs and large bones pre-

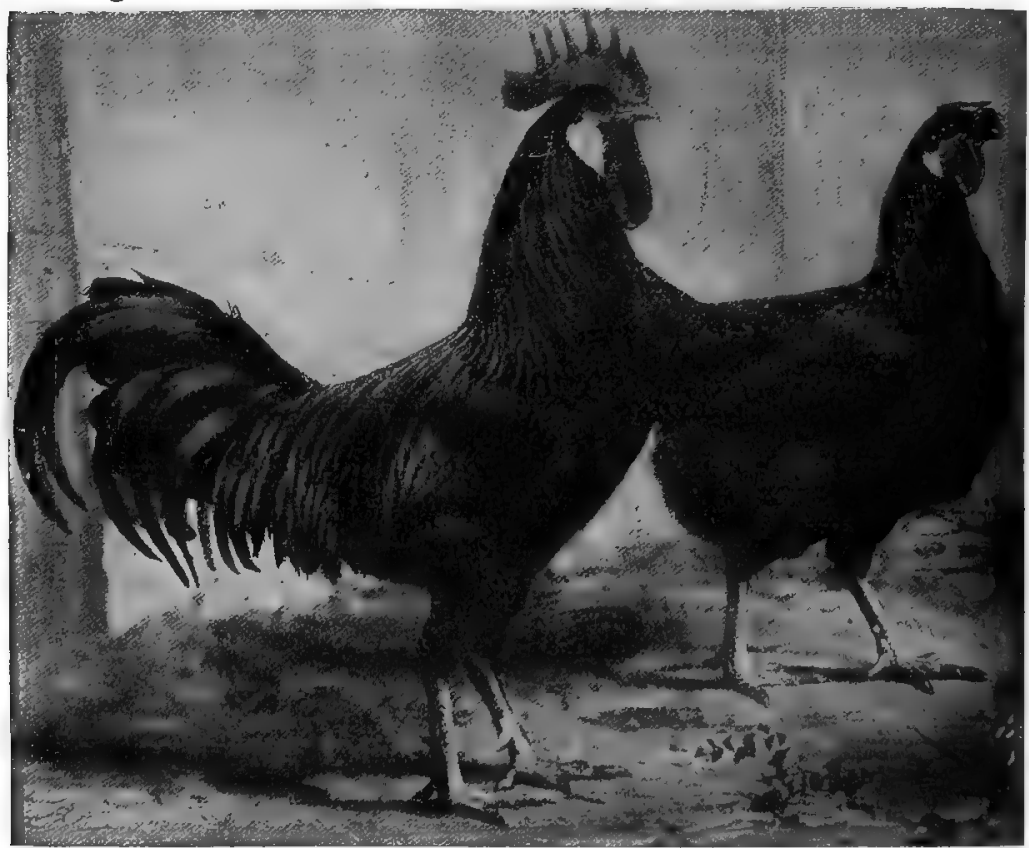

Fig. 37.-A pair of Single Comb Bløck Minoras. This breod is noted for the production of large, white-shelled eggs.

dominate. The black variety is the most popular, white ones being rarely seen. The Minorcas are bred principally for egg production and for show purposes. The one leading cause for their popularity is the latrge, heavy, white-shelled eggs which they produce. Probably no breed lays a larger egg than the Minorca (Fig. 37). 
The Ancona.-The Anconas are similar in form and type to the other egg breeds. Their origin is obscure, but they are supposed to have existed as a common type in Italy. The plumage is dark, spotted with white, which makes them most beautiful birds. They are characterized, also, by a yellow shank, which makes them more desirable than the Minorca when dressed for the table. Externally the An-

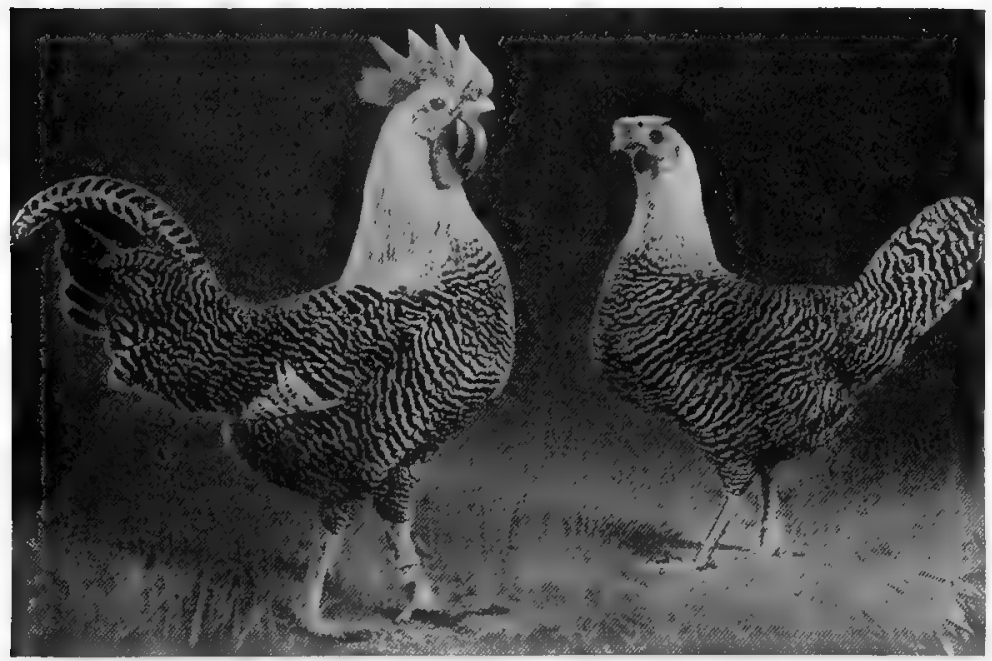

Fra. 38.-The Campines are growing in favor owing to the beautiful white eggs which they lay. The plumage of the male and female is very similar. (Photo by M. R. Jacobus.)

cona resembles the Leghorn more than the Minorca. It is doubtful whether the Anconas will ever attain any greater popularity than they enjoy to-day.

The Campine.-The Campine is a breed just coming into prominence. The strong point of these birds is the fine white-shelled egg they produce. They are supposed to have originated from the old Danish Breckel fowl. They are smaller than the White Leghorn, but resemble it in shape. In color they are dark, streaked with very narrow white 
bars, the male and female having the same plumage pattern. The cockerel does not show the distinctive sex plumage common to most other breeds. The Campines, as a breed, seem to lack vitality, to be subject to a good many diseases, and rather hard to raise. As with all new breeds, they are passing through a stage of popularity due to their novelty, which will, doubtless, soon settle down to a normal basis (Fig. 38).

The Houdans. - The Houdans are a French breed, but their appearance has led authorities to assume that the English Dorking, which is one of the most ancient breeds, was used in originating the Houdan. They possess the fifth toe, characteristic of the Dorking. They produce large, white-shelled eggs, attain a good body weight, and probably make a better dual purpose bird than any of the other egg breeds, because they are full-breasted. They are distinguished by a V-shaped comb. In color they resemble the Ancona, the plumage being black, and the ends of the feathers being tipped with white. They are very popular to-day in France, but this popularity will never equal that of the Leghorn.

\section{LABORATORY EXERCISE}

Exercise No. 9.-Secure characteristic specimens of as many representatives of the egg breeds as possible. The Leghorns, Minoreas, Anconas and Houdans should be represented, the first two mentioned especially. Place them in individual, adjacent coops in the classroom. Devote at least one exercise period to a study and discussion of the body shape of each breed. Special attention should be given to plumage color and to distinctive breed characteristics. Before the exercise is concluded the birds should be moved around in the coops and each pupil be allowed to name the different hirds according to its breed name. The birds may be designated by a coop or pen number. While they are 
being studied, if the standard description, as given in the American Standard of Perfection, is read to the class they will be better able to distinguish the minor points of difference. The birds may be weighed and the results compared with standard weights.

In order to make the study more interesting, if time will permit, different members of the class can bring birds of the same breeds from their own home and can compare them with each other's as to standard qualifications. If desired, this exercise can be concluded with a small poultry exhibition. Show coops can often be borrowed from some poultry association in the vicinity. The pupils should be allowed to set up the coops and run the exhibition. Small prizes can be offered for certain classes. The scholars should be allowed to do some competitive judging, for which prizes can be offered. The exhibition can include eggs and dressed poultry if desired.

\section{THOUGHT QUESTIONS}

1. Where are the egg breeds especially popular?

2. Why is the term "egg breeds" applied to this group?

3. Give in a few words the general external appearance of the members of this group.

4. Describe the disposition of the egg breeds.

5. Are the egg breeds late or early in maturing?

6. Discuss the broody habit as possessed by the egg breeds.

7. What characteristics are possessed by the egg breeds which make them less hardy than the other two groups?

8. Are the egg breeds heavy or light eaters?

9. Do the members of the egg group roam far in search of feed?

10. Describe the number and characteristics of the eggs laid by the so-called egg breeds.

11. Enumerate some of the common members of the egg class.

12. Describe briefly the Leghorn breed.

13. What are the general characteristics of the Minorca breed?

14. Why is the Leghorn much more popular than the Minorca?

15. What are the distinguishing features of the Ancona?

16. What is the most serious fault of the Campine breed?

17. Name two distinct features possessed by the Houdan.

18. What is the most popular breed of this general type in your district?

Reference.-Consult "American Standard of Perfection." 


\section{CHAPTER IV}

\section{THE MEAT BREEDS}

The meat breeds include a number of very similar types and varieties, characterized by their large frames or skeletons. Their ability to put on a mass of flesh is their chief commercial advantage. The meat of these birds is always of fine quality, owing to their slow growth and quiet disposition, and at maturity is very tender. The whole body is plump, but most of the flesh is on the breast, thighs and back (Fig. 39). When young these birds are rather rangy and ungainly looking, because their bones are so long and large, but at maturity they become fleshy all over and very plump. Birds of this group are common in the roaster district of Massachusetts, and the capon district of New Jersey.

\section{CHARACTERISTICS OF THE MEAT BREEDS}

Size and Appearance.-The birds of this group are of large size and heavy in weight, the Brahma being the largest of all our domestic birds, and the leader in this group. They are loosely feathered, which gives them a full, rounded appearance. The Cochin's feathers are exceedingly loose, often extending as far as four inches from the body. Most of the breeds in this group are distinguished by feathered shanks, and in China and Asia, where the majority of them originated, this development was, doubtless, for their protection. The Asiatic breeds look extremely clumsy and awkward. They have, apparently, very short legs, but this dumpy appearance is the somewhat exaggerated effect of their thick feathering, and because their breasts often droop low down from being so fleshy. The general appearance of the heavy meat breeds is much like that of a ball of feathers (Fig. 40). 
Disposition.-Partly because of their size and weight, and partly because of their breeding and management, heavy birds are quiet, dull and lazy. They need care in feeding, as they will not roam far in search of feed. Their powers of flight are limited, owing to their weight, and a fence three or four feet high will confine them with absolute certainty. In order to keep such birds in good physical trim, much of

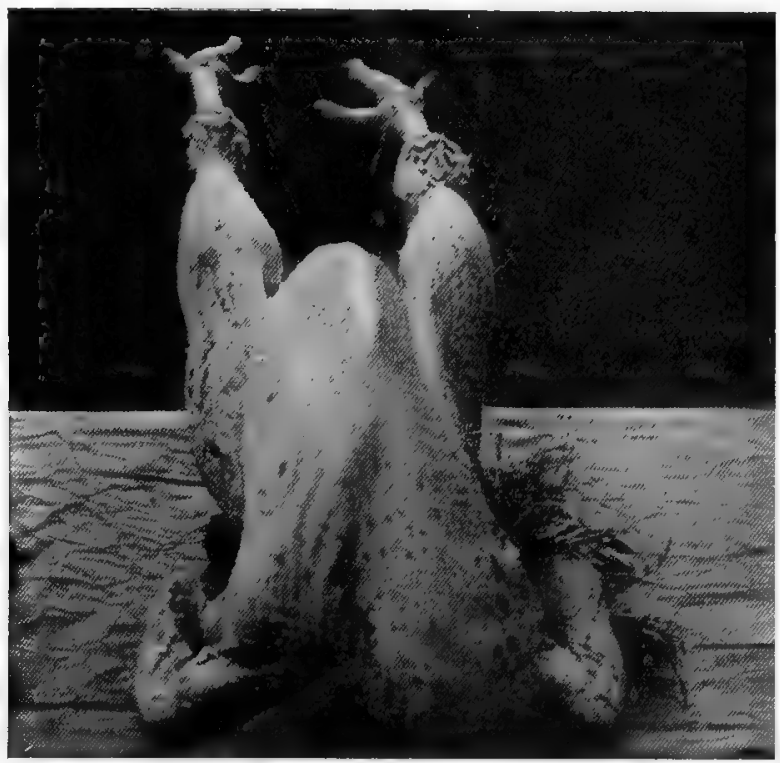

FIG. 39.-The great popularity of the heavy breeds lies in their ability to produce poultry meat in considerable quantity and of the best quality.

their grain must be put in a deep litter, as this compels exercise. Generally speaking, heavy birds thrive best when kept in small flocks, with not more than twelve or fifteen females in a pen.

Maturity.-The meat breeds are slow growers and mature late. The females are usually from five to eight months old before they lay eggs. Owing to this slow maturity, it 
is quite a common practice to hatch the meat breeds about a month earlier than the light and more active breeds, so that they will all mature at the same time in the fall. Accompanying slow maturity in birds of these breeds, we find slow

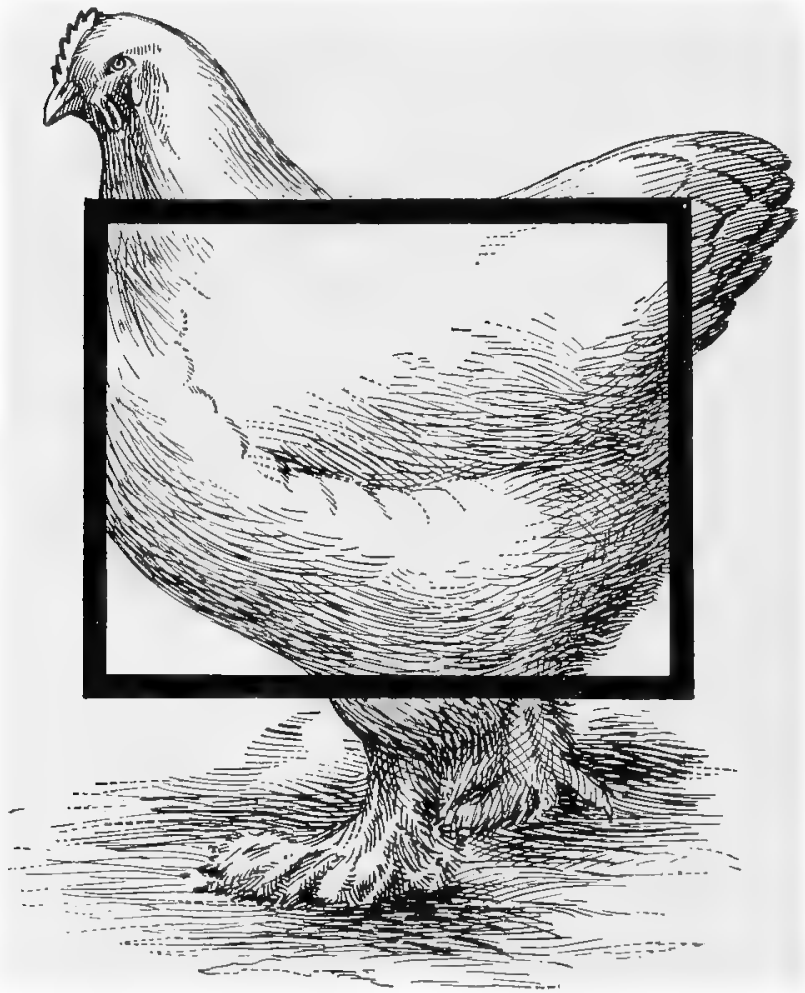

FIG. 40.-The body shape of the heavy meat breeds is very blocky. In many cases it conforms very nearly to a square.

feather growth and a very full body fluff. If not given plenty of range and green feed during the summer, these breeds will become checked. This will result in retarded maturity and generally unfavorable conditions. 
Broodiness.-On account of their quiet, docile nature, the broody instinct is highly developed in the meat breeds, and, as a class, they are persistent sitters. Individuals become broody early in the season, and this broody instinct continues throughout the summer, yet, in spite of this tendency to brood, the birds make poor sitters and mothers. By their weight they are apt to break the eggs in the nest, and by their awkwardness in moving around they may crush the chicks when they are hatched. The dense feathering on the legs and shanks makes it hard for the young chicks to move about in the nest, and many are injured or crushed in this way. Moreover, heavy breeds, because of their size and lack of exercise, are inclined to contract diarrhœa, when confined to the nest.

Hardiness.- The heavy feathering of these birds and the fact that their fluff and feathers are very downy protect them from cold and make them hardy. Their excessive fat makes them warm. Moreover, the head parts, such as comb and wattles, are small, and therefore less liable to freeze in cold, damp winter weather. The Brahma has a very small pea comb. Owing to lack of exercise, they are more or less subject to liver and digestive disorders, so that the giving of corn and hard feed in the rations should be avoided.

Feed.-Since meat breeds are of such large size, they would seem to require a great deal of feed for maintenance, but this is counterbalanced by their sluggish disposition, and disinclination to roam in search of feed, so that little feed is called for to supply energy. They are poor foragers, but like to stay in or near the house, and this necessitates considerable feeding with purchased grains, the bulk of which must be hard grain scattered in deep litter. The cost of feeding these birds is materially greater than with the light, active breeds, as the Leghorn.

Production.-As a rule, it may be said that the heavier the breed, the fewer the eggs laid. This is true of all Asiatic 
classes, which for generations have been bred for rich meat and large size, at the sacrifice of egg production. The eggs yielded are brown, of good size, and rather roundish in shape, and from sixty to one hundred per year is good for the heavy breeds. They excel in producing an abundance of meat of good quality, and they make ideal roasters and capons, but can not be used for broilers. At the broiler age they are exceedingly lean, while the skeleton has attained enormous proportions, which gives them a poor appearance.

\section{THE MEAT BREEDS}

The meat breeds include the Brahma, Cochin, and Langshan, all of which are of Asiatic origin, and belong to the Asiatic class of the Standard Classification. The Cornish Game makes ideal market poultry, and should be classed with the meat breeds. In general, it may be stated that the three breeds of the Asiatic family represent the true flesh producing birds of our poultry industry, for they are the largest of all breeds, and their meat is of fine quality.

Brahmas.-The Brahma may be truly called the king of all breeds, both as to size and quality. These birds are of true American origin, being the result of American breeding upon Oriental types. Asiatic breeds brought to this country were the foundation stock from which they were developed. In appearance the Brahma is characterized by extreme height and breadth, giving a massive appearance. The cocks weigh twelve pounds, but in order to secure this weight, the body must be large. As a rule, the Brahma has a big, full breast and hackles, and a rather high tail. In form the Brahma suggests a large ellipse or oval. The most typical features of the Brahma are the pea comb, and a head rather small in proportion to the body. The full breast is decidedly characteristic. There are two common varieties of the Brahma, the light and the dark. The light 
Brahma is distinguished by white plumage with blacksplashed hackle and tail (Fig. 41). This is by far the most popular color. The dark Brahma has plumage of the same color as the beautiful partridge, while the yellow shanks of the light Brahma, together with the beautiful markings of its plumage, make it the most attractive. The Brabma is

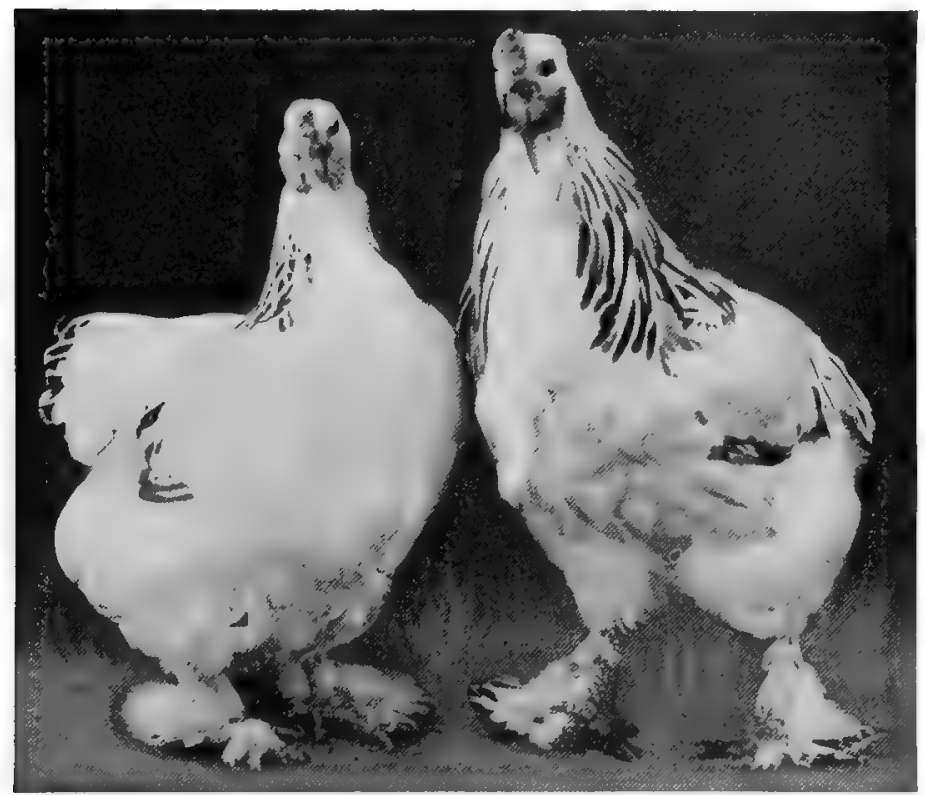

Fra. 41.-A typical Light Brahma pair. The large size and beautiful plumage are very characteristic of this breed.

found throughout the country, but predominates in sections where market poultry is demanded. The Brahma is often used in crossing with general utility breeds, in cross breeding for quicker maturity, good size, and fine meat. The lighter Mediterranean breeds are gradually forging to the front in place of the heavier breeds, but the Brahma should always be used to produce large roasters and capons. 
Langshans. - The Langshan is not as large as the Brahma nor as popular. Its early history is rather obscure. These birds originated in England, but have been materially improved in this country by breeding. The Langshans are much larger, longer legged, and more stilted looking than other meat breeds. They have high tails, which reach to the height of the top of the head. A line drawn from the point of the beak to the bottom of the foot, thence up to the top of the tail would outline the whole body in a V-shape. The Langshan has rather a large comb, a lighter hackle, and shankless feathers. The most characteristic features of the Langshan are the long leg and high tail. There are two varieties, the black and the white, the black being by far the most common. The white Langshan has never attained much prominence. The dull black with the green sheen is very beautiful, but has the serious disadvantage of a black shanki, dark skin, and dark breast, and the American house-wives demand yellow skin and shanks of the American type for the table. The Langshans are fairly good foragers and make ideal roasters and capons (Fig. 42).

Cochins.--The Cochins are quite different in appearance from the Brahmas and Langshans, being neither as large nor as tall. They have very heavy shank feathering, and somewhat resemble a large ball, being as deep as they are long. They have a rather small single comb, and small wattles, but the most characteristic feature is the heavy mass of feathers on the back, called the cushion or saddle. The Cochins, as a breed, are of Asiatic origin, but were greatly improved and developed in England. As an Asiatic breed, they were called Shanghais. There are four common varieties-buff, partridge, white, and black-- the buff and partridge being the most popular, and the buff is the most common of all (Fig. 43). The popularity of Cochins has greatly declined in the last few years, owing chiefly to their small egg yield and secondly, to the fact that they have more and more 


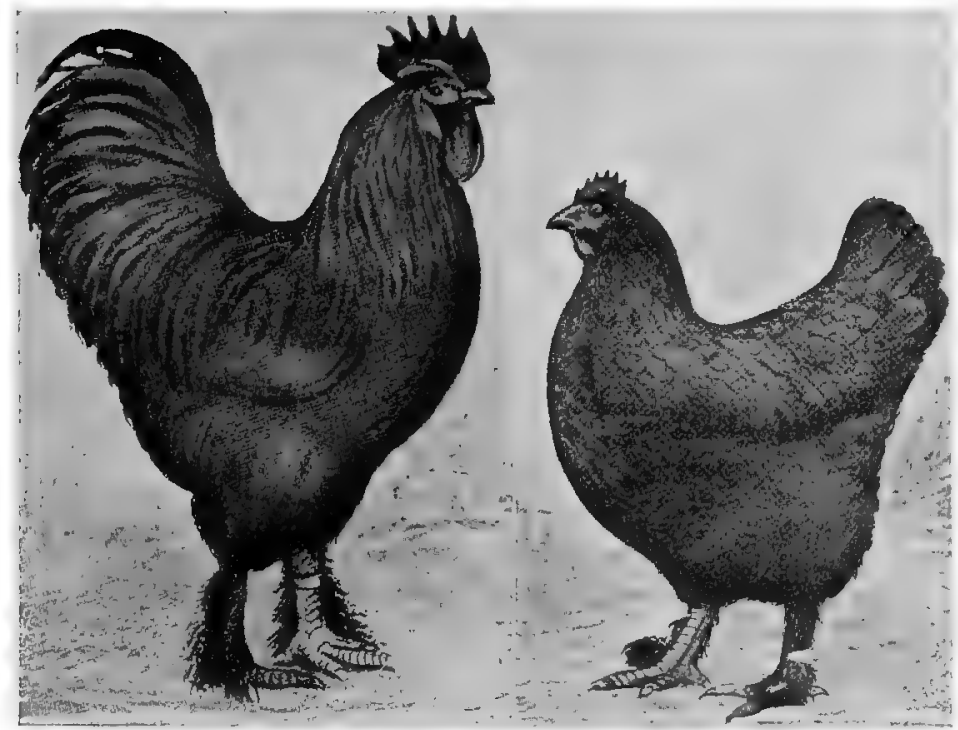

FIG. 42.-A Black Langshan pair, showing the long legs and high tail which is common to this breed. (Photos by Urban Farms, Buffalo, N. Y.)

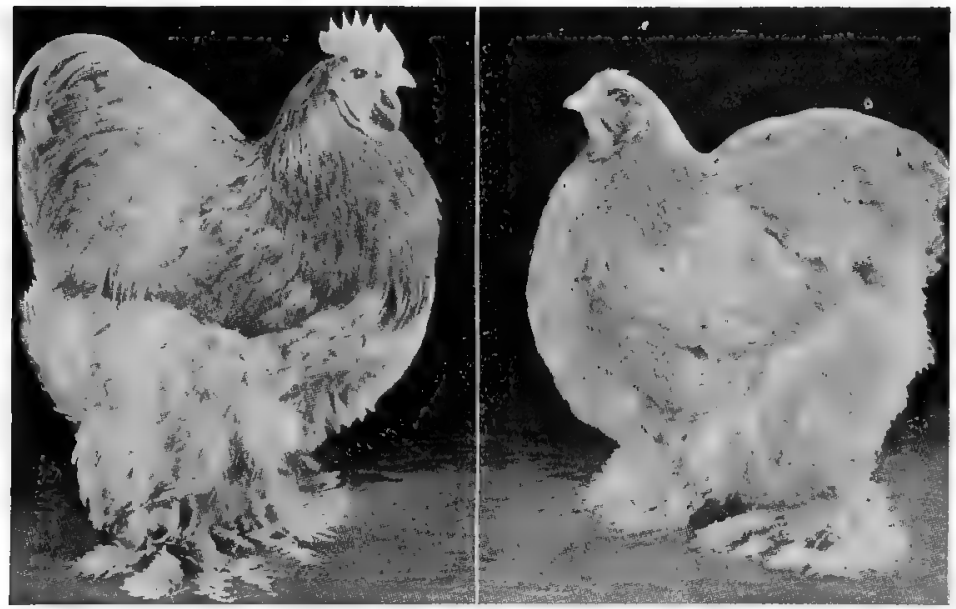

FIG. 43. - The Cochins are one of the most thickly feathered breeds. The Buff variety, pictured here, is very beautiful when well bred. 
been bred primarily for feathers, and lastly for meat. At the present time they are chiefly raised for exhibitions.

Cornish Game.-The Cornish fowl is one of the oldest of our domestic birds, and probably existed in prehistoric times. It has all the characteristics of the game bird, long legs, long neck, and small compact body with full breast. There are a number of different varieties, but the black

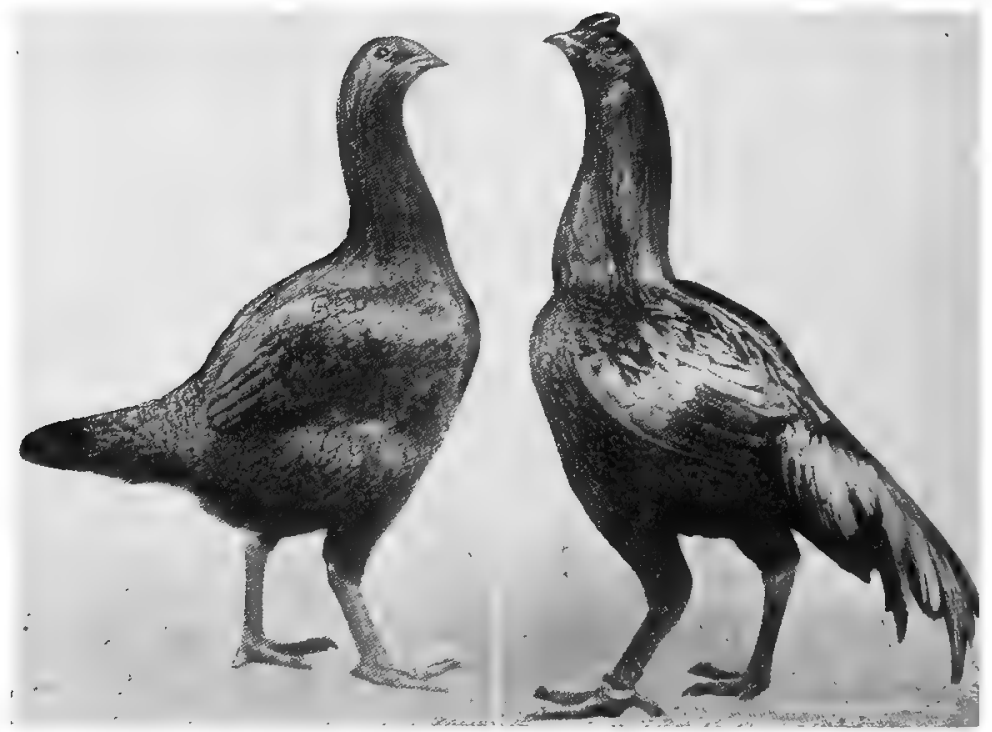

FIg. 44.-A Cornish Game pair. These birds are much heavier than they look, being very close-featbered and hard-fleshed. (Photos by Oak Hill Poultry Yards.)

breasted red is the most common. The Cornish Game, owing to its desirable points and its great antiquity, has been much used in crossing with other types to originate new breeds, and its blood probably circulates to a greater or less extent in all of our general utility breeds. The Cornish Game birds have a relatively small body, but are heavy; the compactness of their flesh makes them weigh from two to three pounds more than their appearance would indicate. 
The Cornish fowl will probably continue to be mated with other breeds to develop flesh production (Fig. 44).

\section{LABORATORY EXERCISE}

ExERcise No. 10.- Secure characteristic specimens of as many representatives of the meat breeds as possible. The Brahmas, Cochins and Langshans should be represented if they can be secured. This exercise should be conducted the same as exercise No. 9 , page 56 .

\section{THOUGHT QUESTIONS}

1. What are some of the general characteristics of the meat breeds?

2. Where are the members of this group especially found?

3 . How do the meat breeds compare in size with the egg breeds?

4. Describe the general external appearance of the meat breeds.

5. Describe the disposition of the heavy meat breeds.

6. Do the meat breeds fly readily or take much exercise?

7. How long does it take the meat breeds to come to maturity?

8. Are the meat breeds persistent sitters?

9. Do they make good sitters and mothers? If not, why?

10. What protection do the members of this group possess which makes them very hardy?

11. Are the heavy breeds large eaters?

12. Discuss the egg producing ability of these birds.

13. What types of products are the meat breeds generally bred for?

14. Enumerate some common examples of the meat group.

15. Describe the external appearance of the Brahma.

16. To what use can the Brahma best be put?

17. What are the peculiar characteristics of the Langshan?

18. What feature of the Langshan makes them undesirable in America for market purposes?

19. Describe the external appearance of the Cochin.

20. Why are the Cochins becoming less and less useful from a utility standpoint?

21. What characteristic is possessed by the Cornish fowls which makes them a member of this group?

22. Enumerate the breeds belonging to this group which are kept in your community.

Reference.-Consult "American Standard of Perfection." 


\section{CHAPTER V}

\section{GENERAL UTILITY BREEDS}

A NUMBER of breeds of fowls are commonly termed general utility. These are distinguished by their ability to yield both meat of good quality and a goodly number of eggs. They are for dual purposes, we might say, because they perform two different functions efficiently (Figs. 45 and 46). They abound on the general farms of the country, and form the characteristic fowl of the small flock grown especially for home use. As a rule, they lay a large number of good-sized eggs during their pullet and yearling period, and after they have ceased to lay eggs, they are killed, and their carcasses bring a good price. They are the type generally demanded for medium and large broilers. They are plump when twelve to fifteen weeks old, and never have the exceedingly large frames characteristic of the meat breeds. If properly managed, they lay eggs in all seasons, especially during the fall and winter; but unless carefully fed and managed, they have a tendency to become so fleshy that it checks egg production. Usually the general utility breeds will be found to be a half-way type, between the egg and meat breeds (Fig. 47).

\section{CHARACTERISTICS OF THE GENERAL UTILITY BREEDS}

Size and External Appearance.-The fowls of this group are medium in size and weight, on an average running from four to eight pounds. Laying hens usually weigh from five to six pounds. They have abundant plumage, the feathers being much closer than on the egg breeds, but they lack the thick fluff characteristic of the Brahma and Cochin. They have yellow shanks, free from feathers, which is one of their chief merits. All the breeds in this cliss have full, wellrounded bodies covered with considerable flesh, and their legs 
are of medium length. In all breeds except the Wyandotte the bodies are much longer than they are deep (Fig. 48).

Disposition.-In disposition the American breeds are just about half way between the Mediterranean and Asiatic types. They are quite active, roaming a considerable distance in search of food, and with some powers of flight; after they once acquire the habit they can fly over a six-foot fence. They are not nervous or easily frightened like the egg breeds, and if carefully managed are easy to handle.

Maturity.-The general utility breeds mature rather quickly, the time varying with the breed. It generally

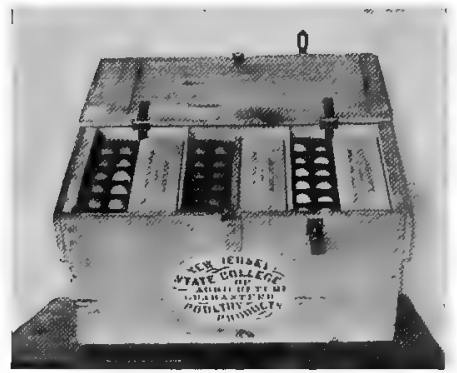

Fig. 45.-Eggs of the general purpose breeds have a brown shell, are of good size andin quite general demand. The Cornell Poultry Department was the first to use the egg stencil to label shipping cases.

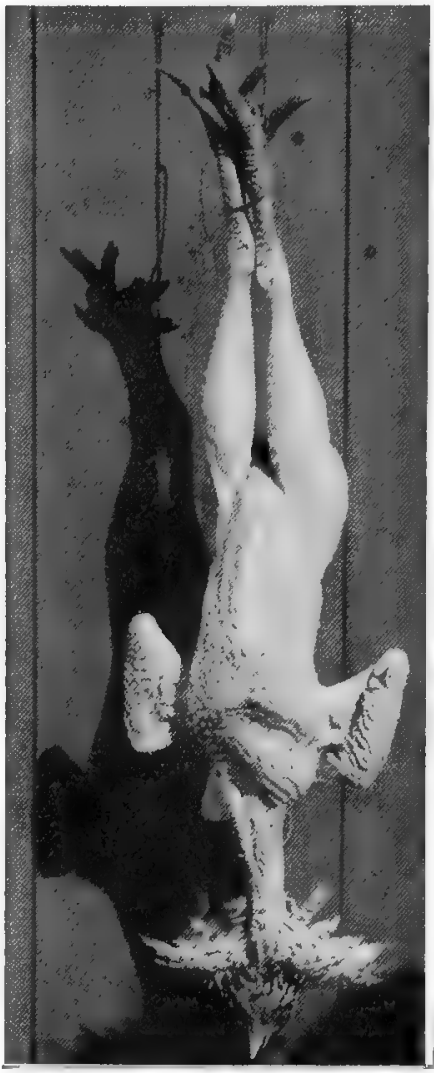

FIc. 46.-General purpose breeds bring in a revenue from both eggs and meat. A Barred Plymouth Rock cockerel dressed for market.

takes from four to six months for the American breeds to begin to lay eggs. Their feather growth is fairly rapid, much more so than in the Asiatic breeds. In breeds in which 
the male and female plumage differ, the sexes can be easily distinguished at about six weeks of age. Owing to their early maturity and plumpness they make excellent medium and large broilers, and the very best small, tender roasters.

Broodiness.-The American breeds have the broody instinct highly developed, and make good sitters and mothers, for they are neither nervous and flighty, like the egg breeds, nor heavy and clumsy, like the meat breeds. Considering all breeds of poultry, the general utility type seems the best

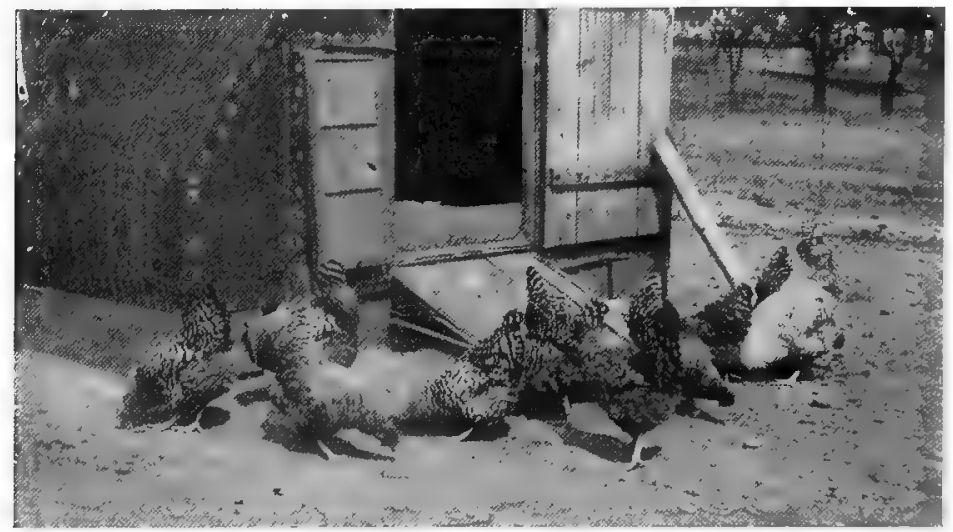

FIG. 47.-A flock of Barred Plymouth Rocks. This breed is the most popular general purpose breed in America.

fitted for natural incubation, because, owing to their broodiness and their size and temperament, they can always be depended upon to bring off a good hatch.

Hardiness.-The general utility breeds possess all the characteristics of the meat breeds which indicate hardiness. They are full feathered, have small head parts, and an abundance of fat to kecp them warm in cold weather. They are not liable to frozen combs and wattles like the Leghorns, but the Amcrican breeds can live in any climate where it is possible to ke'p poultry. They have not been bred exclusively for abundance of feathers, as have the Cochins. 
Feeding.-These birds are all heavy eaters, partly because of their relatively large size, partly because of their active disposition, and the fact that they take considerable exercise. On the other hand they are also heavy producers of meat and eggs. The cost of the feed can be materially cut down by allowing them plenty of green grass range.

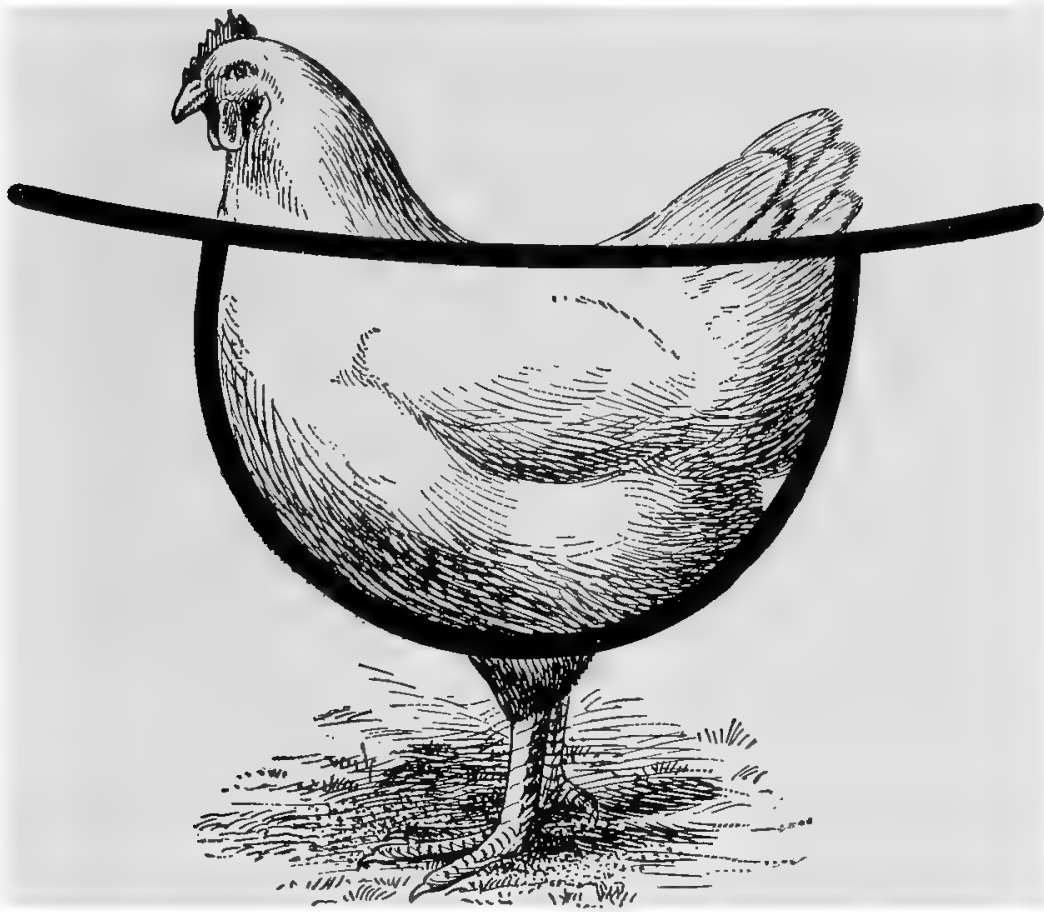

FrG. 48.-The body shape of the general purpose breeds resembles an inverted derby hat, long, rather deep, with full curves.

Production.-For dual purpose production probably no birds are superior to general utility groups. They produce a goodly number of eggs; on the average, from one hundred and twenty to one hundred and fifty in a year can be expected, and the yield is good in winter, which is the season of high 
prices, hence large profits. The eggs are all brown and of good size. Surplus cockerels can be disposed of as broilers in May and June, or, if desired, can be held over and sold in the fall for tender roasters. These fowls are more in demand than any other type. The general utility breeds are often crossed with Brahmas and Cochins for flesh production.

\section{GENERAL UTILITY BREEDS}

The common general utility breeds are of American origin, and comprise the Plymouth Rock, Rhode Island Red, and the Wyandotte. But there are two breeds of English origin, the Orpington and the Dorking. The Orpington has become quite popular in America. The Dorking occupies in England the same position which the Plymouth Rock and Rhode Island Red fill in America.

Plymouth Rock.-The Plymouth Rock is America's most popular breed. This fowl was produced by crossing two common American types, the Black Java and the Dominique being the breeds chiefly used to develop them. The Rocks have gone through a gradual transformation until to-day they are one of the most beautiful as well as the most valuable commercial types. In appearance, the Plymouth Rock is rather long-bodied, deep and round, with fairly long shanks, and an abundant hackle. Their shape has been likened to that of the common, old-fashioned gravy boat. The most common variety of the Plymouth. Rock is the barred. This breed is probably found on the general farms of America in greater numbers than all other breeds combined. The feathers are crossed by narrow black and white bars, which give the bird, when seen from a distance, a dark grey color. The white and buff varieties are growing in popularity. The Plymouth Rocks are good producers of eggs, and make ideal birds when dressed for market. They are, to-day, the most popular breed, as is evident both from the number of persons raising them, and by the number shown and the attention which they attract at poultry shows. 
Rhode Island Reds.-The Rhode Island Red is another breed of true American origin, many different types being used experimentally in its development. The Cornish fowl was one of its ancestors. These birds were bred in New England, and are to-day rapidly growing in public favor. If this present popularity increases, they bid fair to rival the Plymouth Rock for general use. The shape of the Rhode Island Red resembles a rectangle, the lines of the back and breast being parallel (Fig. 49). The legs and neck are

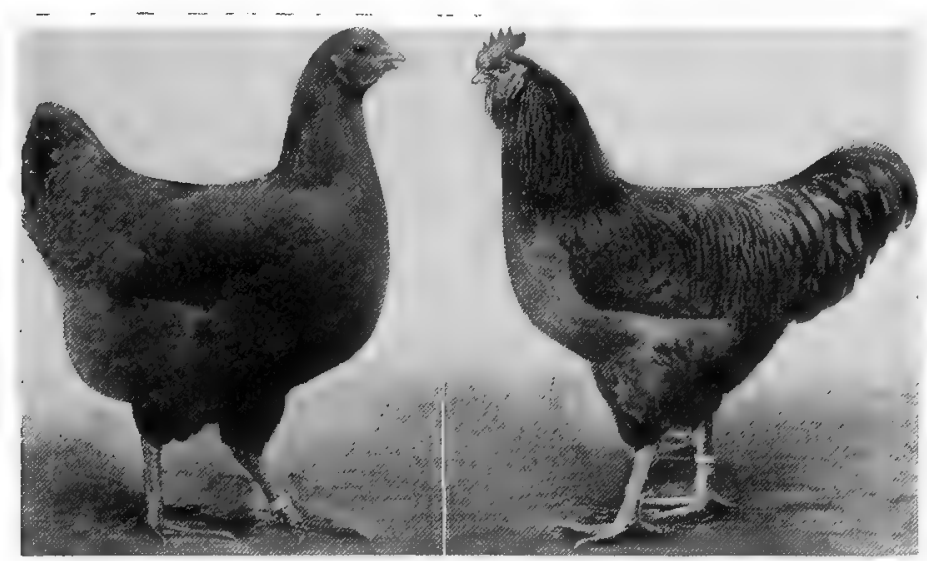

FIG. 49.-Pair of Rhode Island Reds; a very popular and useful general purpose breed. (Photos by Dearborn and Sharpe, Blairstown, N. J.)

rather long, and it has an abundant hackle. Its beautiful dark red plumage, the same on both sides, is one of the most attractive plumage patterns on any breed. There are two varieties of Rhode Island Reds, the rose and the single comb, the latter being by far the more popular. The Reds are found on many American farms, and are exceedingly popular with the suburban and city back yard poultryman. They are essentially a dual purpose bird, as they give a very heavy winter yield of eggs, but their eggs lack uniformity of color. They are most persistent sitters, hence special 
efforts are necessary to break up their nests in the Spring. Their popularity is growing by leaps and bounds. The Rhode Island Red Club of America, an organization composed of breeders of Rhode Island Reds, is one of the largest speciality organizations in America.

Wyandottes.-The Wyandottes are another breed of American origin. Unlike the Rhode Island Reds and the Plymouth Rocks they closely resemble the Cochin in shape, being short-bodied. The silver laced Wyandotte was the first representative of this group, other varieties being subsequently developed from it. The White, which is the most common variety to-day, probably came as a sport from the early type. The most distinctive features of the Wyandottes are the short, wide body and the short leg. They are full feathered, with a small cushion on the back, and very full breasted. Being so plump, they make ideal broilers and roasters. A distinctive feature of the Wyandotte is the rose comb. One variety of this breed has a very beautiful plumage pattern, and is popular at American Poultry Shows, although not quite so much so as the Rocks and Reds. Their eggs are brown. The short body has a tendency to hinder heavy egg production. Probably no breed furnishes a better medium or large broiler, or a fuller breasted, tender roaster than the Wyandotte (Fig. 50).

Orpingtons.--The Orpington is a bird of English origin, and is deep-bodied, full-breasted, and of good weight (Fig. 51). It has a white skin and pinkish-white shanks, which compare unfavorably with the yellow skin and shanks of our American breeds. It is doubtful if the Orpington will ever rival the three general utility breeds that have been described.

Dorkings.-The Dorking is the English utility breed. These birds lay a goodly number of eggs, and tend more to egg production than to flesh development. They are rather long-bodied birds, of dark plumage. The Dorking has a fifth toe which emerges from the hind part of the leg just 


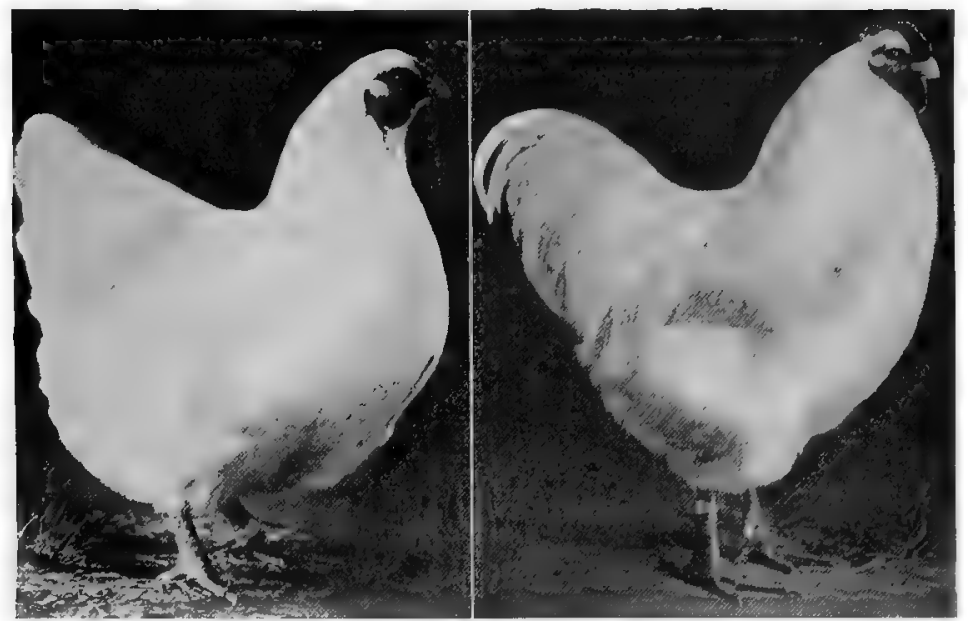

Fig. 50.-The full-breasted White Wyandotte is very popular both for eggs and meat. (Photos by Onlya Farms.)

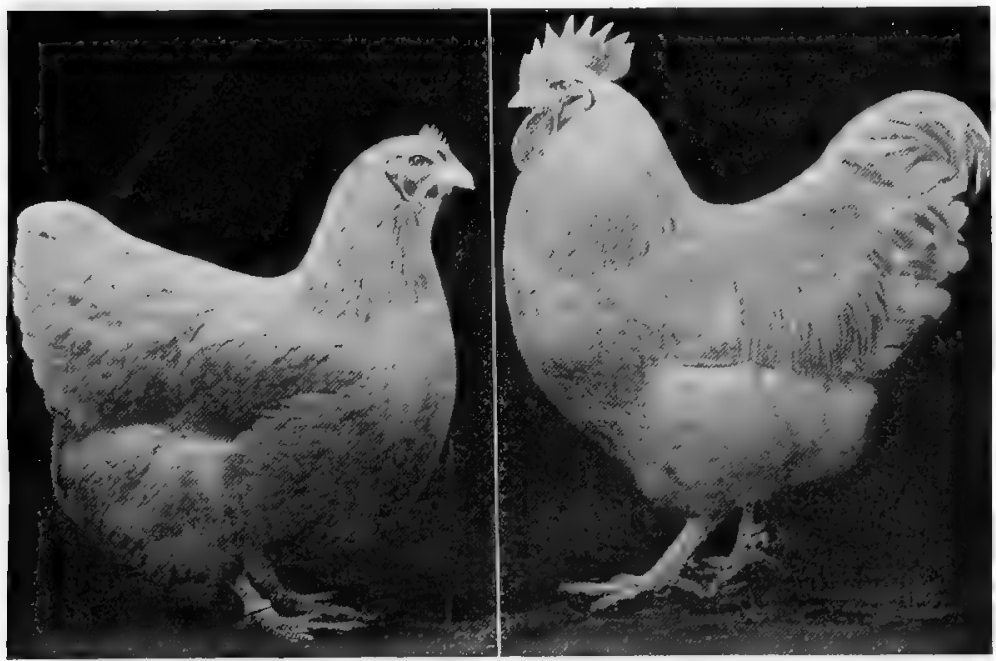

Fxg. 51.-A Buff Orpington pair; a breed which is noted for full breast and deep body. They lay brown-shelled eggs in considerable number. (Photos by Sunswick Poultry Farm.) 
below the spur. The Dorking will never attain much commercial importance in the United States, for there are too many other breeds, whose characteristics better meet the American demand.

\section{LABORATORY EXERCISE}

Exercise No. 11.-Secure representative birds of the general purpose group. Individuals of the Plymouth Rock, Rhode Island Red, and Wyandotte breeds should be included. Devote at least one whole period to a demonstration study of these birds, following the general scheme as outlined for exercise No. 9, page 56 .

\section{THOUGHT QUESTIONS}

1. What does the term "general purpose" mean?

2. Enumerate a few of the general characteristics of the so-called "general purpose" breeds.

3. How do the general purpose breeds compare in size with the egg and meat group?

4. Describe their general appearance.

5. Discuss the disposition of the general purpose breeds.

6. How long does it take the general purpose breeds to mature?

7. Do the general purpose breeds make good mothers?

8. Are the general purpose breeds protected from cold temperatures? If so, how?

9. Are the breeds of this group heavy eaters?

10. What type of egg does this group produce?

11. Can the general purpose breeds be used commercially for the production of meat?

12. Enumerate a few of the leading general purpose breeds.

13. Give a brief description of the characteristics possessed by the Plymouth Rocks.

14. Discuss the popularity of the Barred Plymouth Rock.

15. Tell what you can of the ancestry and popularity of the Rhode Island Reds.

16. Give a brief description of the external characteristics of the Rhode Island Red.

17. What is the characteristic body shape of the Wyandotte?

18. Do the Wyandottes have a single or rose comb?

19. What is the leading distinguishing feature possessed by the Orpingtons?

20. Where were the Orpingtons originated?

21. Where were the Dorkings originated"?

22. What is meant by the fifth toe?

23. What is the most popular member of the general purpose group in your locality?

Reference.-Consult "American Ntandard of Perfection." 


\section{CHAPTER VI}

\section{MISCELLANEOUS BREEDS}

THERE are a number of quite common and useful birds which do not logically belong to either the egg, meat, or general utility breeds. These miscellaneous types are usually found on small farms and in the city poultry yard. They are of no great economic importance, but are usually kept for some special purpose. Some of these types have a very beautiful plumage pattern, which makes them valuable for exhibition. Some are bred for their fancy feathers, many are kept solely for the pleasure they afford, others from the stand-point of association, while still other miscellaneous breeds are kept for any unique feature they may possess. In the following discussion a few of the more common of these types will be described.

Exhibition.-In the last ten or fifteen years the poultry show has experienced a marked development, due to the interest aroused in the possibilities of poultry as a farm crop, and also to the growing interest of the city man in poultry. Where, a few years ago, but two or three poultry shows were held in a state, to-day there are often twenty or thirty. To a certain extent all breeds of poultry are exhibited, but every year there are more of the pure commercial breeds, especially of the egg and general utility types. The value of the breed depends, first, upon its utility, and secondly, upon its fancy features. While the utility breeds occupy a leading place in poultry exhibitions, there are also varieties, which, owing to their beautiful plumage and fancy points, awaken great interest, and the Polish fowl is one of these. There are several varieties of the Polish, classed according to their plumage pattern, the black and the white being the most common. The Polish bird has a beautiful 
crest or topknot on the head, which gives it a very fine appearance (Fig. 52). The White-crested Black Polish is of good size, resembling the Leghorn in type, but a little heavier. The plumage of this variety is a deep, rich black, the head being surmounted by a pure white crest, bordered in front directly over the beak with a few black feathers. This striking contrast of the black and white with the red of the face and wattles, makes them very suitable for exhibition.

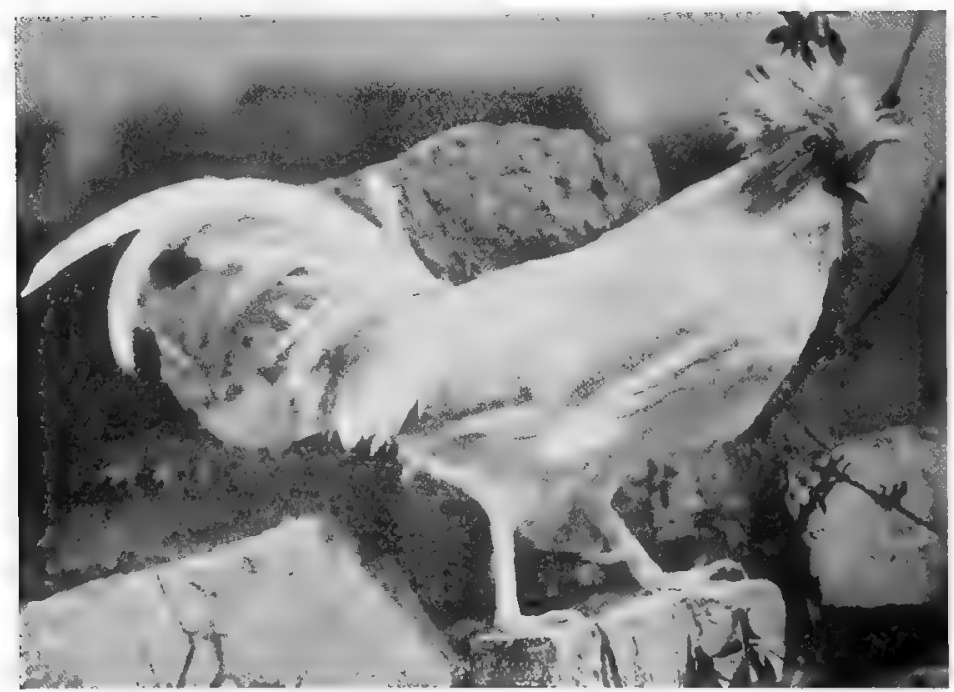

FI, 52.-A White Polish male, A very begutiful bird which shows the characteristics of the Polish breed. (Photo by F. H. Stoneburn.)

The Hamburg is another breed of the same type, represented by six varieties, all of which have most beautiful plumage. As the name implies, the Hamburg breed came from the German city, Hamburg. The spangled and penciled varieties are exceedingly beautiful, the Silver and Golden Spangled having the handsomest plumage of any fowls in existence (Fig. 53). The plumage of the former is white all over the body, spangled with black. They have a rose comb 
and white ear lobes, and are somewhat similar in type to the White Leghorn.

The Blue Andalusian is another fowl which attracts attention in the show room. These birds are the result of crossing black and white varieties of the same breed. They are rather large, with plumage of rare and singular color. This is a distinctive blue, which is much darker on the back and hackle. In order to breed good Blue Andalusians it is necessary frequently to revert to the original cross of black and white parent, as the birds have a tendency to revert to the original type unless new crosses are often made. The Andalusian has no commercial superiority over the Leghorn or Minorca. Several other breeds might be grouped in this classification of special exhibition types, but these three will suffice to describe their characteristics.

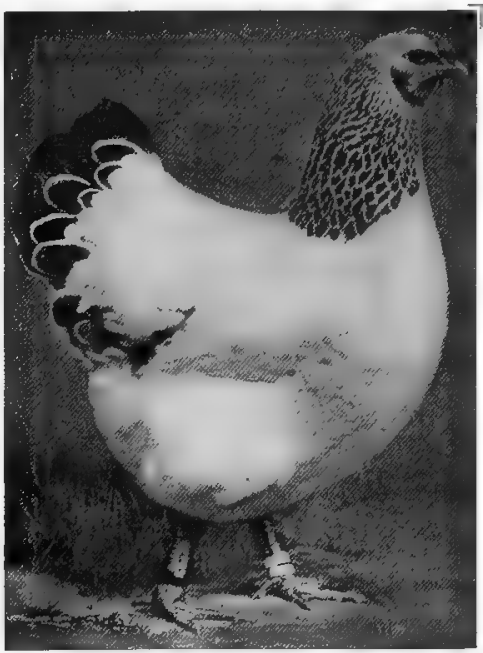

FiG. 53.-A Columbian Wyandotte hen. showing the beautiful color-markings which are so much desired for exhibition. (Photo by Chas. D. Cleveland.)

Pleasure.-In order to succeed in any branch of the poultry business, the poultryman should derive pleasure from his work, but there are birds which are kept solely for the pleasure derived from breeding them. Among these, the Bantam probably takes first rank. In color and body type these birds are, in most cases, the miniature duplicates of large breeds (Fig. 54). The Bantams are often bred as pets for children, simply to give them pleasure. Some Bantams, particularly the Buff Cochins, are used in the hatching and rearing of pheasants or other young birds which are difficult 
to raise. There are two main groups of Bantams, the Game and the Ornamental, and the Game Bantams are subdivided into a number of varieties similar in shape and color to the standard Game fowls. As a rule, the best Game Bantam resembles the standard Game in every respect, except size. The smaller they can be bred and yet conform to type, the better they are. Small Game Bantams weigh only a few ounces, yet possess the style, symmetry, and alertness of the large Game. The Ornamental group are the most inter-

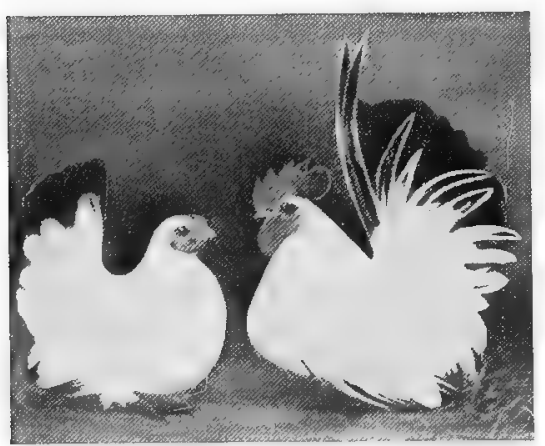

Fig. 54.-Black-tailed Japanese Bantams. These very small birds make excellent pets for the little folks. (Photo by Urban Farms, Buffalo, N. Y.) esting to young people. The Asiatic Bantams, namely the Brahma and Cochin, lead in popularity, while the little Buff Cochin is one of the most common and interesting. These have the typical body shape and color of the large Buff Cochin, but weigh only about fourteen ounces, as compared with the eight or nine pounds of the large Cochin. The Sea Bright Cochins are distinguished by a beautiful plumage pattern, and an alert, upright carriage. The Rose Comb Bantams are another group always seen at poultry shows; they are bred extensively for pleasure. Bantams may be produced from any standard kreed by constantly selecting the small adults for breeding, and hatching year after year the smallest eggs laid by the smallest fowls. If kept up continually, this practice will result in very small and dwarfed specimens.

Association.-Certain breeds of poultry are often kept for the simple reason that the poultryman has become attached 
to, or especially interested in, one particular type. This association or attachment may be because he or she has originated the particular type, or the poultryman may have been acquainted with this particular breed in his youth, and fancies it as a matter of sentiment. Quite commonly the breed is a general favorite in the community, and bred for

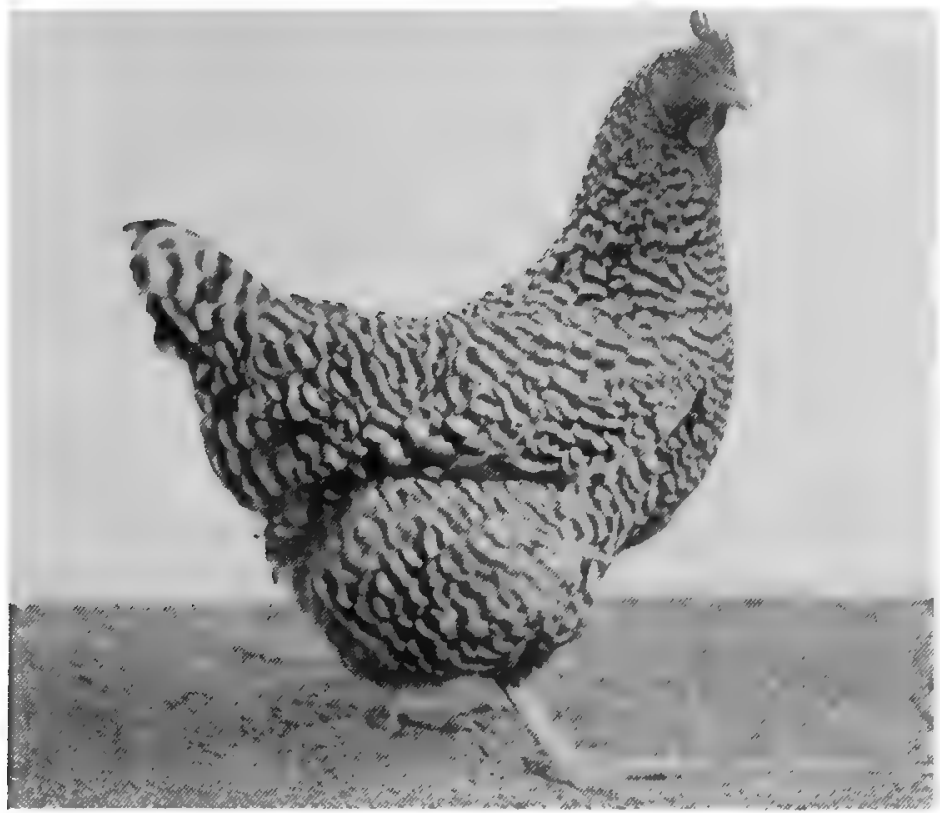

Fis, 55.-Barred Plymouth Rock hen, very common on all farms in the United States and frequently called the "Old Grey Chicken."

no other reason than that it is the prevailing type. A good example of this class is the Barred Plymouth Rock. The fact that this breed is more often found on the farms of the country than any other often leads to the belief that there is no fowl like the old grey chicken (Fig. 55).

Unique Features.-Some of our poultry possesses certain distinctive features or marks which appeal to the fancy of 
the poultryman. Spanish fowls, for instance, are unique in having a pure white face, which always interests and causes comment. The Polish and Houdan have a crest which immediately distinguishes them from all other varieties, and any specimen of this breed will attract general attention by its oddity. Among the most unique fowls in the poultry yard are the Silkies, whose feather growth is characteristic from the fact that it resembles tufts of hair or thread more than feathers. The plumage is white, the skin and face are purplish. They are sometimes called the Woolly or Downy fowl. Next to the Silkie in singularity are the Frizzled chickens, which are so named from the fact that the plumage is curled. Instead of lying flat on the body, the quills of the feathers curve upward, and point toward the bird's head. This makes the feathers look as if they had been curled with a curling iron. This ruffled and erect plumage makes the bird look very plump, but in reality they are not heavy. The prevailing color of the Frizzle is white.

Commercial Value.-Summing up the commercial advantages and possibilities of our breeds, we see that they depend upon two distinct factors. First and foremost are the economic possibilities, which are governed by their ability to produce food for human consumption. Next in importance are their fancy features, such as plumage viewed from the stand-point of beauty. The Silver and Golden varieties, with either spangled or penciled plumage, probably excel all others. In studying breeds and breed types, their economic or utilitarian possibilities should be paramount, not the fancy features.

\section{LABORATORY EXERCISE}

Exercise No. 12.-If possible, have the pupils bring to class as many representative birds, which are classified as Miscellaneous Breeds, as they can find in the vicinity. Bantams, Silkies, Frizzles, Polish, and Hamburgs would make 
a very complete class for study. Go over the birds at hand, paying special attention to the peculiarities of each which place them in the miscellaneous group. Follow the general scheme as outlined in exercise No. 9, page 56.

\section{THOUGHT QUESTIONS}

1. What characteristics cause certain breeds to fall into a miscellaneous class?

2. Are the miscellaneous breeds of any great commercial or economic importance?

3 . Where are the members of this group most usually found?

4. To what is the growth of the poultry show responsible?

5. Upon what two factors does the value of a breed depend?

6. Mention a few of the characteristic features of the Polish breed.

7. For what is the Hamburg famous?

8. Which breed is characterized by a blue plumage color?

9. How are the Blue Andalusians bred?

10. Is an interest and pleasure from poultry work necessary for success?

11. Enumerate the various breeds which are kept for pleasure.

12. What are some of the more common varieties of bantams?

13. Are bantams used as pets?

14. What is the average size of bantams?

15. Are some breeds of poultry bred for association's sake?

16. Give an example of a breed which is very popular, due to associations.

17. What breeds are kept for their unique characteristics?

18. What are some of these unique or odd characteristics?

19. How can the true commercial value of a breed be determined?

20. Are there any representatives of these miscellaneous breeds in your community?

21. If so, are they a success commercially?

Reference.-Consult "American Standard of Perfection." 


\section{CHAPTER VII}

\section{BREEDING AND MATING}

THE hardest problem which confronts the poultry keeper is the mating and hatching. Each year he must raise enough pullets and cockerels to replace those sold on account of age. Proper breeding is a question which confronts both the small back yard poultry keeper and the commercial poultryman, and a clear understanding of the practical nature of the work is absolutely necessary, if good birds are to be produced each year.

Breeding Defined.-Breeding is the science which deals with the reproduction and improvement of domestic animals; and as a natural function breeding is merely the reproduction of the species. When man systematizes breeding operations, his object is to bring about improvement through reproduction. Breeding in itself is a complex problem only partially understood, and in this chapter will be pointed out a few of the more important and practical methods of solving this problem.

Mating Defined.-Mating is a process in breeding. It may be defined as the selection and pairing of individuals possessed of desirable characteristics, with the hope that these characteristics will be reproduced in their young. In artificial matings, the aim of the poultryman should be improvement along some commercial line, such as egg production, meat production, or the possibilities of dual purposes. In practising artificial matings for improvement, the poultry keeper should have in mind a well-defined ideal type, for without some standard or ideal, no definite advance can be made. By constantly selecting towards this type, each succeeding generation should be better allapted to the purpose in view. 
Factors Which Affect all Breeding.-Two distinct groups of factors affect the reproduction of all animals; these are particularly applicable to domestic poultry. These may be termed influence of inheritance, and influence of environment. By inheritance is meant the transmission of characteristics or features from the parent to the progeny. Nearly all the features which young chicks display during their early development are inherited from the parent through the egg. Shape of body is inherited. Color of plumage and color of egg are inherited. In addition to visible characteristics, types of temperament are inherited. The power of egg production is known definitely to be inherited. Disease is in a few instances hereditary, while in others not the disease itself, but a tendency or predisposition to it is transmitted. This factor of heredity is the greatest power for improvement which the poultry keeper can bring to his aid.

The second factor is that of environment, or the influence of surroundings, upon the production, development, and growth of birds. Environment is operative from the time the hatching egg is laid, until the resulting chick has reached maturity and is marketed. Before incubation, holding the egg too long or subjecting it to an improper temperature will check the growth of the embryo or destroy it. Lack of moisture or unsuitable temperature in the incubator will result in a poor hatch of chicks. The same is true during the brooding and growing season. Lack of range, green food and shade will check growth and retard maturity. Unsuitable environment tends to retard the natural development of inherited characteristics. It must be laid down as an elementary principle in breeding that the best results can be obtained only by the combination of two factors. Heredity demands that breeding be from good birds, and environment means providing them with such surroundings as will best promote growth and production. 
Laws of Breeding.-Before discussing special methods of mating and breeding for definite purpose, the common laws of breeding will be briefly stated, for these must be understood before one can mate fowls intelligently.

The most common and one of the most stringent rules in the reproduction of animals is the law of heredity. In plain words, this means that like produces like, and that the young will, in large measure, show the same characteristics as the parents. The action of this law makes it essential for us to mate and to breed from birds which possess those characteristics we desire in the progeny. Scientists have demonstrated that this law is fixed and absolute. Furthermore it has been found that the results of this law of heredity can be computed definitely in figures. The discovery of these facts and their application to poultry breeding are of the greatest value to the poultryman, because they enable him to mate his birds intelligently for the purpose he has in view.

The second important law of breeding is that called variation, and this law is antagonistic or in opposition to the law of heredity. Stated in simple words, it means that many of the characteristics shown by the progeny will differ from those possessed by the parent. This is what is known in science as a counteracting force. Just as we have laws of heredity and variation working in opposition to each other, so we have the laws of gravity and centrifugal force working against each other to hold the earth in balance. Observation of the workings of this law of variation teaches us that there are different kinds of variation. There may be variation in color and quality, in structure and size, in egg production, and in flesh forming ability. It is because of this law of variation that the poultryman is able continually to improve his flocks. By studying these variable characteristics, and by constantly selecting and breeding the varieties best suited to his needs, he will secure better and better birds. 
Atavism is another law of breeding which teaches us that the characteristics of individuals may disappear for a generation or two, and then reappear in a subsequent generation. For example, we sometimes get black birds from a pure Barred Plymouth Rock mating. This black plumage doubtless comes from the Black Java, which is one of the original ancestors of the Plymouth Rock. Atavism may be termed a going back or reversion to an ancestral type or color. We might call it postponed heredity.

Prepotency is another term used in breeding. It means simply the ability of the parent to stamp characteristics on its progeny. Some parents who lack this power are said to be non-prepotent.

The term correlation, as used in poultry breeding, means the relation which may exist between a part of the body and the ability. of the birds to produce eggs. For example, scientists are wondering to-day whether there is any correlation between the form of the body and egg production. Should this be proven, it will be a simple matter to pick out birds that are good layers.

Sports are oddities, or abnormal individuals, and these may illustrate a type of variation, which is spontaneous in its nature. A sport is an animal which is different from the

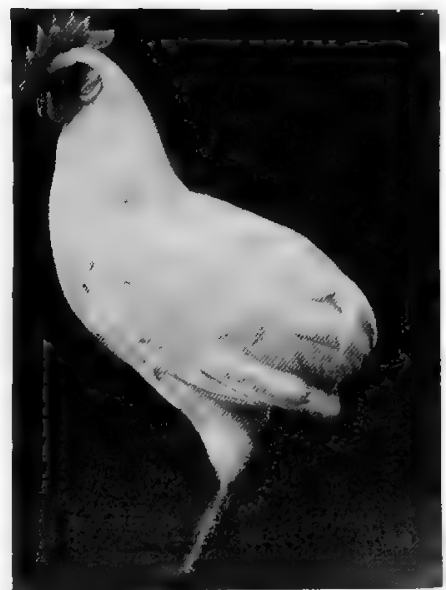

Fra. 56.-A tailless Leghorn commonly called a sport.

normal type, and exhibits characteristics utterly unlike those of its kind; for example, a tailless, a wingless, or a fourlegged chicken (Fig. 56). In studying these rules, the student should fix in his mind the fact that in breeding we select 
birds which represent the very best of those characteristics which we desire to produce, for the reason that, by mating them, the progeny are likely to inherit these characteristics. Moreover, in accordance with the law of variation, some individuals will show even finer characteristics than their parents. To secure continuous improvement year after year, these better variations should be selected and reproduced each year.

Importance of Special Matings.-An elementary principle of breeding is the importance of making special matings for special purposes. Such matings should be made early each spring, the best females from the whole flock being chosen and mated with male birds possessing the characteristics desired. This custom eliminates inferior birds from the breeding pen, and enables the poultryman to exercise his most powerful weapon, namely, the power of selection. Mating by selection is the breeding from a few of the best birds. Mass breeding, which permits the saving of eggs for hatching from all birds in the flock, leads to no definite improvement.

Special matings for breeding purposes should be small, usually from eight to twelve females being mated to one male bird. With the light, active breeds, twelve are none too many; with the heavy breeds, eight are usually sufficient. This mating should be made in January or early February. The birds should be put in small breeding houses, that are well-ventilated, dry and clean. They should be given free range, and fed an abundance of hard, dry grain scattered in deep litter. This method of feeding with plenty of range will induce exercise which is one of the essentials for health and vitality. The object in special matings is to get fertile eggs, which contain strong, vigorous germs. When set in the incubator such eggs will hatch large, healthy chicks.

Breeding for Egg Production.--When breeding for egg production in breeding pens, a few points should be especially 
considered, and the most important is vigor. Vigor is a strong, inherited constitution (Fig. 57). Vigor means freedom from disease and good health. It also means the ability to transform feed material into eggs. Vigor in poultry is manifested by a good sized body, by an erect carriage, with a rather high tail, and by a bright, prominent eye. A short, thick beak and a deep head are also common signs of high vitality. Want of vitality is most often indicated by a low, drooping carriage, a drooping tail, narrow body, long beak

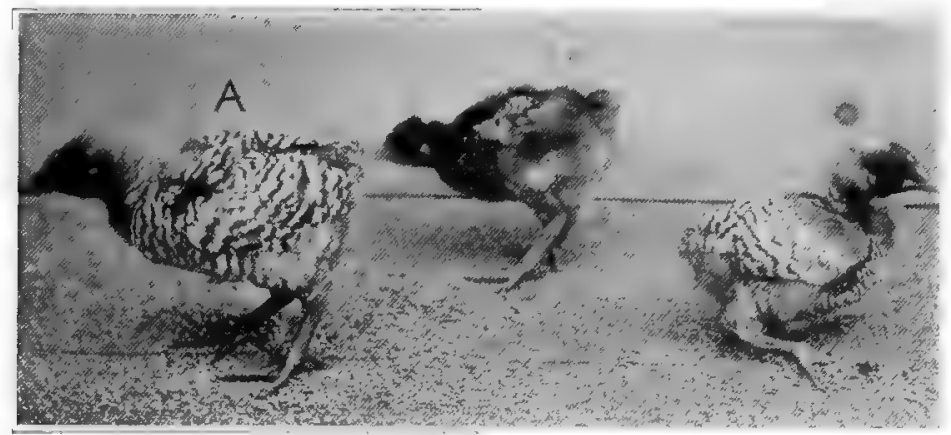

Fig. 57.-Barred Plymouth Rock chicks, showing different degrees of vigor. The one marked "A" is of normal size, the other two should be disposed of for meat at an early age.

and head, and a depressed eye. It may be due to heredity, to improper feeding, or to faulty housing. Whatever the cause, birds showing lack of vitality should never be used for breeding.

Size must be considered in mating for egg production. The large hen usually lays a large egg, which in turn will hatch a large chick. Observation proves that the small egg hatches the small chick, which at maturity is the small adult. If we wish large eggs for market, we must use a good sized bird from which to hatch the pullets for laying.

In choosing fowls for special matings, try to breed only from birds capable of large returns (Fig. 58). Egg production in a female is inherited from the father; hence if we wish to 
have a heavy producing flock the cockerel in the breeding pen must be from a mother that is a heavy producer.

Birds hatched late should never be used for breeding, as they are apt to be immature, small of size, and to lay small eggs. This applies to both male and female. Maturity means not only good growth, but high vitality, and also means strong chicks when hatched. Pullets should never be utilized for breeding. When used year after year they have often been the cause of failure in poultry enterprises.

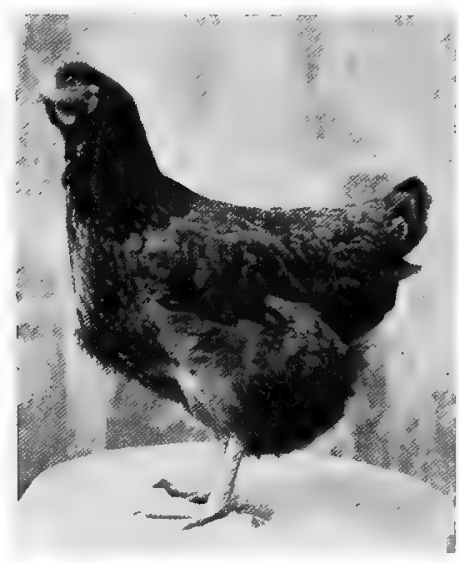

Fig. 58.- A Rhode Island Red hen with a large egg record. Note the great depth of body and aigns of vigor.

They are small and lay a small egg. The ideal practice is to mate yearling hens to vigorous, mature cockerels.

In choosing the breeders, a good appetite indicates good production and stamina. So does an alert, active habit, shown by the desire to be off the perch, and working in the litter, or roaming over the range. If these five requisites are borne in mind, and matings for egg production made accordingly, the resulting chicks will be more likely to reach maturity at the proper time and make good, healthy layers than if they were neglected.

Breeding for Meat Production.-In breeding for meat production, the same special matings should be made, and the same general rules apply. Size is most important, because a large body means a large amount of meat, but the kind and quality of the meat should also be considered. The meat a fowl produces depends somewhat upon the type of meat desired. If broilers are demanded, small-boned, plump, 
quick-maturing birds are best. If roasters are the object, large sized, full-meated, slow-growing birds which are tender at maturity are more desirable. Vigor, stamina, and good health are just as necessary here as in breeding for egg production.

Pedigree.-The dairyman who hopes to succeed in his business must know the exact ability of his cows to produce milk. He can then dispose of the unprofitable ones. The time has come for the poultryman to follow the same plan. He should weed out unproductive birds, which might be called culls or drones, and substitute in their places birds which are good layers. This is known as pedigree breeding. By following certain methods, he can rear a line of fowls whose power of egg production is known. By consulting these records when he makes special matings, there will be immediate and continuous improvement. There are three steps in pedigree breeding: First, trap nesting. Trap nesting for a large laying flock is not profitable, and scarcely feasible. The trap nest should always be placed in a separate mating and breeding pen, and is so arranged that when the hen enters to lay the egg she is caught. When the attendant removes the egg he marks on it the number of the hen, then releases her, and sets the nest. When a lot of eggs have been saved from trap nested birds, they are hatched in an incubator. Eggs from the same hen can be put in small compartments or in small cheese cloth bags. This is called pedigree hatching, and is the second step in pedigree breeding. When the chicks are hatched they should be distinctly marked, either by toe-punching or leg banding. The pedigree process necessitates considerable labor, but its immediate results in increased egg production are so apparent that the slightly increased labor and cost are time and money well spent.

The only way in which poultry can be bred successfully is to make special matings with selected birds. 


\section{LABORATORY EXERCISES}

Exercise No. 13.-Practice work in selecting breeding birds can best be secured by taking a trip to one or more nearby poultry flocks which are owned by some of the pupils. The class can then go over each bird, separating the breeders from those which are to be sold or killed. When making the selection each bird should be examined carefully for the characteristics which are outlined in the text. The object for which the flock is to be kept should be considered first. That is whether the flock is to be managed for egg production or for meat. In this selection size, health and vigor are the first considerations.

- Exercise No. 14.- If a small flock is maintained on the school property the pupils should be given experience in operating trap nests and keeping records of individual production. Simple trap nests can be easily built. This work can be taken up as a project in carpentry. Knowing the production of the hens in the flock an effort should be made to pedigree the chicks hatched and thus allow the pupils to study the inheritance of egg production and common external characters of plumage color and comb characters.

\section{THOUGHT QUESTIONS}

1. In what way is the work of mating and hatching a hard problem for the poultry keeper?

2. What is meant by breeding?

3 . What is the direct object of all poultry breeding?

4. Define the word mating.

5. Describe the difference between mating in nature and artificially, as with poultry keeping.

6. What are the two controlling factors which affect all breeding work?

7. What is meant by inheritance in breeding?

8. Discuss the effect of environment upon all breeding work.

9. What is the true meaning of inheritance and environment when applied to breeding operations?

10. Define the law of heredity.

11. What is the great value of the law of heredity?

12. What is meant by the law of variation?

13. Ilow does the law of variation make possible continued improvement? 
14. The law of atavism means what to the poultryman?

15. Give an example of atavism.

16. Define the meaning of prepotency.

17. What do we mean by correlation in breeding?

18. What is a sport? Give an example.

19. What is meant by special matings?

20. Mating by selection has what advantage over mass mating?

21. Enumerate factors which should be considered when breeding for egg production.

22. Why is it essential to breed from rather large, mature birds?

23. What special features should be considered when breeding for meat production?

24. Describe the process of pedigreeing.

25. What are the advantages of pedigree breeding?

Reference.-Consult "Animal Breeding" by Shaw. 


\title{
PART II \\ HATCHING AND REARING
}

\author{
CHAPTER VIII
}

\section{THE EGG}

THE hen's egg is a mass of cells and tissue of different kinds, encased in a shell or protective coat.

Function of the Egg. - In all nature the egg is the reproductive body, but the function of the hen's egg is twofold. The fertile egg contains in its center, the germ, which, on the application of heat, will develop into a young chick, and also, surrounding the germ or embryo, the yolk or food material which nourishes the embryo during its growth. From a reproductive standpoint, the egg contains both the chick and its food supply. The entire mass is encased in a protective shell which retards evaporation, so the egg can be kept a considerable time without injury. In addition to its reproductive function, the egg is used by man for human food, and because of the excellency of the food, and the great demand for it, poultry keeping has become a matter of great commercial importance. The egg of the domestic fowl is not only large of size but highly nutritious, the protein in the egg being especially valuable and considerable in amount.

Structure of the Egg.-The component parts of the egg are the shell, the membranes, the albumen, and the yolk. The shell is an outer envelope or case surrounding the egg to protect its contents. It is largely composed of carbonate of lime, which the bird secures by eating oyster shells, bone and grit. Sometimes hens lay soft shelled eggs. This is 
either because the bird has not eaten enough of shell forming feed, or because there is disease of the oviduct. The growing chick must breathe while in the shell, and nature has provided for this by making the shell porous, with hundreds and hundreds of small openings, through which the air passes, and through these same openings the liquid part of the egg evaporates. Shells vary greatly in color and structure. The Leghorn lays a white egg, which is rather brittle and thin, and the heavier breeds usually lay dark or brown eggs, which are much thicker and tougher. Owing to an abnormal condition of the oviduct, eggs are sometimes laid with irregu-

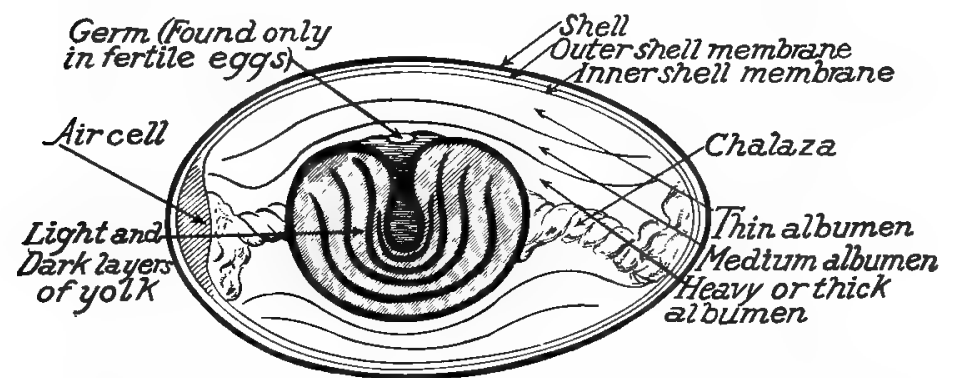

Fic. 59.-The cross-section of an egg showing the location of the contents.

lar shells; often they are spotted and rough. In collecting eggs for hatching, only the clean, smooth-shelled ones should be used. The liquid part of the egg evaporates very quickly in a warm temperature, and the best way in which to check it is to lower the temperature or, if possible, to close the pores in the shell. Commercial cold storage means the keeping of eggs at a low temperature to prevent evaporation. In the home eggs are often preserved by placing them in a solution of silicate of soda, which coats the egg, and thus closes the pores or openings in the shell (Fig. 59).

There are two shell membranes lying immediately under the shell, and in close contact with it. These are called the outer and inner membranes. The outer one lines the shell 
itself and adheres to it, and the inner one is closely adherent to the outer. Examination of an egg a few days old will show that at the large end these two membranes are detached from each other and that there is a small air space between them. This is commonly called the air cell. As evaporation takes place the air cell grows larger, because the liquid evaporated leaves more room for the outside air, which finds its way in at the large end. Sometimes the air cell may be misplaced, being often found on the side of the egg. This is because the egg is old, and has been lying on its side for a long time; the heavy liquid has settled at the bottom and the air cell risen to the top. At hatching time the shell membranes should be soft and easily broken; if dry and rough, the hatch will be poor, for the chicks cannot pick their way out of the shell. These membranes are composed largely of nitrogenous material. Lying immediately under the shell membranes are dense layers of a white substance called egg albumen, which contains considerable nitrogen or protein, has no smell, and very little taste. The white of the egg readily coagulates, and when an egg is dropped into boiling water, this process of coagulation may be easily seen. A study of the egg shows three distinct layers of albumen. First, is a thin liquid near the shell; next, in the center of the egg surrounding the yolk, is a very heavy, dense layer; and a medium layer lies between the two. Egg albumen has two distinct functions to perform. First, it acts as a protective cushion around the chick during its development, preventing sudden jars and shocks. Its main function, however, is to provide the growing chick in the shell with nutriment which goes directly into the formation of its body. At each end of the egg, in the albumen, will be found a thickened string or cord, which appears to be twisted, and attached to each end of the yolk. These cords are called the alloumen cords or chalazæ. Their function is to hold the yolk suspended in the center of the 
egg, and surrounding the yolk is a membrane to keep it in place. The yolk is rich in fat. It is usually round and yellow. Its function is to nourish the developing embryo. When the chick begins to grow, a number of blood-vessels develop which feed on and absorb the yolk. In the upper part of the yolk is a little indentation or hollow, in which the little chicken develops during the incubation period. Sometimes yolks are a very light yellow, at other times very dark; this color is materially affected by the kind of feed given. That portion of the yolk which still remains when the chick is ready to hatch is absorbed into the chick's body, and furnishes its nourishment for the first day or two.

Formation of the Egg.-The egg is the product of the reproductive organs of the female, which are quite complex, and consist of the ovary and the oviduct. Since the young chick develops outside of the mother's body, the egg also must be complicated in structure in order to protect and nourish the embryo.

In the hen the ovary lies in the center of the cavity of the body, and is attached to the back bone, and closely resembles a bunch of grapes. The small yellow yolks or ovules vary in size from that of a pin head to that of a walnut, and each is attached to the ovary by a stem or string. The mother hen has in her body at maturity a certain number of ova or very small yolks, and the rapidity of their development depends largely upon the care and feed given her. The yolks are developed from the surplus feed consumed which is not needed for her growth or maintenance. As the feed is deposited in the yolks, they grow and mature, one being always a little ahead of the others. When a yolk is fully grown, the sac or pouch which encloses it breaks in its middle line, and the ovum drops into an open tube, and after the yolk has fallen what remains of the sac dries up and disappears. In a day or two another yolk reaches maturity, and goes through the same process. The rapidity of develop- 
ment of the yolks determines the frequency with which the eggs will be laid (Fig. 60).

The tube into which the yolk drops is called the oviduct; it is the channel through which the egg passes from the

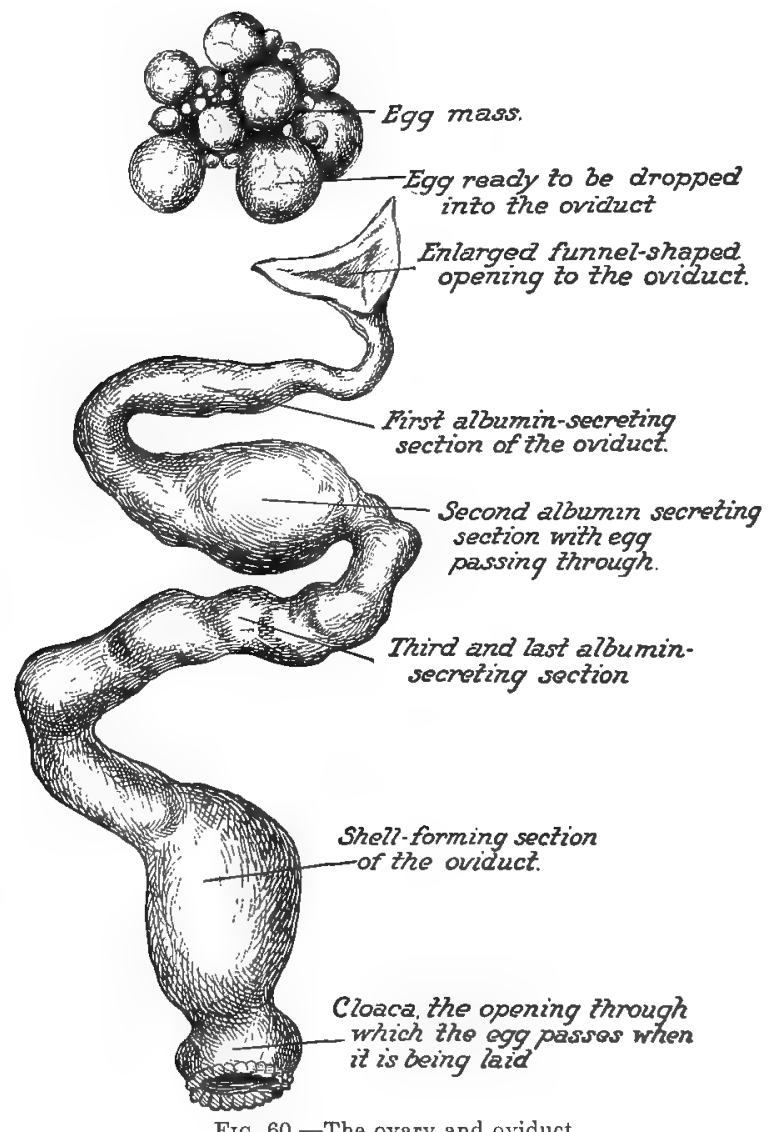

ovary until it is laid. This oviduct is divided into two separate parts; in one of which the albumen is added to the ovum, and in the other the shell forming material is stored 
up. During the breeding or laying season this tube is very large and nearly fills the cavity of the body. When the hen ceases to lay it shrivels up and occupies but little space. The opening of the oviduct into which the yolk falls is large and funnel-shaped. The upper part supplies the thickened, gelatinous albumen; the next two folds furnish the albumen which forms the two thinner layers; the last layer is very watery. As the egg mass passes through the oviduct, it revolves around and around, and this rotary motion gives the egg its elliptical shape. It is during this stage of formation that the thick cords within the yolk are formed. These cords have a knotted, twisted appearance due to the revolution of the egg.

Contraction of the walls of the oviduct force the egg through the tube. The secretion of albumen is caused by the stimulating effect of the passage of the egg. Just before the egg leaves the oviduct, it passes through a short, thickwalled portion, which secretes the fluid that forms the shell. The shell is put on as a liquid coating, which immediately hardens, and the perfect egg passes into an enlarged sac, called the cloaca, and here it remains until the hen lays it in the nest. It takes about twenty-four hours for the egg mass to pass through the oviduct. When hens are in heavy lay, there are often two eggs in the oviduct, one just entering, while the other is receiving its shell.

Malformed or misshapen eggs are usually due to either the bird's being too fat, or to a diseased condition of the oviduct. A double yolked egg, an egg within an egg, small or peculiarly shaped eggs are frequently seen.

The Egg as Food.-From the standpoint of human food, the egg is very valuable. It is similar in composition to the adult bird, but is more concentrated. The solid matter in an egg, exclusive of the shell, contains 50 per cent of protein or nitrogenous material. There is also nearly 40 per cent of fat, and three per cent of ash or mineral matter. The 
protein is found almost entirely in the albumen or white portion, and the fat almost wholly in the yellow portion or yolk.

The Cooking of Eggs.-Eggs are cooked in various ways, the most common being to boil them for a certain length of time. To make them easily digestible, the best way is to put them in water which has been brought to the boiling point. Then set them on the back of the stove, and let them remain in the hot water for from seven to ten minutes, according to the degree of hardness desired. Eggs fried in hot bacon or ham fat are very palatable, but hard to digest. Sometimes the entire egg is stirred up and quickly cooked or scrambled on a hot frying pan. Eggs are usually found in the picnic basket, boiled very hard, and, after the removal of the shell, are eaten with pepper and salt. They are extensively used for the making of cakes, puddings, and other dainties. If properly prepared, they are easily digested, and form the most palatable and most highly relished article of food. They are used primarily as a breakfast dish and in cakes. Their use has materially increased during the past few years, due to the increase in the cost of beef and other forms of meat.

\section{LABORATORY EXERCISES}

Exercise No. 15.-Have each pupil bring to school a medium-sized white saucer and some wood tooth-picks. This material is to be used in the study of eggs and embryos. Each pupil should provide himself with a new laid egg of normal size and shape. In order to best study the structure of the egg proceed as follows: Slightly crack the shell at the very center of the large end. Carefully pick away the cracked part of the shell and examine the air cell and the shell membranes. Carefully enlarge the opening and pour the contents of the egg into the saucer. Pour it out carefully so as not to rupture the yolk. Study the internal structure 
of the egg, looking especially for the parts mentioned in the text. A portion of the albumen may be dropped into boiling water to see the effect of heat upon same. Different eggs should be compared to see the different colors of yolks. Examine the pieces of shell carefully and find the small pores or openings through which air enters the egg. Some eggs may be hard boiled and studied to show the normal position of the contents.

Exercise No. 16.-An old hen which is in laying condition should be secured and killed by bleeding. With the aid of a knife the teacher can open the abdomen by making a long cut down the breast bone clear to the tail. The skin on each side can be laid back and after removing the gizzard and intestines the ovary and reproductive organs can be easily seen. The class can then be shown the different organs and parts of organs which are utilized in manufacturing the eggs. If the birds selected are in good laying condition an egg can often be found partly formed in the oviduct.

EXErcise No. 17. - If the school has facilities for domestic science work the girls will find considerable value from one or more exercises dealing with the preparation of eggs for human food. After the eggs are prepared a lunch may be served to which the boys may be invited and all may become familiar with the appearance and taste of eggs prepared in different ways. At this time the digestibility and healthfulness of the different methods may be explained

\section{THOUGHT QUESTIONS}

1. Of what does the hen's egg consist?

2. What are the functions of the egg?

3. What is the nutritive value of the hen's egg for human food?

4. Describe in a very general way the parts of the egg.

5 . What is the structure of the egg shell?

6. How does the porous structure of the shell affect the keeping quality of the egg?

7. What material is often used to preserve eggs for home consumption?

8. What are known as shell membranes and where do they lie?

9. Where is the air cell located and how is it formed? 
10. What is the albumen?

11. Where does it lie in the egg?

12. What is the function of the albumen?

13. Where are the chalaze located and what is their function?

14. What is the appearance of the yolk?

15. Of what is the yolk composed?

16. What is the function of the yolk?

17. Of what do the reproductive organs of the female consist?

18. Describe the appearance of the ovary.

19. Describe briefly the structure of the oviduct.

20. Describe the passage of a yolk down from the oviduct, stating when and where the different parts are made.

21. What is a common cause for misshapen eggs?

22. What two food materials are present in the egg which make it especially valuable for human food?

23. Enumerate the different ways of cooking eggs for eating.

24 . Which way do you prefer eggs cooked for yourself?

Reference.-United States Farmers' Bulletin 128, Eggs and Their Uses as Food. 


\section{CHAPTER IX}

\section{THE HATCHING EGG}

The purpose when producing hatching eggs is to secure a fair number of good-sized fertile eggs, which will hatch into healthy chicks.

Fertility.-The most important quality in eggs for hatching is that they be fertile, and the germ of high vitality. One of the common causes of infertility is low vitality in the parent stock, and this lack of vitality may be inherited, or due to improper environment. Another frequent cause of infertility in the early spring is frozen combs. In February and March, when eggs are being saved for hatching, and there are spells of cold, damp weather, the cocks often freeze their combs and wattles and this unfits them for breeding for from four to six weeks. Most of the eggs saved under such circumstances will be infertile, or the germs they contain will be weak, and will not develop properly, or the eggs will hatch poorly. Season has its effect upon the fertility of eggs. During the spring, which is the natural breeding season, eggs are always of higher vitality than in any other season of the year. In the hot summer months the germs in the eggs are often weak.

Another cause of low vitality is that there are too few breeding males. It is wiser to mate a small number of females to one male, and thus insure high vitality, than to crowd the females. If the breeders are too fat the result will be infertile eggs as well as low vitality. Quite commonly the germ dies, and in these cases the eggs, when tested, will appear infertile. Holding the eggs too long before incubation, keeping them at too high a temperature, or subjecting them to violent shocks or rough handling before incubation 
will kill the germ. Infertility and low vitality of the germ go together, are equally important, and their prevention will mean better hatches and stronger chicks.

Care of the Breeding Stock.-The breeders selected and mated in the spring for the purpose of hatching eggs need special care, in order to keep them in good physical condition. They must be guarded against disease, and their vitality sustained. The aim should be to secure only a fair number of fertile eggs. Heavy egg production during the breeding season or just previous to it is not desirable; forcing impairs the health and vigor of the breeders, and results in poor eggs for hatching. Breeders should be given free range; this means liberty to go out of the breeding pen whenever they wish to do so. When there is snow on the ground or the weather is unfavorable, they rarely take advantage of their freedom. Breeders need plenty of exercise, especially the heavier types, which have a tendency to take on too much fat. The bulk of their feed should be scattered in deep, clean litter, of such a nature that it will bury the grain, and compel them to scratch to get it. Green feed in some form is desirable in the winter; cabbage, mangel beets, and, in the absence of these, sprouted oats, are best. If the poultry yards or ranges could be seeded with rye or wheat in the fall, the birds would have plenty of early, succulent, green feed immediately at hand. A moderate amount of protein in the form of meat scrap should be given to all breeders; 20 per cent of meat in the dry mash ration is quite safe.

The breeding flock should be kept in a well ventilated house which is light and sunny, and has enough floor space to prevent any crowding. Each breeder needs a space at least five to six feet square, especially if eggs are set for hatching early in the season when the birds can not get out of doors.

Collecting the Eggs.-Eggs for hatching should be collected often; in cold winter weather, three or four times a 
day is none too frequent, for if once chilled, they are spoiled for hatching. In the spring they should be collected at least twice a day to prevent their becoming soiled. If collected frequently, the heat from the hen's body will not start germination. Broodiness should be watched for, and all hens in the breeding pen that seem broody should be immediately removed, as their presence in the nest is apt to spoil for hatching the eggs laid by other birds. In col-

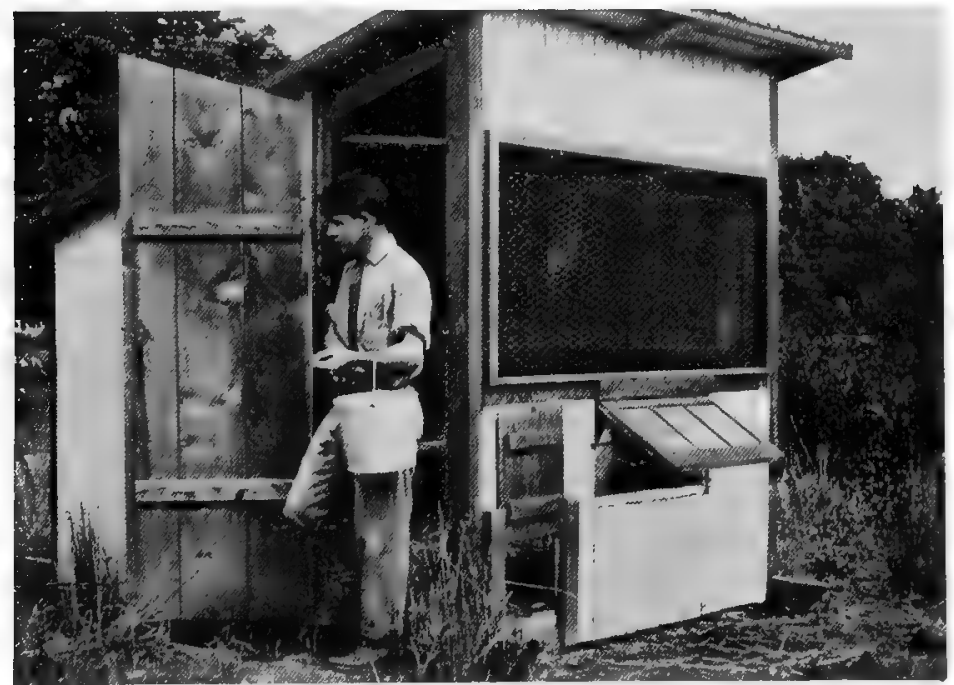

F1G. 61.-Carefully collecting his hatching eggs in order to keep them in good condition for incubation.

lecting hatching eggs, handle them carefully, and collect in heavy, metallic pails (Fig. 61). There should be no sudden jars or shocks, for this may injure the germ, or rupture the air cell. Plenty of nests for the breeding birds should be provided so that the hens will not be crowded.

Saving the Hatching Eggs.-Hatching eggs should be kept but a short time before incubation; the shorter the better. Experiments prove that the hatching qualities of eggs de- 
crease in direct proportion to the length of time they are held before incubation. Eggs kept over three weeks are rarely profitable. Incubator eggs should be kept in a cool temperature previous to incubation; 50 degrees Fahrenheit is about right. A high temperature in the room is apt to start the development of the germ, but if the air is not warm enough to keep the germ growing, the result is death. If possible, hatching eggs should be placed with the large end up, as this keeps the air cell in its normal position, and prevents the necessity of frequent turning. When the eggs are placed on the side, they should be turned carefully every other day. A common method is to pack them securely in boxes and turn the box every other day.

Selecting the Hatching Eggs.-If the pullets desired are to lay eggs uniform in shape and color, these points must be borne in mind when selecting the eggs from which they are to be hatched. Especially is this true with regard to color. If the breed used lays white eggs, all eggs with tinted shells should be sold for food, and nothing but ivory-white shelled eggs should be placed in the machine. If this rule is followed for two or three generations, we can absolutely eliminate tinted eggs from the strain. If brown shelled eggs are produced, we should select those as nearly as possible of uniform shade. Hatching eggs should also be selected for uniformity of shape. Put no exceptionally long eggs in the machine; they are often infertile, and frequently the chick does not form properly, hence can not get out of the shell. Neither should perfectly round eggs be hatched. A uniform, normal shape is best. Malformed eggs should never be set for hatching (Fig. 62). They are usually infertile, but even if they should contain a germ they will rarely hatch. Size is important in selecting eggs for a hatch, and extremely large or small ones should be rejected; if abnormally large, they are usually double yolked, and rarely hatch out. Birds which lay such eggs are usually extremely fat or out of health, 
consequently their eggs are infertile. Extremely small eggs are usually the first or the last of a clutch, and will produce

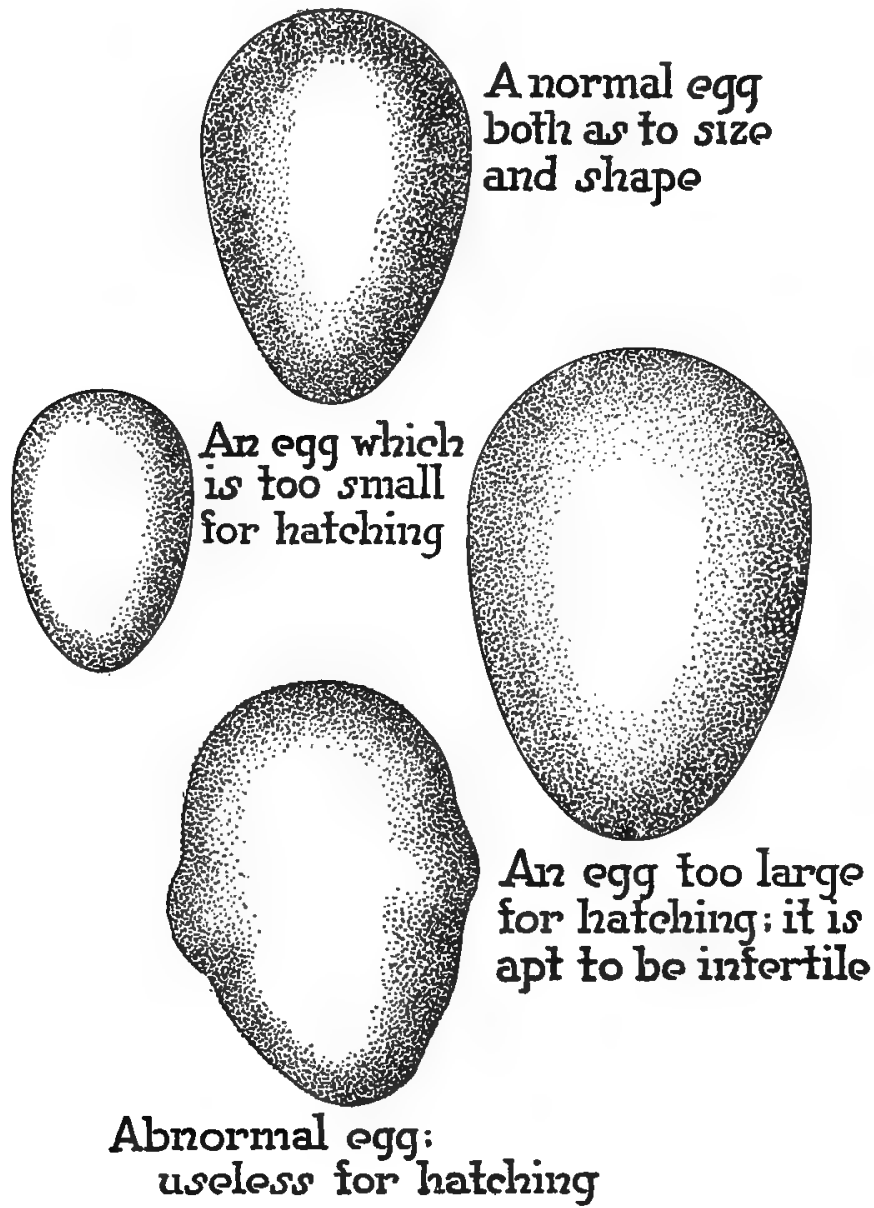

Frg. 62.-Normal and abnormal eggs for hatching.

only small chicks of low vitality. Eggs of medium size, weighing about two ounces, are the best. The shells of eggs 
placed in the incubator should be clean and perfect, free from thin porous places, and neither rough nor covered with patches of hard substance. It is most important that the eggs placed in the incubator or under the hen should be average eggs, and perfect in all respects.

Development of the Chick.-The fertile eggs contain, when laid, a germ which has undergone some slight development. This germ is called the embryo. But nature has ordained that this little germ stop growing as soon as the egg is laid. If, however, the egg is subjected to a temperature of 103 degrees Fahrenheit, it again starts to grow. Placed in the incubator and subjected to this degree of temperature, the germ must be kept growing continuously, if the egg is to hatch a strong chick. The direct cause of the incubation of the embryo is steady heat, the incubation temperature being 103 degrees Fahrenheit.

The growth of the chick within the shell comprises two periods: First, the formative period, in which the various organs and parts of the chicks are formed, this period occupying the first three or four days. Secondly, the development period, which lasts until the twenty-first day. During this time the organs previously formed grow and develop.

The original embryo in the fertile egg consists of but a few cells, and in its early growth these few cells divide into other cells. From these simple cells a very complicated embryo, with many hundreds of cells, develops in a few days. Each cell develops into a different type of structure. During the first, or formation period, all of the organs of the body take shape. First to appear are the spinal cord and brain, or what will later comprise the nervous system. Next comes the back bone and the ribs. The eye and ear are formed early in the second day. The head and blood vessels make rapid early growth, as the latter must nourish the embryo by carrying to it the food material contained in the yolk. The digestive system is well developed on the third day, at 
which time the lungs and respiratory organs also make their appearance. The legs and wings are visible on the fourth day. From this time on, these organs grow steadily and gradually assume more and more the appearance they will have at hatching. By the seventh day, the head and body of the chick have attained a large size, the eye being especially prominent. The feathers can be readily seen on the ninth day, looking like little hairs all over the body. On the fourteenth day the embryo can be seen to move about in the egg, its head lying at the large end near the air cell, and its feet being curled up in the small end.

Eggs which contain a growing embryo should be candled frequently in order to view them through the shell, and sometimes they should be broken to study the internal appearance. The air cell rapidly increases in size, being as large as a quarter on the fourteenth day. On the twentieth day the embryo fills the entire cavity of the egg, with the exception of the air cell. That part of the yolk which has not been used by the embryo will be absorbed into the chick's body on the nineteenth day, and will furnish its feed the first few hours after hatching.

Hatching.-If the egg is fertile and the proper temperature be maintained, hatching should take place on the twentyfirst day. This process is very interesting to young people. The chick emerges from the shell in the following way: On about the twentieth day it ruptures the membrane of the inner shell and pushes itself up, so that its head occupies the cavity which was previously the air cell. The chick then breathes the air, and is strengthened for its attack upon the shell, which it breaks by hitting it tap after tap in one place with its beak. After one small hole is punctured the chick renews this tapping process around the shell until it has cut all around the upper or large end. Then, by bracing its head against this lid, and pressing with its feet against the lower or small end, it ruptures the remaining shell, and 
throws the cap off. After rupturing the shell the chick usually lies quiet for a while to recover its strength, and get ready to walk. During hatching the feathers or down are encased in little oily sacs, which, after the chick breaks the shell, quickly dry out and become very fluffy and soft. A normal chick requires about an hour to an hour and a half to get out of the shell after it has begun to pip. A good hatch should start on the evening of the twentieth and be entirely over by noon of the twenty-first day.

\section{LABORATORY EXERCISE}

Exercise No. 18.- Select four uniform eggs and place them under a sitting hen or in an incubator. In six days place four more eggs with those previously set. In six more days place still four more eggs with the previous ones. When the eggs are placed in the nest the date on which they are set should be plainly written on the shell. The eggs selected must come from a flock in which a male bird is kept. Eighteen days from the time that the first four eggs are set all of them can be removed and taken into the classroom. After carefully brealking the shell the contents of each egg should be poured into a clean white saucer, each dish being labeled with a paper showing the date the egg was set. From this date the pupil can determine the age of the embryo. By the aid of a wooden toothpick it is a simple matter to separate the embryo from the egg mass. First with the naked eye and later with the aid of a small hand lens allow the class to study the different embryos, locating the different organs which are mentioned in the text. After the study has been made the class should be encouraged to make pencil drawings of what they see. Infertile eggs will frequently be found and they can be compared with the fertile egg. If facilities are available, some of the embryos may be preserved in alcohol for museum samples. 


\section{THOUGHT QUESTIONS}

1. What is the purpose when producing hatching eggs?

2. What is the most important requirement of the hatching egg?

3. Enumerate some of the most common causes of poor fertility in hatching eggs.

4. What are some of the causes of dead germs in hatching eggs?

5. What is the importance of vigor in the breeding stock?

6 . What are some of the essentials in the management of the breeding stock?

7. What are the special factors to be considered when housing the breeders?

8. Discuss the important points to be remembered when collecting hatching eggs.

9. How long should eggs be kept before they are placed in the incubator?

10. What is the proper temperature at which hatching eggs should be kept before they are placed in the incubator?

11. How would you select eggs for hatching?

12. What is the average weight of an egg suitable for hatching?

13. What is the direct cause of the incubation of the embryo?

14. What is the correct degree of heat to incubate the chick?

15. Into what two periods can the development of the chick within the shell be divided?

16. Describe briefly the formation of organs in the growing embryo.

17. Describe the development of organs just before hatching.

18. Why is the yolk absorbed just before hatching?

19. Describe the way in which the chick gets out of the shell.

20. How long does it take a normal chick to get out of the shell?

21. What is the length of the incubation period?

Reference.-Consult any standard text on Elementary Embryology. 


\section{CHAPTER $\mathrm{X}$}

\section{THE MOTHER HEN}

ON all poultry farms the sitting hen is more or less used to hatch the eggs and rear the chickens. The instinct of the hen to sit on the eggs is called broodiness. Until recently the hen was used exclusively as a means of hatching eggs, but the last few years have seen a marked development

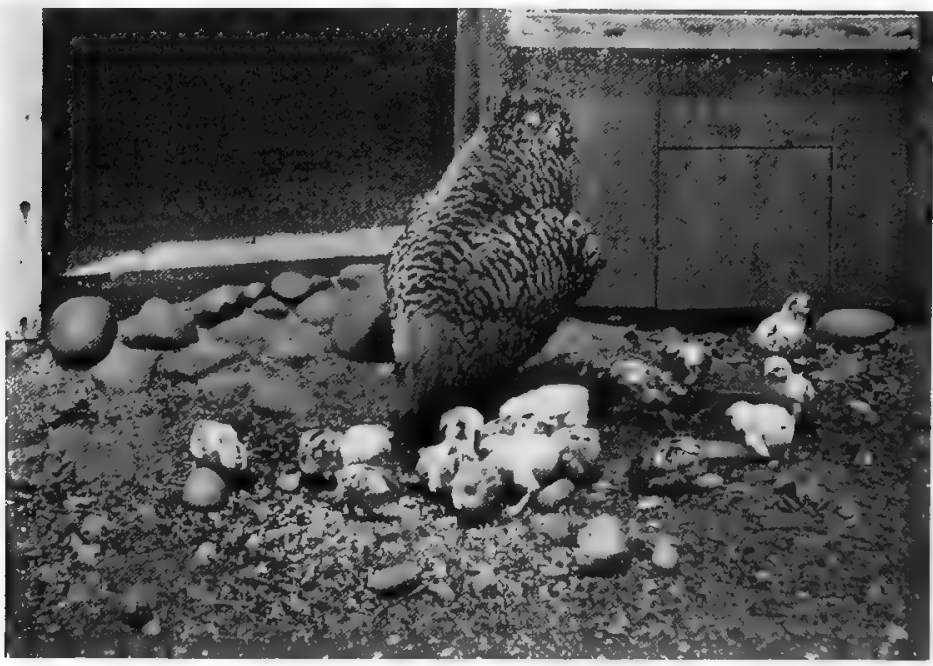

FIG. 63,-This mother hen hatched seventeen fluffy chicks from seventeen eggs. The nest was in a corner of this small 3 by 5 -foot colony house.

in artificial methods. When the hen sits on the nest and hatches the eggs we commonly call it natural incubation. Here the hen, herself, generates the heat necessary to develop the embryo. After hatching she also takes care of the chicks until they are big enough to look after themselves (Fig. 63).

Desirable Points in a Good Mother.-The success in natural incubation depends entirely upon the qualities pos112 
sessed by the hen. It is, therefore, vital that only good hens be used for breeding. In choosing the sitting hen, gentleness is one of the desirable traits. The broody hen should be easily handled. Large size is another desirable characteristic in a good mother hen. A moderately large bird can cover about fifteen eggs, and give to all of them the same degree of temperature. If a small hen is chosen, she can cover fewer eggs, and those near the edge are apt to be chilled or cooled. The hen weighing from five to seven pounds makes an excellent mother. Health is another important requisite, and only strong, vigorous hens should be used for hatching eggs. Those which have ever had any poultry disease should be rejected. Such birds are apt to lack vitality and can not endure the strain of sitting. A broody bird should not be over fat, but merely plump. If thin or emaciated, she is likely to have tuberculosis or similar trouble. The breast of a good breeder hen should be fairly free from feathers, and the skin over the breast feel warm to the hand. This is because of the large amount of blood circulating through this region during the broody period.

The Hen's Nest.-The sitting hen should always be provided with some form of shelter to protect her from rain, and from the heat of the sun, and it should be so constructed that it can be closed, thus confining the hen to the nest; above all, so it can be closed at night to keep out rats, skunks, and weasels. A large sugar barrel makes a good shelter. Five or six of these can be placed in a row, and all covered with a strip of roofing paper. This will make them water proof, and help to preserve them. Small individual sheds or houses, about two feet square, can be built for shelters. They take little material and very cheap boards can be used. Where a large number of hens are to be set, one section of a laying house is sometimes used. The nests can be arranged along the walls, two or three tiers high. Whatever the type of small shelter, it should be built in a protected 
situation, preferably the south side of a building, or the south side of a board fence or stone wall, where they get the direct sun's rays and are sheltered from north winds. If built in an orchard or where there is green sward and natural shade, the chicks will grow much better. It is wise to locate the hatching shelter where the chicks are to be permanently reared, as too much changing about is undesirable.

Making the Nests.-No matter what the type of shelter, earth or soil nests are best. When the nest is built directly on the ground, the soil can be scooped out and packed up in the corner, thus making a hollow in the center. If the nest is built in a box or a shelter with a wooden floor, three or four shovelfuls of dirt, or some thick sods, should be placed in the bottom of the nest. The hollow in the earth should be about fourteen inches in diameter, and three inches deep in the center. The corners should be filled in so that the eggs can by no chance roll out of the nest, and become lost. After the soil is hollowed out, the nesting material should be added; straw cut into six or eight inch lengths makes a fine nest. Shavings and leaves are also often used. The straw should be shaped to conform to the curve of the earthen nest, and should be packed down solid so that the eggs will not be buried in it. Nesting material to the depth of one inch is sufficient.

Setting the Hen.-After the nest is made, the hen for sitting should be selected, and placed on the nest, preferably in the evening, before dark (Fig. 64). At this time she does not get frightened and is much easier to handle. She settles down on the eggs immediately, and is more contented than if she were handled in the day time. For the first twentyfour hours it is well to put false eggs under her, and keep them there until she has proven to be a good sitter. After one day's trial the false eggs can be removed, and real ones to be incubated substituted. In placing the permanent eggs in the nest be carcful to distribute them well. Do not put 
one on top of the other, and place only as many in one nest as the hen can completely cover. When the hen is placed on the eggs, hold her firmly, with both hands, and place her gently down upon them. She immediately feels the eggs beneath her, and settles down upon them without commotion.

Management of the Sitters.-For the first two or three days on the nest, the sitter should be very closely confined. After this time she should be confined to the nest most of the time except when let off for feed. A good plan is to let

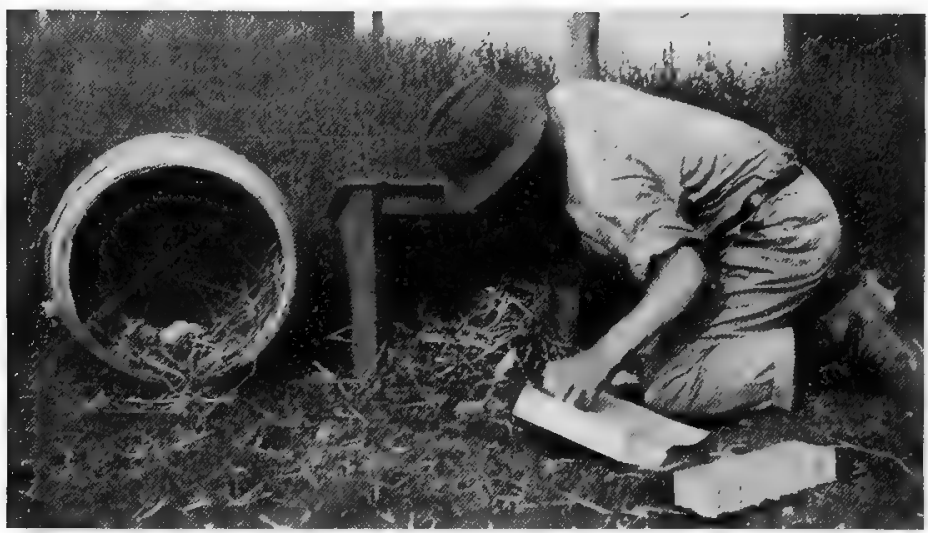

FIG. 64.-A barrel and a box nest. The young man is carefully shaping the nest and placing the eggs.

a broody hen off twice a day, morning and night. Each hatching nest should have attached to it a small, slatted coop, where water and feed can be kept, and the hen allowed to enter and leave the nest as she sees fit. Feed for the sitting hen should be clean cracked corn and wheat, in equal parts. Clean fresh water should be kept before her all the time, and a little green feed given her once a day. If a number of sitting hens are placed side by side, they can all be let out at the same time for feeding. The attendant should, however, make sure that the hens go back singly to the nest. If they are not watched, two hens may go back to one nest, 
and leave the eggs in one nest to get cold. The nest should be cleaned during the middle and at the end of the hatch, and any broken eggs or soiled nesting material be removed. When putting the hen on the nest dust her thoroughly with a good lice powder, and repeat this about the eighteenth day of incubation. This is to keep her free from body parasites. If she is not infested, the chicks are more likely to be free from them (Fig. 65).

The eggs should be tested or candled about the tenth day, and a record made of any infertile eggs and dead germs. The development should also be noted, as well as the size

A

B
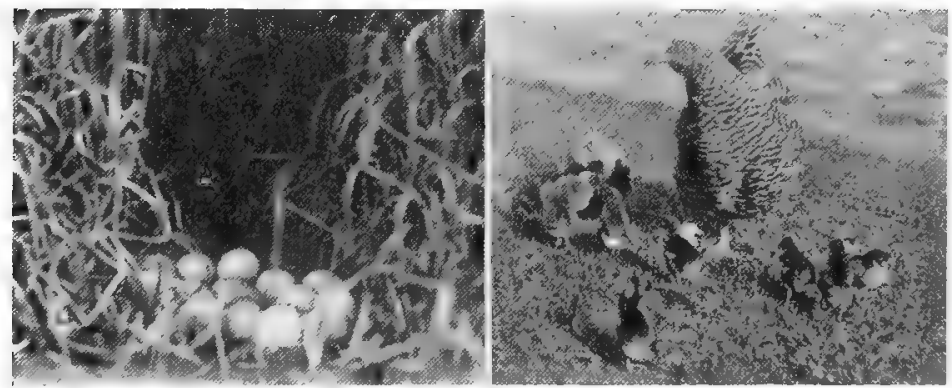

Fig. 65.-The story of the stolen nest. A, The stolen nest in the tall grass under the grape vine. Thirteen eggs to be kept warm for 21 days. B, On the twenty-second day the proud mother brings forth twelve fluffy little youngsters.

of the air cell. Infertile eggs are recognizable by the fact that they are absolutely clear, while a normal egg which contains a good germ will appear to have a dark spot about the size of a pea. Extending from this will be detected dark lines or blood vessels. At the end of the tenth day, a dead chick is revealed by the presence of this dark spot, fixed or attached to the shell so that it does not move about when the egg is rotated. The live germ moves when the egg is turned around. The dead embryo will be encircled by a fixed red line about half an inch or one inch from it. The air cell at this time should be about one-half to five-eighths of an 
inch in depth. In a good egg the line of demarcation between the air cell and the egg mass should always be clear, sharp, and distinct.

\section{NATURAL HATCHING RECORD}

Nest No.............

Date.......... Hen No........... Breed..........

No. Eggs set.................... Kind

Brief description of nest and method of management $\ldots \ldots \ldots \ldots \ldots$.

\begin{tabular}{l|l|l|l}
\hline & Eggs Infertile & Dead Germs & Cracked \\
\hline $\begin{array}{c}\text { Result of Tests: } \\
\text { Seventh day ....... } \\
\text { Fourteenth day .... } \\
\text { Total ........... }\end{array}$ & & & \\
\hline
\end{tabular}

Number vigorous chicks hatched....

Number chicks dead in the shell. .

Per cent hatch of total eggs set

Per cent hatch of fertile eggs left after first test

A record should always be kept showing the results of the egg test. At the end of each hatch this record should give the number of eggs put in, the date when they were set, the date when hatched, the number of vigorous chicks hatched, the number of infertile eggs, and the number which died in the shell. It will be useful for the pupils to refer to in future years, and compare the results attained by present and past experience. At hatching time the hen sticks pretty closely to the nest, and as a uniform and rather high temperature is needed to bring the young out of the shell she should not be disturbed or annoyed after the nineteenth day until 
the hatch is over. On the twenty-second or twenty-third day she will herself bring all the strong chicks off the nest to search for feed.

Care of the Chicks After Hatching.-Immediately after the mother hen brings the hatched chicks off the nest, it should be cleaned and all broken shells and unhatched eggs removed, after which the nest should be dusted with a good lice powder, and clean nesting material put in. The shelter should be inspected to see that it is dry and rain-proof.

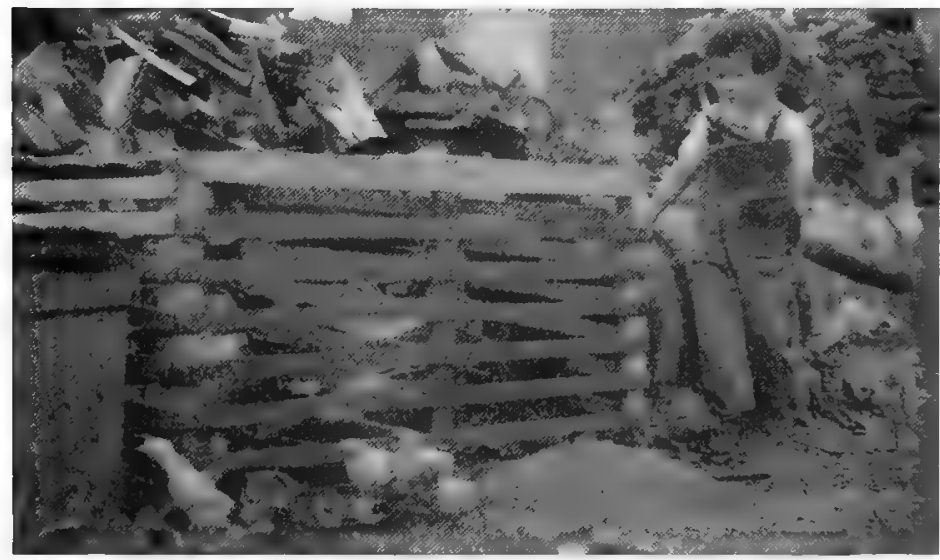

Fia. 66.-After the chicks are hatched the hen should be confined near the nest by a slat coop, the chicks being allowed to roam at will. Here we see the youngest member of the family taking interest in the little chicks.

If the ground immediately in front of the nest is dirty, it should be spaded up and made clean. The chicks need no special feed the first day, but merely access to clean, fresh water and plenty of grit. Dry cracked grain is the best feed for young birds. A common practice, and a good one, is to confine the hen in a small slatted coop in front of the nest shelter. Here she can be fed and watered, and the chicks can be fed outside of this coop, which permits them to pass out through the slats, and thus get away from the mother hen (Fig. 66). A good ration for the chicks is equal 
parts of fine cracked corn, cracked wheat, and pinhead oatmeal. After they are four or five weeks old, this can be gradually changed to cracked corn and whole wheat, equal parts. If they can be given wheat bran in an open pan or hopper until they are two weeks old, they will probably grow faster and be a little bigger. Clean, fresh water should always be kept within easy reach, and the shelter so placed that they can have plenty of green grass.

Protecting the Chickens Against Lice.-The one serious handicap to natural incubation is the tendency of the young

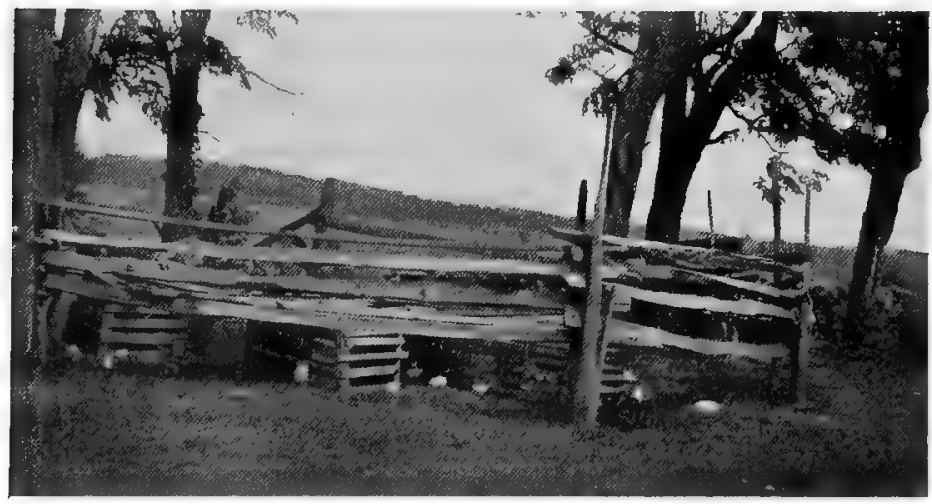

FIg. 67.- On the farm the chicks can be reared in the pasture. The coops can be protected from the cows and horses by a temporary rail fence as shown in this picture. After the hens are removed the chicks will continue to live in the same coops.

chicks to get hen lice from the mother hen. The effect of these parasites on the young chicks is to retard their growth, lower their vitality, and, if numerous, to cause many deaths. The first indication of hen lice on the young chicks is the fact that they do not seem active, or to grow fast. They carry their wings and head low, and their bodies seem short. Close inspection of the down at the top of the head will reveal minute insects burrowing into the skin. The remedy is to rub lard thoroughly into the head and neck, and into the down clear to the skin. If the mother hen is dusted 
thoroughly with a good lice powder at the beginning of the hatch, and again just before the eggs pip, danger from this parasite is materially reduced.

Weaning.-As soon as the chicks are old and big enough to look out for themselves, they should be separated from the mother hen, who, if put back into the laying house, will begin again to lay, and thus increase the egg yield and revenue. After they are five weeks old, the chicks will grow faster if not compelled to stay at night in the warm shelter with the hen (Fig. 67). The time for the mother hen to be removed from them depends somewhat upon season and weather conditions. She should never be taken away before they are five weeks old, and never during cold, rainy weather. As soon as it is possible to distinguish the pullets from the cockerels, they should be separated, as the pullets grow better by themselves, while cockerels will more rapidly become plump for broilers if kept rather closely confined under forced feeding. Natural incubation is a natural process. Given a good sitting hen and good eggs, the result will always be satisfactory.

\section{LABORATORY EXERCISE}

Exmrcise No. 19.-Allow members of the class to set one or more hens. Barrels or boxes may be secured for nests. The pupils should follow instruction carefully, as given in the text, when making the nest, selecting the sitters and managing the hens during incubation. If hens are not owned by the school, some members of the class will doubtless be willing to contribute some for the work. The setting of hens at home should be encouraged. The pupil should keep a careful record of the work and report from time to time upon the results obtained. Prizes may be offered for the best hatches and broods. The above work is best carried on as laboratory work before and after school, rather than as exercises during school hours. 


\section{THOUGHT QUESTIONS}

1. Define the meaning of the word "broodiness."

2. Define the meaning "natural incubation."

3 . Upon what does the success of natural incubation depend?

4. Enumerate the desirable points in a good mother hen.

5. Why should the sitting hen's nest be protected?

6. Describe the use of barrels for shelter for the hen's nest.

7. Can the laying pen be used as a place to set hens?

8. Describe a good location for the hatching nests.

9. Describe the process of making a nest.

10. When is the best time to set the hen?

11. Why are false eggs often placed under the sitter for the first day on the nest?

12. How closely should the sitting hen be confined to the nest?

13. What feed should be given the sitter?

14. Describe the necessity and method of dusting sitting hens with lice powder.

15. When should eggs be tested?

16. What should be looked for when the eggs are tested?

17. Describe the appearance of an egg containing a dead germ, a live germ, and an infertile egg on the seventh day.

18. Describe the management of the nest immediately after hatching.

19. What should be the early feed for the newly hatched ch

20. What is the effect of lice on young chicks?

21. What is the remedy for head lice in young chicks?

22. Why and how should the chicks be weaned?

23. Why should the sexes be separated as soon as they can be distinguished?

Reference.-United States Farmers' Bulletin 585, Natural and Artificial Incubation of Hen's Eggs. 


\section{CHAPTER XI}

\section{ARTIFICIAL HATCHING}

$\mathrm{BY}$ artificial hatching is meant doing without the sitting hen, and supplying artificially the heat necessary for hatching the eggs. Heat generated by burning kerosene, coal, or gas is commonly used for this purpose. In natural incubation the management is simple, for the mother hen takes charge of all the details, but in the artificial process the poultryman is responsible for every step. Artificial incubation dates back to prehistoric times. We have ancient records which prove that the Egyptians and Chinese hatched eggs in specially constructed ovens, which in some cases were heated by fermenting manure, in others by fire. No thermometers were used to determine the temperature, but operators, through years and generations of practice, became so expert that they could tell the proper heat just by remaining in the room. The past twenty-five years have seen a remarkable stride in the development of commercial incubators, which to-day are used more or less extensively on all poultry farms.

The Incubator.-The incubator is a machine designed essentially for the hatching of eggs. There are two types of incubator, one known as the hot air and the other as the hot water machine, the hot air being commoner (Fig. 68). In these the heat is conveyed to the eggs by a current of warm air which forms around the lamp chamber, and when hot enough is passed down over the eggs from above. The air in the incubator compartment of the hot air machine is heated by a tank or by pipes which pass above the eggs. There are two general types of incubators, the individual and the mammoth machine. Individual incubators range 
in size from those with a capacity of 60 eggs to those as high as 460 eggs. They are generally heated by kerosene lamps, but, when available, gas is more profitable. The small 60egg incubator is especially adapted to the use of the poultryman who hatches only from one to two hundred eggs, and also to the pupil who must begin in a small way, and get his experience before trying any of the larger types. Mam-

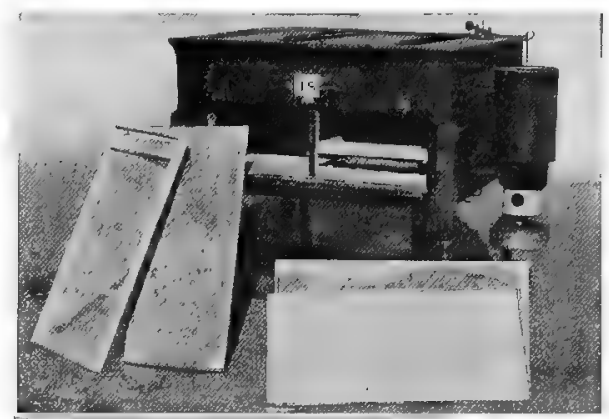

FIG. 68.-An individual incubator which has a capacity of 240 eggs and is heated by a kerosene lamp.

moth incubators hảve come on the market but recently. They are intended for use on large farms where thousands of eggs are hatched every spring, and range in size from 1,500 to 30,000 egg capacity. Heat is generated either by coal or gas. Burning coal heats hot water which circulates in pipes above the eggs. In most of these mammoth machines, the heat is regulated by the expansion and contraction of the water in the heating system. Slight variations in temperature are met by raising or lowering the egg trays, or by allowing the hot air to escape through a perfectly controlled regulator or ventilator.

In selecting an incubator for home use, the individual machine will probably be the best, and the one selected should bear a good reputation, and be well built and durable, with an egg capacity of from 60 to 220 eggs. In choosing a particular make of machine it is safe to purchase one of 
the higher priced ones, as they are sure to be well built and generally have a good reputation. It is poor policy to select a cheap machine which is only good for one or, at the most, two seasons.

Placing the Incubator.-The incubator should be placed in a cellar, or a room below the ground level. The cellar of a dwelling house, if it can be kept at a uniform temperature, is very satisfactory, but insurance restrictions should be looked into before placing an incubator in a dwelling. If the machine is placed below the ground level, the temperature can be kept more uniform. When a number of incubators are to be operated, a cellar specially constructed for the purpose and at least five feet below the ground is best. The incubator room should be built with masonry walls and a concrete floor, but may have an asbestos or metal ceiling. Such a room is practically fire-proof. The incubator cellar must be well ventilated, and a good arrangement is to have double window sashes, the outer one hinged at the top and the inner one hinged at the bottom. When opened at an angle of 90 degrees the air will circulate through the room without causing a draft to blow on the incubator itself.

Requirements of the Incubator.-Heat is the primary factor in an incubator, for we must generate by artificial means the heat which in natural incubation would be generated by the hen's body, and this demands a temperature in the incubator of 103 degrees Fahrenheit. It is well to start with a temperature a little below this, usually 102 degrees, and gradually increase it until at the end of the hatch the heat may be as high as 104 degrees. Great variations in temperature are detrimental to the hatch. An excessively high temperature of 108 degrees will kill the developing chicks, while an average temperature of 105 to 106 degrees will bring the hatch off too soon, and leave many dead in the shell. Too low a temperature will cause postponement of the hatch, and but few chicks will be able to break 
the shell, owing to retarded development and want of vitality. In an individual incubator the heat is regulated by a thermostat and damper (Fig. 69). The action of the thermostat is based upon the expansion of metals, or in some thermostats on the expansion of gases. As the heat in the incubator rises, the metal or gas expands, and this expansion is transmitted to the damper over the heat box by means of levers. If the incubator is too hot, the damper rises, and allows the heat to escape. When the incubator is running at too low a temperature, the metal contracts, the damper falls, and more heat is thrown into the machine.

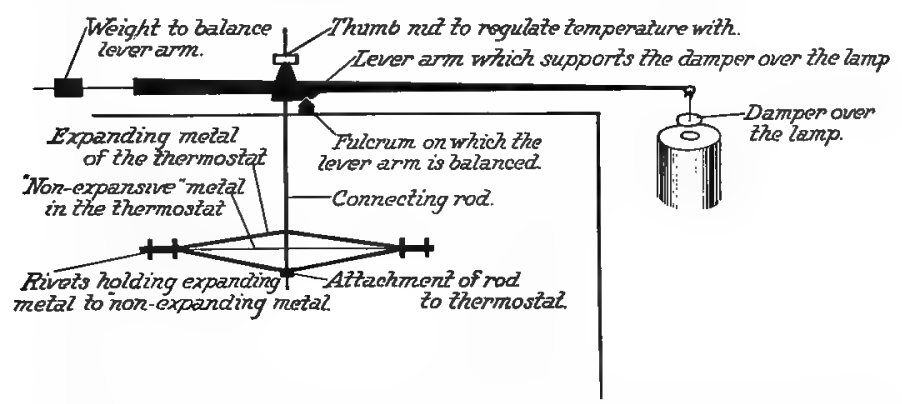

FIG. 69.-Sketch of the parts of a self-regulating device for an incubator.

The second requirement is moisture. Moisture prevents evaporation, and also softens the membrane of the egg, thereby making it easier for the chick to get out, hence a relatively high degree of moisture is essential towards the close of the hatch. The moisture content is read by the instrument called the hygrometer. Normal air contains about 40 to 45 per cent of moisture, or relative humidity, as it is called. During the latter part of the hatch the humidity should run as high as 58 per cent.

Fresh air is the third of the important requisites in an incubator, and to secure this in the machine some form of ventilator must be used. In some incubators the bottom of the machine is open or slatted; in others fresh air is carried 
into the incubator through ventilators made for the purpose. As a current, or rapid movement, of air increases evaporation, ventilators in incubators are usually covered with muslin or burlap to strain the air and thus retard the circulation.

\section{CARE OF THE INCUBATOR}

After securing an incubator it is advisable to start it up and see if it will maintain the proper temperature. It should be thoroughly tested and adjusted, and run for at least

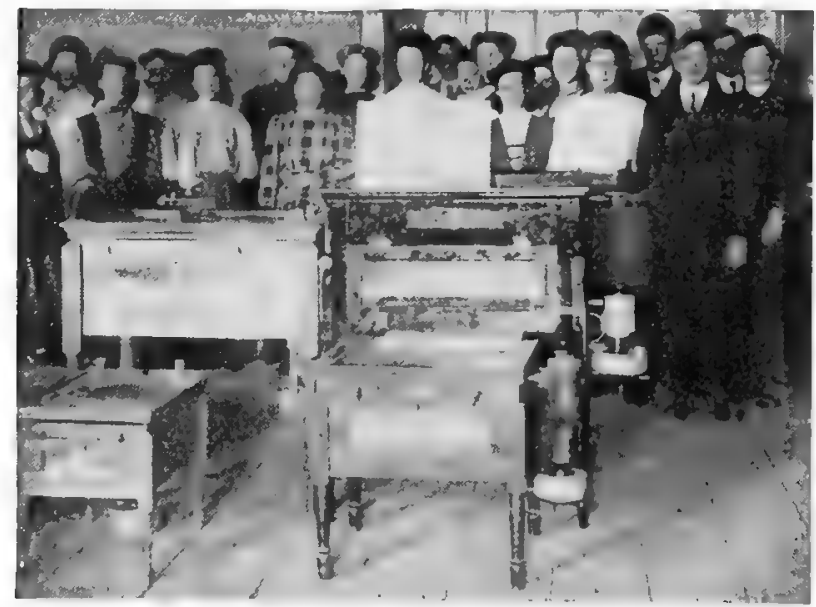

FrG. 70.-A class studying different makes of incubators. (Photo from U. S. Office of Experiment Stations.)

three days before eggs are placed in it (Fig. 70). If it is old and has been operated before, it should be taken apart and the interior thoroughly disinfected with a three per cent solution of carbolic acid. This will prevent the transmitting of germs from one brood to another, and will insure better hatches.

Care of the Lamp.-The lamp is the source of heat, and must be attended to regularly once a day so that the temperature will be kept at the proper point. The observance of 
the following rules is advisable. The best time to take care of the lamp is at noon. Never trim and fill it just before the eggs are to be handled, as kerosene on the eggs will be detrimental to the hatch. After trimming and filling the lamp put it in the burner box. Be sure that the chimney fits tight. Wipe off all oil from the lamp and burner. Clean the box or bracket frequently so that there will be no soot, charred wick, or kerosene within it. On first placing the lamp in the machine turn it low so that it will not flare up. After a few minutes it may be raised to the desired height without danger of smoking. The incubator should be situated where it will be protected from drafts. Drafts are apt to cause smoking, which will always result in lowering the temperature and sometimes cause fire.

Humidity.-By humidity we mean the water or moisture which is in the air. Artificial incubation calls for a high degree of humidity. There are three ordinary methods of providing it. One is by wetting the floor and thus keeping the incubator cellar damp. Another method is to place trays filled with sand on the bottom of the incubator and keep the sand well moistened with water. Another common mode is to sprinkle the eggs with luke warm water. In rooms which are very dry these three methods may be combined. If eggs are sprinkled, the best time to do it is just before they hatch.

Putting the Eggs in the Machine.-In putting the eggs into the machine they may be allowed to cover the tray entirely, but should never be piled one on top of the other. This would increase the labor of turning the eggs, and those on top would be subjected to a higher degree of temperature. Before putting the eggs in the incubator, if they have previously been kept in a cool place, they should be gradually accustomed to greater heat. If they have been shipped a considerable distance, they should be unpacked and allowed to stand for a few hours with the large end up before putting 
them into the tray; this permits the air cell to assume its normal position.

Turning.- In artificial incubation we attempt to imitate nature. The hen on the nest turns the eggs frequently by means of her feet, beak, and body; in the incubator, the attendant must do this with his hands. A good rule is to begin on the third day of incubation to turn the eggs and to turn them twice a day, morning and night, until the first signs of pipping are noticed, which will usually be on the twentieth day. The object of turning is to change the position of the embryo, so that it will not adhere to the shell and die. The growing embryo also needs oxygen, and turning helps to keep the air cell in its proper position. The best way to turn the eggs is to remove about one-tenth of those in the tray and roll the others about in the tray by means of the palms of the hands. It is unnecessary to turn each egg half way over.

Cooling.-The hen occasionally leaves the nest, and thus permits the eggs to cool; so in artificial incubation, especially in warm weather, we must artificially cool the eggs, not only to lower the temperature, but to supply them with pure, fresh air. A good rule for cooling is as follows: Do not cool for any longer time than is required for turning, if the temperature of the room is lower than 50 degrees Fahrenheit. During the first week cool merely during the operation of turning; in the second and third weeks gradually increase the length of time for cooling until just before hatching when the eggs can often be cooled for from a half hour to an hour each day with advantage. Good hatches have been known to take place when the eggs had been left out all night, but this is risky.

Testing the Eggs.-The eggs should be tested on the seventh and fourteenth days. Testing is a process which informs the operator of the progress of the hatch, and the condition of the hatching eggs, and also gives him an oppor- 
tunity to eliminate the infertile eggs, which will never hatch. The machine can be handled better if there are only fertile eggs in it. On the third day one can also pick out the eggs that contain dead germs, which, if left in the machine, decompose and cause an offensive smell. While testing the eggs, the rapidity of evaporation can also be determined by the size of the air cell; the larger the air cell, the more rapid the evaporation. Never turn the hatching eggs at testing time, for the process of testing moves and cools them sufficiently. A simple homemade tester can be fashioned from a wooden box, eight inches wide by eighteen inches long, and lined with asbestos. The lid can be hinged on, and a door made to latch. Place an ordinary kerosene lamp in the box and set the box up on one end. Cut a hole in one side, exactly on a level with the flames of the lamp. The hole should be a little less in diameter than the transverse diameter of the egg. When testing the egg, pass each one in succession before this opening, holding it close to the opening so that no light will escape anywhere except through the egg. (For a. description of fertile and infertile eggs and dead germs, see Chapter X.)

Hatching Records.-A record should be kept of every hatch. This can be of simple form, but should show the number of eggs put in, the breed and the date. It should also record the temperature, taken twice daily, the number of infertile eggs tested out, of dead germs found, and the number of vigorous chicks hatched. From this record can be figured the percentage of the hatch and this data is valuable for future hatching seasons.

Care at Hatching Time.-About the nineteenth or twentieth day the attendant should be on the look-out for signs of pipping, and when he notices the first cracked egg, he should sprinkle them all with luke-warm water. The machine should be immediately closed and kept closed until the hatch is over. During this time the temperature must be 
kept at about 104 degrees Fahrenheit. Sprinkling the eggs will cause a high humidity. If the incubator has a glass door, darken it with a piece of burlap or dark cloth to keep the chicks quiet. This will prevent them from trampling on each other in an effort to get to the light. When the hatch is about over, the trays should be removed, the burlap frame inserted, and the chicks allowed to drop into the nursery.

\section{INCUBATOR RECORD}

Incubator number. Make Date eggs set........... Number of eggs set. .

Capacity........... Kind of eggs set................

TEMPERATURE RECORD

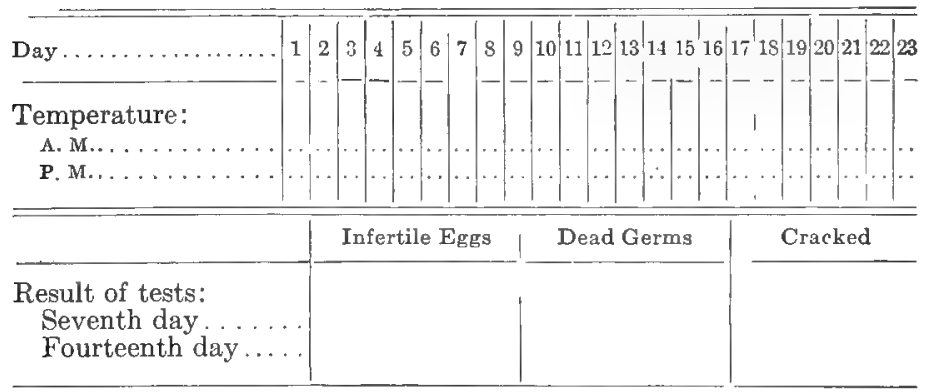

Number of vigorous chicks hatched $\ldots \ldots \ldots \ldots \ldots \ldots \ldots \ldots \ldots$ Number of chicks dead in shell.

Per cent hatch of total eggs set.

Per cent hatch of fertile eggs after the first test.

Remarks about the hatch.

\section{Steps To Be Avoided in Artificial Hatching.-Poor hatches} often result from the following causes, which the pupil must make every effort to prevent. If the thermometer does not register properly, it will mislead the operator into running the hatch at either too low or too high a temperature, therefore, all the thermometers should be tested in warm water, and compared with a thermometer known to register accu- 
rately. The eggs must be fresh and of good quality, and properly cared for, as previously described. The greatest care must be given to the incubator from the time it is set until the hatch is over. A successful hatch must come off on time, starting on the twentieth day, and being completely over by the end of the twenty-second. In short, a poor thermometer, poor eggs and lack of attention are the three most common causes of unsatisfactory hatches in an incubator.

\section{LABORATORY EXERCISES}

Exercise No. 20.- Secure a small incubator. If one can not be secured locally, some manufacturers are very willing to donate small machines for classroom work. In the presence of the class, the machine should be gone over carefully and the form and use of every part explained. Later the machine can be taken to pieces and the internal construction studied. Special attention should be devoted to the perfection of construction, the means of temperature control, method of ventilation, and the means of applying moisture. A trip to a large hatching establishment, where mammoth machines are operated, will make the study more interesting.

Exercise No. 21.-Place a small incubator in a cool, shady corner of the schoolroom. Appoint certain members of the class to care for it. The eggs can be brought by some of the pupils. Follow carefully the instruction given in the text. Each day a short period can be set aside, when those running the machine can explain to the class the work done that day. Each member should keep a little book with a complete record of all operations and results, as specified in the text.

EXERCISE No. 22.-If two or more incubators are available, run them both at the same time. Operate both alike in every respect, except in one machine place moisture, by using sand trays, and in the other machine use no moisture at all. Study the results as determined by the number and weight of chicks hatched. 
Exercise No. 23.-Have one or more members of the class construct a homemade egg tester, as described in the text. When the eggs are being hatched for the above exercises, they can be tested frequently, to study the appearance of fertile and infertile ones and to watch the development of the embryo as seen through the shell.

Exercrse No. 24.-Weigh fifty eggs before placing them in the incubator. Weigh them each day until the chicks hatch. Weigh the chicks after hatching. How do you account for the regular loss of weight? How much is the loss per 100 eggs for the entire twenty-one days?

\section{THOUGHT QUESTIONS}

1. What is meant by the term "artificial hatching"?

2 . What kinds of fuel are sometimes used to generate the heat?

3. Describe the ancient Egyptian ovens.

4. What is an incubator?

5 . What two types of incubators are in general use?

6. Describe the difference between the individual and mammoth incubator.

7. Describe the general type of individual incubator.

8. Describe the mammoth incubator as to its usefulness.

9. What are some of the important points which an incubator should possess?

10. Describe a suitable location for an incubator.

11. What is the proper heat to incubate an egg?

12. How is the proper heat maintained and controlled?

13. What is the proper degree of moisture for incubation?

14. Why is fresh air necessary for incubation?

15. How would you prepare an incubator to receive the eggs?

16. What are the essential points in the care of the lamp?

17. How is the proper moisture content maintained?

18. What precautions should be taken when putting the eggs in the machine?

19. Give a rule for turning the eggs in the machine.

20. Why should the hatching eggs be turned during the period of incubation?

21. Give a rule for cooling the hatching eggs.

22. What is the best practice to follow in testing the eggs?

23. What hatching records should be kept?

24. What special attention should the incubator receive during the time the eggs are hatching?

25. Enumerate some things which should be avoided in artificial hatching.

Reference.-United States Farmers' Bulletin 236, Incubation and Incubators. 


\section{CHAPTER XII}

\section{BROODING}

BROODING is the process of caring for the young chicks from the time they are hatched until they are old enough to go without artificial heat. The brooder might be termed an artificial mother. Brooding is an important operation on the poultry farm, for it is just at this juncture that many losses occur, and if succeeding generations of pullets are to be successfully reared, it will depend largely on the brooding.

Points of a Good Brooder.-An ideal brooding equipment embraces four distinct features.

First, there must be a hover, either circular or square, the circular being preferable. This hover is usually darkened, and kept at an even and fairly high temperature of about 90 degrees Fahrenheit. It should be easy to ventilate and very accessible for the birds.

Second, surrounding the hover should be a brooder compartment, well lighted, and a little cooler than the hover. In this space the chicks can withdraw from the heat of the brooder whenever they wish, yet at the same time it confines them in close proximity to the hover and heat.

Third, connected with the hover compartment, but within the brooder house, should be a light run or yard, the floor of which should be covered with clean sand and fine litter. After the chicks are a few days old, they can be allowed to run in this in-door pen, and thus become gradually accustomed to a cooler temperature before being let out of doors.

Fourth, all brooder houses should be provided with an out-door run which furnishes some shade, a rather dry and sandy soil, and an abundance of green feed (Fig. 71).

Types of Brooder Houses. - Three general types of brooder houses are in use; the small colony brooder, the large colony 
brooder, and the long intensive brooder house. The small colony brooders are usually about $3 \times 5$ feet or a little less in size, and form in themselves a complete house. They are

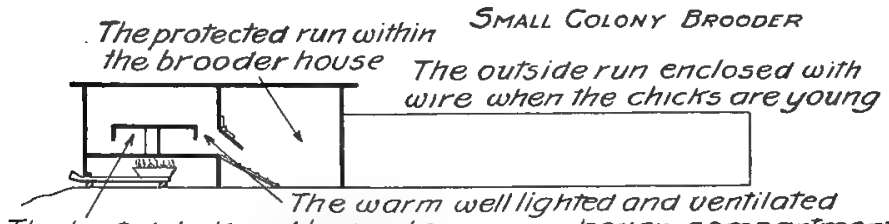

The heated darkened hover be-

neath which the chichs go to getwarm
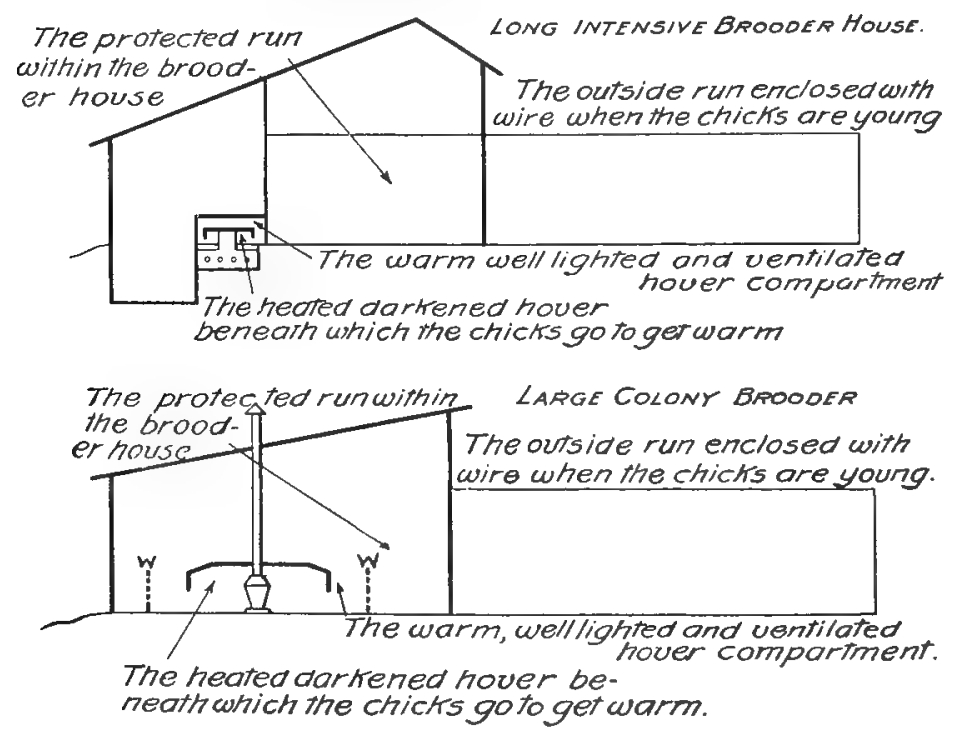

FIG. 71.-Three types of brooders, showing how each supplies the four requirements for successful brooding.

portable, and are usually heated by a kerosene lamp. Each brooder will hold from 50 to 75 chicks (Fig. 72).

A large colony brooder has recently been put on the market, which has a capacity of from 300 to 1500 chicks. Most of the large brooders have coal stoves, above which are arranged 
metal hovers or reflectors which throw the heat down to the ground; others are heated with gasolene or with kerosene; but all of the colony brooders are designed for large commercial poultry plants where many thousands of chicks are to be reared (Fig. 73).

The long intensive brooder house is rather expensive to build, but is most satisfactory. These long brooder houses are from 14 to 16 feet wide, and sometimes vary from 50 to

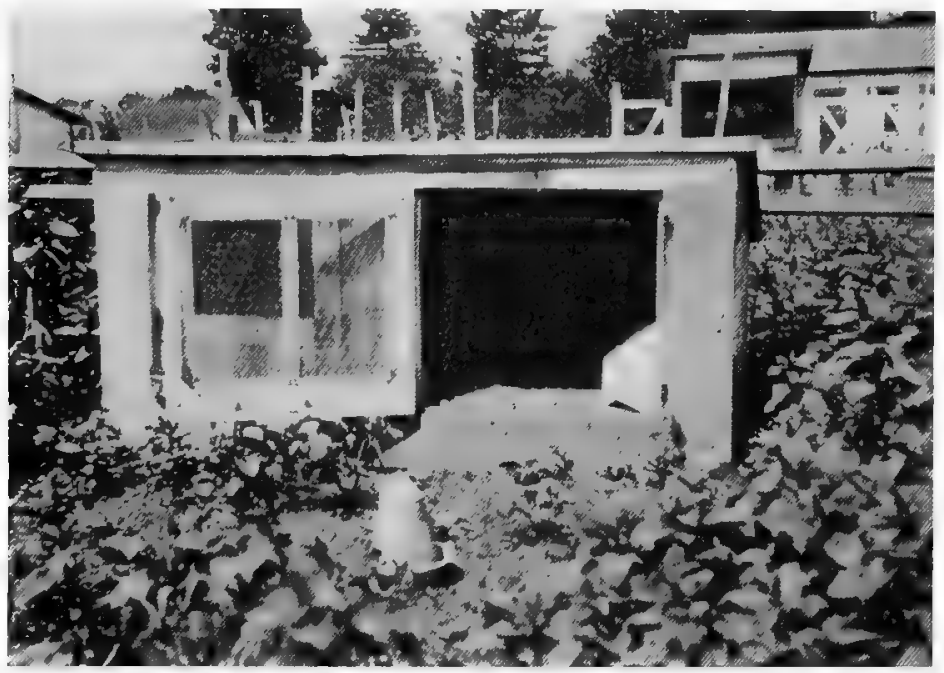

Frg. 72.-A small out-door brooder heated with a kerosene lamp and holding fifty chicks.

several hundreds of feet in length. Different types of hovers are used in these, the small individual portable hovers being quite common; each in itself being a unit. The heat is provided by kerosene lamps. Fireless brooders were tried some years ago, but were not practicable. Long brooder houses are frequently heated by hot water pipes running along the top of the hovers, and usually elevated six to eight inches from the ground. Muslin frames are generally placed over the pipes to hold the heat and deflect it down to the brooder 
floor. But the most satisfactory method yet devised for heating long brooder houses is what is known as the mammoth brooding system. This consists of a circular hover heated by hot water pipes which run in an insulated box below the brooder floor. The heat ascends to the hover through a galvanized drum or cylinder. Of these three different types the small colony brooder is best adapted for use on small poultry plants, the large brooder to large com-

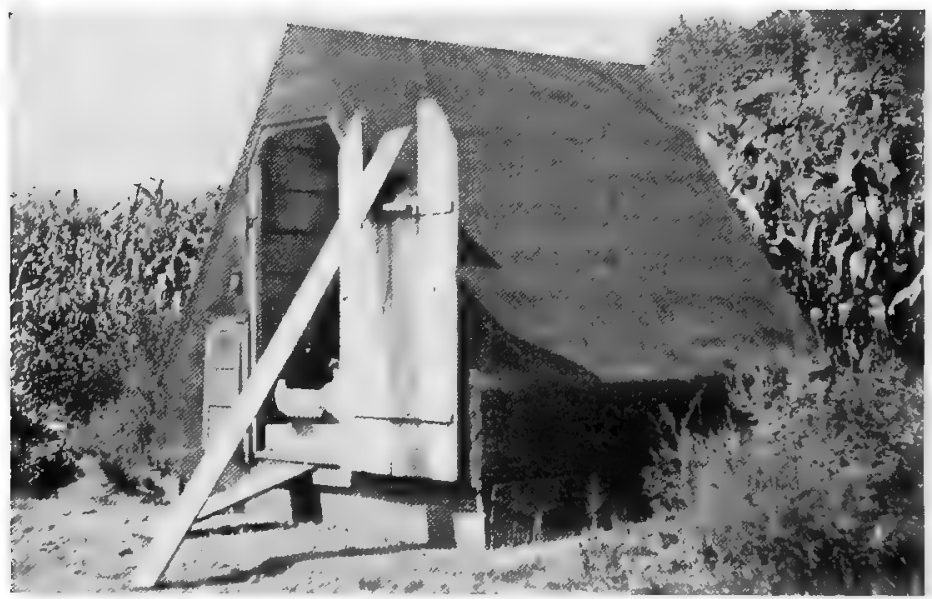

FIG. 73.-A gasolene brooder house. Capacity two hundred chicks. This house is being used as a shelter for growing pullets.

mercial farms, and the intensive system to broiler farms, where there is much early winter brooding (Figs. 74 and 75).

Operating the Brooder.-Before placing the chicks in the brooder, it should be thoroughly cleansed, the old sand and litter removed, the hover floors and walls scraped, and the whole washed with a three per cent solution of creolin. Fresh, clean sand should be put on the brooder floor to the depth of half an inch, and over this some fine clover or alfalfa. The brooder should be cxamined carefully to see that it is in perfect order, and then the lamp lighted, and the 
brooder run for at least thirty-four hours to see if the proper temperature can be maintained, that is, 98 degrees Fahren-

A.
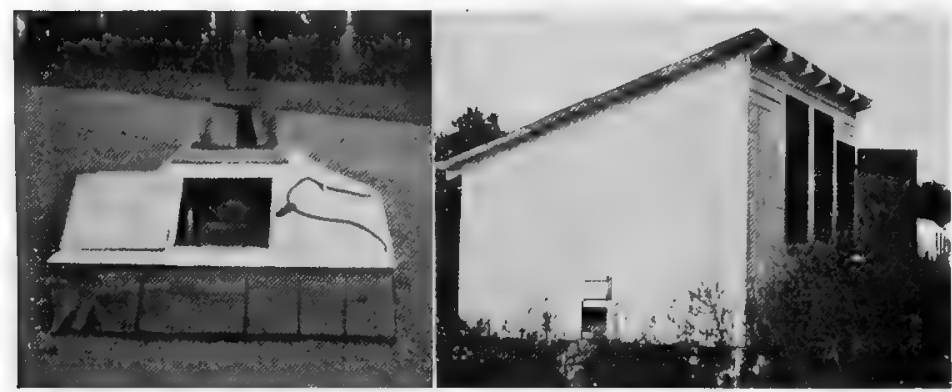

Fra. 71. - A, A coal-burning brooder stove having a capacity of heat for 300 chicks. B, A house eight by twelve feet in which the stove is placed.

heit. Before the chicks are put under the hover, fresh water should be provided, and a large quantity of grit put in two or three piles near the hover curtain.

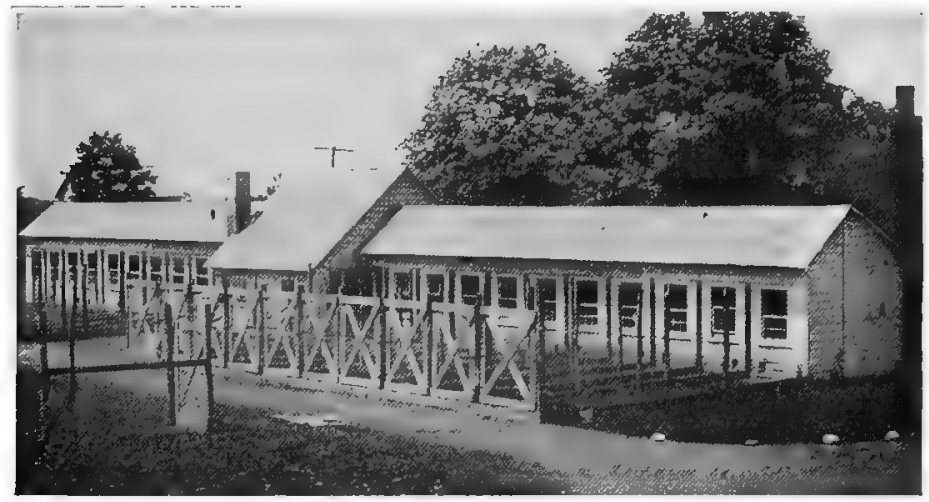

FIG. 75.-A modern, commercial, long-pipe brooder house, which has a capacity of 2000 chicks up to ten weeks of age.

Putting in the Chicks.-The chicks should be left in the incubator for at least thirty-six hours after hatching, to allow them thoroughly to dry off and to get up on their 
feet. Then they should be transferred from the incubator to the brooder in covered baskets, especially when they are apt to become chilled. They should be placed carefully under the hover. This practice teaches them where the heat is and they will more quickly know where to go in search of it later. In the small circular hover, about two feet in diameter, no more than 50 to 75 chicks should be put. More can be crowded in, but in most cases it will only result in an increased mortality. The best plan is to put them in the brooder just after dinner, and for the remainder of that day give them all the clean, fresh water and grit they can eat.

Degrees of Warmth.-The following temperatures on the floor at the level of the chick will be about right for the average brooder. At the start run the brooder at from 98 to 100 degrees, from 94 to 96 degrees the second week, from 90 to 92 the third week, and from 80 to 85 the fourth week. The idea is to keep the brooder fairly warm, and allow the chicks to get away from the heat when they wish to. They will come back to it when they need it. A very high brooder temperature is not desirable, as it lowers the vitality, causes digestive disorders, and will carry off many of the chicks. On the other hand, too low a temperature is apt to chill them and make them crowd together. A uniform temperature, starting at 98 and very gradually becoming cooler, is the best.

Feeding the Baby Chicks.-The following outline describes a very effective method of feeding baby chicks, but there are probably numerous rations equally as good. Whatever ration is decided upon, the idea should be to feed little but often during the first few weeks. Keep them hungry, and make them scratch in the litter in search of feed.

The first eighteen hours in the brooder the chicks should be given fine grit, shell, and fresh water, and short cut alfalfa and clover put on the floor for them to pick at. The next day they should be given pinhead oatmeal or rolled oats; three feedings will suffice, and they should be given 
only a small amount or what they will eat up between the feedings. For the remainder of the first week in the brooder, they should have a good fine cracked grain ration, scattered on the floor of the brooder in the litter, five times a day. The following grains make an ideal chick ration when the poultryman desires to mix his own feed:

Cracked corn. ................ 20 pounds

Fine cracked wheat................... 25 pounds

Grit...................... 5 pounds

Pinhead oatmeal............... 5 pounds

To supplement this, feed sprouted oats or green grass, and once a day, hard boiled eggs in small amounts. On the

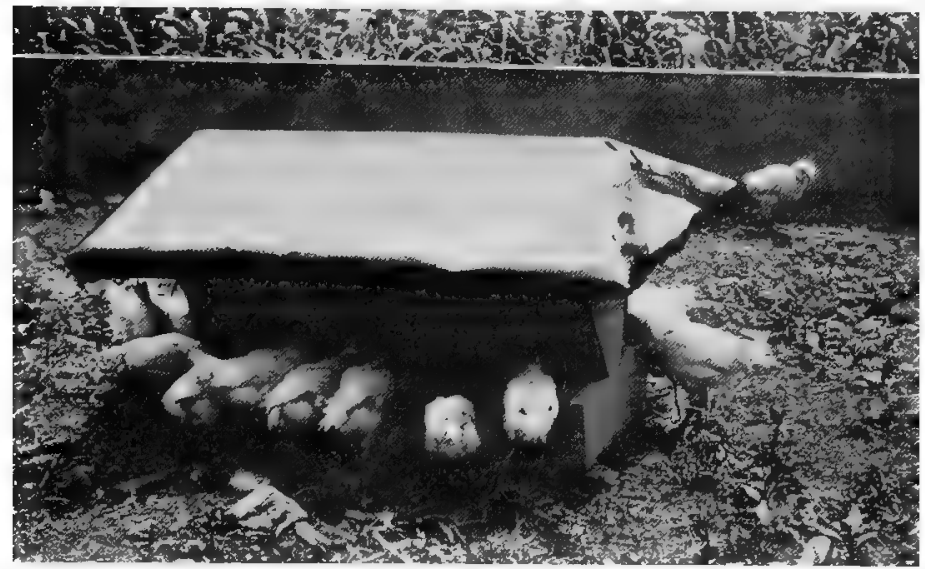

FIa. 76.-An out-door, dry mash hopper for growing chicks. It is rain proof and always ready.

seventh day wheat bran should be put before the youngsters in small hoppers, but after this time, the noon feeding of grain can be omitted. From the third week until they are put on range, the following ground grains should be added to the wheat bran, the entire mixture being kept before them all the time in hoppers (Fig. 76). The mash consists of:

50 pounds wheat bran 5 pounds corn meal
5 pounds sifted ground oats

2 pounds meat scrap 
Until they begin to forage, this grain feed can be given three times a day, at morning, noon and night. If available, sour skim milk, kept constantly before them in hoppers or fountains, is good. This is the generally accepted practice in feeding brooder chicks, but it may be possible to modify the ration slightly.

Importance of Fresh Air.-From the time the chicks are a few days old they should be encouraged to go out of doors as much as possible; the fresh air will make them grow more rapidly. Poor results in artificial brooding are often due to keeping the chicks in too high a temperature, and to lack of fresh air.

Things to be Avoided in Brooding.-The heaviest loss in brooding chicks may be attributed to one of the four following causes: First, overheating, or running the brooder at too high a temperature, and keeping the chicks confined to the heat, which results in delicate hot-house birds without stamina, which develop a severe diarrhœea. Second, chilling, or keeping at such a low temperature that the birds crowd together to keep warm, and many die of suffocation, while others are generally weakened in constitution. Third, there is often considerable loss because the young chicks pick at each other's toes. This is called cannibalism, due to a thirst for blood, and is particularly common with the light, active breeds. The habit can be largely overcome by putting the birds out of doors on clean grass range, and giving them meat scrap, wheat bran and ground bone, mixed in equal parts, and put where they can get it all the time. Fourth, many brooder chicks are lost as the result of infectious diseases. Contagious white diarrhœea may beinherited from the mother hen, and is quickly communicated by one bird to another. Bacillary diarrhoea in a flock can be checked by giving an abundance of sour skim milk, but when flocks are affected by this disease it is better to begin with new stock and eggs from another source.

Weaning.-After chicks are five weeks old the temperature should be gradually lowered and artificial heat done away with. This will wean the chicks from warmth so that they can 
be put on range in a cool house when about eight weeks old. But a gradual lowering of the temperature, and the hardening of the chicks before they are put out in the cool house, is essential to successful rearing. If not gradually accustomed to doing without heat, many will die from the sudden change.

\section{LABORATORY EXERCISES}

EXERCISE No. 25.-Visit one or more poultry farms in the vicinity to make a study of brooders. A better scheme, where possible, is to have in the classroom two or more types of small brooders. These should be studied externally and internally, as the incubator was studied. The different types studied should be examined to see in what way they provide the four compartments or conditions which are required by a successful brooder as specified.

Exercise No. 26.-A small out-door brooder should be placed in the school yard in some dry place which is protected. The south side of the building is a good location. The chicks which are hatched in former exercises can be brooded in this brooder. Special care should be used not to overcrowd the brooder, and the pupils attending it must follow very carefully the instruction for temperature and feeding.

\section{THOUGHT QUESTIONS}

1. Define the meaning of the term "brooding."

2. Enumerate the four requirements of a successful brooding equipment.

3. Enumerate three general types of brooder houses in common use.

4. Describe the small colony brooder.

5. What are the characteristic features of the large colony brooders?

6. Describe the long intensive brooder house.

7. What operations are necessary to prepare the brooder for the chicks?

8. How should the chicks be carried from the incubator to the brooder?

9. How many chicks should be placed in one brooder compartment?

10. What is the proper degree of warmth for the different ages of chicks?

11. What are the two principal requirements in feeding brooder chicks?

12. Describe in detail a practical method of feeding brooder chicks.

13. What is the importance of fresh air in brooding chicks?

14. What is the effect of overheating the hover?

15. How will chilling cause a high death rate?

16. What is meant by cannibalism and how can it be prevented?

17. What infectious disease is very dangerous to young chicks?

18. How and why should the brooder chicks be carefully weaned? 


\section{CHAPTER XIII}

\section{REARING THE YOUNG BIRDS}

From the time the chicks leave the brooder house until they are placed in the laying house in the Fall the aim should be to promote their uniform and steady growth. Any check or set-back in their growth will result in delayed maturity, and retarded development often leads to lack of vitality, and sometimes death from disease. Slow, irregular growth means adults of small size. Hence, every effort should be made to create a congenial environment, conducive to the best development of the birds.

Early Care.-When the chicks are taken from the brooder and put in colony houses, every precaution must be taken to prevent their becoming chilled. The danger, of course, depends somewhat upon the season of the year. If properly weaned in the brooder house until six weeks old, they can be safely put on range any time during May or June. Earlier in the season than this, it is wiser to keep them in the brooder house until they are ten to twelve weeks old. If it is necessary to move them early while the weather is cool, it is a good plan to provide a temporary hover in the colony house. This should consist of a board, three to four feet square, suspended from the ceiling by cords, with a burlap drop curtain, eight inches deep, around the edge. When the chicks are in the colony house, this hover can be let down to within ten inches of the floor, and the chicks will naturally hover under it and their body heat be conserved, which will prevent chilling. As the chicks grow older the hover can be raised two or three inches a day, until finally dispensed with.

Crowding, or putting too many chicks in the colony house, should be guarded against. A colony house $6 \times 8$ 1.12 
feet should house through the growing season 50 birds. If more than this number are put in such a house, their growth will be slow and they will be small at maturity.

Advantage of Free Range.-When possible the growing stock should be given plenty of range to roam over (Fig. 77). There are many reasons why free range is an advantage. It induces plentiful exercise, which means health; it reduces the cost of feed by providing natural green grass and weed seeds. The birds also secure many grubs and insects which take the place of meat in their rations. Free range is cleanly, while small yards are easily contaminated.

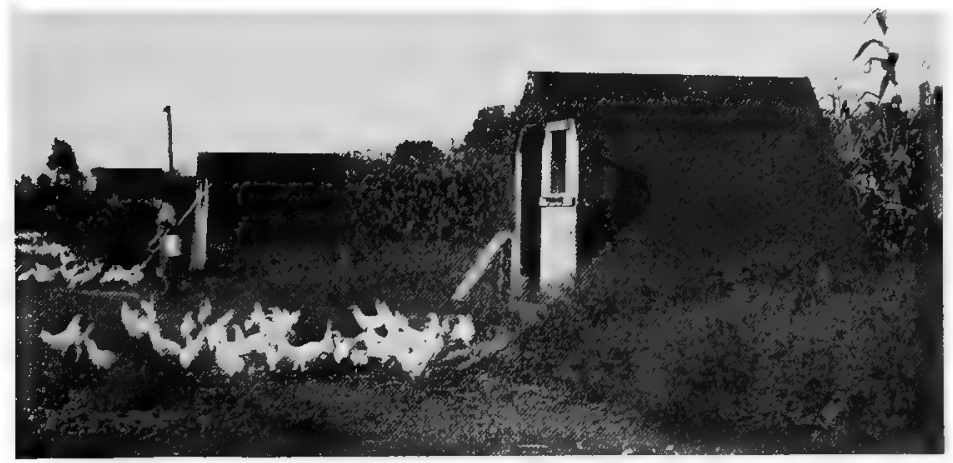

FIG. 77.- Leghorn pullets being reared on free range. The shelters are placed near the corn field to give shade.

Necessity of Green Feed.-To promote the best growth the chicks require an abundance of succulent material, that is, green growing plants, such as grass, weeds, and grains. On free range plenty of this green feed will be found. But it is often necessary to keep the youngsters in a limited area, or to confine them because of some garden crop which they may injure. Under these circumstances, double yarding can be resorted to. Double yarding is dividing the total space for the birds into two yards, and placing the house exactly in the center, therefore, partly in each yard. The 
birds can then be confined to one yard while a crop is being grown in the other. When this green crop gets to be four or five inches high, the chicks can be turned in to feed on it. Then another crop can be planted in the yard where they previously fed. By this system of rotation the chicks can be continuously provided with green fodder, and the frequent cultivation keeps the yards clean and sanitary. It is the next best thing to free range. During an average season the sowing of four crops will be found to work to the best advantage, if alternate crops are used. Peas and oats should be seeded early, this crop followed by buckwheat, and buckwheat in turn by soy beans, which should be followed by winter wheat and rye, and the latter crop allowed to grow all winter. Thus early green feed in the Spring is provided.

Shade Very Desirable.-The yard should have shade to protect the birds from the direct rays of the sun. If they stay all day in the heat of the sun, they grow slowly, and their bodies often become so sumburnt that they do not feather properly. Natural shade from plants or trees is best (Fig. 78). Wild trees or forest growth, if not too thick, makes admirable range, as do fruit orchards. Peach, apple and plum trees are among the best to plant on the poultry range. The corn field also is a good place in which to rear the youngsters. The colony house can be moved along the edge of the field, and the chicks find suitable shade and range in the corn. Sunflowers and castor beans are frequently used in small yards to provide shade, and beauty as well.

When natural shade is not available, artificial shelters may be constructed. Such shelters are commonly made from boughs of trees, preferably evergreen, about two feet above the ground. Boards or burlap fastened to a frame may also be erected above the ground to give shade. These artificial shelters are generally unsatisfactory because they 
more or less attract heat, and the air underneath such a tent is intensely hot during the middle of the day.

Fresh Air Houses.-Chicken houses for summer use should be merely shelters, the main requirement being plenty of fresh air, although low cost is an important consideration. The small colony house may be only a shed, with a roof and one wall, the other three sides being covered with wire. But whatever the type of shelter, it should afford protection from all four-legged enemies, from the rain, and from the

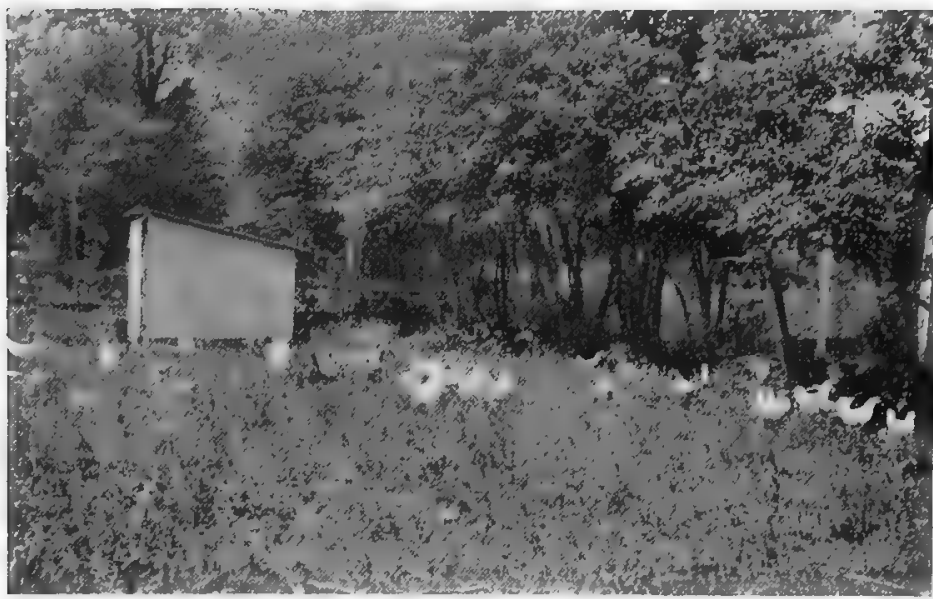

Fis. 78. - in ideal corner of a pasture for the growing birds. Shade in abundance, plenty of green grass, and a small brook running under the trees give the birds everything they need.

sun. Portability is next in importance, for it is often desirable to move the house from place to place in order to give the chicks green feed. A house can be so built as to be used for both the growing stock in the summer and the laying birds in the winter, and such a house is called an adaptable colony house, because it can be used for more than one purpose.

Desirable Types of Colony Houses.-The following is a brief description of three useful types of small colony houses. 
Figure 79 shows a small house, $6 \times 8$ feet, built on runners. It has a gable roof, and in order to facilitate the circulation of air and make the house cool, the side walls are hinged to the roof at the eaves. This house will accommodate 50 pullets during the summer, and furnish them all necessary protection from enemies. It can be built of very cheap material, the cost being only $\$ 9.50$.

Figure 80 shows a very desirable type of adaptable summer colony house. It can be used for the summer growing stock, also for laying birds in the winter. In the following discussion will be outlined working plans, list of material, and directions for building such a house.

Building a Small Colony House.--Subjoined is a list of material required to build one adaptable summer colony house, as pictured in the accompanying working plan (Fig. 81):

215 sq. feet yellow pine, tongued and grooved, $8 \mathrm{in}$. boards $10 \mathrm{ft}$. long

$12 \mathrm{ps} .2^{\prime \prime} \times 4^{\prime \prime}$ hemlock, $10 \mathrm{ft}$. long

2 ps. $-4^{\prime \prime} \times 4^{\prime \prime}$ hemlock, $10 \mathrm{ft}$. long

$3 \mathrm{ps} .2^{\prime \prime} \times 2^{\prime \prime}$ hemlock, $16 \mathrm{ft}$. long

1 ps. -2 " $\times 2$ 2" hemlock, $12 \mathrm{ft}$. long

1 ps. $-2^{\prime \prime} \times 2^{\prime \prime}$ hemlock, $10 \mathrm{ft}$. long

2 ps. $-1^{\prime \prime} \times 3^{\prime \prime}$ hemlock, $10 \mathrm{ft}$. long

80 sq. ft. roofing paper

2 prs. 3 in. hinges

3 prs. 4 in. hinges

1 door latch

2 yards muslin

$20 \mathrm{ft}$. one inch mesh wire

5 lbs. eight-penny nails

$1 \mathrm{lb}$. six-penny finishing nails

1 box tacks

$1 \mathrm{lb}$. medium staples

Approximate cost of above materials, $\$ 13.65$.

The size is six by eight feet. It is of shed-roof construction, built on runners, so that it can be easily moved about. The front has a door in the center, with windows at either side of the door, each provided with a muslin curtain. In summer there is plenty of ventilation from the fact that the 
lower parts of the end walls are on hinges, and can be lifted up. This house complete, including all material but not labor, costs $\$ 16.00$. Hemlock or yellow pine should be used for all runners and for the frame; yellow pine, tongued and grooved, will do for the roof.

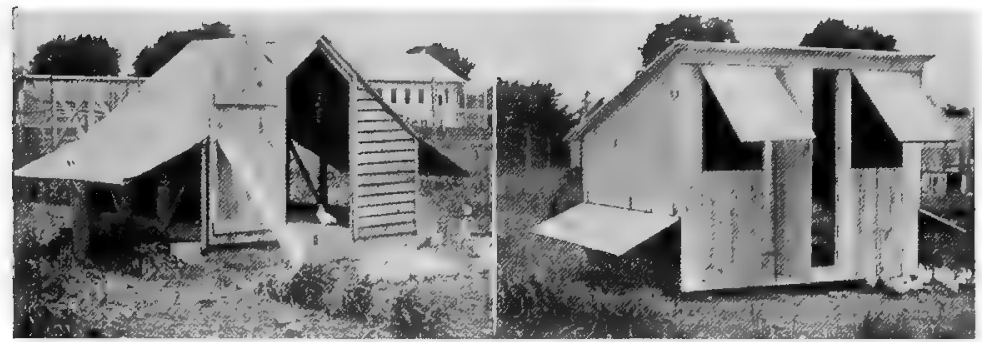

FIa. 79.-A cheap fresh air shelter for the growing birds during the summer.

Fia. 80.-A house which can be used for growing chicks during the summer and for layers during the winter. (For working plans, see Fig. 81.)
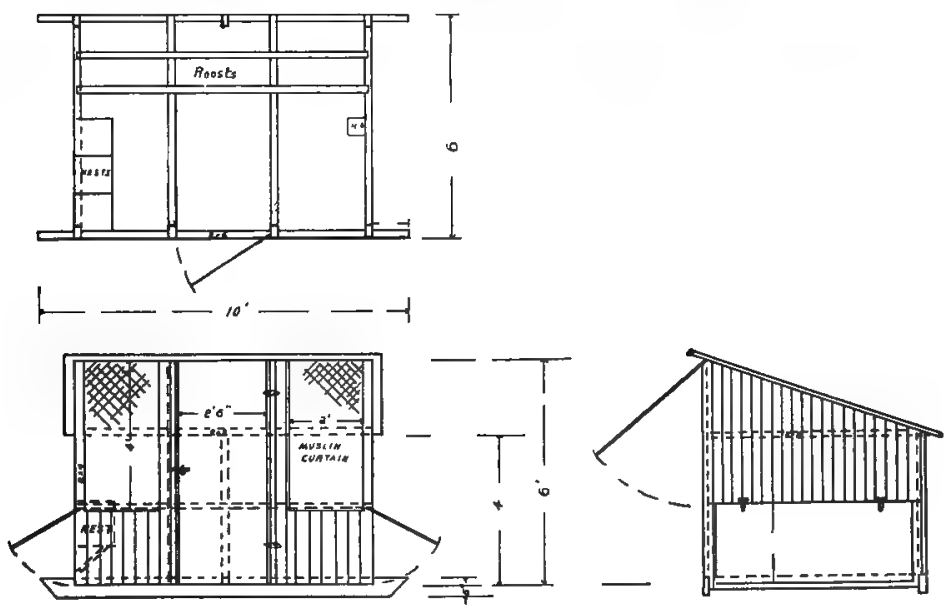

Fig. 81.-Working plans of adaptable summer colony house, $6 \times 10$ feet, 6 feet high. 
Feeding.-Feeding the youngsters during the summer months is a simple process. Only two rations are necessary, a grain feeding and a dry mash. A good grain ration for use on the range consists of equal parts of cracked corn and whole wheat. This should be scattered broadcast about the range morning and night. The dry mash ration should consist of the following proportion of ingredients:

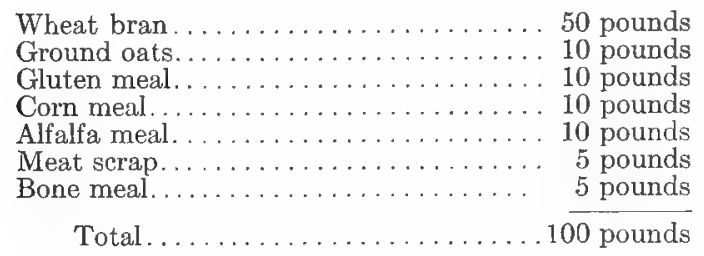

This should be put in large feeding hoppers located near each other about the range. The mash enables the chicks to balance their own ration, promotes the more uniform development of the birds, and greatly reduces the labor of feeding. Plenty of fresh water should be at hand. If the range is not piped with running water, large drinking vessels or barrels can be located at accessible points, and frequently replenished with water, which is allowed to drop continuously.

Management.-Three important things the poultryman must bear in mind when caring for the growing stock during the summer. The first is to protect them from enemies. If rats are allowed to become plentiful, they will prey upon the chickens, and many will be lost. If the range is wooded land far from the house, hawks and crows may do considerable damage. Weasels and minks, if abundant, will kill large numbers, and so may dogs or cats if not properly trained. The poultryman must watch the growth of his birds, and have conditions such that they will grow continuously without any setback. Lastly, he must feed abundantly. If the chicks are to gain in weight, they must be 
given all the feed they can clean up, for they are very active, and need a good deal to give them energy.

Care at Maturity.-As the pullets approach maturity, also, their growth must be watched. They should be put in the laying house two or three weeks before good egg production can be expected, which will be about the middle of October, and this early housing accustoms the birds to their quarters. No animals are so easily affected by change of environment as poultry, and if the poultryman gets his fowls in laying houses, under close observation, he can, to a certain extent, control the time of their maturity. This often means all the difference between a good and a poor winter egg yield.

\section{LABORATORY EXERCISES}

Exercise No. 27.-If funds are available, purchase the lumber necessary to build the summer colony house described in the text and allow the pupils to build same. The class can be divided into a number of sections, with four or five in a section. Usually enough interest will be maintained so that most of the work of construction can be done outside of regular school hours. If land is available, these buildings which are built by the pupils can go towards equipping a small poultry plant to keep as a part of the teaching equipment.

Exercise No. 28.-If there is room in the school yard a small area should be set aside on which a succession of crops can be planted in order to demonstrate how to provide a continuous supply of green feed to growing chicks, which of necessity must be closely confined. It is best to plant these crops in a poultry yard. If no yard is near, an area ten feet square will serve to give practice. By having the crops growing, the pupils will not only become familiar with the appearance of the seed and the manner of planting but they will also become acquainted with its habit of growth and the appearance of its leaf and stalk. 


\section{THOUGHT QUESTIONS}

1. What is the primary object in the management of young chickens during the summer?

2. What is the effect of a check or setback in the growth?

3. What factor is essential to secure a good growth?

4. What special factors should be considered in the care of chicks when they are first placed on range?

5. How many chicks should be placed in a colony house?

6. Why is free range best for growing poultry?

7. What is succulent material?

8. How can a continuous supply of green feed be obtained in small yards?

9. Why is plenty of shade necessary to growing birds?

10. What are some of the best kinds of plantings to make shade?

11. How can shade be provided from an artificial source?

12. What is the leading requirement in the summer houses for chicks?

13. What other features should the summer colony house possess?

14. Describe a desirable type of summer colony house.

15. How many different rations do growing chicks require?

16. Give a suitable dry mash ration for growing chicks on the range.

17. Give a suitable grain ration for growing birds on the range.

18. What natural enemies are responsible for much loss on the range?

19. Is liberal feeding necessary with growing poultry?

20. Why should the maturing pullets be placed in their houses early in the Fall? 


\section{PART III \\ HOUSING}

\section{CHAPTER XIV}

\section{LOCATION OF THE HOUSES AND YARDS}

THE selection of a suitable site for the poultry plant and the proper location of the house and yards often makes all the difference between success and failure for the poultryman. With the place already purchased, the problem is simply how best to develop a small poultry plant on a particular location. To the prospective poultry keeper with no farm purchased, the question is, first, the choice of a suitable location, and secondly, the establishment of his plant on the location he selects.

Choosing the Poultry Farm.-While the choice of the poultry farm will fall to but few, three factors in connection therewith will be appreciated by all poultrymen, and apply equally as well to the small Hlock which caters to the retail trade as to the large plant which caters to the wholesale trade. The markets must be studied. In choosing the farm, one in close proximity to several large centers of population should be selected; the nearer the city, the greater the demand for eggs and poultry, but the land will also be more expensive. The nearer to the market the quicker will be the delivery, and quick delivery means that the eggs and poultry will be fresh when they reach the consumer.

Markets are of two general types, wholesale and retail. The former, to which poultrymen ship their eggs and poultry in considerable quantities, are in large cities. The eggs are shipped direct to wholesale dealers or commission merchants, who in turn sell them, and charge commission for their 
work. Retail markets are those in which the poultryman sells his eggs and poultry direct to the consumer. This is the ideal method for the poultryman who has a small flock and lives near the consumer, since a large number of eggs and poultry can be disposed of in the course of a year by delivering them directly to the family trade, and higher prices are received for them. There is more labor involved in marketing them, yet with a small flock this is certainly the best method.

The poultry farm selected should have good transportation facilities. A rural trolley line is a great advantage, but it should also be near a railroad which gives good passenger, freight, and express service. Good roads between the farm and the station, or between the farm and the city or market, are also important.

If the poultryman has a telephone and rural free delivery, these will prove of great convenience. He can easily communicate with his customers, and more quickly supply them with the kind of produce they desire. Transportation and means of communication play a big part in the management of either small or large flocks.

Locating the Poultry House.-In locating the poultry house, several factors must be taken into consideration. The character of the soil is important: A sandy loam is best, for a top soil of this kind usually has a gravelly subsoil, and this combination will drain well, warm up quickly in the spring, and also dry very quickly after rains. Heavy clay soils should be avoided, for they are cold and damp, and very sticky in the winter and late in the spring; after rains the birds' feet and the nests usually get very dirty. The character of the soil is one of the chief things to be tatken into account when locating the poultry buildings.

Drainage must also be considered. Drainage is determined largely by the topography of the limd, hilly or rolling country being best, as it promotes good surface drainage. All sur- 
face drainage should, of course, be away from, rather than towards, the buildings. The poultry house should be located on a hill slope (Fig. 82). This makes it certain that there will be no stagnant water at any season, for the filth or droppings of the birds about the yards will be carried off to lower points, and contamination of the runs prevented. Perfectly level lands should be avoided, especially if the soil is heavy, for they are often spongy and wet in the spring and early summer.

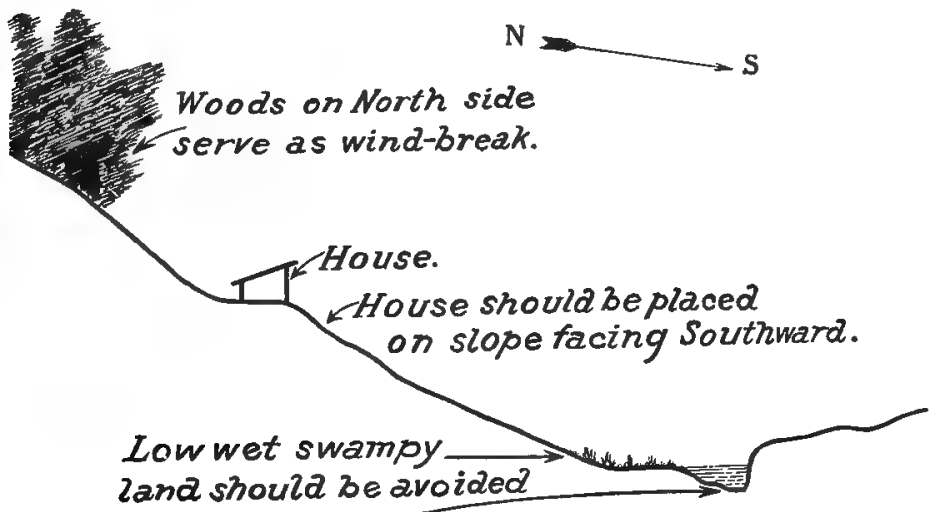

The bottom of the valley where there is a river. Avoid such a place near the river bank.

Frg. 82.-The cross-section of a hill showing the proper location of the poultry house.

A good circulation of air is likewise essential. Probably few of us appreciate the fact that there are currents in the air, the same as in water. Cool air flows down to a lower level, and warm air ascends. Bearing this in mind, do not locate the poultry house in a hollow or at the foot of a hill. Such situations are cold, and apt to be damp and frosty in winter. Part way up the slope the air will be clearer and drier.

The exposure of the slope largely determines its desir- 
ability, the best exposure for a poultry house being on land which slopes to the south. Here it gets sunshine the greater part of the day, and if built just beyond the crest, not directly on the top of the hill, it is protected from the north winds by the hill behind it. Northerly slopes should be avoided, as they are cold and bleak in winter.

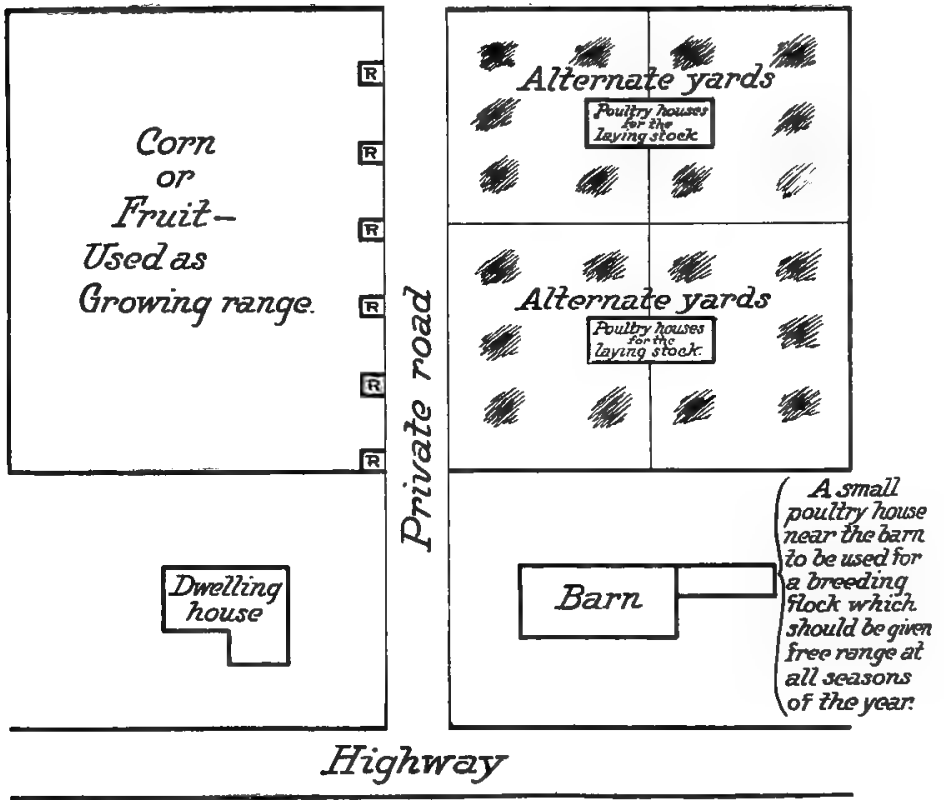

FIg. 83.-A desirable plan for a two-acre poultry plant on a general farm. One acre for adult birds in orchard and one acre in corn used as range. Fourhundred-bird capacity.

Natural vegetation on the site is a big advantage, and sod is to be preferred. If shade is lacking, corn may provide it, while fruit trees are growing. Wild forest growth furnishes good shade, but in some spots may need thinning out to let in the sun. Whatever site is chosen, green feed will probably be lacking, but this can be secured by clearing a strip immediately in front of the poultry house, and planting it 


\section{LOCATION OF THE HOUSES AND YARDS 155}

for permanent sod. If there is an orchard on the farm, it makes an ideal spot for the poultry house, and the same piece of ground serves a double purpose, and is made to yield a double revenue (Fig. 83).

Ideal Location for the House.--Summarizing, the following describes an ideal location for a poultry house; the poultry house and yards should be located in undulating country and on a southerly slope which is not too steep. The soil should be a dry, porous, sandy loam with a subsoil of gravel, and covered with sod. Plenty of natural shade should be at hand. Surface water should drain away from the poultry house by means of natural water courses. The site should be easy of access, and near enough to the dwelling for the birds to be under observation.

The Poultry Yards.-Wherever possible, the birds should be allowed free range; sometimes, however, they must be yarded. Often the question is whether to yard the poultry, or to fence in the crop which they will damage. But in ideal conditions there is unrestricted range, the two principal advantages being the reduction in the cost of feed, and more cleanly and sanitary conditions of the birds. Sanitary runs on the farm mean healthy birds. Usually if an effort be made, a place can be found for the birds which permits unrestricted range. Where poultry are bred under intensive conditions on small areas, for example, in villages, it is absolutely necessary to yard them, but the yard should be as large as possible, and double yarding and rotation of crops the method (Fig. 84).

Alternating yards are becoming more and more popular as a means of keeping the birds healthy under limited range. The term "alternating" simply means that each pen of birds is provided with two yards, which may be designated 1 and 2. In some cases both yards are in front of the house, in others one yard may be in front of, and the other behind, the house. It is also becoming the custom to give each pen 
of birds, if there be more than one, a small exercise yard, connected with which is a much larger one, in which green feed grows, and into which the birds are turned loose at frequent intervals to pasture. This method works admirably where there are a number of pens close together, as in a long laying house.
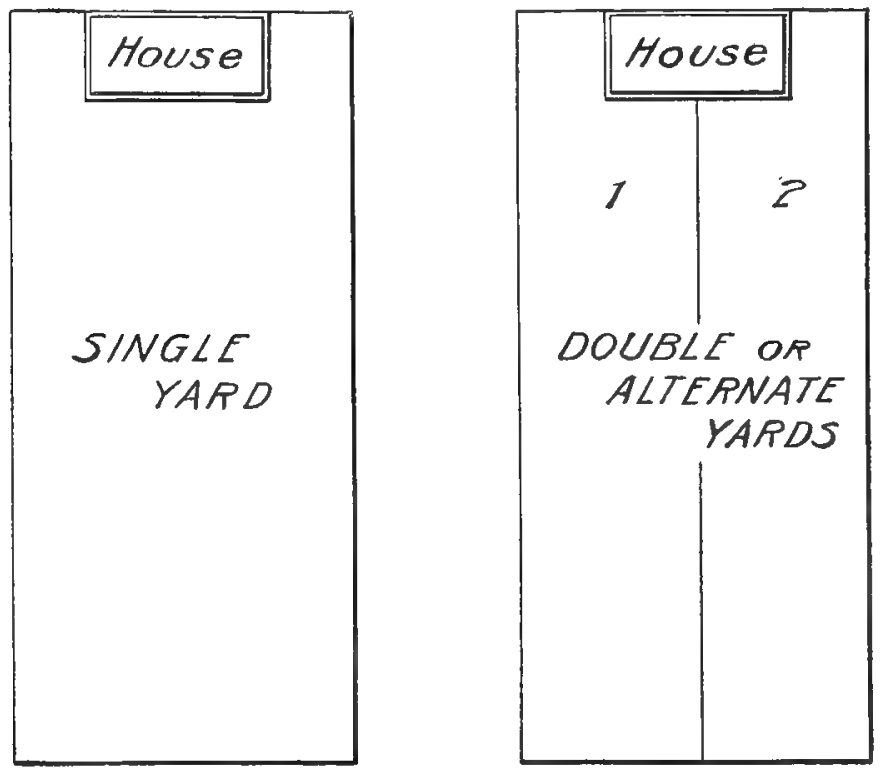

Frg. 84. - Single and double yard. Birds are allowed first in yard No. 1 and then in yard No. 2 , green orops being grown in each yard while it is vacant.

The success of the alternating yard system depends upon securing a good rotation of crops. The subjoined outline shows a simple system adapted to almost any climate. Other crops may be sown, but the principle will be the sime (Fig. 85).

$$
\text { YARD } 1
$$

Seeding time

April 15......... Peas and oats July $15 \ldots . . .$. . Soy beans
YARD :-

Seeding time

Crop June 1 .......... Buckwheat September $1 \ldots .$. . Winter wheat and rye 
In locating yards the idea should be to have them on ground which slopes away from the poultry house, so that waste from the yards is carried away from the house, not towards it.

Ideal Fence Construction.-Where birds are kept closely confined, fences must be provided of such a height as to prevent them from flying over the top. It is quite a problem to know how to build fences that will be durable and at the same time economical. Three things must be considered in constructing a fence, namely, the posts, the fence material, and the gates. There is probably no cheaper or more dur-

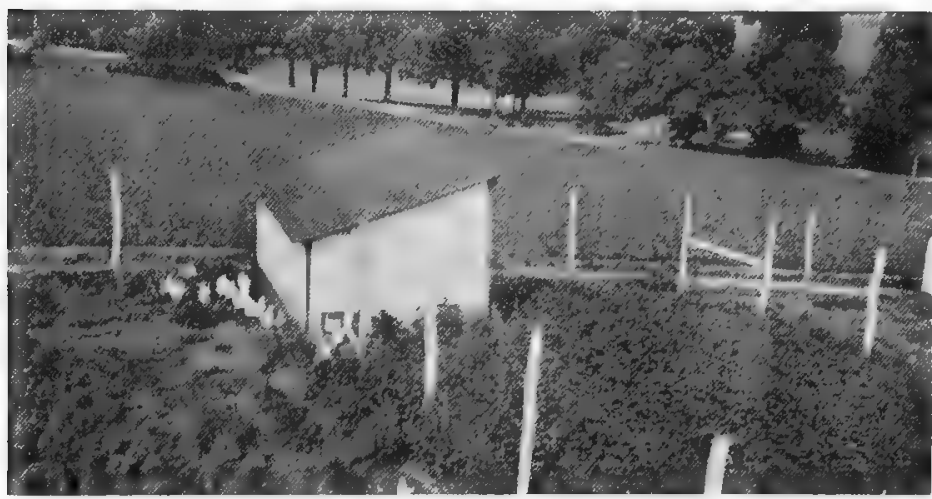

FIQ, 85.-A poultry house with a double yard. At the left the birds are feeding on peas and oats. At the right soy beans are growing for future forage.

able post than one of locust or cedar, three to six inches in diameter. If dipped in tar before being sunk in the ground, and kept painted, they will last a long time. The fence posts should be set at least $2 \frac{1}{2}$ feet in the ground, with the dirt well packed around them, and the corner posts securely braced. The distance between the posts should be from twelve to fifteen feet, according to the height of the fence, and this depends upon the breed to be fenced in. A threefoot fence will confine the heavy breeds, like the Brahma and Cochin; a six-foot one will confine any of the medium sized breeds, while a fence seven to eight feet high, if the 
yards are not too small, will shut in the lighter breeds, like the Leghorn. Sometimes a few birds of the flock will persist in flying over, having discovered their powers of flight. This habit must be broken before others contract it from seeing them, and it can be done by clipping a wing, cutting the primary flight feathers off about one inch from the wing proper (Fig. 86).

Woven wire makes the best poultry fence. Owing to the fineness of the wire, the common hexagonal poultry netting

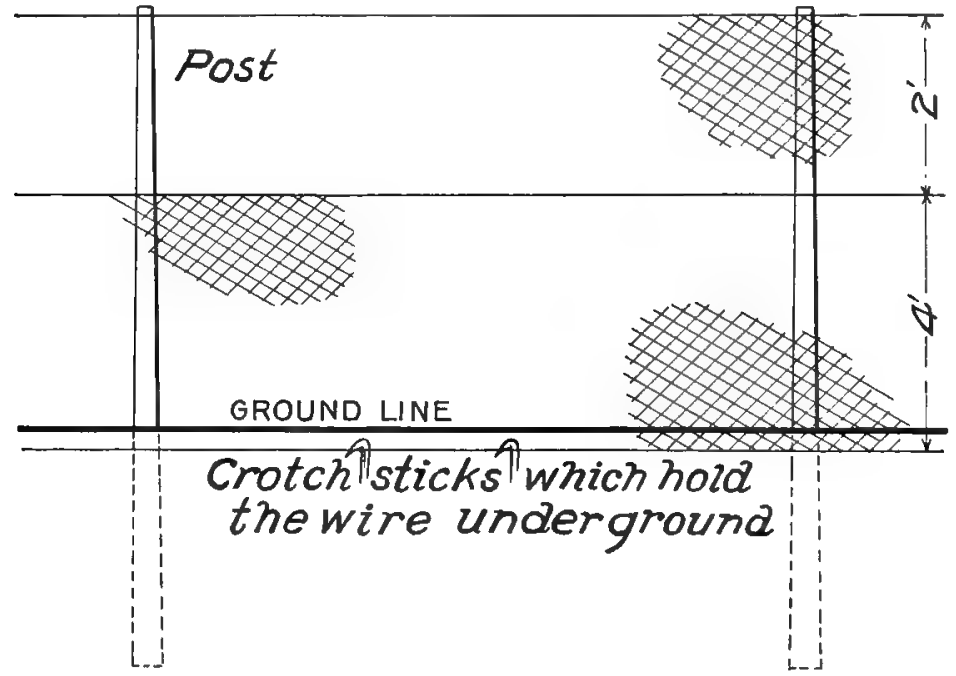

Fro. 86.-An ideal fence for poultry. Hexagonal mesh poultry netting is used.

does not last very long unless it is painted. Painting makes any wire fence more durable, and unless galvanized, it should be painted at least every two years.

In planning the yards, make few gates, but their location and construction is important. It takes considerable time to open and close them, and they are apt to get out of repair. Where gates are necessary, locate them in the natural line of travel from one pen to the other, or from the feed house 


\section{LOCATION OF THE HOUSES AND YARDS 159}

to the pens. They should be well built (Fig. 87) so they will not rack to pieces. Three by six inch yellow pine boards if lapped at the corners and securely nailed, make good gates. They should be braced diagonally, covered

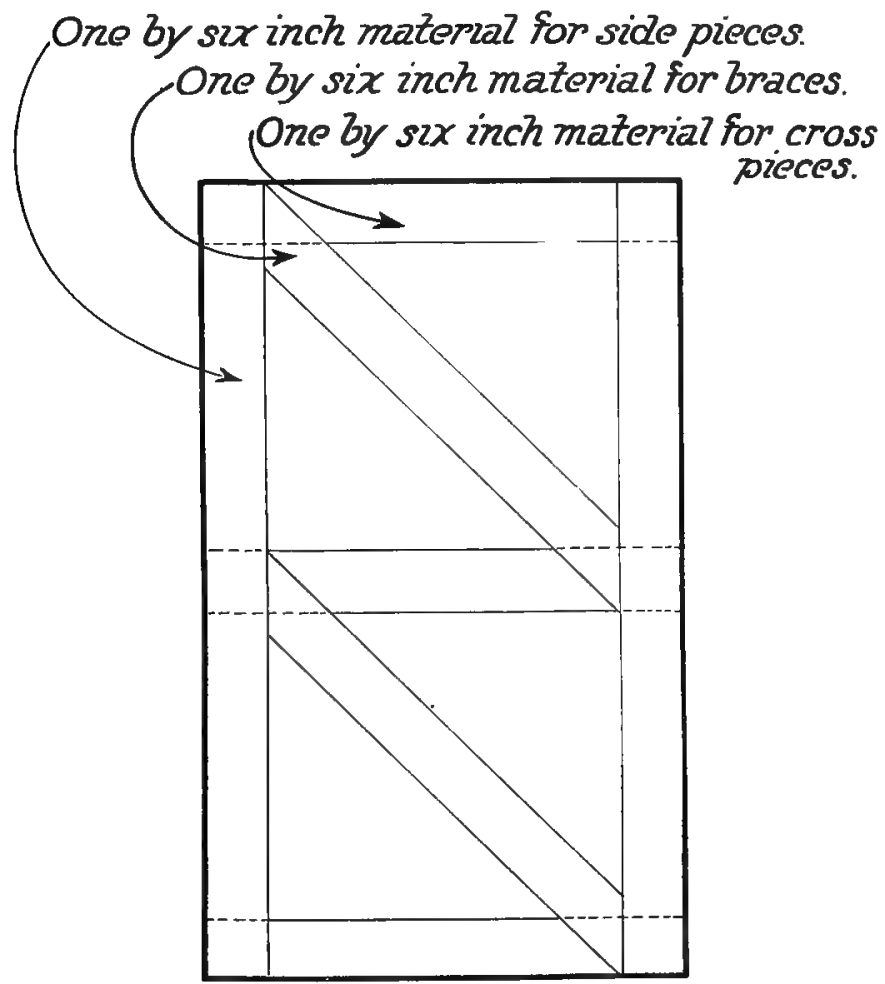

FIG. 87.-A neat, well-built gate for a poultry fence.

with poultry netting, and so hung that if left partly open they will swing shut.

Arrangement of Poultry Buildings.-The general plan of the poultry plant, even when started in a small way, should allow for future development. The buildings should be so 
grouped as to make an attractive appearance from the highway, to be easily accessible, and to reduce the amount of labor. The principal buildings, such as feed room, incubator, and brooder houses, should be centrally located, with the young stock range near the residence or in the center of the plant. In this position the youngsters can be better protected, and more closely watched. To the pupil starting out with a small pen of birds, proper location is the most important consideration, for if successful with his small flock, he will doubtless wish to enlarge his poultry plant in the near future.

\section{LABORATORY EXERCISES}

Exercise No. 29.-To demonstrate the water holding capacity of soil and to show why a light soil is drier and warmer than a heavy soil, secure three glass tumblers. In the bottom of each place four or five small stones about the size of one's thumb. Secure two types of soil, one pure sand and the other a heavy clay soil. In one tumbler place clear sand, filling the tumbler to within one-half an inch of the top. In a second tumbler place the same amount of the clay soil. In the third tumbler place the same amount of a mixture of one-half sand and one-half clay. Into the top of each tumbler pour an equal amount of water, about onehalf a tumblerful will be sufficient. Watch the rapidity with which the water soaks down through the different types of soil. Note in which tumbler the water reaches the open spaces around the stones first. With a pencil stir the top of each tumbler and note the condition of the top soil. Which of these three types of soil is best for poultry?

Exercise No. 30.- - If an effort is being made to organize a small flock for the school have the pupils build the fences according to the plan described in this chapter. Be sure that the posts are firmly set.

Exercise No. 31.-Have each pupil lay out on paper an ideal arrangement of the essential buildings for a small 
poultry farm. This should include all houses, yards, fences and roads. The plans can be placed on the wall and discussed by the entire class, the good and poor points in each being pointed out.

\section{THOUGHT QUESTIONS}

1. How important is the proper location of the poultry house and yard?

2. How does the problem of location differ with the poultry keeper owning his own land and the one who has not yet secured his location?

3. When choosing the location for a poultry farm what consideration should be given to markets?

4. What are some of the most desirable methods of transportation?

5. How important are the rural telephone and the rural free delivery?

6. Describe the best soil for poultry.

7. What kind of soils should be avoided? Why?

8. What factors should be considered with reference to water drainage?

9. How does air drainage affect the location for the poultry?

10. Why should low places be avoided?

11. What exposure is best for the birds?

12. Is sod land good for poultry?

13. What advantage, if any, is an orchard on the site selected?

14. Describe in a few words an ideal location for the poultry house.

15. What is the problem of the average poultry keeper in reference to yarding his birds?

16. What is meant by "alternate yarding"?

17. Give a simple crop rotation for double yards.

18. What three things should be given special consideration in the construction of the poultry fence?

19. Discuss posts for poultry fences.

20. What kind of material makes the best fence?

21. What special features should be considered in building and placing the gates?

22. Is it necessary to plan the lay out of the buildings with reference to a possible future growth and the general appearance when complete?

References.-United States Farmers' Bulletins: 403, The Construction of Concrete Fence Posts; 524, Tile Drainage on the Farm. 


\section{CHAPTER XV}

\section{ESSENTIALS OF A POULTRY HOUSE}

ThE design of the poultry house and its construction largely determines the conditions surrounding the birds, that is, creates their environment.

Factors in environment are temperature, moisture, sunlight, and feed, and these affect the health and greatly influence production. The environment must be congenial

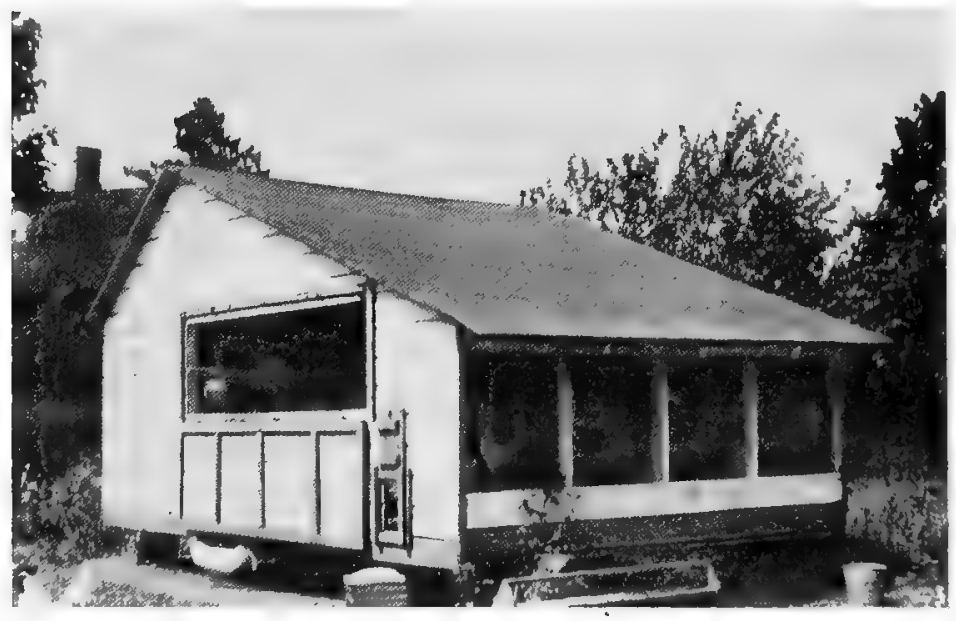

FIG. 88.-An open, fresh air poultry house.

and calculated to keep the birds well and contented; otherwise, they may become lazy and unhealthy, or poor producers. The modern poultry house combines all the features necessary to produce ideal conditions.

Principles in Design.-The poultry house should be dry and admit plenty of sunlight, with enough floor space for the number of birds (Figs. 88 and 89 ). There should be protection from 
extremes of temperature. The building should be rat-proof, and easy to clean. All fixtures should be simple in design.

Dryness of the Poultry House.-Moisture breeds disease, and germs of several undesirable types thrive and multiply in dark, damp places, hence a damp poultry house is unsuitable and unhealthful for the birds. Moisture in the poultry house may be from several causes. First, there is moisture from the air, which is usually due to imperfect ventilation. Second, the moisture exhaled by the birds,

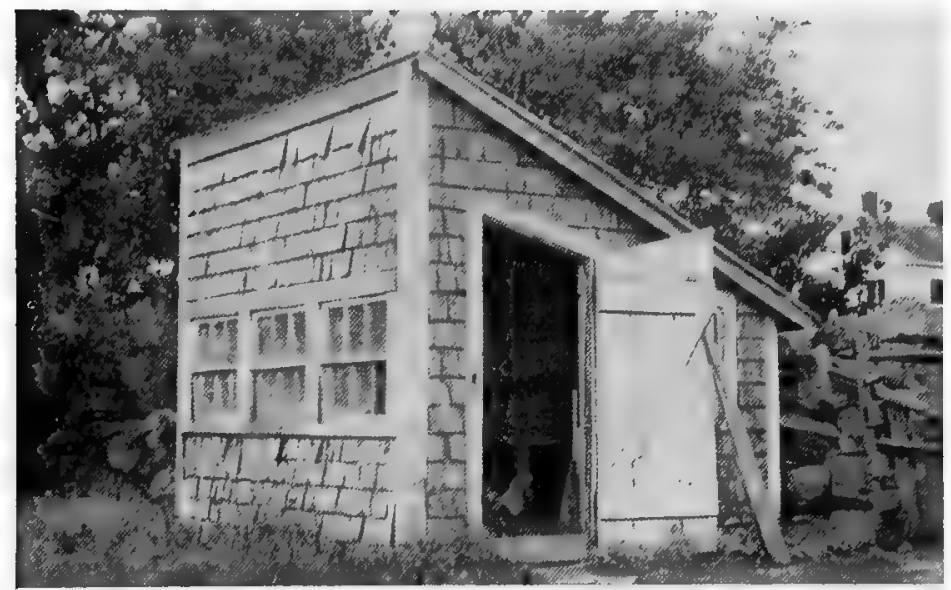

Fra. 89.-A closed, poorly ventilated, old type of poultry house.

which unless carried off and replaced by fresh, pure air, may be seen as beads of water on the rafters and walls. The third type of moisture comes from the soil, especially if this be heavy and damp. When the house is located on such a spot the dampness must be counteracted. Soil water should never be allowed to work up and dampen the litter, and this can be prevented by a good concrete floor placed on ten inches of cinders. Sometimes dampness is due to surface water, especially in the spring of the year when the ground is frozen; on this account a house should 
never be located in a hollow, for at certain seasons, when water can not seep into the ground, it may flow into the house. Perfectly dry floors and dry, pure air are the primary essentials in constructing a poultry house (Fig. 90).

Need of Sunlight. -Plenty of sunlight in the poultry house helps to make it sanitary by destroying harmful germs, and also makes the birds more contented. This is evident to any one who watches them in cool winter weather. They

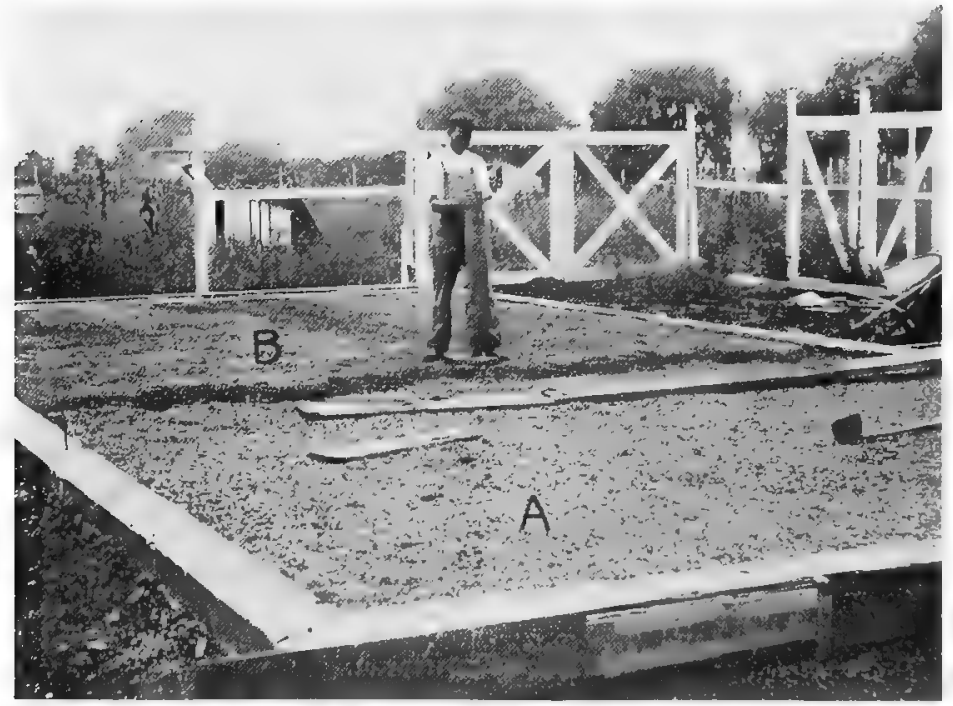

FIG. 90.-Building a floor to the poultry house which will be perfertly dry. $A$, cinders six inches deep; $B$, concrete three inches deep.

wallow in the dust, then bask in the sunlight. To get all the sunlight possible, the house should face the south. The design should be for a rather high front, yet not so deep that the sunlight can not penetrate to the back. A good rule with regard to sunlight is to have the house so designed and situated that at some time during the day the direct rays of the sun will strike every part of the floor.

Importance of Thorough Ventilation.-Good ventilation 
is especially necessary in the poultry house in winter, when a considerable number of birds are kept closely confined to their quarters week after week. Poultry are very active, and have a high body temperature. In the course of a day they exhale a lot of impure air, which is a poison. Hygiene demands that this be removed and replaced with pure air laden with oxygen. This air breathed out is heavily laden with moisture. The constant removal of this moisture laden air by ventilation makes the house drier. Good ventilation in the poultry house is best insured by the liberal use of muslin curtains in the front. If these are left open

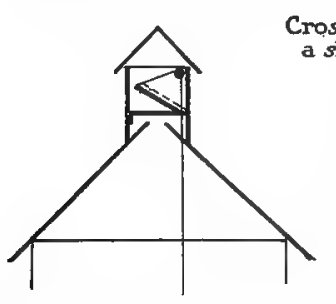

Cupola ventilator, with trap-door to control amount of air passing through
Cross-seetion of a muslin-covered frame

FIG. 91.-Four ways of ventilating the poultry house.

much of the time, the atmosphere will be almost as pure as that out of doors. In snowy, wet weather and on very cold nights these openings can be closed by frames covered with light-weight muslin, which readily permits the air to pass through. Slatted shutters resembling blinds are frequently recommended for use in place of muslin curtains; these should be hinged so that they can be thrown open when not needed (Fig. 91).

Ventilators in the back of the poultry house are desirable for summer use, and, if constructed rightly, will help to keep the house cool during the hot weather. Sometimes the ventilation is by means of flues or pipes connected with chimneys on top of the house. If of good design these 
work satisfactorily but they are often too small or too badly arranged to answer the purpose.

Plenty of Floor Space for the Birds.-The layers must have all the floor space they need for exercise, especially large laying flocks in winter. The house is built for the birds and its capacity is determined by the floor space. All fixtures, such as hoppers, nests, water fountains, etc., should be elevated above the floor, as this will increase the capacity of the house. The birds must not be crowded. Crowding increases the likelihood of disease, and creates unsanitary conditions. Four to five square feet of floor space should be allowed each bird.

Protect the Birds from Extremes of Temperature.-Birds can bear extremely low temperature without injury, if there are no drafts and the air is dry. But if an air current, laden with moisture, circulates rapidly through the poultry house, it does not need a very low temperature to freeze their head parts, and injure them for production. Frozen combs are quite common with the light, active breeds, unless care is exercised in designing the houses and manipulating the ventilators. During winter the birds should be induced to take all the exercise possible by scratching in the litter; this keeps them warm by increasing the circulation. They should be given considerable whole or cracked corn during the winter, as it is a very heating and fat-forming feed, therefore, beneficial to them.

The Construction Should Be Rat=proof.-Whatever the type of poultry house, every effort should be made to build it so that rats can not get into it. The surest method is to construct foundation of concrete, and after the house is completed a concrete floor two or three inches thick should be laid for further protection. The danger of rats carrying off young chicks is great, and frequently there is heavy loss from failure to guard against them. One-inch mesh poultry netting tacked underneath wooden floors, or buried in the 
ground where dirt floors are used, will help to keep rats out. The boards used in building a poultry house should be such as will not harbor mites or other parasites. Dressed lumber is best. All fixtures should be portable, and as simple as possible in type, so as to admit of rapid and thorough cleansing whenever it is desirable to clean the house.

Simplicity.-The poultry house should be built of durable materials, for it does not pay to spend one's money on a cheap house which is only temporary. If built on a good foundation, and of good, first-class material, the house is a permanent building, to be cared for as such. The simpler its design, the more attractive it will be; simplicity of the exterior and freedom from fancy corners and costly trimmings enable one to keep it in a good state of preservation at little cost. When completed the poultry house should immediately be given two good coats of oil paint, any knots in the boards being shellaced beforehand. This treatment will keep the boards from shrinking and coming apart, thus forming cracks, and will the better preserve the house.

Economy but not Cheapness.-In designing and building his house, economy should be first and foremost in the poultry keeper's mind, but not cheapness at the sacrifice of efficiency; and efficiency in every respect is probably best secured by a house of shed-roof shape, from four and one-half to six feet high in the back, and from seven to eight in front. The height will depend upon the depth, but it must be high enough to permit the attendant to care for the birds without inconvenience. The house should approach a square in shape, this being more economical, as less building material is required. Twelve by twelve, fourteen by fourteen, or sixteen by sixteen are common dimensions for the floor areas of small poultry houses.

An Ideal Plan.-The following summary demonstrates the type of house which at present is accepted as the best. The floor space should be ten to twenty feet square. The roof 
should be of one pitch, with the highest part in front and the lowest part at the back. A height of from five and one-half to six feet must be maintained in that part of the interior where the poultryman must move about to do the work. If small and portable, the house should have a wooden floor; if large and permanent, the floor must be concrete. The house should be built so that at least two-thirds of the front can be open, these openings to be covered with muslin and glass, using twice as much muslin as glass. The roosting boards, dropping boards, and nests should be in the back part of the house, away from the open front, and fixtures should

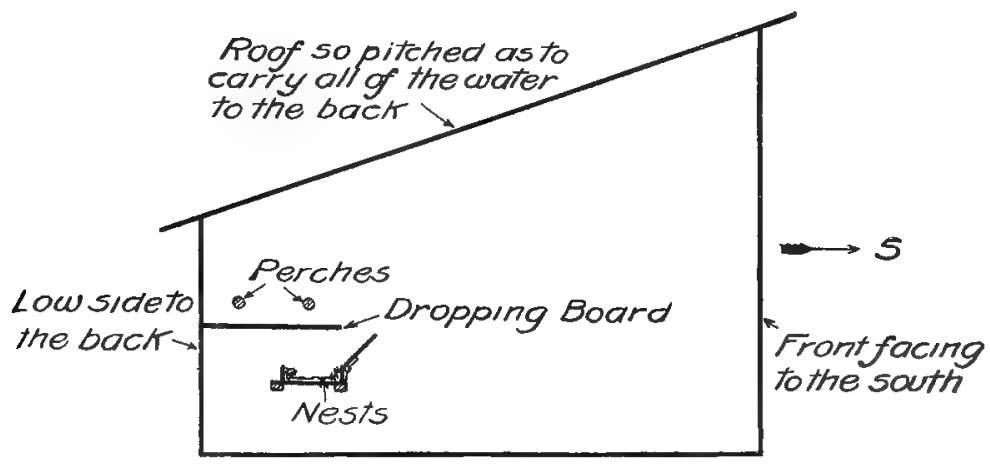

FIG. 92,-Cross-section showing an ideal arrangement in a poultry house.

be elevated above the floor (Fig. 92). Features which have been enumerated will be described more in detail in succeeding chapters.

\section{LABORATORY EXERCISES}

Exercise No. 32.-The Effect of Dampness.-Secure two tumblers. Place about one inch of dirt in the bottom of each. Moisten the soil in one and leave the other dry. Place in each a small piece of bread, about the size of a thimble. Place an inverted butter plate, or piece of card-board, over the moist tumbler and leave the other one open. Set the tumblers away on a dark shelf. Look at them daily and ob- 
serve the growth of mould spores on the bread. On which piece of bread does the mould form first and fastest? Why? The open tumbler represents a dry, ventilated compartment. The wet tumbler represents a wet, non-ventilated place. The same condition shown here takes place in a wet, poorly ventilated poultry house.

Exercise No. 33.-Muslin Ventilation.-Purchase a yard of light-weight muslin and a few tacks. On some windy day tack this muslin over the outside of the lower part of one of the school house windows. Be sure to put the muslin over a window on the side of the school house towards which the wind is blowing. Then open the lower sash and allow the pupils to stand inside of the window in front of the muslin curtain. Compare the atmospheric conditions felt here with those felt when the next window adjoining is opened and they are allowed to stand in front of an open unprotected window. Explain from this object lesson the advantages of the curtains as used in poultry houses.

\section{THOUGHT QUESTIONS}

1. What is the relation between the design of the poultry house and the birds' environment?

2. What is meant by environment?

3. What are some of the factors of environment?

4. Enumerate the modern principles in the design of a poultry house.

5. Why should the house in.which the birds are kept be free from moisture?

6. Discuss three kinds of moisture which may be found in the poultry house.

7. Why is plenty of sunlight desirable in the house?

8. Give a good rule to govern the amount and distribution of sunlight.

9 . Why do birds need plenty of fresh air in the house?

10. How can the poultry house best be ventilated?

11. Why is automatic ventilation by the means of flues not the best?

12. How much floor space should be given each bird?

13. How can the birds be protected from extremes of temperature?

14. How can a poultry house be made rat-proof?

15. Is simplicity in poultry house construction important?

16. How does a coat of paint help preserve the house?

17. Diseuss economy vs. cheapness in poultry house construction.

18. Describe an ideal plan for a poultry house.

Reference.-United States Farmers' Bulletin 574, Poultry House Construction. 


\section{CHAPTER XVI}

\section{REMODELLING OLD POULTRY HOUSES}

ON ordinary farms and often on small village lots, will be found auxiliary buildings, such as sheds, out-buildings, etc., which by a little ingenuity can be remodelled into good poultry shelters at small cost. Basement barns, slightly reconstructed, make excellent winter quarters for laying hens. Where poultry houses of antiquated type can be reconstructed at small cost, the aim should be to make such changes as will give efficiency and durability. If the remodelled house

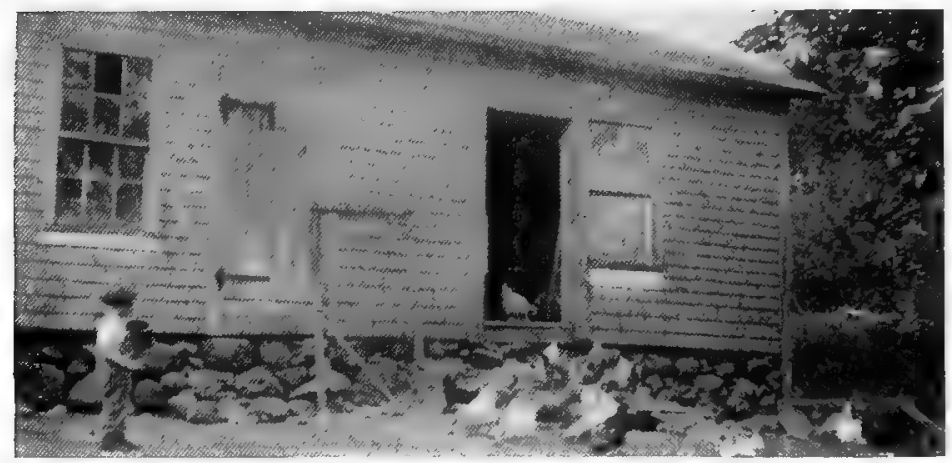

FIG. 93.-.The boiler room of an old grist mill was remodelled into a poultry house for twenty-five birds so that the little man might have a place for a special flock all his own.

is to be satisfactory, it must be water-tight and should be air-tight on three sides (Fig. 93). It must be so arranged that plenty of sunlight can enter it, with openings that will constantly admit plenty of fresh air, yet not be.drafty. Care must be taken to see that it is dry, especially that the floor of the house is not wet and moist. In old buildings, special precautions to guard against rats should be taken. 
When completely remodelled, the buildings should be thoroughly cleansed and made ready for the birds.

Economy calls for careful use of both labor and material in the remodelling. The labor is simple, and of such a nature that the poultryman can do much of it himself. Materials rarely need be purchased. Old boards can be taken from other buildings, or those usually found in considerable number about the farm can be used. Burlap obtained from ripping up old bags can be used in place of muslin; it is just as serviceable, although not quite so good-looking. Openings for windows can be cut in the wall in such a way that no window frame is needed. Stones picked up about the farm can be used for floor and concrete work.

\section{SUGGESTIONS FOR REMODELLING A HOUSE}

The following suggestions are offered with the idea that they may be useful when putting an old house into suitable condition for layers:

Thorough Cleaning the First Requisite.-The first thing to do is to clean out any rubbish and filth which may have accumulated in the building. If it is an old poultry house, all litter should be removed, the dropping boards thoroughly scraped, and the walls and floor swept. The window lights should be cleaned on both sides. If the floor is of dirt, six inches of the top soil should be removed. The interior of the house should then be sprayed with a five per cent solution of carbolic acid. These procedures will prepare the house for remodelling. Next, openings in the front wall should be marked out with a pencil, and then cut. They should be planned with reference to the studding and framework of the building. The idea should be to arrange for as much sunlight as possible, and to have it well distributed over the floor. The window openings should be so cut that there will be about one square foot of glass to twenty square feet of floor space, and the curtain openings planned so that 
there will be one square foot of muslin to ten square feet of floor space. Window openings should be cut vertically, that is, up and down. Curtain openings should be rather wide and horizontal. The openings in the walls must be cut a little smaller than the window sashes which are to fit them. The sash can then be hinged on the inside, the wall acting as the jamb against which the sash shuts. The openings in the wall should be covered with one-inch mesh poultry netting. This confines the birds to the house and also keeps out sparrows. Sparrows will eat a considerable amount of the poultry feed in the winter. They are also apt to infect the flock. The window sashes should be hinged to the wall inside so that they can be opened. The best way is to hinge them on the side so that they will swing against the wall out of the way. The muslin curtains can either be attached so that they will roll up, or they can be tacked to frames, and hinged to the top, and folded up against the roof.

Finishing the Floor.-If the floor is of wood, it should be carefully examined to see that it is in good repair. It must be tight, that is, free from cracks and holes. Any cracks should be covered with boards. The upper surface must be fairly smooth. If the floor is very poor, yet must be retained, a good plan is to cover it with one-inch mesh poultry netting, and over this lay a fresh floor, using eight- or ten-inch shiplap, or tongued and grooved yellow pine boards. If a dirt floor is to be put in a poultry house, the best way is to spread four to six inches of stones, gravel or cinders, which will give good drainage, and over this place a coat of cement or concrete two or three inches thick. This should be tamped well to bring the water to the surface. A common mixture for such a flooring is one part cement, three parts sand, and five parts cinders, or crushed stone. Such a floor has the advantage of dryness, is absolutely sunitary, and is proof against rats.

Repairs to Walls and Roof.- The wills of the house should 
be looked over carefully to see that they are tight, as cracks or holes may cause undesirable drafts. Such holes may be covered by battens on the inside. The roof should be inspected to see that it is in good repair, and strong enough to hold any weight to which it may be subjected; for example, heavy snow. If it has been papered, and the paper is badly worn, a new one must be put on. If a shingle roof, any missing shingles should be replaced with new ones. If the shingles are in poor condition, it is better to entirely reshingle, since the roof must be absolutely water-tight.

Building Dropping Boards, Perches, and Nests.-All of these fixtures should be built in the back part of the house, which is the warmest and best protected. Put the dropping boards close to the back wall, about two or three feet above the ground. Their height will depend upon the breed kept, and their width upon the number of perches. Fourteen inches should be allowed between the perches, and eight or ten inches of perch to each bird. The top of the dropping boards should be as smooth as possible, so that they may be easily cleaned, and if they can also be easily removed it is an advantage. The perches should be elevated above the dropping boards about six inches, in order that a hoe can be manipulated under them to clean the boards. The perches should be movable and of durable construction. Round poles, two or three inches in diameter, make good perches. Nests can be built under the dropping boards or fastened to one of the side walls; either place is good. Provision should be made for the birds to enter them under the perches or from behind, and there should be a door or opening in the front for the removal of eggs. The nests should be planned and built about twelve to fourteen inches square, one for every four or five birds. They should be dark and, if possible, movable.

Finishing Touches.-After the house has been remodelled and the fixtures completed, it should be made habitable by giving it a thorough spraying with the disinfecting 
solution recommended in Chapter XXX. If the floor is of wood or concrete, about two inches of sand should be scattered over it, and this covered with six to eight inches of good coarse litter; straw or a poor grade of hay is best. The feed hoppers, grit boxes, and drinking fountains should be attached to the wall or placed on shelves or tables. The house is now ready for the birds, which should be put in and kept closely confined for a week or two, until they get accustomed to it. Decide on the number of birds the house will accommodate, but it is not wise to have more than one bird to about four square feet of floor space.

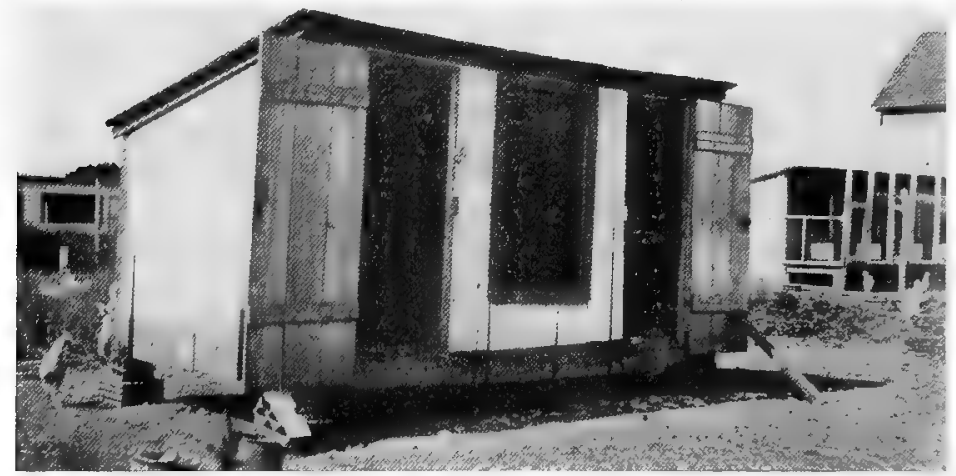

FiG. 94.-An old tool shed remodelled into a very fine small-flock poultry house.

Such remodelling as outlined will take but little time, and can be done when other work is slack. Little skilled labor is called for, and the use of waste material found about the farm so reduces the cost that a far greater number of birds can be kept (Fig. 94).

\section{LABORATORY EXERCISES}

Exercise No. 34.-Remodelling a Poultry House.-If there are any small buildings about the school grounds which are not used for any definite purpose let the class follow the instructions given in this chapter and remodel one into a 
laying house for poultry. Such practice can be secured by purchasing a small and rather dilapidated building from some one in the neighborhood. Only a very small building should be used, as larger houses would entail too much work and expense.

Exercise No. 35.-Improving Poultry Houses.-A number of poultry houses in the immediate vicinity can be visited and suggestions made as to changes which would make them more efficient. Such, for example, as more light, better floors, more roost room, etc. Such a discussion will aid in fixing the desirable points in mind. Full notes should be taken on each house studied.

Exercise No. 36.-Laying a Concrete Floor.-Valuable experience in laying concrete floors can be secured by purchasing one or more bags of cement and, if no poultry houses are present on the school grounds, a door step, or a piece of sidewalk, can be laid in the same manner. Concrete floors or walks should consist of three layers. First an under or drainage layer consisting of six inches of cinders or stone. Above this a layer of concrete consisting of one part of cement, three parts of sand and five parts of cinders or stone. This mixture should be thoroughly mixed before any water is added; it should then be mixed with water until all is added that will hold without running off. This rough coat should be well tamped and left rough to better hold the finish coat. The finish coat should be made about one inch thick and should consist of one part of cement to three of sand. It is best to finish the top coat smooth. This can be done with a flat piece of board or a plastering trowel. When it is desired to build steps, or to form any piece of concrete, leaving square corners and plane vertical surfaces, it is best. to use wood forms, which should be lightly nailed together so that they can be easily removed. Concrete should be allowed to harden at least forty-eight hours before it is stepped on. 


\section{THOUGHT QUESTIONS}

1. Is it possible to remodel old buildings so as to make them suitable poultry houses?

2. What special conditions should be secured in order that the remodelled house be efficient?

3. What is the first requisite in remodelling an old building?

4. What special precautions should be practised to insure cleanliness?

5. How should the openings which are cut in the front wall for windows and curtains be planned?

6. How should a wooden floor be repaired?

7. If the finished floor is to be of dirt how should it be prepared for the birds?

8. How should a concrete floor be made?

9. What attention should be given the walls to put them in proper condition?

10. What should be done to the roof?

11. Where should the dropping boards, perches, and nests be located?

12. Describe the construction of the dropping boards.

13. What special feature should be considered in building the perches?

14. Describe the process of making the remodelled house habitable for the birds.

15. What should be the size of the nests?

16. Is there any building on your place that can be made over into a suitable poultry house? Describe it.

References.-United States Farmers' Bulletins: 461, The Use of Concrete on the Farm; 481, Concrete Construction on the Live Stock Farm. 


\section{CHAPTER XVII}

\section{BUILDING A POULTRY HOUSE}

THis chapter deals with the actual construction of a poultry house designed for laying hens. The specifications call for a house six by eight feet, giving a capacity of from ten to twelve birds, depending upon the breed. If it is desirable to keep a larger flock, the capacity can be doubled by increasing the width of the house, making it eight feet deep and twelve feet wide. This will give a capacity of from twenty to twenty-five birds. Such a house is designed especially for a beginner, and is adapted to the small flock, whether on the farm or in the city back yard. The house described is economical of construction and easy to build, and is most satisfactory, as proven by years of usage.

\section{GENERAL DESCRIPTION OF THE HOUSE}

If designed to be portable, the house should be put on runners, and have a wooden floor. If permanently located, it must go on a concrete foundation, and have a concrete floor. The house should be of the shed roof type, eight feet high in front, and five feet in the back, with a depth of eight feet, and a width of six feet. The area of the floor will be six by eight feet. Halfway between the top and the bottom of the front wall, and extending all across the width of the house, is an opening three feet deep and six feet wide for air and sunlight (Fig. 95). It is covered with inch mesh netting, also by a muslin curtain, attached to a frame. A small glass window sash is inserted just below the muslin curtain to admit sunlight when the curtain is down. There is a small ventilator at the back of the house which can be used in the summer for free circulation of air between 
the double walls at the back. This is a good arrangement, as it cools the house off during hot summer nights. A door two feet wide and six feet high is cut in one side near the front. The top of the door follows the slant of the roof, thus giving a few inches in height. The frame of the house is built of yellow pine and hemlock, the floor of pine boards, and the walls of eight-inch tongued and grooved yellow or

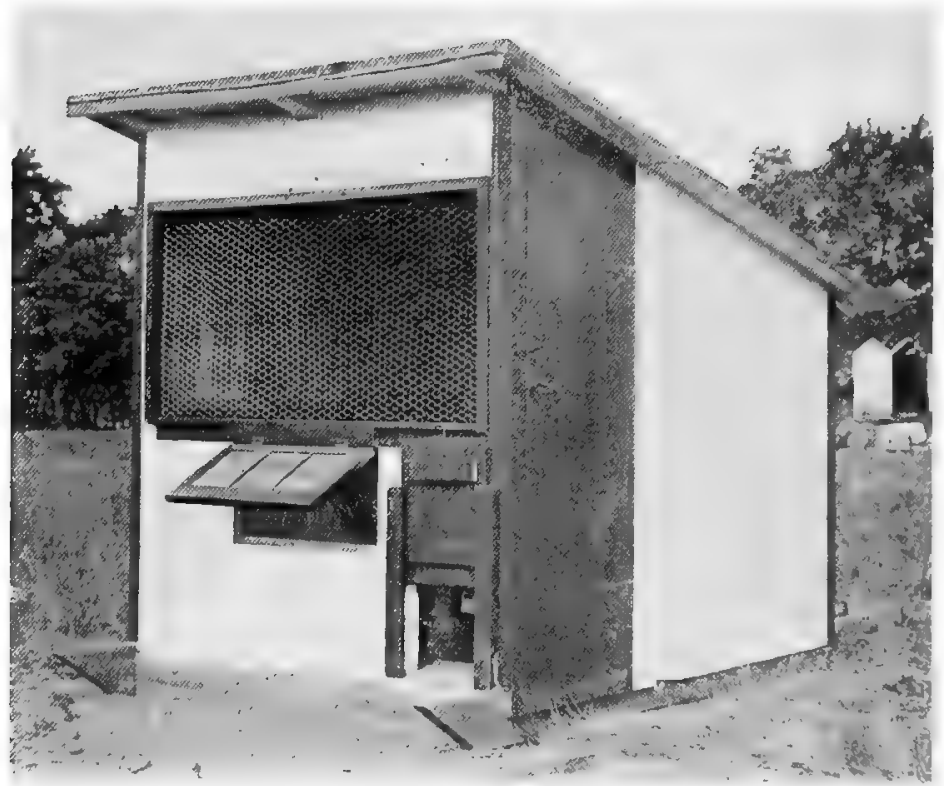

Fra. 95.-The small-flock poultry house as it will appear when finally completed.

white pine, the boards being laid up and down. The roof is made of shiplap, and ten-inch yellow pine boards, covered with a good grade of roofing paper. The interior fixtures consist of four nests placed on the side wall opposite the door, and a hopper hung on the other side of the wall near the door. The roost and nests are built in the back and lowest part of the house. The dust box is located in the center 
of the front, immediately below the small window, and the water vessel on a shelf at one side of the dust box. These brief specifications will give some idea of the type of house to be built (Fig. 96).

\section{LIST OF MATERIAL TO BUILD ONE SECTION}

The following list specifies the amount of lumber required to build a house as above described.

Runners, -2 ps. hemlock $2^{\prime \prime} \times 10^{\prime \prime}$ by 10 feet long

Floor timbers, -6 ps. hemlock $2^{\prime \prime} \times 4^{\prime \prime}$ by 6 feet long

Posts, - -1 pe. hemlock $2^{\prime \prime} \times 4^{\prime \prime}$ by 16 feet long

Posts, -1 pc. hemlock $2^{\prime \prime} \times 4^{\prime \prime}$ by 10 feet long

Plate,-1 pc. hemlock $2^{\prime \prime} \times 4^{\prime \prime}$ by 12 feet long

Roofing rafters, -4 ps. hemlock $2^{\prime \prime} \times 4^{\prime \prime}$ by 10 feet long

All studding, - $3 \mathrm{ps}$. hemlock $2^{\prime \prime} \times 4^{\prime \prime}$ by 8 feet long

All studding, -2 ps. hemlock $2^{\prime \prime} \times 4^{\prime \prime}$ by 12 feet long

Boards for first floor and roof,-120 sq. ft. $1^{\prime \prime} \times 10^{\prime \prime}$ Y. P., T. \& G.

Material for nests, dropping boards, and hoppers,-50 sq. ft. $1^{\prime \prime} \times 6$ " Y. P., T. \& G.

Perches, -2 ps. hemlock $2^{\prime \prime} \times 2$ " by 12 feet long

Frame for muslin curtains, -2 ps. hemlock, $1^{\prime \prime} \times 4^{\prime \prime}$ by 12 feet long

One cellar sash with glass, - 3 lights each $6^{\prime \prime} \times 8^{\prime \prime}$

1 roll, 3-ply roofing paper

100 sq. ft. red felt building paper

Explanation of the Above Terms.-The term "timber" is used to describe large, thick sticks of wood ranging in size from two by four inches to two by six inches or larger, and are usually of hemlock or yellow pine. Their cost is figured by the board foot. The term "T. \& G." is the abbreviation for "tongued and grooved." It means that each board has a groove on one edge, and on the other edge a tongue or narrow projection of wood which fits into the groove when the boards are laid together. "Beaded" is a term which means that the boards are furrowed on one or both sides, in order to give the wall a neater and more finished appearance. The initials "Y. P." stand for yellow pine, and "W. P." stand for white pine. The word "roofers" is a trade name which denotes yellow pine tongued and grooved. Shiplap is a term which means boards with a lip on each side. When 
these boards are laid together, the lips fit over each other, and make a tight joint. "Barm boards" is a trade name for shiplap yellow pine. The following miscellaneous material will complete the house and make it ready for the birds:
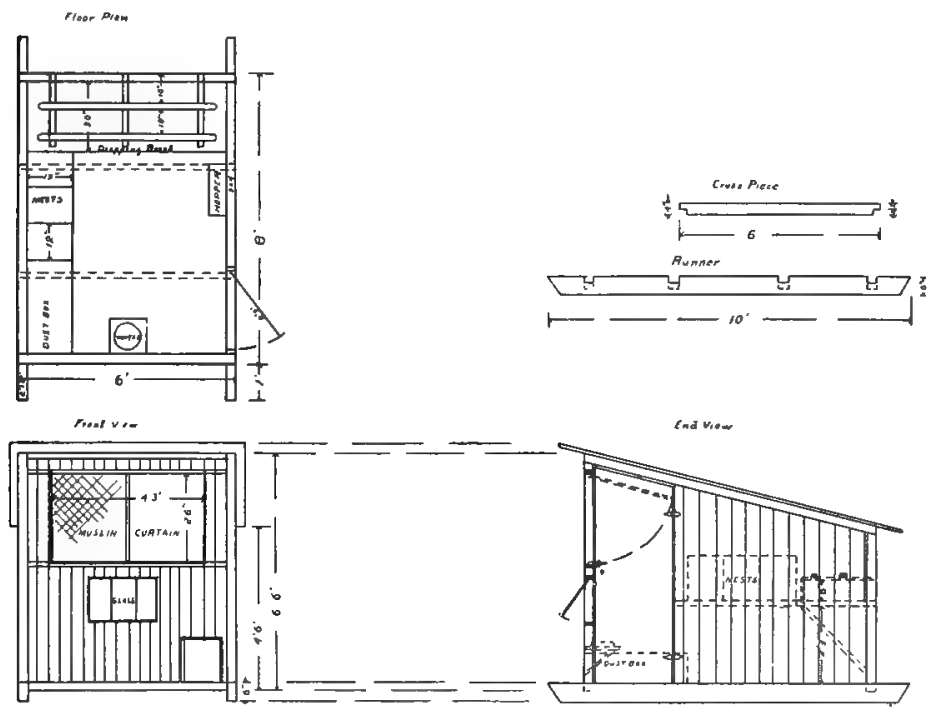

FIG. 96.-Working plans of the small-flock, portable poultry house.

2 lbs. 20-penny wire nails or 2 pairs 6-inch strap hinges

$$
\text { spikes }
$$

$10 \mathrm{lbs}$. 10-penny wire nails

1 box carpet tacks

$1 \mathrm{lb}$. poultry staples

2 pairs 4-inch strap hinges
1 barn door latch

1 hasp and staple

1 padlock

4 hooks and eyes

A piece of one-inch mesh poultry netting, three feet wide and seven feet long, will be needed to tack across the large opening under the muslin curtain, and light-weight muslin, one yard wide and two yards long, to talk on the frame for this opening; also two- or three-ply standard grade roofing paper for the roof. The above material will cost $\$ 19.50$, and can be secured at almost any lumber yard and hitrdware store. 


\section{TOOLS NEEDED FOR THE WORK}

The following tools are necessary. Two sawhorses, one hammer, one crosscut saw, one ripsaw, one screw-driver, one spirit level, one try-square, one steel square, and one two-foot rule. The sawhorses can be made by the students.

\section{DIRECTIONS FOR CONSTRUCTIION}

The following details for building the house should be taken up in the form of laboratory exercises, and are here given as such. They are designed for the construction of a portable house, six by eight feet, with a wooden floor.

Fig. 97.

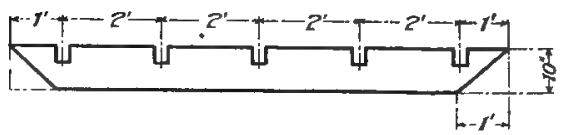

Fra. 98.

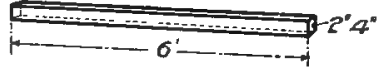

Frg, 97.-Detail drawing giving dimensions for runners.

FIG. 98.-Detail drawing giving dimensions of floor joist.

\section{LABORATORY EXERCISES}

Exercise No. 37.-Constructing the Runners.- Select for the runners, two hemlock planks, each ten feet long, two inches thick, and ten inches wide. Square both ends, so that the board is exactly ten feet long. Notch the runners so that they will take the floor joists, and also level the ends, according to the detailed sketch. This beveling makes the house slide easily when moved (Fig. 97).

Exercise No. 38.-Cutting the Floor Rafters.-Select the two by four pieces of hemlock ordered for the floor joists. Cut each of them six feet long, and square the ends. To secure uniformity cut one as pattern and make the others just like it. Fit these floor joists into the slots in the upper part of the runner, and nail securely with ten-penny nails (Fig. 98). 
Exercise No. 39.-Leveling the Runners and Squaring the Corners.-The next process should be to level both runners by the use of the spirit level. Place pieces of board or bricks under the runner, and on them the spirit level. When the bubble in the center of the spirit level is in the center of the glass tube, the runners are level. Next square the corners by using the large steel square; after all of them are perfectly square they should be held so permanently by nailing cleats diagonally across from corner to corner (Fig. 99).

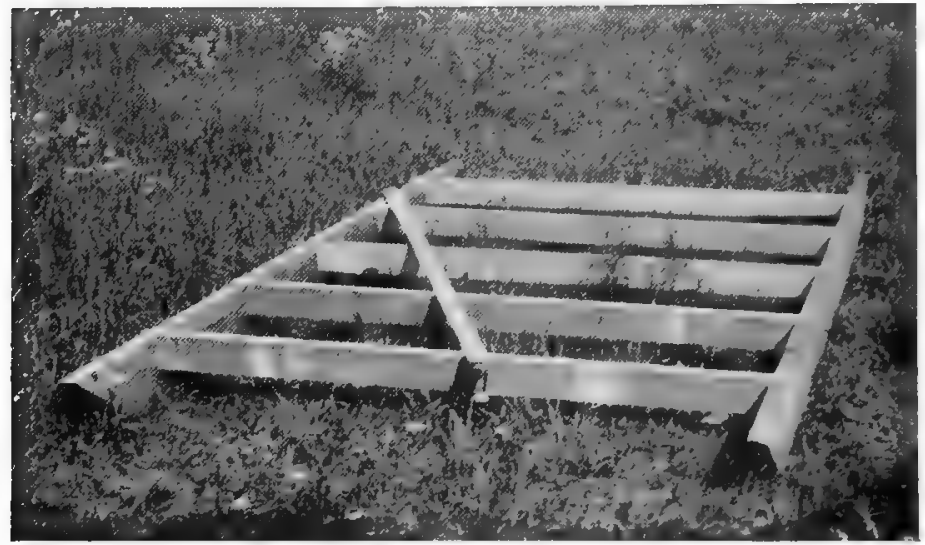

FrG. 99,-The runners and floor rafters in place, showing the stick used to hold them square.

Exercise No. 40.-Laying the Rough Floor.--Select from the pile of lumber the yellow pine shiplap boards, which were ordered for the rough or lower floor, and lay them diagonally from corner to corner. The best plan is to begin at the center and work towards the ends. The boards should be securely pressed together, then nailed, and finally sawed off to make the work neat. All sawing should be to a line, and straight and even. Each board should be fastened with two nails in each floor joist and runner.

Exercise No. 41.-Erecting the Posts.-Select the two by four sticks ordered for posts. Cut two posts eight feet long, 
and two five feet long. Be sure that the ends are perfectly square. Nail the eight-foot posts securely at the front corners, and flush them with both sides of the corners. Use the spirit level to plumb the corner posts. They should be braced with shingle laths both ways. One end of the laths should be nailed high on the posts, the other end being tacked to the runner or frame when the post is plumb.

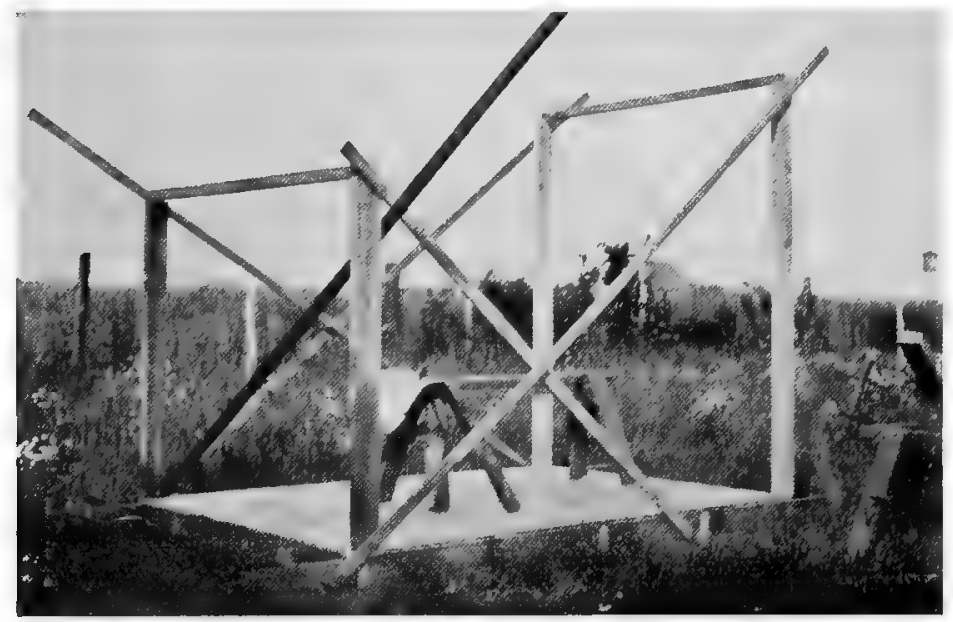

Fra. 100.-The posts erected and braced, showing the plates in place.

Set the five-foot posts at the rear corners of the house in the same way (Fig. 100).

Exercise No. 42.-Erecting the Plates.-The plates are two by four strips which connect the tops of the two rear posts and the tops of the front ones. For these cut two pieces of hemlock two by four, and six feet long. Be sure that they are exactly the right length and the ends square. Nail to the top of the posts with twenty-penny spikes.

Exercise No. 43.-Erecting the Roof Rafters.- Select the pieces designed for rafters. Saw one piece exactly ten feet long, and notch the lower side of it as shown in figure 101. 
These notches will fit into the plate at the front and back of the house. Place one rafter to see if it fits, and if it fits perfectly use this as a pattern and cut three exactly like it. Space them two feet from the center, and have the outer one flush with the ends of the plates. Spike them securely with twenty-penny spikes (Fig. 101).

Exercise No. 44.-Erecting the Studding.-Make the right stud for the door of two by four hemlock, and set it up on one side, two feet from the corner post. It should be perpendicular to the runner, and parallel with the corner posts. Erect intermediate timbers, three feet from the floor, between all posts and the outer studding. Do not put any

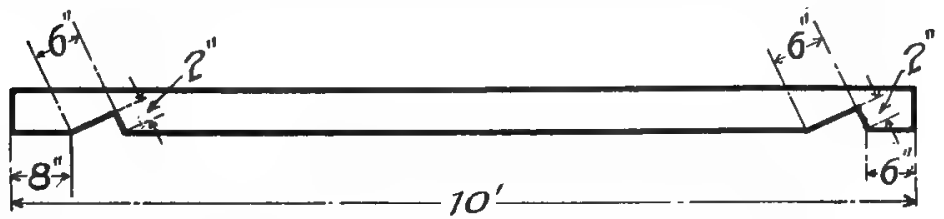

FIG. 101.-Detail drawing giving dimensions of roof rafter.

intermediate sticks across the space left for the door. Cut all intermediates a little long so that they will fit between the posts, and be flush with the outer edge. Nail them securely. Next fit the intermediates at the top and bottom of the curtain opening.

Exercise No. 45.-Erecting the Walls.-Select from the pile of lumber the one by six inch tongued and grooved pine lumber, and with this cover the back, the side, and the front walls. Leave openings for the door, curtain, and windows as specified. Before nailing them, saw the top of the boards so they will be flush with the top of the rafters. Be sure to keep them perpendicular. Drive them together securely, nailing each board as soon as fitted, driving two nails in each board where it crosses a rafter or stud. Keep the corners square and plumb. On the side walls make the boards conform to the slope of the roof (Fig. 102). 


\section{BUILDING A POULTRY HOUSE}

Exercise No. 46.-Laying the Roof.-Select the boards for the roof from the lumber pile. Lay them perpendicular to the rafters. Begin laying the roofing boards at the back, or lower part of the house, making the under part of the first board flush with the ends of the rafters. Cut each board exactly seven feet long. Lay them so that six inches project on each side of the roof, and the last board is flush with the upper end of the roofing rafters. Cover roof with a two-ply roofing paper, according to directions found with

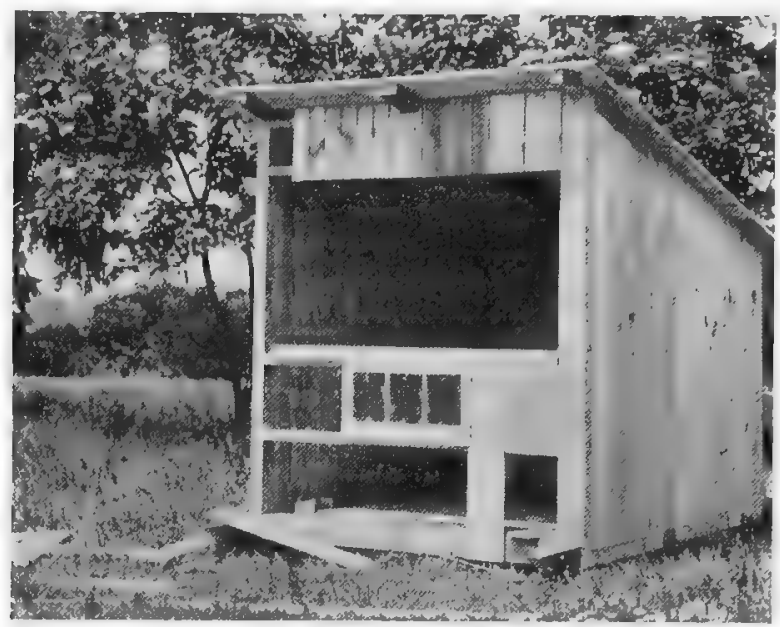

Frg. 102.-Boarding up the walls. Note openings left for muslin curtain, window and exit for the birds.

the roll. Lay the paper carefully and nail securely. Tar all joints before and after nailing.

Exarcise No. 47.- Laying the Finished Floor.-Cover the rough floor which was first laid with red felt building paper, lapping it to the width of four inches. Lay the top floor boards over this, lengthwise of the building. Fit them carefully about all posts and studding, and blind nail them, as this gives a better finish. Drive the boards firmly together, and cut them the exact length required. Next, double-board 
the back wall on the inside, following the same method of construction as on the outside wall.

Exercise No. 48.-Miscellaneous.-Cut an opening in the back wall for a summer ventilator and cover it with a sliding board. Fit a glass sash into the opening, planing it down to the exact size. Hinge the window at the top, so that it will swing up and down, and provide two hooks and eyes, one to fasten the window up, and the other to hold it open. Cover this window opening with one-inch mesh wire, tacking it on the inside. Make a one by four-inch muslinframe of white pine, the outside of the frame just a little smaller than the opening in which it is to swing. Follow the accompanying sketch as to its method of construction and bracing. Cover it with light-weight muslin, using carpet tacks. Hinge it at the top, so that it will swing up and in, and cover the large opening. Cover the large opening in the front wall with one-inch mesh poultry netting, putting the wire on the outside. Make a door of the right size to fit the opening left for it. Brace the door on the inside diagonally, and hinge securely on the side farthest from the corner post, with heavy strap hinges. Put a barn door latch on the door to hold it shut, and provide a hasp and staple for locking it. The house itself is now complete, and ready f.or inside fixtures.

\section{THOUGHT QUESTIONS}

1. What is the floor area of the small-flock poultry house?

2. For what purpose is the small-flock poultry house adapted?

3. Describe in a general way the plan of the house to be built.

4. Define the meaning of the following terms: Timber; T. \& G.; W. P.; Y. P. ; shiplap; barn boards.

5. How are the different sizes of the nails specified?

6. Describe the following pieces of hardware: Strap hinge; barn door latch; hasp and staple.

7. What is the total estimated cost of all material for the small-flock poultry house?

8. See what this list of materials will cost in your community.

9. Give a list of the tools needed to build a small house of this kind.

10. What is the function of the runners?

11. Describe the cutting of the floor rafters. 
12. Why is it necessary to level the runners and square the corners?

13. Describe the method of laying the first or rough floor.

14. Where are the timbers called posts located?

15. What is meant by the term "plate"?

16. What is the function of the roofing rafters?

17. The word "studding" refers to what timbers?

18. How should the walls be built?

19. What kind of material is used for the roof?

20. What kind of water-proof material is used for the roof?

21. How should the second or finished floor be laid?

22. What miscellaneous construction work is necessary to complete the house?

Reference.-United States Farmers' Bulletin 474, Use of Paint on the Farm. 


\section{CHAPTER XVIII}

\section{THE INTERIOR OF THE POULTRY HOUSE}

The subject of this chapter is the poultry house equipment, commonly called the poultry fixtures or appliances. They constitute those parts of the house which should be movable, but are sometimes built to be stationary, though the practice is an unwise one.

\section{ESSENTIAL FEATURES}

Simplicity both in design and construction is essential for interior equipment, and the simpler it is the cheaper. This is true not only because of the material required, but the amount of labor necessary to construct it. The simpler it is, too, the easier it will be to operate, and the plainer the construction, the easier to disinfect it and keep it clean.

Portability is an important consideration. All fixtures should be so constructed that they can be readily removed and put out of doors in the sun; the more complicated ones, such as nests, so that they can be taken apart for cleaning. If the fixtures, such as perches and nests, are movable, it is much easier to keep the house free from mites and parasites. The working qualities of the equipment are important also, and all the parts should be well adapted to the purpose for which they are to be used. Durability counts for much if the appliances are often handled. They should be made of material strong enough to last, woll put together and securely fastened to the walls or other places of attachment.

Fixtures should be elevated above the floor. This leaves the entire floor space to the birds, and decreases the cost of housing per bird. Fixtures should be so made as to be calsily cleaned. If posible make them of hard woul, free from ralkiks and creviceit. Only dressed lumber should be used. 188 
If these points are borne in mind when constructing appliances, the poultry house will be much more satisfactory. The following fixtures should receive most careful consideration.

Dropping Platform. - The dropping platform is a wooden shelf, either stationary or movable, located under the perches, to receive the droppings of the birds at night. In this way it is easy to collect the droppings, and by keeping them out of the litter the house is kept clean (Fig. 103). Some houses have pits under the perches, instead of dropping boards, and in the pit bark, shavings or other absorbent. The pit, however, is objectionable. It is unsanitary, often more or less offensive, and hard to keep free from parasites.

\section{Brace holding the front of the platform.}

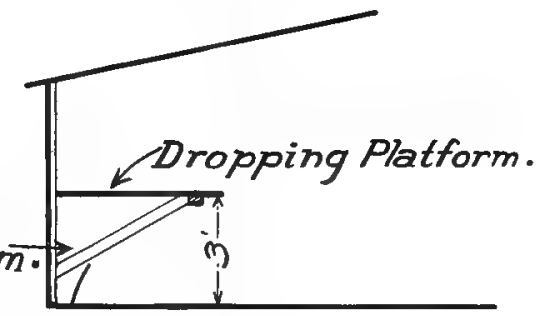

Fig. 103. - Sketch showing the best location of the dropping board, in the low, back part of the house.

Properly cared for, the droppings should be lightly covered with dry loam, sand or gypsum. This dries out the moisture from the droppings, and keeps the house sweet and clean. The droppings on such platforms should be collected twice a week, at least, and oftener if possible. In narrow pens dropping boards can be constructed in one piece, and set on cleats, nailed to each side wall. The dropping board can readily be removed by pulling it out, just as a drawer is drawn out. The boards should run from back forward to eliminate all danger of catching the hoe in cracks between the boards when cleaning.

Perches.-Perches are usually put in the low, back part of the house above the dropping platform or dropping pit. 
Some poultry houses have small roosting pens of special design with poles or perches resting across two sawhorses. The droppings thus fall directly on the ground, and are occasionally covered with loam to keep them dry. The perches are used by the birds to roost on at night. Fowls are so formed that they need a small, round or nearly round stick about which to lock their feet when sleeping. Branches of trees or saplings, two or three inches in diameter and ten feet or more in length, make good perches. If these are lacking, two by two or two by three hemlock sticks will

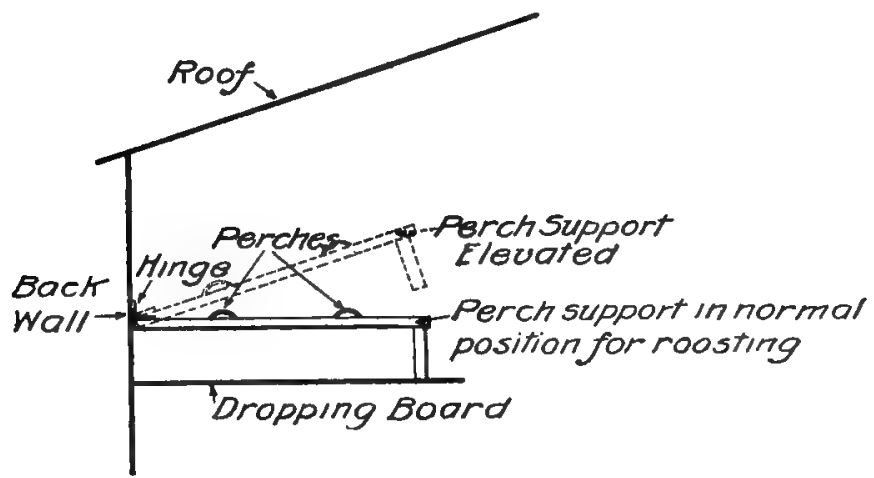

Fig. 104.-The best form of perches. They are made in sections and hinged to the back wall.

be satisfactory, set on edge, the upper edges rounded. Each perch may be a unit in itself, in which case it is usually set on a cleat or in a groove made especially for that purpose. An ideal way is to make the perches in sections, each section hinged to the back wall, and supported in front by legs eight or ten inches long. This raises the perches high enough above the dropping boards for easy cleaning (Fig. 104). There should be plenty of perches in the house, in order to prevent crowding, eight to ten inches of perch room per bird being about right. The perches should be about fourteen inches apart, to keep the birds from soiling each others' plumage, 
and the back perch should be no closer to the back wall than twelve inches.

Nests. - Nests are constructed to provide a place where hens may lay their eggs. The two most common locations are either under the front of the dropping board or along the wall. In any case they must be darkened, for the birds like dark nests, and they lessen the danger of egg eating. Whether on the wall or suspended, nests should be so de-

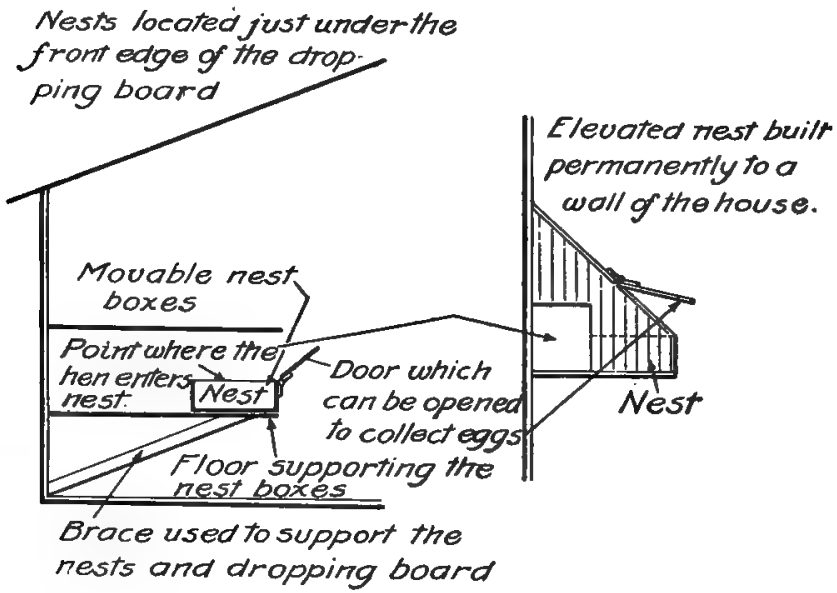

FIG. 105.-Two of the best types of poultry nests.

signed that the laying hen can enter from the back (Fig. 105). The eggs can best be removed from a drop door in the front. Nests should always be built of plain or dressed lumber, and ten to fourteen inches square. If open, the sides should rise at least four inches above the bottom of the nest to keep the eggs from rolling out when the hen leaves the nest (Fig. 106). When closed nests are built, there should be at least twelve inches between the bottom of the nest and the ceiling. One nest to four hens is the right proportion during the spring and summer, but in the winter, or non-laying season, this number is not needed (Fig. 107). 
Trap Nests.-Trap nests, as the name implies, are especially designed to catch or detect the hens which lay eggs; they are used in pedigree poultry breeding. The general

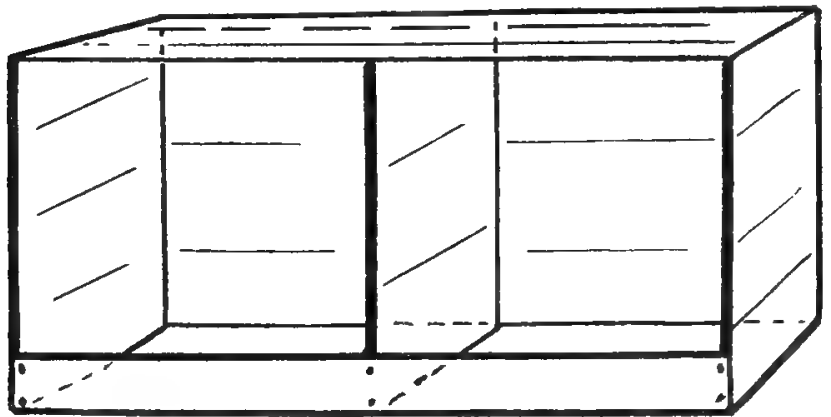

FIG. 106.-An egg crate, if turned on its side and a narrow, four-inch strip nailed along the bottom of the openings, makes a very satisfactory nest. It can be attached to the wall or suspended under the dropping platform.

plan of these nests is the same, although there are some ten to twenty different styles. When the hen enters the nest to lay her egg, she releases a spring or trigger which closes

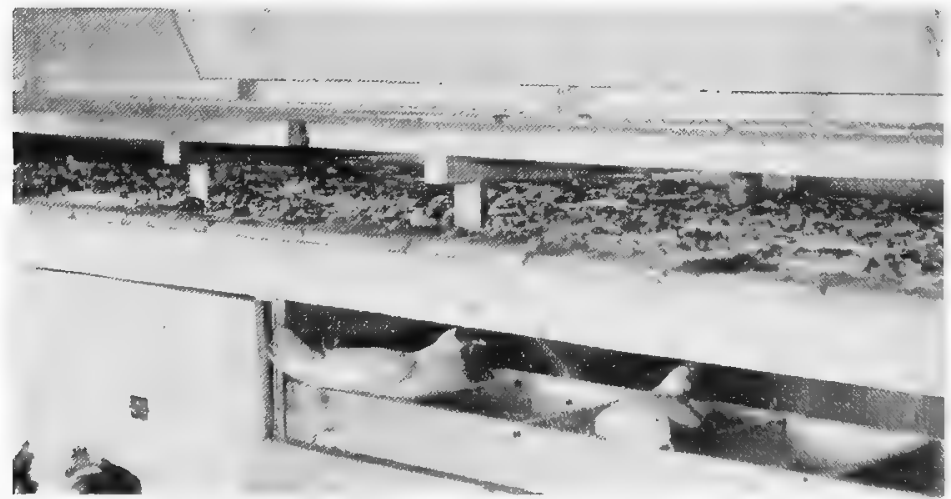

FIG, 107.-Nests located under the dropping platform as sketched in Fig. 105. (Photo by A. L. Clark.)

the door behind her, and fastens it so that no other hen can enter, nor can the hen which is caught loave until the at- 
tendant releases her. When he sets her free her leg band number is read, and recorded on a card for the purpose. Such records, if carefully made, show the egg production of individual birds for a given length of time.

In order to keep the eggs from getting broken, some sort of nesting material is usually placed in the bottom of the nest. This may be straw, a poor grade of hay, or planer shavings. Straw litter is very good, as it is dry and keeps clean.

Water.-Water pans or fountains should be set on shelves or fastened to the wall in an elevated position. Two types of water vessels are in general use: one an open pan or trough, the other a syphon fountain. The pan is easy to fill and clean, but, unless provided with some specially constructed cover, the birds are apt to get into it, and soil the water. Syphon fountains are of various styles and makes. They work on the principle of a vacuum or absence of air. As the water flows out of the opening at the bottom, air pressure on the outside is caused by the absence of air on the inside of the vessel. This outside pressurc holds the water at a given height until more air enters as more water is released. The drinking vessel should be of good size, so that the birds can always have plenty of fresh water. Regardless of the type, they should be so located that the birds can not tip them over if they should alight on them when flying. A heavy galvanized drip pan for a refrigerator, four to six inches deep, makes a durable drinking pan.

Hoppers. - The feed hoppers generally used are designed for two purposes, the feeding of both mash or ground grains, also often for feeding grit, shell and meat. Many types of hoppers are on the market, but it is hard to find one which feeds the mash down continuously as the birds eat it, yet does not waste it. Hoppers of different types can be made at home at much less cost, yet are very satisfactory. All hoppers should be attached to the walls or placed on raised platforms (Figs. 108 and 109). 


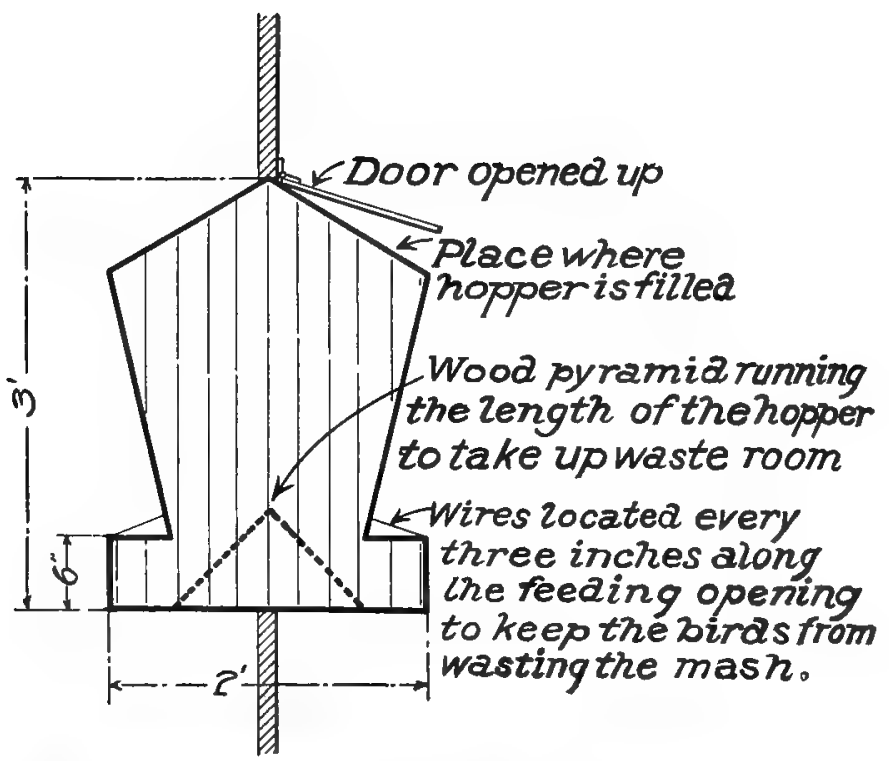

FIG. 108.-An efficient, homemade hopper, so constructed that the birds can feed from both sides.

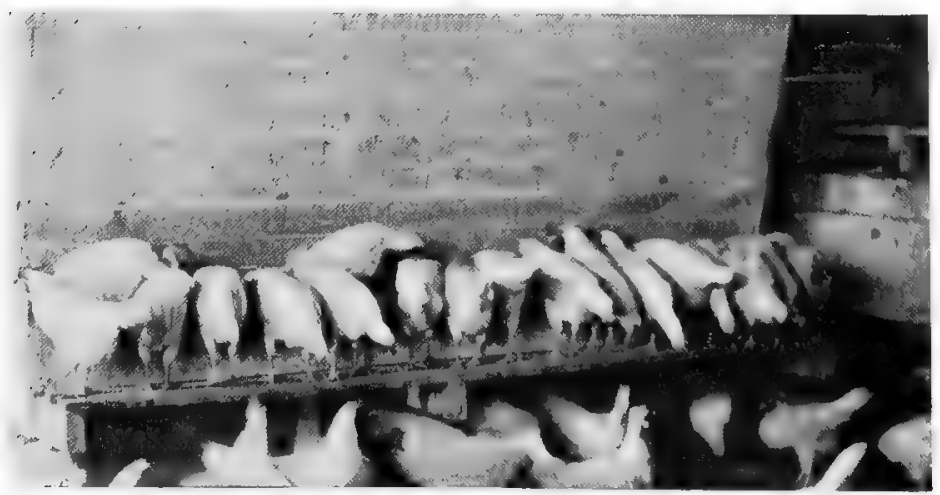

FIa. 109.-White Leghorn pullets feeding from a hopper of the same size and type as sketched in Fig. 108. Note the length of hopper and distance above the floor. (Photo by A. L. Clark.) 
Dust Boxes.-The dust box is a necessary part of all poultry house interiors. Its purpose is to provide a dry, fine dust or soil in which the birds can bathe themselves. Access to such a box reduces the danger of body lice to a minimum. The best places for the dust boxes are in the front corners of the laying house, because these are well lighted and the birds naturally love to bask and dust in sunlight. A good method for constructing dust boxes is to use a corner of the building (Fig. 110), the walls forming two sides of the box, and build the other two sides by nailing together at right angles, in the form of the letter $L$, two twelveinch boards. These boards can then be fitted into the corner, thus making a box three or four feet square. Fill this with equal parts of very fine road sand and dry loam, and add a small

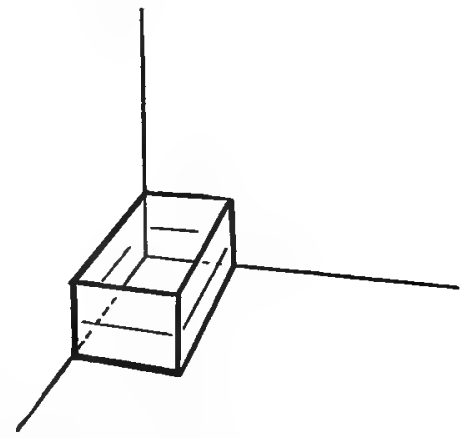
amount of tobacco dust. FIG. 110.-Sketch of a dust box built into The dust boxes, to best do the corner of a laying pen.

their work, should be kept free from stones or large clods of soil. No litter should be allowed to accumulate in them.

Litter on the Floor.-As soon as the interior fixtures are completed and in place, it is well to cover the floor with some good litter or scratching material. Coarse straw, shredded corn stalks, hay and shavings are used (Fig. 111). The litter should be quite deep, so that the birds will have to work to find the grain scattered in it. It is also essential, from the standpoint of health, that it be kept in good order, which means that it should be dry, coarse, deep, and clean. After filling the mash hoppers and water fountains, the house is absolutely ready for the birds. 


\section{LABORATORY EXERCISES}

Exercise No.49.-Amount and Value of Poultry Manure.Secure the co-operation of at least three or four members of the class by getting them to keep an exact record, for about one month, of the time it takes them to clean off the dropping boards. Also the amount of absorbent used, and the amount of droppings produced from a given number of birds. From

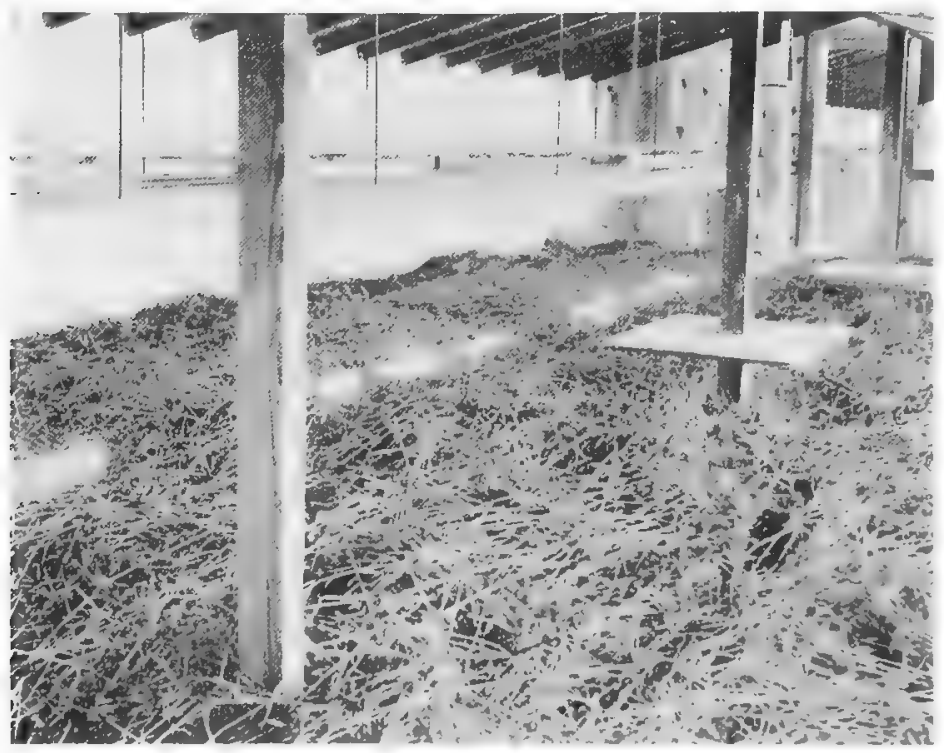

Fia. 111.-A commercial poultry house in excellent condition for the layers. The litter on the floor is about fifteen inches deep.

their figures the class can determine the amount and value of droppings produced per one hundred birds for a given period.

Exercise No. 50.--Perch Rmm. - Get as many members of the class as possible to measure for a number of consecutive nights the amount of porch room occupied hy a given number of bircls. The figures obtained c:un be presented to

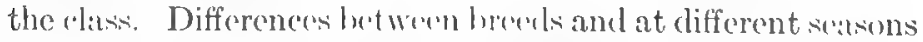
will be noted. The causes maty le explained by the cliss. 
Exercise No. 51.-Types of Dry Mash Hoppers.-Have the members of the class bring to school different types of commercial or homemade dry mash hoppers. A collection representing many kinds can thus be secured. A period may be set aside when these can be studied and their advantages and disadvantages described.

Exercise No. 52.-A Dust Bath.-Secure one peck of dry sand and a peck of dry loam. Allow the class to see these thoroughly mixed. To this may be added a small amount of tobacco dust. If available the addition of one peck of sifted hard coal ashes helps to make the mixture dry and powdery. Such a mixture makes an admirable dust bath. By mixing it in the classroom and calling attention to the necessity of fineness and dryness these facts will be impressed on the mind of the pupil.

\section{THOUGHT QUESTIONS}

1. Is it best to build the interior fixtures of the poultry house movable or permanent? Why?

2. Enumerate the essential features in planning the interior equipment.

3. Discuss portability as applied to the interior appliances.

4. What can you say of the efficiency of the appliances?

5. Are durability and permanence necessary factors to consider?

6. Should all fixtures be elevated from the floor? Why?

7. Define the meaning of "dropping platform."

8. What is the function of the dropping platform?

9. Is a pit under the perches desirable? Why?

10. Describe the management of the droppings.

11. Describe the location and construction of the perches.

12. How much perch room should be allowed each bird?

13. Where are the two most common places to locate the nests?

14. What size of nest is best?

15. How many nests are necessary?

16. What is a trap nest?

17. What is the manner of operating trap nests?

18. What material is best to use in the nests to keep the eggs from getting broken?

19. Discuss the common types of receptacles for watering the birds.

20 . What is the purpose of hoppers?

21. What is the function of the dust box?

22. Give a good mixture to use in the dust box.

23. What kind of material can be used on the floor of the house as scratching litter?

24. Describe some useful and unique appliances which you have seen in use.

Reference.-United States Farmers' Bulletin 347, The Repair of Farm Equipment. 


\section{CHAPTER XIX}

\section{BEST TYPES OF POULTRY HOUSES}

MANY different types of poultry houses are to be found on poultry farms in America. Poultry keepers, therefore, should study the desirable features of these various types, and at least attempt to devise more uniform and satisfactory buildings for their birds. Types of construction differ because of diverse conditions. The size of the flock, the breed, and the climate all affect the design of the poultry house.

\section{THE EVOLUTION OF THE MODERN POULTRY HOUSE}

Originally all birds roosted in trees. To-day many of them show a preference for roosting in the open air. Especially is this true of young stock during the summer. When man began to breed birds commercially, he constructed for them simple shelters, which were merely roofs over their heads. From this crude beginning the construction of poultry houses has gone through successive stages of development until, about thirty years ago, very expensive houses were erected, many of them beautiful in design, and some artificially heated. The latter were apt to be poorly ventilated and unsatisfactory. From the heated houses, poultry keepers changed to a glass front house. This house was built to be durable, the walls being usually double-boarded with paper between. Such openings as were provided in the front of the house were covered with glass sash. Automatic ventilators were inserted in the roof, but often did not work as they were expected to. These glass-front houses were found to be very hot during the day and very cold at night, and the birds did not thrive in them.

Recent years have shown a sudden change from this tight, warm house to the open front or muslin front house. The first stage in its development was the elimination of 198 
some of the glass windows and substitution in their place of muslin windows. The fresh air movement led in many cases to the entire front of the house being left open. Practice seems to be generally uniform with regard to the desirability of muslin and glass in the front of the house. Such houses admit of adequate ventilation, the birds thrive well, and egg production is well maintained.

The Modern Standard Type.- The modern standard type of poultry house is one built rather low with a shed roof. The back and side walls are solid, the front largely open. About two-thirds of the open area is covered with a muslin curtain, and one-third with glass. This glass is provided to let in light on stormy days when the curtain is lowered, and the curtain is used when it is necessary to close the

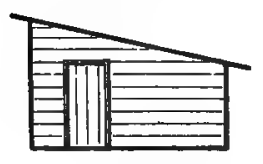

Shed

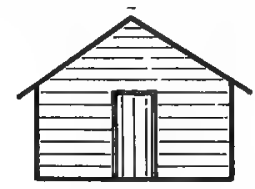

Gable

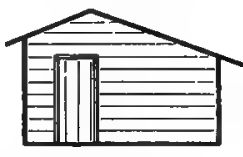

Broten Span

Fra. 112.-Three common types of poultry house roofs.

opening. This type of house is recommended by practically all of the state Colleges in the land, and is found on most of the large and successful poultry farms.

Roofs.-The roof is an important feature of the poultry house, because it is rather expensive to build. Three types are common; the shed roof, the gable roof, and the broken span. The shed roof house is all of one pitch. The gable has two pitches at the same angle, with a ridge in the center. The broken span has two pitches, the back slope being much longer and extending to a lower point than the front one. Houses of the shed roof type are most popular, for the reasons that they are cheapest to build, they require less lumber, have a higher front, and therefore, admit more sunlight, and all rain water is carried off behind (Fig. 112). 
Materials for Building a Poultry House.-Wood and tile are both used in poultry house construction, but wood by

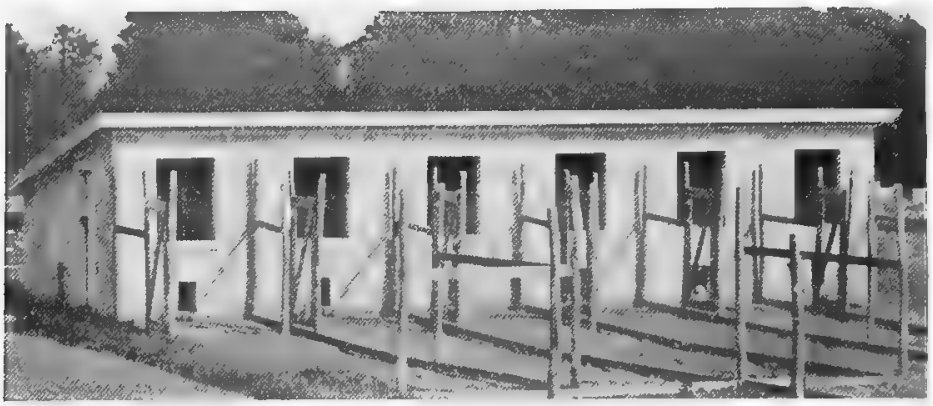

Fra. 113.-A poultry house built of hollow tile and stucco. This material costs just about one-half more than the same house would have cost built of wood.

far more frequently. It is the cheapest and best material. Tiles cost about one-half more than wood, but do not equal

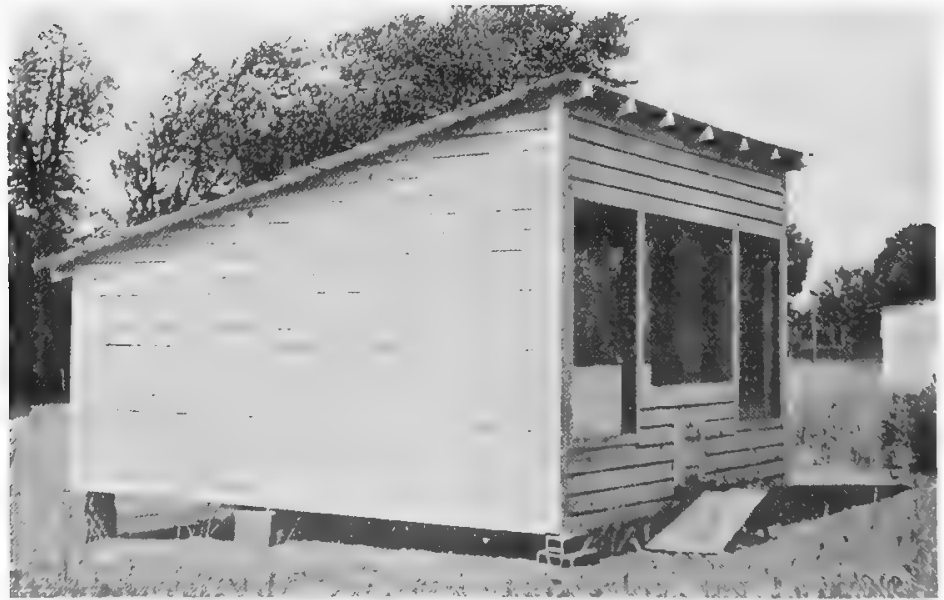

Fic. 114.-A colony laying house with a capacity for forty laying hens.

it in efficiency (Fig. 113). Sometimes concrete and brick are used, but are generally unsatisfactory, and such construc- 
tion is costly. Experience proves that houses built with concrete or solid brick walls are apt to be very damp.

\section{HOUSES DESIGNED FOR EITHER SMALL OR LARGE FLOCKS}

We will now discuss six different types of poultry houses, all of which are recommended as desirable for flocks of different sizes and under different conditions.

Small=flock Colony Laying Houses.-The house shown in figure 114 is twelve by fourteen feet in size, and is designed for forty laying hens. As will be noted, it is of the shed roof type, eight feet high in front and four and one-half feet high in back. In the center of the front is a large opening, shaded by a muslin curtain of three by five feet. If the house is built to be permanent, it should have a concrete floor. The sill is four inches square. All studding is of two by four inch hemlock, and the siding of white or yellow pine shiplap. The roof is made of one by ten yellow pine shiplap, covered with a good three-ply roofing paper. The perches, nests, and dropping boards are attached to the back wall, and all other fixtures to the side wall. The following list gives the lumber required to build such a house:

Sills.

2 ps. $4^{\prime \prime} \times 4^{\prime \prime}$ hemlock 12 ft. long

2 ps. $4^{\prime \prime} \times 4^{\prime \prime}$ hemlock $14 \mathrm{ft}$. long

Posts. ................ pc. $4^{\prime \prime} \times 4^{\prime \prime}$ hemlock $10 \mathrm{ft}$. long

1 pc. $4^{\prime \prime} \times 4^{\prime \prime}$ hemlock $16 \mathrm{ft}$. long

Plates................2 ps. $2^{\prime \prime} \times 4^{\prime \prime}$ hemlock $12 \mathrm{ft.} \mathrm{long}$

Studding.............. pe. $2^{\prime \prime} \times 4^{\prime \prime}$ hemlock $16 \mathrm{ft.} \mathrm{long}$

4 ps. $2^{\prime \prime} \times 4^{\prime \prime}$ hemlock $10 \mathrm{ft}$. long

6 ps. $2^{\prime \prime} \times 4^{\prime \prime}$ hemlock $14 \mathrm{ft}$. long

7 ps. $2^{\prime \prime} \times 4^{\prime \prime}$ hemlock $16 \mathrm{ft}$. long

Roof rafters...........7 ps. $2^{\prime \prime} \times 4^{\prime \prime}$ hemlock $16 \mathrm{ft}$. long

Boards for roof and inside fixtures, $450 \mathrm{sq} . \mathrm{ft} .1^{\prime \prime} \times 8^{\prime \prime}$ yellow pine, tongued and grooved

Siding. ............ $350 \mathrm{sq}$. ft. of $6 \mathrm{in}$. white pine shiplap

Two glass sashes. .....3 $3^{\prime} \times 5^{\prime}$, each sash with 12 panes of glass

For trim and muslin frames 200 linear ft. white pine 1 " x 3 "

150 linear ft. white pine $1^{\prime \prime} \times 4^{\prime \prime}$

Miscellaneous material includes roofing paper, cement and sand for foundation, muslin, wire, and hardware. 
The cost of material is $\$ 42.50$. Houses of this type are quite generally used on village lots, and on farms where flocks of about forty to fifty birds are kept.

Multiple Unit House.-This house, as described, is shown in figure 115. It is the prevailing type on many large poultry farms. The multiple unit house is so called because it is built on a unit basis. Each unit is $20 \times 20$ feet, and has a capacity of one hundred birds, which allows four square feet

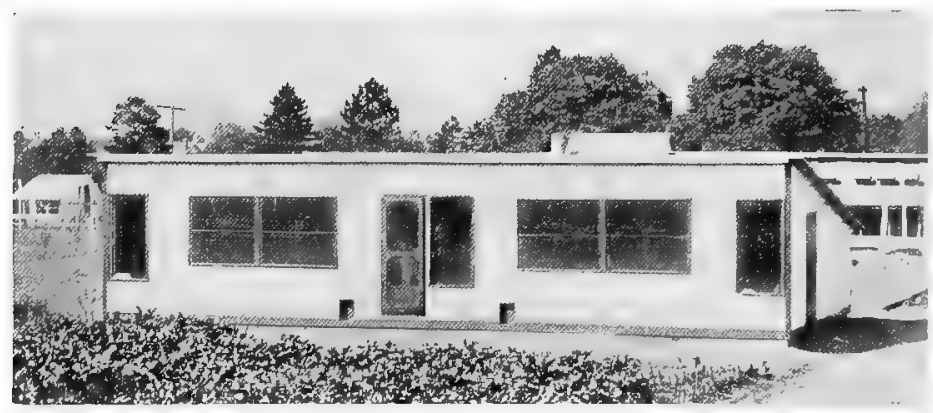

FIG. 115.-A double Eection of a standard multiple unit laying house. An ideal poultry house for flocks of 100 birds and greater.

to a bird. Figure 115 illustrates two units of this type of house. Specifications follow.

The outside dimensions are $40 \times 20$ feet. Sills are $4^{\prime \prime} \times 6^{\prime \prime}$, bolted to a 'concrete foundation wall eight inches wide and twenty inches deep, laid on tamped cinder or crushed stone. The entire depth of the foundation trench is three feet.

The construction is shed roof type, with nine-foot studding in front, and four and one-half foot studding at the back. All studding and rafters are of $2^{\prime \prime} \times 4^{\prime \prime}$ hemlock or yellow pine. A $2^{\prime \prime} \times 6^{\prime \prime}$ girder runs the length of the building to support the rafters, its own weight being sustained every ten feet by $4^{\prime \prime} \times 4^{\prime \prime}$ posts, resting on concrete piers. The plates should be made of $2^{\prime \prime} \times 4^{\prime \prime}$ material doubled, and joints broken. 


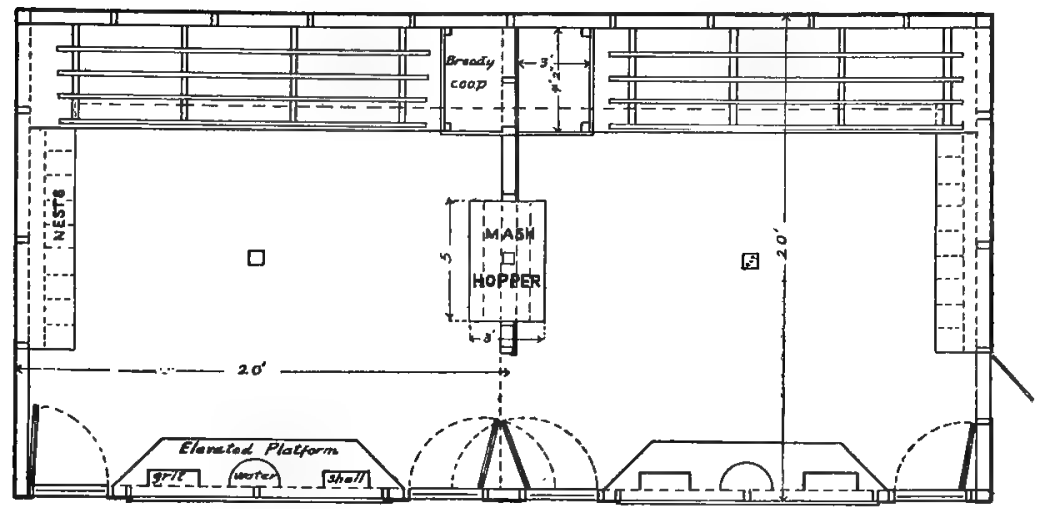

Cross Section.

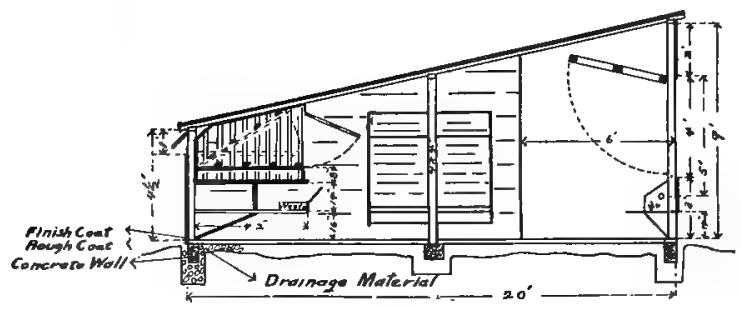

Front View.

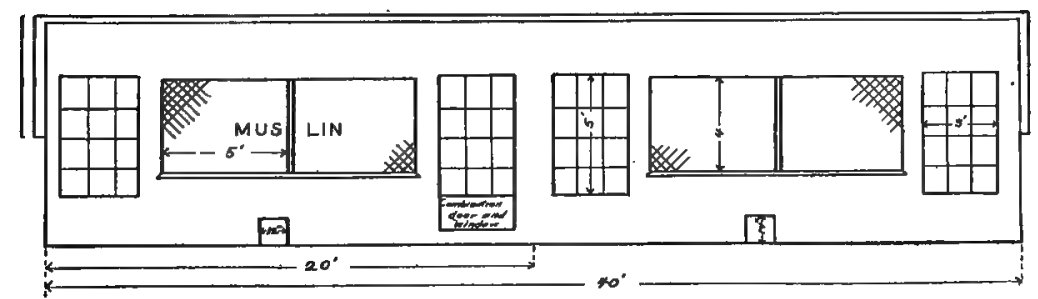

Fig. 116.-Working plans of a double section, multiple unit house.

All outside walls and roof are to be single boarded, preferably of eight- or six-inch tongued and grooved yellow pine; white pine could be used, but is more expensive. The roof 
and back wall should be covered with good roofing paper and all joints carefully lapped and cemented.

The muslin curtains in the front wall are hinged at the top so as to be lifted up. The three by five glass sashes are hinged at the side and open, as indicated on the floor plan. One window in each pen should be so constructed as to let that part of the wall be opened when desired; this makes a combination door and window, which will greatly facilitate cleaning, filling hoppers, etc., in an extremely long house.

The dropping boards, perches, and nests are best located on the back wall, the perches being hinged to the wall so that they may be hooked up when cleaning. The nests are darkened by a hinged door in front, which can be let down when the eggs are removed.

The partition wall between the units is built of boards, and extends to within six feet of the front wall, the remaining space being left absolutely open. This protects the birds from any drafts when on the roosts. If desired, portable light wire partitions may be used to separate the units. A large dry mash hopper should be built into this middle partition between each pair of units. If four or more units are built, it is only necessary to have a hopper in the center of each two units, the other dividing partition being used for nesting space. There is an elevated shelf below the muslin front to hold the water fountain, and hoppers for grit and shell.

When the house is completed the concrete floor should be laid according to specifications. Figure 116 shows the working plans of this house. The following materials are required to build it:

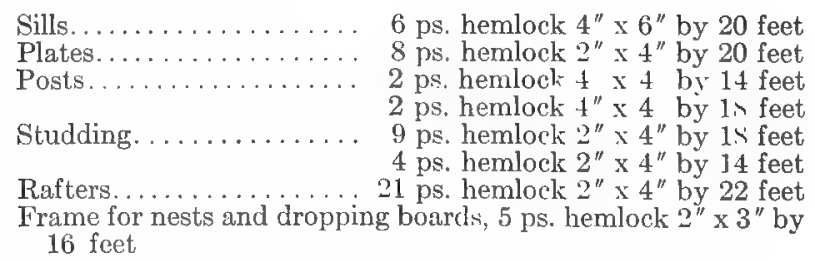


Roof, dropping boards, walls, and nests, 2,300 sq. ft., eightinch tongued and grooved yellow pine

Curtain frames and trim, 200 linear feet white pine, $1^{\prime \prime} \times 2^{\prime \prime}$

Nests, 100 linear feet white pine, $1^{\prime \prime} \times 4^{\prime \prime}$

Broody coop, one bundle plaster lath

Nails, 10 lbs. 20-penny wire, 50 lbs. 10-penny wire, 20 lbs. 8-penny wire

Approximate cost of the above.............. $\$ 75.54$

Roofing paper, 1,000 sq. ft., or 11 rolls at $\$ 3.00 \ldots \ldots \quad 33.00$

Four special sashes, $3^{\prime \prime} \times 5^{\prime \prime} \mathrm{ft}$, at $\$ 2.00 \ldots \ldots \ldots \ldots . \quad 8.00$

Muslin, 8 sq. yards at 20c. per yard............. $\quad 1.60$

Hardware, such as hinges, locks, hooks and wire.... 4.75

Foundation and floor:

Cement, 35 bags at 50c. each............. 17.50

Cinders or gravel, 30 yards at $\$ 1.00 \ldots \ldots \ldots \ldots \quad 30.00$

Sand, 5 cubic yards................... $\quad 7.50$

Total cost. . .......... \$177.89

Such a house is very economical when a poultryman wishes to keep only 100 birds, but intends to enlarge his plant in

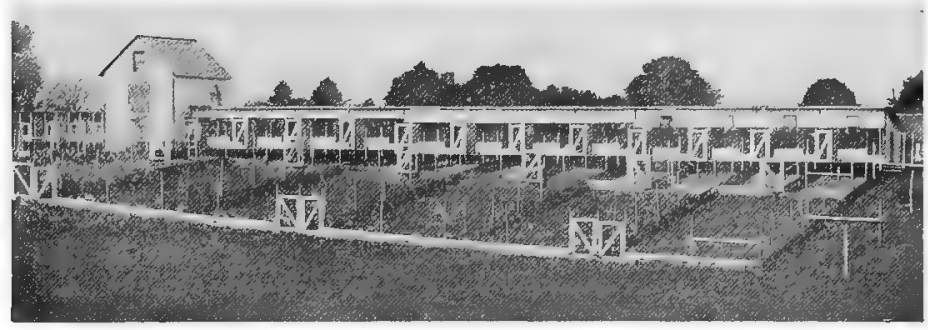

Fig. 117.-A long laying house, especially adapted to the large commercial flock for egg production or for many small flocks for breeding.

the future, the time elapsing before he does so depending, of course, on the success of his enterprise.

Long Breeding House.-Many poultrymen think it a good plan to have special breeding pens, each accommodating from twelve to fifty birds. These are best taken care of by building a long laying house. Figure 117 shows a common type used for breeding flocks. Here we have a house of the shed roof type, 16 feet wide and 144 feet long, divided into twelve pens, each pen being twelve by sixteen feet. On account of the slope of the ground the house drops ten 
inches to every forty-eight feet. Two solid partitions are built across the house, forty-eight feet apart, to break drafts. The arrangement of the dropping boards, nests, perches, etc., is very similar to that in other standard types. The openings in the front permit the use of both muslin and glass in standard proportions. The following is a list of materials required to build a forty-eight foot section of this type.

Foundation $2 \mathrm{ft}$. deep and eight inches wide: 20 bags cement,

2 cu. yards gravel, 6 cu. yards cinders

All framing hemlock or yellow pine

Sills:

8 ps. $2^{\prime \prime} \times 6^{\prime \prime} \times 20^{\prime}$ doubled

8 ps. $2^{\prime \prime} \times 6^{\prime \prime} \times 16^{\prime}$ doubled

3 ps. $2^{\prime \prime} \times 4^{\prime \prime} \times 16^{\prime}$

End and division studs:

10 ps. $2^{\prime \prime} \times 4^{\prime \prime} \times 8^{\prime}$

5 ps. $2^{\prime \prime} \times 4^{\prime \prime} \times 7^{\prime}$

10 ps. $2^{\prime \prime} \times 4^{\prime \prime} \times 6^{\prime}$

10 ps. $2^{\prime \prime} \times 4^{\prime \prime} \times 7^{\prime}$, doubled, for doors to hinge on

Side wall studs:

36 ps. $2^{\prime \prime} \times 4^{\prime \prime} \times 81 / 2^{\prime \prime}$

23 ps. $2^{\prime \prime} \times 4^{\prime \prime} \times 51 / 2{ }^{\prime}$

Extras for short pieces:

3 ps. $2^{\prime \prime} \times 4^{\prime \prime} \times 12^{\prime}$

Corner and division posts (doubled):

Rafters:

18 ps. $2^{\prime \prime} \times 4^{\prime \prime} \times 812^{\prime \prime}$

10 ps. $2^{\prime \prime} \times 4^{\prime \prime} \times 5 \frac{1}{2}$

25 ps. $2^{\prime \prime} \times 4^{\prime \prime} \times 18^{\prime}$

Girders (doubled):

4 ps. $2^{\prime \prime} \times 4^{\prime \prime} \times 20^{\prime}$

Plates:

2 ps. $2^{\prime \prime} \times 4^{\prime \prime} \times 8^{\prime}$

8 ps. $2^{\prime \prime} \times 4^{\prime \prime} \times 20^{\prime}$

4 ps. $2^{\prime \prime} \times 4^{\prime \prime} \times 8^{\prime}$

Roof boards, 900 sq. ft. shiplap

Roof paper, 800 sq. ft.

Supports for dropping boards, etc.:

32 ps. $2^{\prime \prime} \times 3^{\prime \prime} \times 4^{\prime}$

Perches:

20 ps. $2^{\prime \prime} \times 4^{\prime \prime} \times 3^{\prime}$

12 ps. $2^{\prime \prime} \times 2^{\prime \prime} \times 10^{\prime}$

700 sq. ft. shiplap for inside sheathing, dropping boards, and partitions

250 linear $\mathrm{ft}$. shingle laths for nest platform

Siding, 550 sq. ft. novelty siding, four cloth curtains $4^{\prime \prime} \times 5^{\prime \prime}$; four window sashes, $5^{\prime \prime} \times 3^{\prime \prime}$ 


\section{BEST TYPES OF POULTRY HOUSES}

Trimming, doors, nest, etc.:

200 linear feet $1^{\prime \prime} \times 2^{\prime \prime}$ dressed white pine

100 linear feet $1^{\prime \prime} \times 3^{\prime \prime}$ dressed white pine

500 linear feet $1^{\prime \prime} \times 4^{\prime \prime}$ dressed white pine

200 linear feet $1^{\prime \prime} \times 8^{\prime \prime}$ dressed white pine, matched

3 prs. double swing butts

5 prs. 5 -inch strap hinges for doors

12 prs. 4-inch strap hinges for windows, curtains and small doors

5 barn door latches

The total cost of this material will be approximately $\$ 217.00$, or about $\$ 4.50$ per running foot.

This makes the cost per bird for all material $\$ 1.12$, allowing four square feet to a bird. A house of this kind is admirably

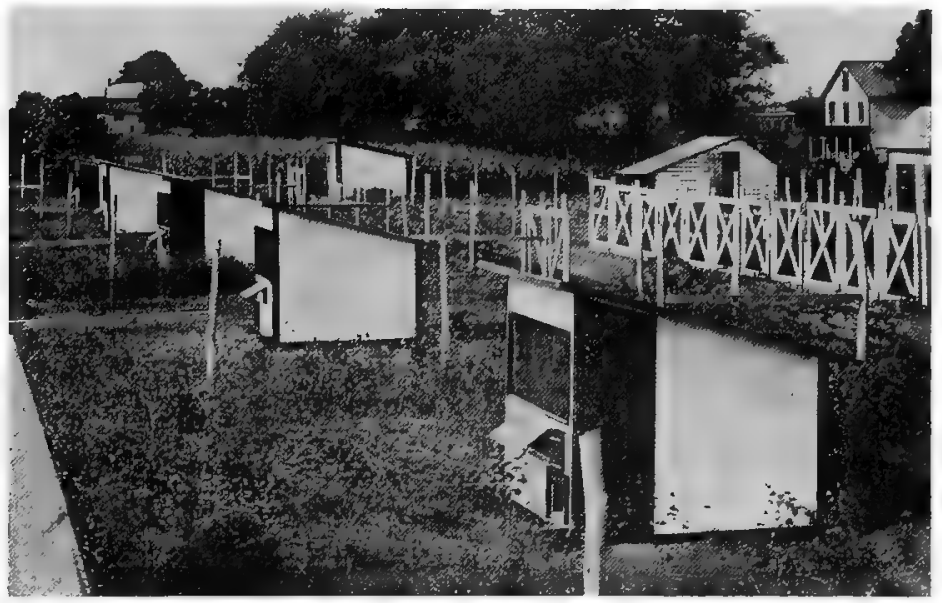

FIG. 118. - A group of small-flock poultry houses such as were fully described in Chapter XVII. They are especially useful to the suburban or small-flock poultry keeper.

adapted for special matings during the breeding season, and can be utilized the balance of the year for ordinary laying flocks.

The City Lot Poultry House. - The amateur poultry keeper and the city lot poultryman rarely keep more than 15 to 25 birds. Figure 118 shows a group of houses adapted to this purpose. They are described in detail in Chapter XVII, and a list of materials is given. This house can be built for about $\$ 20.00$. 
Scratching Shed House.-In many sections the prevailing type of poultry house is known as a scratching shed type, from the fact that an open shed adjoins the laying room. The floor of this is kept covered with litter, and in winter when they must be confined the birds have access to it. Figure 119 shows a scratching shed house with a broken span roof. It is forty feet long and ten feet wide, and is divided into four sections, the two in the center being the laying and roosting quarters, and the outer ones open scratching sheds. Such a house is ample for 100 hens. It is considerably more

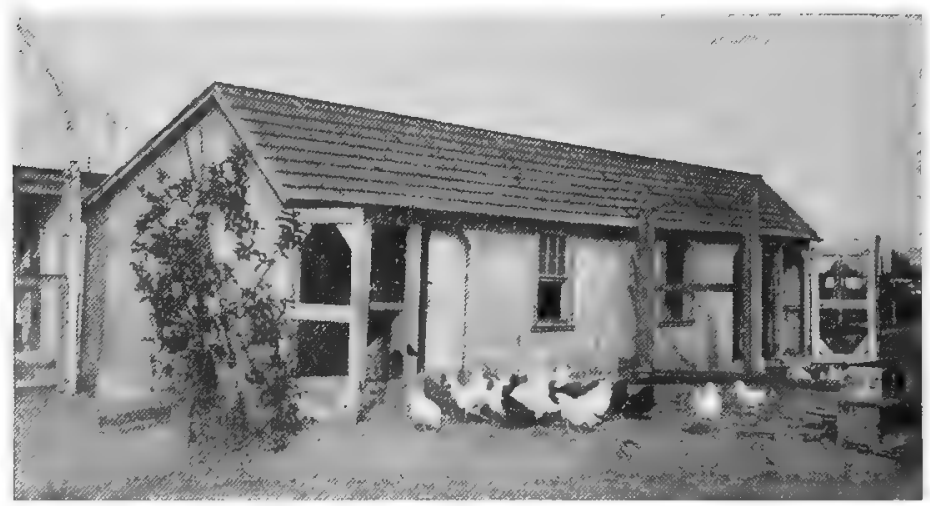

Fra. 119.-A double-pen, scratehing shed, laying house with \& broken or twothirds span roof.

expensive than the multiple unit type, the material costing $\$ 130.00$. This house is used in cold, bleak climates, where the birds must be closely confined for many months.

A Gable Roof House.-Gable roof, or even span, houses are quite popular. They cost more to build than the shed roof kind, but, owing to the area in the peak are usually woll ventilated, and cooler in summer than the shed roof house. They are apt to be cold in winter, unless special precautions are taken against excessive cold. Figure 120 shows a good type of gable roof house. This house has a floor surface of sixteen by thirty-two fcet, and is six feet high to the 
plate. It has a capacity of from eighty to one hundred birds, depending upon the breed, but costs more than the multiple unit house.

Six different types of poultry houses have here been described. All are useful and satisfactory styles. It is hoped that the pupil, by close observation, will now be able to select the one best adapted to his purpose; and the best type for each individual poultryman will depend greatly upon the number and the kind of birds he expects to keep.

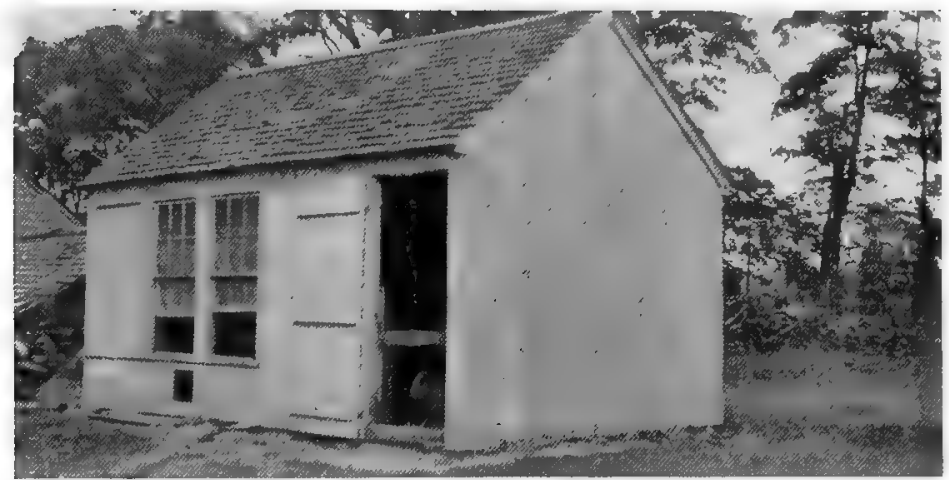

FrG. 120.-A type of gable or even span poultry house which is especially common in southern New England.

\section{LABORATORY EXERCISES}

Exercise No. 53.-A Study of Poultry Houses.-Take the class on a trip to near-by poultry farms to study poultry house types and methods of construction. As many different types as possible should be visited. The possibilities and cost of each should be discussed on the ground. Each pupil should have a notebook and take notes. The owners of the plants visited will usually be willing to discuss them with the class and give reasons for their choice of houses.

Exercise No. 54.-Drawing Poultry Appliances.-One or more periods can be profitably used in drawing parts of poultry equipment, such as hoppers, nests, perches, etc. Types of roofs and simple outline drawings of house designs 
can be made which if kept by the pupil will often be of value in the future. Such work should be very simple. If drafting is included as a part of the course of study, such work should rightfully be included in that course.

Exercise No. 55.-Materials for Poultry Houses.-One or more exercises devoted to figuring materials required to fill a certain specification will be very helpful. A house of a certain size and design can be described by one of the pupils and then the entire class with the aid of the teacher can figure out piece by piece the kind, size, and amount of material required to build it. A house which is owned by one of the students, or which one might wish to build will create more interest. Figure materials in the following order: Sills, posts, plate, studding, rafters, walls, roofs and miscellaneous material. For values it is well to secure figures for lumber from some lumber yard or local sawmill. At this time the meaning of board feet and ways of measuring lumber should be explained.

\section{THOUGHT QUESTIONS}

1. Name three factors which especially affect the kind and type of poultry house to be built.

2. In ancient times where did poultry stay at night?

3. Describe the evolution in poultry house design from early time until the present age.

4. Why is the modern fresh-air poultry house so efficient?

5. Describe briefly the modern standard type of poultry house.

6. Enumerate three different types of roofs which are commonly used for poultry houses.

7. What are the advantages of the shed roof over the other types of roofs?

8. What materials are sometimes used for poultry houses?

9. Which material is cheapest and best?

10. Briefly describe the features of the small-flock colony laying house.

11. What is the cost of the small-flock colony laying house?

12. Describe the multiple unit laying house.

13. Discuss the usage and cost of the multiple unit house.

14. What are the features of the long breeding houses?

15. What is the cost of the long breeding house?

16. Describe briefly the scratching shed house mentioned in the text.

17. What are the possibilities of the scratching shed house?

18. Describe briefly the city lot poultry house.

19. What are the advantages and disadvantages of a gable roof house?

20. Describe a type of poultry house which is common in your community and is giving satisfaction.

Reference.-United States Farmers' Bulletin 574, Poultry House Construction. 


\section{PART IV \\ FEEDING}

\section{CHAPTER XX}

\section{ELEMENTS OF THE BIRD'S BODY AND COMPOSITION OF ITS FEED}

Chemical analysis shows a close similarity between the composition of the bird's body and the composition of its feed. This similarity is chiefly apparent in the kinds of material present. Different feeds vary greatly in their composition. Birds of different ages, and of different breeds, also vary in their structural elements. Yet materials varying in composition and especially suited to the different requirements of feeding may be found. A general knowledge of the composition of the birds, and of available feeds, is necessary in compounding a practical ration. Birds generally are of active temperament, and endowed with great energy. This temperament and energy mean the consumption of a large amount of materials to produce heat. They also have an extremely high body temperature, which in turn calls for feed of a certain composition. They also yield products whose heavy weight is out of all proportion to their body weight. This explains why the laying hen consumes so much more feed than the one which does not lay.

\section{COMPOSITION OF THE BIRD'S BODY}

The bodies of all animals, birds included, consist of four well defined groups of elements, commonly classed as protein materials, fatty materials, ash, and water. The following discussion will tell us something about these materials, and the amounts thereof which are found in the body (Fig. 121). 
Protein.-Protein is the chief element in all living tissues. Common examples of it, as seen in the bird's body, are lean meat, gristle, feathers, etc. A common example, as seen in the product of the bird's body, is the white of the egg, or albumen. It is complex in its nature, consisting of nitrogen,

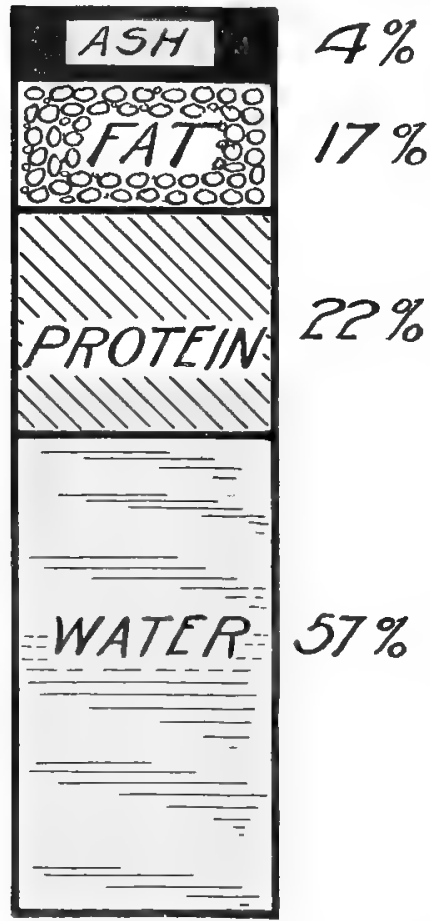

FIa. 121.-Diagram showing the upproximate composition of the bird's body. Note the large amounts of water and protein. oxygen, hydrogen, carbon, and sulfur. It is characteristic because of the large amount of nitrogen which it contains, this being about fifteen per cent. No nitrogen is found in either of the other three groups here classified. The body of the average bird contains approximately 22 per cent of protein.

Fat.-As an example of fatty tissue, we have the yellow fat in the abdominal parts of a hen. Fatty tissue consists of minute cells, surrounded by a tough cell wall. The oil or liquid in the center of this wall is the fat. Fat is in reality stored up oil, or a reserved feed supply. Should the bird become short of feed, it would draw upon this fat and use it to nourish the body. In the body of the average bird, there is from 15 to 20 per cent of fat, and much more than this in old fowls, capons, and roasting chickens which are especially fattened for market.

Ash.-Ash is a true mineral matter. As the name implies it is the material which would be left if the birl's carcass were burned by fire. The ash in the body is in the skeleton 
or bony framework and is composed largely of lime and phosphorus, the body of the average bird containing about 4 per cent of ash. It is especially desirable in the feed of a young growing animal, since it is needed for the formation of the skeleton.

Water.-This is in the body in large quantities, the body of the average bird containing more than 50 per cent. It is diffused between and within the cells, and also permeates the entire body structure. Water is composed of two chemical elements, hydrogen and oxygen, two parts of the former being combined with one part of the latter to form the liquid. The general composition of the bird's body varies with its age, breed, and activity. The older it becomes, the bigger the ash content, and the less the water and fat in its body; this is especially true of male birds. The White Leghorn breed, which is very active, develops considerable tough, fibrous tissue and little of the tender, juicy flesh which is unexcelled for eating. Hence, the more active the breed, the tougher and more fibrous becomes the meat.

\section{COMPOSITION OF FEED MATERIALS}

Materials which are valuable for poultry feeding are similar in composition to the constituents of the body which they furnish. The same compounds found in the feeds are present in the body. To this number a new one is added, namely carbohydrates. In the following paragraphs we will discuss the five compounds found in feeding stuffs,protein, carbohydrates, fat, ash, and water.

Protein.-Common examples of protein feeds are meat scraps, linseed meal, cottonseed meal, and other so-called concentrated by-products. Protein in feeds is of the same chemical composition as when found in animals (Fig. 122). It is essentially a nitrogenous material, and is the determining factor in poultry feeding for all purposes. In the feeding of birds it has many uses, but it is essential for the formation 
of flesh, that is, lean meat, and is most necessary for egg production. Eggs contain over twelve per cent of protein, therefore necessitate a rich, nitrogenous ration, and protein must be supplied in the feed to the full amount required by the animal. Experiments show that its place can not be taken either by carbohydrates or fat.

Carbohydrates.-Carbohydrates are not found in the animal's body as such. They are, however, a very common constituent of the grains, corn, barley, etc. In composition they are somewhat similar to protein, except that they con-

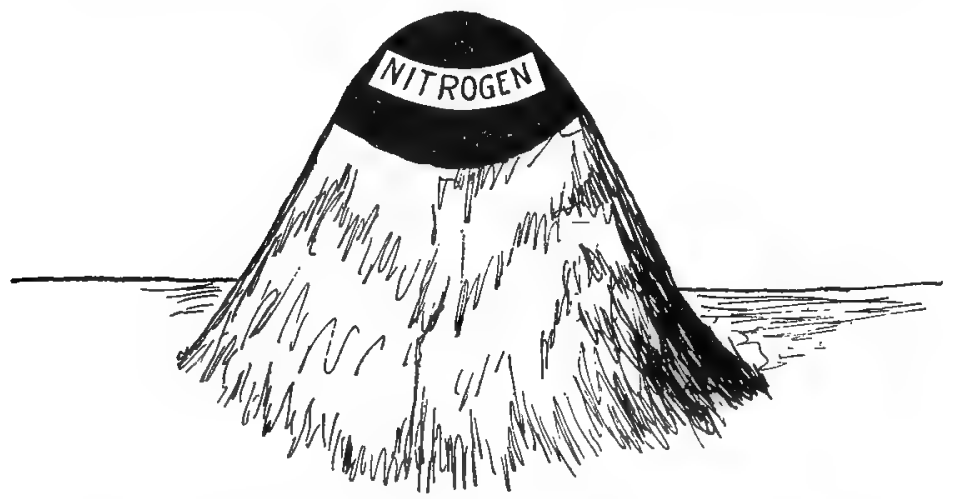

FIG. 122.-Diagram showing the approximate amount of nitrogen in protein. Assuming that the whole pile is made up of protein the amount of nitrogen present would be represented by the black portion on top.

tain no nitrogen. Carbohydrates, as the name implies, contain the chemical elements of carbon and hydrogen and oxygen. The uses of carbohydrates are threefold. Taken into the body of the bird, they are digested and assimilated, and thereby energy is developed which enables the bird to move. After digestion a portion of the carbohydrates is used to maintain the heat of the bird's body. The amount of carbohydrates fed in excess of the amount of heat and energy developed, is stored up in the body as reserve material. This reserve supply usually takes the form of fatty tissue. 
The carbohydrates in the average ration will generally be sufficient, for they are in all farm-raised feeds (Fig. 123). In balancing a ration an excess of carbohydrates must be avoided, and this can best be done by giving concentrated protein feeds.

Fat.-The fat in feed is quite similar in composition to that found in an animal's body; in one case it is a vegetable oil, and in the other, animal oil. Its uses are identical with those of the carbohydrates, and need not be considered separately.

Water.-Water is a common element in all feeding stuffs. Since the bird's body contains more than fifty per cent of water, and the egg which is produced more than sixty-five per cent, it is essential that large amounts of water be given the birds. There is a very high water content in young, tender,

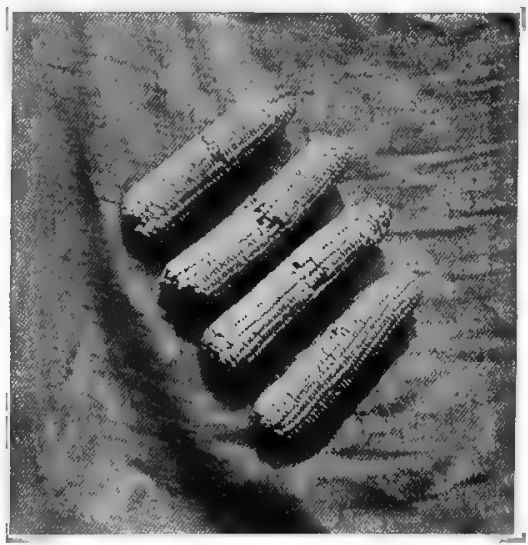

FIG. 123.-Corn which can be raised on every American farm is one of the best sources of carbohydrates. It can be fed to birds either whole, cracked, or as cornmeal in the dry mash. growing plants. Birds on free range get large quantities from this source. There is also considerable water in fresh cut fodders, but, owing to the fact that they wilt quickly, they do not furnish as much water as when the birds eat them directly from the root. The water contained in growing plants often runs as high as 80 to 85 per cent. In dry grains and hay much of the water has evaporated, and there is left only about ten to twelve per cent. When given to the birds in feed, water serves many purposes. First, it is desirable as an appetizer, for it is a well-known fact that succulence or juiciness increases the palatability of feed. 
Water, by circulating and filling up the tissues of the body, distends it and makes it appear plump. Water also plays an important part in regulating the body temperature. Assimilation, or the diffusion of feed materials through thin walls, is greatly promoted by the water ingested. Water, also, is the vehicle by which materials are conveyed from one part of the body to another. These facts demonstrate that some knowledge of the chemical composition of the body is essential to an intelligent study of feed materials themselves.

\section{LABORATORY EXERCISES}

Exercise No. 56.-Composition of a Bird.-Kill a fat hen. Cut her up into six or eight pieces by severing the wings, legs and neck. Open the abdominal cavity and separate some of the body fat. With the material thus afforded it will be possible to show to the class portions of the body containing each of the compounds which go to make it up. Lean meat and feathers will illustrate essentially a nitrogenous product. The body fat may be closely examined as to structure. The bones will serve as an example of ash or mineral matter. If scales are available the pieces can be weighed and then placed in a double boiler and heated for a few hours, after which the flesh should be weighed again. How can the loss of weight be accounted for?

Exercise No. 57.-Composition of Feeds.-Feeds of the different groups should be secured and can be used in connection with the study of their composition. The difference between dry and green fodder can be illustrated by mowing some grass on the school lawn and weighing it immediately; then spread it out thin and allow the sun to dry it for two days. When it is thoroughly dry, weigh it again. How can the difference in weight bo accounted for? In which condition do the poultry like the grass best, green or dry? Why? 


\section{THOUGHT QUESTIONS}

1. Discuss the similarity between the character of feed given to poultry and character of the product desired.

2. Discuss the temperament and energy of birds as it affects their feed requirements.

3. Enumerate the four compounds which are found in birds' bodies.

4. Give some examples of protein.

5. Of what chemical elements is protein composed?

6 . What percentage of protein is nitrogen?

7. What percentage of the bird's body is protein?

8. Give some common examples of fat.

9. Of what is fat composed?

10. What is an average per cent of fat in a bird's body?

11. What is ash?

12. Give an example of ash as seen in the bird's body.

13. What per cent of the bird's body is ash?

14. What portion of the bird's body is water?

15. Of what two chemical elements is water composed?

16. How does age, breed, and activity affect the composition of the bird's body?

17. Enumerate five compounds which are found in feeding stuffs.

18. Give an example of protein feeding stuffs.

19. For what purpose are protein feeds necessary?

20. Eggs contain how much protein?

21. What are carbohydrates?

22. Mention some common carbohydrate feeds.

23. Enumerate the uses of carbohydrates in the bird's body.

24. What is fat?

25. What are the functions of water?

26. How much water in green growing plants? How much in dry fodder?

Reference.-United States Farmers' Bulletin 22, Feeding Farm Animals. 


\section{CHAPTER XXI}

\section{DIGESTION, ASSIMILATION, AND NUTRITION}

BIRDs, like all other animals, in order to grow and produce must eat. The bird in its ability to produce is somewhat like a machine. The feed it consumes is the raw material, and the raw material is first digested, then assimilated, and produces the finished or manufactured product. That product is the egg. Birds differ from ordinary machines, in that they use some of the raw material to repair the body. There are three processes in this nourishing and building up of the body; namely, digestion, assimilation, and nutrition.

Digestion.-Digestion may be defined as a process in which raw material is so changed that it can be assimilated by the blood, and may furnish nutriment to the body. Digestion is largely a process of chemical changes. The digestive organs of the bird are the parts used to perform this operation; and these organs, taken as a whole, are called the alimentary tract, or the digestive system.

Assimilation.-Assimilation may be defined as a process whereby material already digested is taken up by the blood vessels and arteries. This assimilation takes place in the lower part of the alimentary tract, or the intestines, and is largely brought about by diffusion.

Nutrition.-Nutrition may be defined as the process of transporting and distributing assimilated material to all parts of the body. It is the ultimate process in the promotion of growth, the repair of waste, and the yielding of a product outside of the body. Blood is one of the leading carriers of nutriment.

Nutrients.-Nutrients is a term used to designate certain groups of feed materials which are eaten by animals. These 218 
feed nutrients are classed as protein, carbohydrates, fat, and ash. They must be present in the feed in the right proportion if the body is to be properly nourished.

\section{THE DIGESTIVE TRACT IN BIRDS}

The digestive tract is made up of many different organs and groups of organs, each with its own function to perform and each constructed especially for the work which it has to do.

Division of the Work of Digestion.-The digestive tract performs four different kinds of work, and the organs of digestion are so designed and constructed that each one is especially fitted for the work assigned to it. One group of organs, called the mouth parts, is for seizing the feed. Another organ, known as the gizzard, is used for grinding the feed, and takes the place of the teeth in most animals. The upper part of the digestive tract performs, to a greater or less extent, the actual work of digesting the feed, while, as was previously mentioned, the lower part is especially designed and adapted to promote the assimilation of the digested material into the blood (Fig. 124).

Mouth Parts.- The mouth parts are hard, horny growths which project outside of the body. In land birds, the mouth part is called the beak, in water birds, the bill. The beak of the land bird is sharp and pointed, the upper and lower parts closing tight together. They are designed to pick up grains and to cut blades of grass. In water fowls the bill is wide and blunt, and is especially designed for scooping in the mud or digging in the wet soil.

The Gizzard.-The function of the gizzard is to grind the feed, and this is quite necessary since the bird has no teeth with which to chew it. Birds subsist chiefly upon hard grains, like corn and wheat, which must be subjected to considerable grinding before they are reduced to fine particles. The gizzard looks very much like a large ball, slightly flattened, 
and is, in a full grown fowl, about two or three inches in diameter. It is dark red in color, and often covered with fat.

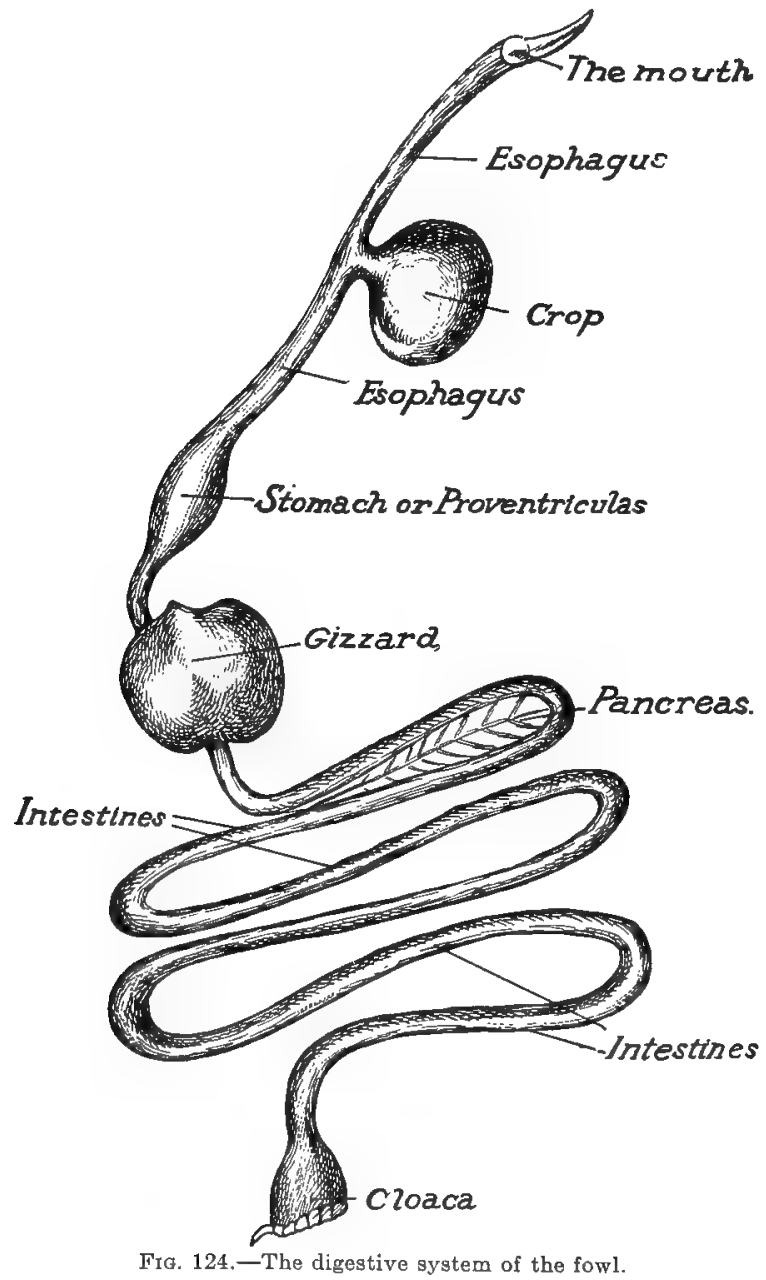

The bird eats considerable grit, which immediately finds its way into the gizzard, and this grit, assisted by the action 
of the muscular walls, grinds the feed. The feed is whirled around and around in the gizzard until it becomes a soft mass, when it passes into the intestines.

Other Digestive Organs.-Digestion is carried on, more or less, in all parts of the digestive tract, the chief divisions of which, named in the order in which the feed passes through them, are as follows: The mouth, œsophagus, crop, stomach, gizzard, and intestines. In practically all of these organs the changes of digestion are brought about by the solvent action of fluids, or chemical secretions, which ooze from the numerous membranes that line the walls of the organs. The secretions act upon the feed, and convert it into more easily digested forms. Some of the fluids are acid in reaction, others are alkaline. Some act upon one nutrient, some on another.

Assimilation.-Assimilation takes place by diffusion and in the lower portion of the intestines. By diffusion is meant the passing of a liquid through a porous membrane. The intestinal walls are covered with little hairs, called villi. The walls of the intestine and the so-called villi are full of small capillaries. The only partition lying between the blood and the digested mass is the thin wall of these blood vessels, and the digested feed has now become so fine that it can pass through this membrane into the blood.

Nutrition.-When assimilated by the blood it is carried to all parts of the body for the process of nutrition. After it is digested, most of the nutriment is transported from the intestines to the arteries just outside of the heart, by means of a large duct, or tube, called the thoracic duct. This thoracic duct pours into the arteries large quantities of digested food material. The heart is the center of the circulating system, being neither more nor less than a pumping engine. It receives from the veins the impure blood which comes from all parts of the body, and this, after passing through the right side of the heart, is sent to the 
lungs, where it gives off the poisonous carbon dioxide and takes in oxygen. After being purified in the lungs, the blood is brought back to the left side of the heart from which it is once more pumped to all parts of the body. So it nourishes and builds up the tissues. From this brief discussion of feed consumption and assimilation may be noted the close analogy between the bird and the machine, which, if borne in mind and followed, will lead to a better knowledge of the requirements of individual fowls for different types of production.

\section{LABORATORY EXERCISES}

Exercise No. 58.-Osmosis a Process of Assimilation.Fill a small paper bag full of a strong salt solution. Carefully tie the top and place the bag in a pail of clear, fresh water. After remaining in the water for ten minutes carefully remove and taste of the water in the pail. How did the salt get into the fresh water?

Exercise No. 59.-A Study of the Digestive Tract.-Dissect a mature fowl. Carefully remove the entire digestive tract, including liver and pancreas, without rupturing any part. Lay the organs out carefully on a table or drawing board in such a way that the course of feed through same can be described. The function of the organs and the location may be discussed very clearly in this way.

\section{THOUGHT QUESTIONS}

1. In what can a bird be likened to a machine?

2. Define digestion.

3 . Where does digestion take place?

4. Define assimilation.

5. Where does assimilation take place?

6. Define nutrition.

7. What is a nutrient?

8. Of what is the digestive tract made up?

9. What are the four different types of work performed by the digestive tract?

10. Describe the mouth parts of land and water birds.

11. What is the function of the beak? 
12. Describe the location and appearance of the gizzard.

13. What is the function of the gizzard? How does it do its work?

14. Enumerate the digestive organs in the order in which the food passes through.

15. What is the cesophagus?

16. Where is the crop located? What is its function?

17. Where is the stomach located and what is its function?

18. Describe the process of assimilation.

19. Describe briefly the process of nutrition.

20. Describe the course that the blood takes in passing once through the circulatory system.

References.-United States Farmers' Bulletins: 142, The Principles of Nutrition and Nutritive Values of Foods; 506, Food of Some Well Known Birds of Forest, Farm and Garden. 


\section{CHAPTER XXII}

\section{COMMON POULTRY FEEDS}

IT is not the object of this chapter to describe every kind of poultry feed obtainable, but to enumerate and classify those most common and necessary. The pupil should try to become familiar with feed types, since by cultivating his powers of observation along this line he will learn to distinguish good feeds from inferior ones.

\section{SIMPLE CLASSIFICATIONS OF POULTRY FEEDS}

All feed material contains more or less protein, carbohydrate, fat, ash, and water. A classification based on the proportion of these ingredients in different feeds, will be of assistance in compounding rations. Many feed materials belong to two groups; for example, cereals both contain protein and are rich in carbohydrates. We will follow the plan of grouping such feeds in the class to which they more prominently belong.

Animal and Vegetable Feed.-All true feed material is from either animal or vegetable sources. Meat scrap is a good example of a valuable poultry feed which is of animal origin. The grains are good examples of vegetable feeds.

Protein Feed.-Protein is the element which determines the value of a ration. This is true whether fed for flesh or for egg production. Many varieties of feed fall into this group; only a few, however, are special protein carriers. Protein feeds are hard to grow at home, therefore many of them must be purchased, and they are rather expensive.

Meat Product.-Meat products of animal origin constitute our main supply of protein feeds, meat scrap, meat meal, and dry blood being the three leading forms. Meat 
scrap is composed largely of the refuse of slaughter houses, which is boiled under pressure, then put in a large press, and squeezed until all the liquid is forced out. Meat scrap contains lean meat, fat, and considerable bone. Meat meal is meat scrap ground into small particles. Dried blood is a refuse product from slaughter houses, sometimes but not commonly used as a poultry feed. It is dark in color, and finely ground.

In purchasing meat products, quality should be the first consideration. Meat scrap is more used than any other meat product. It varies greatly in quality, but there is a high grade meat scrap which contains 50 per cent of protein, and is put up most carefully. There is a lower grade which yields from 30 to 35 per cent of protein, but is often poorly rendered, and contains products which are undesirable in the rations. Good meat scrap should contain about 50 per cent of protein. Dry granulated bone is another protein product which yields 25 to 30 per cent of protein. In certain sections where available, fish scrap is utilized, much of it being derived from the manufacture of glue. Fish scrap contains in the neighborhood of 40 per cent protein. Milk albumen is another highly nitrogenous feed material; it is manufactured especially for poultry feeding. The protein content varies considerably, 50 per cent being the average analysis.

\begin{tabular}{|c|c|c|c|c|}
\hline \multicolumn{5}{|c|}{ Meat Products } \\
\hline & Dry Matter & Protein & Carbohydrates & Fat \\
\hline Meat Scrap. High Grade. & 90 & $50-60$ & none & 25 \\
\hline Dry Granulated Bone. . & 92 & $25-30$ & none & 3 \\
\hline Fish Scrap ....... & 90 & $35-50$ & none & 15 \\
\hline Milk Albumin & 85 & $20-50$ & none & 3 \\
\hline
\end{tabular}

Concentrated Vegetable Products.-There are five concentrated by-products which on analysis yield a high protein content, and are used quite extensively for poultry feed. Cottonseed meal ranks high as a protein carrier, containing 42 per cent of protein. The meal is of a very bright yellow color. It is a by-product from the manufac- 
ture of cottonseed oil from cottonseed. It is not used extensively in poultry rations as it is apt to contain a great deal of undesirable products. Soy bean meal ranks next as a protein carrier, averaging 35 per cent of protein. It is a grayish-yellow meal, made from the soy bean seed, which must be finely ground when fed to poultry. It is not used extensively owing to the limited supply. Linseed oil meal is a common protein carrier, containing about 32 per cent of protein. It is a dark gray meal, exceedingly fine in texture, the by-product resulting from the manufacture of linseed oil from flax seed. One of the most common sources of vegetable protein is gluten meal, which yields 30 per cent of protein. It is a yellow meal, lighter in color than cottonseed meal, and is a by-product from the manufacture of starch from corn. It is probably more used than any other material as a source of vegetable protein. Buckwheat middlings is another highly concentrated product, not as yet much used in poultry feeding. It is a by-product of the manufacture of buckwheat flour from buckwheat. Analysis shows about 28 per cent of protein.

\begin{tabular}{|c|c|c|c|c|}
\hline \multicolumn{5}{|c|}{ Mill Products } \\
\hline & Dry Matter & Protein & Carbohydrates & $F_{\varepsilon}$ \\
\hline Cottonseed Meal. & 92 & $40-45$ & 25 & \\
\hline Soy Bean Meal. & 90 & $34-36$ & 30 & \\
\hline Lindseed Oil Meal. & 90 & $32-34$ & 35 & \\
\hline Gluten Meal...... & 92 & $28-30$ & 45 & \\
\hline Buckwheat Middlings. & Si' & $28-30$ & 40 & \\
\hline
\end{tabular}

\section{CARBOHYDRATE FEEDS}

This group comprises a large number of valuable feeds, all of the cereals belonging to this class. Carbohydrate feeds can be, and are, largely raised at home. None of them come from an animal source, not being found in animals. The carbohydrates which are most commonly found in poultry feed are starch and sugar.

Corn and Its Products.-Corn is the most widely used poultry feed. It is raised extensively on most farms, and is 
often fed to poultry to the exclusion of all other grains. This is poor policy, for it will not conduce to good egg production. Corn is not a well balanced ration. It averages 70 per cent of carbohydrates, which is too high a carbohydrate content to be fed exclusively, while the protein content is small. Four kinds of corn are sometimes used for feed; these are dent, flint, sweet, and pop corn (Fig. 125). Dent and flint are most common, while the two latter are in great demand for other purposes. Corn may be fed either whole, cracked, or ground up into meal. When whole or cracked it is usually fed in the litter; when as corn meal, in the mashes.

Composition of Corn

$$
\begin{array}{ccc}
\text { Dry } & \text { Pro- } \\
\text { Matter } & \begin{array}{c}
\text { bahy- Fat } \\
\text { drates }
\end{array}
\end{array}
$$

Corn (Dent). $90 \quad 10 \quad 70 \quad 5$ Corn (Flint). $91 \quad 10 \quad 70 \quad 5$

\section{Wheat and Its Products.-} Wheat is the best exclusive feed for birds. It is palatable, highly nutritious, can be raised easily, and is relatively cheap (Fig. 126). It contains 71 per cent of carbohydrates, while the protein content is much higher than in corn.

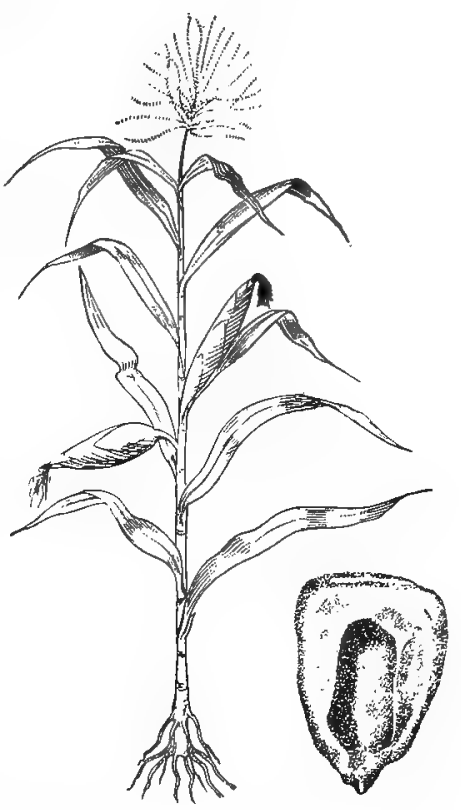

Fig. 125.- - The characteristic growth of the corn stalk and one corn kernel, much enlarged. (Dent variety.)

There are two kinds of wheat, winter and spring, winter wheat being the best. Wheat is used quite extensively in the scratching rations for poultry.

Bran and Middlings. - These are two by-products from the manufacture of wheat flour. They contain about 15 per cent of protein and 55 per cent of carbohydrates. They consist 
largely of the outer shell of the wheat kernel, and are rather coarse in texture. Wheat bran is used as the base of all poultry mashes, and is especially valuable for baby chick feeding.

Wheat and Its Products

\begin{tabular}{|c|c|c|c|}
\hline & Dry Matter & Protein & Carbohydrates \\
\hline Wheat & 90 & 12 & 71 \\
\hline Bra & 88 & 15 & 54 \\
\hline t Middlings. . & 88 & 15 & 60 \\
\hline
\end{tabular}

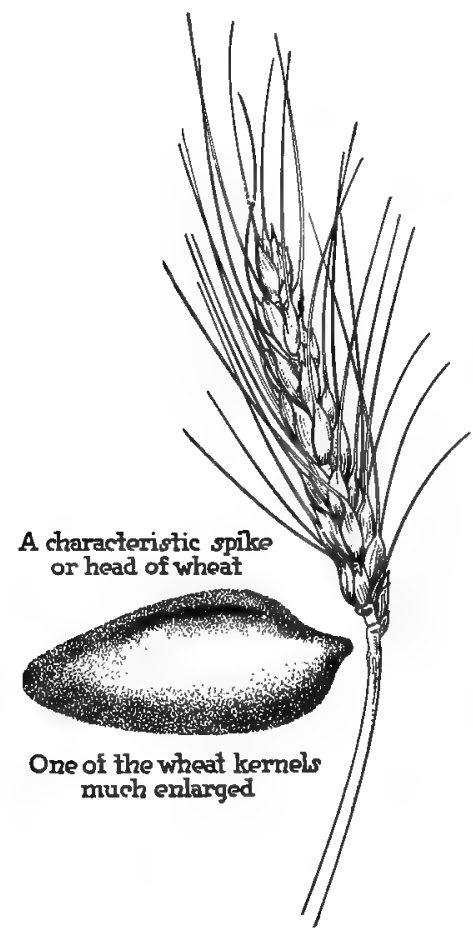

Fia. 126.-Wheat is one of the best single poultry feeds.
Oats and Its Products.Oats are fed quite extensively for they seem to be relished by the birds, and are readily raised at home. Oats contain 60 per cent of carbohydrates while the protein content is much higher than in corn, and about equal to that in wheat. Oats are generally fed whole in the scratch litter, or ground in the mash (Fig. 127). Oatmeal and rolled oats often form the exclusive feed of young chicks. Clipped oats are whole oats from which the sharp spikelet of the husk has been clipped. When available these are superior to whole oats. Oats contain the following percentages: Dry matter 89 , protein 12 , carbohydrates 60 , fat 5 .

Buckwheat.-Buckwheat is used only to a limited extent. It contains 65 per cent of carbohydrates, but an objection 
is the hard, thick shell. This grain contains the following percentages: Dry matter 88, protein 10, carbohydrates 65 , fat 2.

Barley.-Barley is sometimes substituted for wheat. It is not grown or fed extensively in America, but is one of the leading grain crops of Europe (Fig. 128).

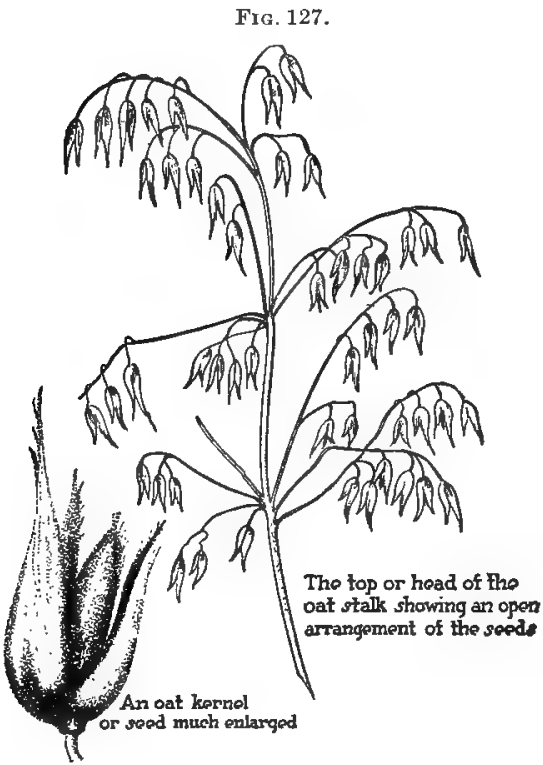

FIG. 128.

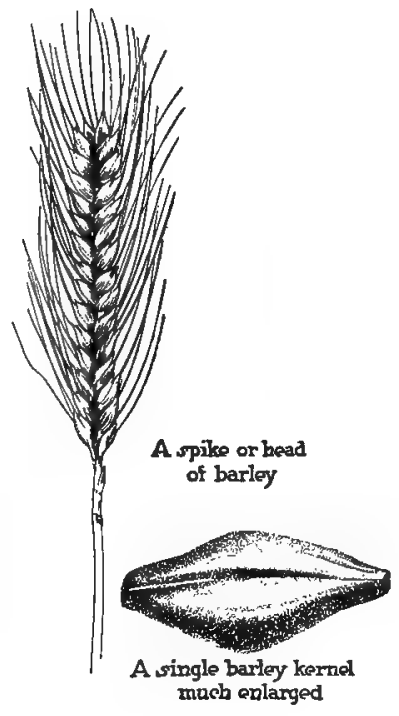

Fig. 127.-Many oats are fed to poultry, as they are raised in large quantities

FIG. 128. - When it can be secured at a reasonable price barley makes an excellent poultry feed.

There are many other carbohydrate grains which are scarcely familiar enough to merit mention. Common examples of these are sorghum, broom corn, and kaffir corn. Where these can be obtained at a nominal cost, they can be profitably used in the grain ration. Barley grain contains: Dry matter 90 per cent, protein 12, carbohydrates 70 , fat 2. 
Potatoes.-Potatoes are examples of carbohydrate feed, containing about 20 per cent. As poultry feed, their use should be limited to small and cull potatoes, and these only in small amounts, as they are rather soft, and not easily digested. The composition of potatoes may be expressed in the following percentages: Dry matter 20, protein 2, carbohydrates 18, fat 0 .

Dry Beet Pulp.-Beet pulp is a by-product from the manufacture of beet sugar from sugar beets. Dried beet pulp

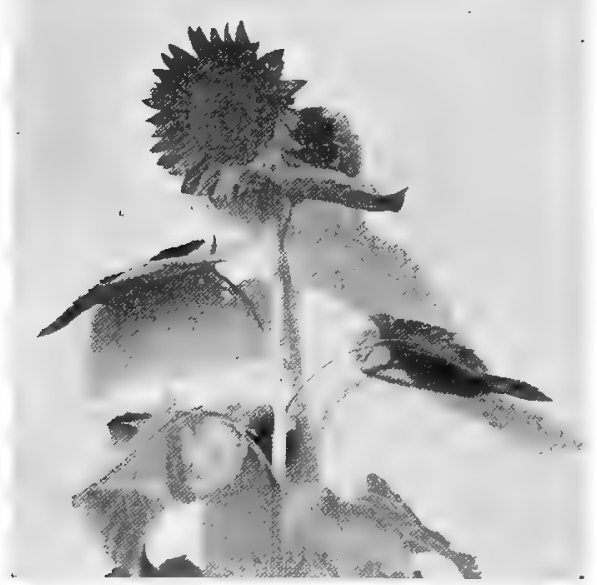

FrG. 129.--Sunflowers make excellent shade when they are planted thick, and the seeds make a very rich and valuable poultry feed.

is usually given after it has swollen by being soaked in water. It contains 61 per cent of carbohydrates, and, theoretically, is a good feed, but birds do not seem to relish it.

\section{FATTY FEEDS}

Considerable fat is present in all feeds, especially in meat scrap, a good grade of meat scrap often containing as high as 25 per rent of fat. Sunflower seeds miake a profitable substitute for meat scrap, when it is desirable to give more 
fat in the rations, for they contain 20 per cent of fat (Fig. 129). The advantage of feeds rich in fat is that they hasten the molt. The feathers seem to come out more quickly, and more quickly look sleek. The use of fatty feeds during July and August is especially recommended. Sunflower seeds contain: Dry matter 92 per cent, protein 16, carbohydrates 22 , fat 20 .

\section{FEEDS CONTAINING ASH}

The ash in poultry feeds promotes the growth of the bony frame of the bird. When fed to hens it goes to form the egg shell. Sometimes the presence of phosphoric acid in the ration materially increases the digestibility of other feeds.

There are two types of ash, one from a vegetable source and the other from a mineral one. Wheat bran is a good example of vegetable ash. Bran contains 5 per cent of ash which is found in the outer shell.

Mineral ash is best obtained from dried bone. This product contains about 50 per cent of lime, and from 25 to 40 per cent of phosphoric acid. Dried bone is excellent feed for young growing chicks, and can profitably be given to the extent of 10 per cent in the dry mash ration. Green bone is not recommended; as a rule, it is impossible to secure a good supply, and the labor required to prepare it is considerable.

Oyster shell is fed to adult birds to form the shell of the egg; it contains 95 per cent carbonate of lime.

\section{FEEDS CONTAINING WATER}

Since the bird's body and the substance of the egg must both contain a high percentage of water, considerable water is necessary in the ration. This can be supplied to the birds in two ways; first, by giving them plenty of fresh water to drink, secondly, by giving them succulent feed. Succulent feed is feed which contains the juices originally present in 
the growing plant. The difference between succulent and dry feed should be studied. Grass is succulent when just mowed or cut, but after lying in the sun for five or six hours, the juices dry out. Succulence not only makes feed more palatable, but also promotes digestion. Green feed and grass contain 80 per cent of water, dry fodder and grains not more than 12 or 14 per cent.

Succulent and Dry Feeds Compared

\begin{tabular}{|c|c|c|c|c|}
\hline & $\underset{\text { Matter }}{\text { Dry }}$ & Protein & $\begin{array}{l}\text { Carbo- } \\
\text { hydrates }\end{array}$ & Fat \\
\hline Clover (Green). & 30 & 4 & 14 & 1 \\
\hline Clover (Dry)... & 90 & 16 & 45 & 3 \\
\hline Lawn Clippings (Green) & $\therefore 24$ & 2 & 14 & 1 \\
\hline Lawn Clippings (Dry)... & $\ldots 85$ & $\overline{7}$ & 42 & 3 \\
\hline
\end{tabular}

Source of Succulence.-In the summer, birds allowed range get plenty of succulent feed from the grass and weeds, but when confined special crops must be grown to provide this green feed. Rape, millet, oats, buckwheat, soy beans, and swiss chard can all be used with profit. For winter feeding we must cultivate some crop which can be stored. Mangel beets and cabbage are the best adapted for the purpose, cabbage being especially adapted to fall feeding, and mangel beets for winter use. In the absence of any good succulent feed for winter the artificial growing of cereal, such as oats, is recommended.

\section{LABORATORY EXERCISE}

Exercise No. 60.-Identifying Poultry Feeds.-Secure a pint sample of all the common poultry feeds in the vicinity. These can be kept in mason jars. Small portions of each feed material can first be given the class for study in order that they may become familiar with the appearance and form of each grain and feed. Later a mixture of different grains may be given and the class will, with a little experience, be able to tell of what grains the mixture is composed. If delicate scales are available, by picking out and separating 
the different grains it will be possible by weighing the mixture and later weighing each kind of grain to tell the percentage composition of each. This exercise may well occupy two or more periods.

\section{THOUGHT QUESTIONS}

1. Classify feeds according to their chemical composition.

2. Of what value is such a classification?

3. All feed materials are from what two general sources?

4. Give a common example of an animal feed.

5 . What is the determining factor in a ration?

6. Can protein feeds be readily grown at home?

7. Give three common forms of meat products which are fed to poultry.

8. How is meat scrap prepared?

9. What is the difference between a low and a high grade meat scrap?

10. What is the protein content of dry granulated bone and fish scrap?

11. Enumerate five vegetable products carrying a high protein content.

12. Are all carbohydrate feeds from an animal or a vegetable source?

13. Discuss corn as a carbohydrate feed.

14. Discuss the relative amounts of carbohydrates and protein in wheat.

15. Is wheat bran commonly used as feed for poultry?

16. How are oats generally fed to poultry?

17. What can you say of buckwheat and barley as poultry feeds?

18. Can many potatoes be safely fed to poultry?

19. Would you recommend the feeding of dried beet pulp to poultry?

20. What feed element is very abundant in sunflower seed?

21. How much ash does wheat bran carry?

22. Discuss dry ground bone as a source of mineral matter.

23. For what purpose is oyster shell fed?

24 . In what two ways can water be supplied to birds?

25. Discuss the supplying of succulent feeds to poultry.

References.-United States Farmers' Bulletins: 298, Food Value of Corn and Corn Products; 318, Cowpeas; 372, Soy Beans; 420, Oats, Distribution and Use; 424, Oats, Growing the Crop; 455, Red Clover; 565, Corn Meal as a Food and Ways of Using It. 


\section{CHAPTER XXIII}

\section{HOME-GROWN POULTRY FEEDS}

THE possibility of growing some of the feed for the birds on the home farm will depend largely on the area of land available. Another important consideration is the character of the soil, that is, whether it is productive or non-productive. The chief advantage of home-grown feed is its good quality. Many poultry feeds can be raised cheaper than they can be purchased, the greatest drawback being the excessive labor required. Where heavy crops are grown, there is always a tendency to slight the poultry work.

Classification of Home=grown Poultry Feeds.--To make a systematic study of the home growing of poultry feeds, it is well to divide them into four groups. The first, and probably the largest, group will be home-grown grains, such as corn, wheat, etc. Another group should include dry fodder, and here alfalfa belongs. Root crops should constitute a third group, while grasses and green crops make up the fourth class of feed material, which it is desirable to raise on the home land. All home-grown feeds must fall under one or the other of these classes.

\section{GRAIN FEEDS}

Grain feed can be profitably grown on the home farm if there is plenty of available land, plenty of labor at a moderate price, and if a large number of birds are kept. Granted these conditions, the four grain crops which may be grown are as follows:

Corn.-Corn is more cultivated than any other grain for poultry feed, but at least four or five acres should be available before it can be considered a crop worth raising. In addition to using corn for feed, the stalks can be cut into 
short lengths for litter, and the corn field should be so located as to afford range for the growing chicks. These different uses make the raising of corn most satisfactory. An acre of corn, properly planted, on fertile soil, should yield an average of sixty bushels, at a selling price of about fifty cents per bushel. The value of the product per acre will then be about $\$ 30.00$. The question whether it is desirable and

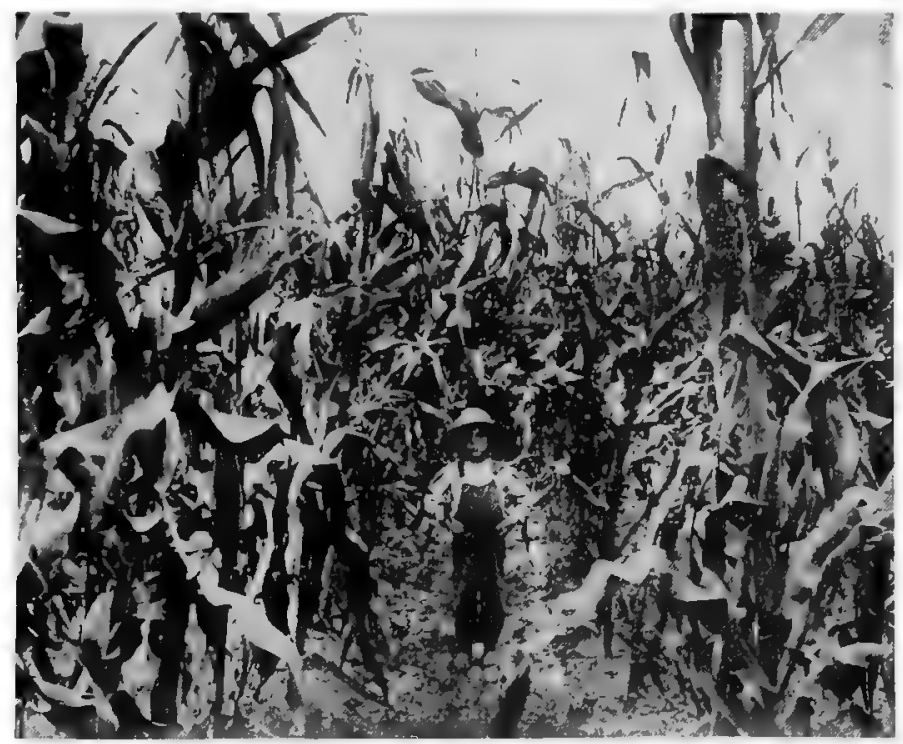

Fig. 130.-A small patch of corn should be grown in connection with every' flock of poultry. It can be utilized for feed in many forms, for ahade, and later for litter. ( $\mathrm{O}$. B. Martin, Plant Industry.)

profitable to raise corn can be determined by comparing these figures with the results obtained by trying an experiment, on a small area, with whatever grain one desires to grow (Fig. 130).

Wheat.-Wheat, as a poultry feed, is not usually grown on the farm where the poultry are kept. One reason for this is that so much machinery is required to harvest it, and 
get it in shape for feed. A common practice with poultry keepers is to purchase winter wheat from grain farmers in the vicinity, such wheat costing from 90 cents to $\$ 1.00$ per bushel. It is usually of excellent quality, and if it is possible to store a large quantity, it should be purchased in the fall. An acre of wheat will yield about 20 bushels and this at market price should be worth $\$ 1.00$ per bushel. This gives the total value of the feed raised per acre as $\$ 20.00$. The profit in growing such a crop can best be determined by comparing it with the cost of purchasing the same.

Oats.-Oats are cheaper to grow than to purchase. When raised on poultry farms they are not generally threshed, but harvested just like hay, then stored up in barns, and fed as litter in the poultry house. A combination of Canadian peas and oats makes a desirable crop. They can be cut before they are ripe, which prevents them from shelling out. The addition of the peas, which carry a high protein content, makes this combination almost a balanced ration. Sometimes the peas and oats are allowed to ripen before harvesting, then are threshed, and the resulting mixture of peas and oats is ground and fed in the mash. The straw can be used for litter.

Buckwheat.-If land is available it is usually more economical to grow buckwheat than to purchase it. Two or three acres will keep 1000 birds supplied with buckwheat the year round. The best way is to harvest the crop before the grain is ripe. Grain and straw can be fed as litter without threshing, and a bundle of straw can be put in the pen each week. Of the four grains mentioned, corn is probably the most profitable one to raise on the poultry farm.

\section{DRY FODDER}

The dry fodders used by the poultry men are clover and alfalfa. Short cut alfalfa and clover are expensive to purchase, and the quality can not always be assured from the 
external appearance. On every poultry farm a small area should be planted with alfalfa or clover, preferably alfalfa. This can be cut and cured as hay, then cut into short lengths and fed in the dry mash. If desired, it can be wet with hot water and fed moist. Fine, dry cut hay of this type is very wholesome for young chicks on the brooder floor. Dry alfalfa in the mash acts as a source of vegetable protein, alfalfa hay containing 12 per cent of protein. One acre may be expected to yield from four to five tons of cured hay.

Root Crops.- The necessity of succulent feeds has been previously mentioned, and root crops form an ideal succulent feed. They are particularly valuable because they give a relatively big yield per acre, are easy to store for winter feeding, retain a high water content throughout the storage period, are easy to feed and are relished by the birds.

Mangel Beets.-Mangel beets are the best root crop, because they give the biggest yield, and are very succulent. The seed should be sown on rich fertile soil, in drills, two and one-half feet apart. This admits of horse cultivation. After they are an inch or two high they should be thinned out so as to be no closer together in the row than eight inches, which will allow each root to develop to its maximum size.

To secure the greatest benefit from the beet crop, the tops should be harvested and fed to the birds in the fall before freezing. They can be cut off with a corn knife, leaving the roots intact. The roots should then be dug up and stored before severe freezing (Fig. 131). The ideal way to store them is in root cellars specially built for the purpose. Where there is no such building, they can be stored in a pit dug in the ground. The beets should be packed in the pit, then covered with corn stalks, and this in turn with a foot of soil. Packed in this way they will keep a long time without any risk of freezing. Mangel beets can be chopped fine and fed to birds 
and will be relished. A common way to feed them is to cut them in halves and hang them on the wall with a spike. The birds will eat the inside, and leave only the outer shell. There are various other root crops, such as potatoes, carrots, turnips, etc., but they should be fed only as a by-product.

\section{GRASSES AND GREEN CROPS}

There is every reason for keeping the yards and ranges covered with growing green grass, for this materially reduces the cost of feed, and tends towards cleanliness.

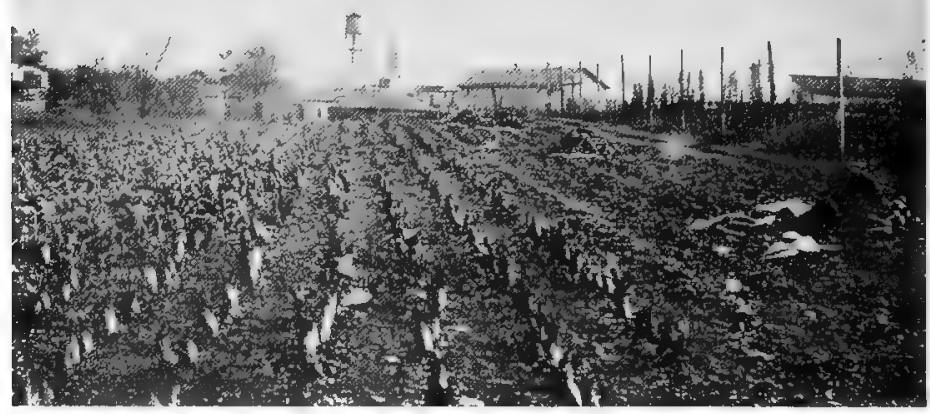

FrG. 131.-Mangel beets make the best winter succulence for poultry. The beets on the left of this picture are shown with the leaves on; those in the center have been topped and the green leaves fed to the birds; those at the right bave been pulled and are shown in small piles, drying before storing in pits or root cellars.

Two Methods of Providing Green Feed.-The birds can be provided with green feed during the summer in either of two ways. Growing it in the yards is best. But if the yards are small, and this is impossible, it can be grown on separate plots, and, after harvesting, be carried to the birds.

Crops to Use.-Alfalfa or clover is the best crop to yield summer succulence. When the yards are large, and kept permanently sodded, clover, alfalfa, and blue grass are all desirable (Fig. 132). An excellent combination is clover and blue grass. If the yards are only of medium size and only one seeding can be made, a good stand of Swiss chard 
or dwarf Essex rape will provide considerable succulent feed. As the birds eat the crop off it grows again from the crown.

When a rotation of crops is desired, the following will be found adapted to the various seasons: For early spring, Canadian peas and oats, spring vetch, and oats or barley. A good summer or hot weather crop consists of either buckwheat, soy beans, or cow peas (Fig. 133). For late fall seeding, clover, winter vetch, winter rye, or winter wheat will be best. These crops for each season have been desig-

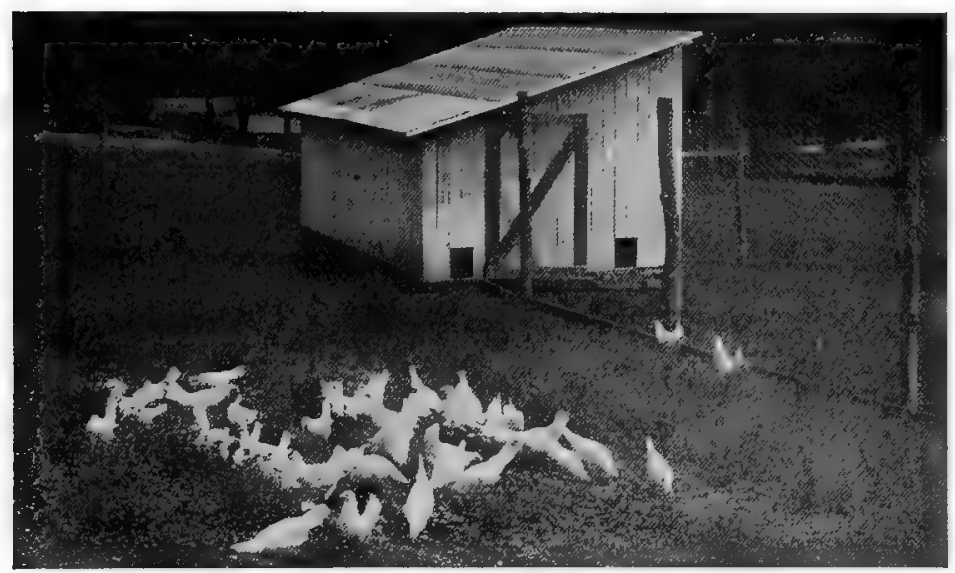

Fra. 132,-Leghorn pullets feeding in a heavy alfalfa pasture.

nated in the order of their desirability. It is quite the custom to sow them broadcast, and harrow or brush in the seed. We must seed heavily in order to get a thick stand and short, succulent growth.

\section{CROPS NECESSARY TO THE POULTRYMAN}

Every poultryman, whether he keeps 10 or 500 birds, should raise some of these crops, the amount to depend upon the number of birds he keeps. Alfalfa should be grown and used as hay; much of it can be cut green, and fed as a succulent crop. Mangel beets should be planted to provide 
winter succulence. Whenever possible, the runs should be kept permanently sodded. On summer runs, a green crop or summer succulent feed should be planted as recommended.

\section{LABORATORY EXERCISE}

Exercise No. 61.-A Study of Seeds and Growing Plants. -A small quantity of seed of the different crops mentioned which are suitable for home production should be secured.

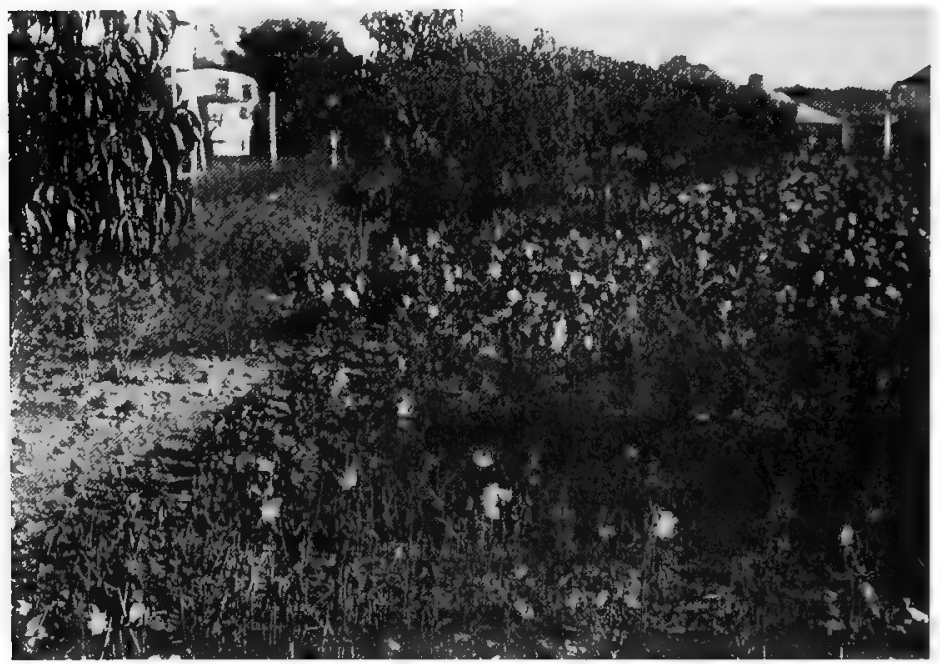

FIG. 133.- Soy beans can be used for shade and green feed and will mature seeds at the same time. The soy beans in this picture are shown after a large flock of pullets had been running in them all summer. The bare vines in the foroground are seen to be full of seed pods.

If land is available on the school grounds or near at hand, plots should be laid off and the class allowed to plant a small area of each. The seeds should be studied first so as to enable a quick and accurate identification. The method of germination and the form of growth should be observed. If land is not available the same work may be accomplished in a small way by planting the seeds in flower pots and growing in the school window. 


\section{THOUGHT QUESTIONS}

1. What fact determines largely the amount of feed which can be grown at home?

2. What are the two leading advantages and disadvantages of the home growing of poultry feeds?

3. Into what four groups can all home-grown feeds be elassified?

4. When should grain feeds be raised?

5. Discuss the home growing of corn for poultry.

6. Is wheat generally grown on the farm where it is fed?

7. What should be the value of wheat raised to the acre?

8. Is it generally cheaper to grow oats than to purchase them?

9. What crop can be profitably grown with oats? Why?

10. How can home-grown buckwheat best be fed to poultry?

11. What two dry fodders can profitably be grown on the poultry farm?

12. What is the protein composition and yield per acre of alfalfa?

13. Give a number of reasons why root crops should be grown by every poultry raiser.

14. What is the leading root crop for poultry feeding?

15. What is the best way to feed beets?

16. What two methods are in general use for supplying green crops to poultry?

17. Give a good combination of grasses to plant if a permanent sod is desired.

18. Outline a good rotation to provide continuous green feed during the year on small yards.

19. Enumerate the necessary crops for every poultry flock.

References.-United States Farmers' Bulletins: 164, Rape as a Forage Crop; 224, Canadian Field Peas; 278, Leguminous Crops for Green Manuring; 295, Potatoes and Other Root Crops as Food; 339. Alfalfa; 415, Seed Corn; 428, Testing Farm Seeds in the Home and in The Rural School; 433, Cabbage; 443, Barley, Growing the Crop; 537, How to Grow an Acre of Corn. 


\section{CHAPTER XXIV}

\section{FEEDING FOR GROWTH}

ThERe are three definite objects in the feeding of poultry. All young growing animals are fed for growth, or the building of tissue. Poultry are also fed for some product to be yielded by the body, the egg being the product desired, and in order to put birds in condition for market they are fed for increase of flesh. To best attain these three objects, different rations must be fed in each case, and different systems of feeding followed, if the greatest efficiency is to

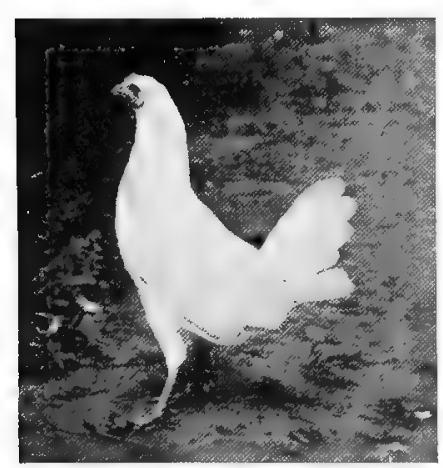

FIG. 134.-The maturing pullet; she is the ultimate aim when feeding for growth and maturity. be obtained. In this chapter we will discuss feed requirements and the methods of feeding for growth. Feeding methods nccessarily apply to pullets from hatching time to maturity. Feeding for growth can be divided into two periods; the brooding stage and the growing stage. During the brooding period the object of all feeding and management is to get the chicks safely through the stage of their helplessness. If during these few weeks they are not properly cared for in the brooder house, there will be great mortality, which is often largely due to improper feedıng. It is at this early period that the framework of the body, or skeleton, starts to grow, and without a strong, heavy skeleton, it is impossible for the bird subsequently to carry a heavy weight of flesh. The brooding period ceases when the chicks 242 
are taken from the brooder house and put on range. From this time until maturity the object of feeding is to promote uniform and continuous growth, for such a development conduces to greater uniformity of flesh, and higher vitality at maturity (Fig. 134).

\section{FEEDING BROODER CHICKS}

A simple method of feeding the brooder chicks is outlined in detail in Chapter XII, page 138. A general knowledge of what chicks require, and the essentials in their management, is necessary in order to purchase or mix their rations.

Principles Involved.-The feed should be limited during the brooding period. It is well known that just before the chicks are hatched that part of the yolk which remains is absorbed by the body. This serves as food, and nourishes the chick for the first thirty-six to forty-six hours after it emerges from the shell. Heavy feeding of concentrated feeds during the first three days is apt to upset the digestive system, and to cause death.

Frequent feeding is, however, most essential. The young chick grows rapidly, and develops in size much faster than any other animal. It has, too, a very small stomach, so that in order to provide a continuous supply of nourishment, feedings must be frequent. The chicks can not store up at one feeding large quantities for future needs.

Moreover, the chicks should be kept hungry, for hunger makes them active. Digestive organs crowded with feed will soon become impaired so that diarrhoea and death will result. It is a good plan to feed small amounts at short intervals, giving only enough to make it certain that the chicks will be hungry before the next feeding, and they should be made to clean up all of the feed given before they are fed again. They must be kept busy, and this is accomplished by feeding them in the litter, by limiting the amount given, and by making them hunt for their feed. Exercise is the best 
incentive to a good appetite and good digestion. Dry feeds are the safest, and the best rations are dry, finely cracked chick grains. After the birds are a few days old, they can be given a simple dry mash consisting largely of wheat bran. Wet, "sloppy feeds, especially if allowed to become sour, seriously impair digestion.

Plenty of grit should be given the little chicks. As they have no teeth, grit grinds their feed, and is a material aid to digestion. The feed is also acted upon and made more digestible by the digestive fluids. A liberal amount of ash is good for the young chicks, as it goes largely into the formation of the frame. Ash assists materially, too, in the digestion of feed. Wheat bran and dry, granulated bone are the two best sources.

When two weeks old, the chicks have passed the danger point. From this time on they should be given all they will eat, provided they are hungry at feeding time. They should not be allowed to lose their appetite, as this will check their growth for the time being.

\section{Rations for Brooder Chicks and Methods of Feeding.-} The following rations for chicks have been formulated after careful tests and a study of the results obtained. They are recommended for use with brooder chicks.

\section{Mixture No.1. Scratching Ration}

Find of Feed

Finely cracked corn.

Finely cracked wheat............... 40 pounds

Rolled oats. .
Amount

40 pounds
20 pounds

Total.

100 pounds

This scratch ration should be fed in the litter on the floor of the hover, and should be given the chicks for the first time on the second day they are in the brooder. For the first two weeks it is well to give the mixture four times a day, but only a small quantity at a time, and this will keep the chicks hungry and active. Wheat bran should be kept before 
them continually for the first two weeks, in shallow open pans or small baby chick hoppers. After this time a change should be made, and the following dry mash substituted for the wheat bran, feeding it in hoppers, and keeping it before them all the time. When the change is made, the feeding of the seratching ration can be reduced to three times daily. The following is the chick dry mash:

Kind of Feed Chick Dry Mash

Wheat bran ................ 50 pounds

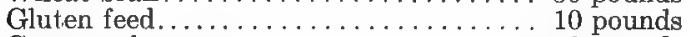

Corn meal . ...................... 10 pounds

Ground oats.................. 10 pounds

Beef scrap.................... 10 pounds

Granulated bone.............. 10 pounds

Total............ $\overline{100}$ pounds

There are two miscellaneous brooder feeds which can be used to advantage. Hard boiled eggs in considerable quantities can be given to the chicks after they are a week old. The eggs should be boiled thirty minutes, and only as much given as the chicks can clean up quickly. If any is left in the litter to become sour and moldy it is very injurious. Infertile eggs from the incubator can be largely used for this purpose.

Sprouted oats and vegetable tops, or young green grass should be given during the early brooding period. Out-door runs to the brooder house, covered with alfalfa or clover, are quite a necessity.

Cost of Feeding a Young Chick up to Eight Weeks of Age.-The cost of feeding a chick in the brooder house during the brooder period varies considerably; on the average it is from six to eight cents, but during the winter it costs a little more than this.

\section{THE GROWING PERIOD}

In addition to the feed, the requirements for the growing period are detailed in Chapter XIII. The method of feeding there recommended applies equally well to cock- 
erels and to pullets. But, if the best growth is to be attained, the sexes must be kept apart.

Principles Involved.-The following principles should be understood before attempting to feed young stock during the growing period. The rations must be designed to promote growth, and must contain a considerable amount of protein, which is necessary for the production of lean meat or flesh. It should also provide a liberal amount of ash to form the skeleton, or bony frame.

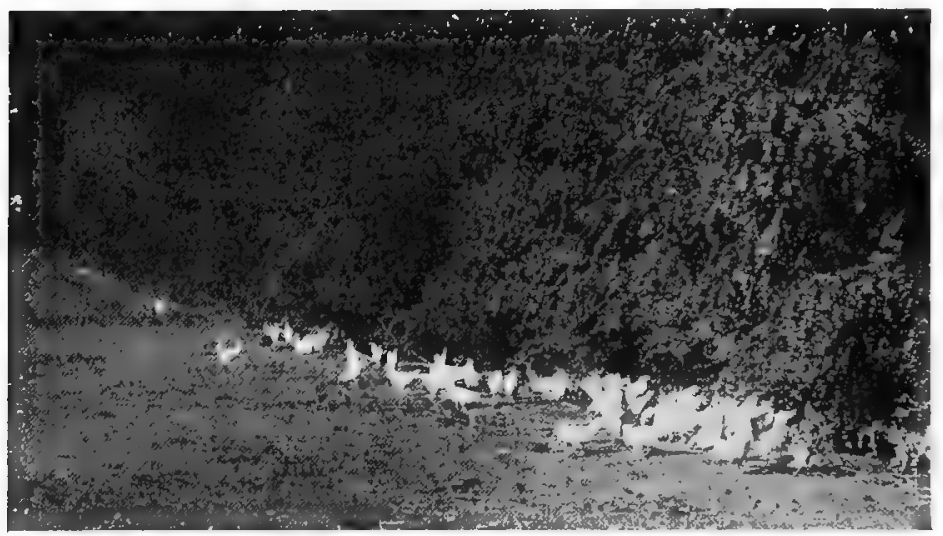

FIG, 135.-Leghorn pullets on range. If given opportunity they will always pick the cool shady hedge rows rather than the open sunny places.

The feed supply should be constantly available. Growing chicks are always hungry, and it is impossible to gauge their appetite by feeding them once or twice a day. If their feed supply is always where they can have free access to it, their growth will be uniform. This constant feed supply not only equalizes the growth, but it enables the summer or late hatched chicks to get their share of it. If they were all fed together with a scratch ration, the summer chicks would be crowded out by the strong older chicks.

Plenty of range is good for them. Large runs mean sanitary conditions, and also afford plenty of exercise (Fig. 135). 
Grass ranges insure that the feed is obtained from a natural and inexpensive source. Dry feeding is the cheapest. Excessively rapid growth is not desirable, but it should be uniform and continuous. This can best be secured by a feed of dry cracked grains and dry mash, which involves less labor, and is productive of a more uniform and economical growth than the practice of feeding wet, sloppy mashes to growing chicks.

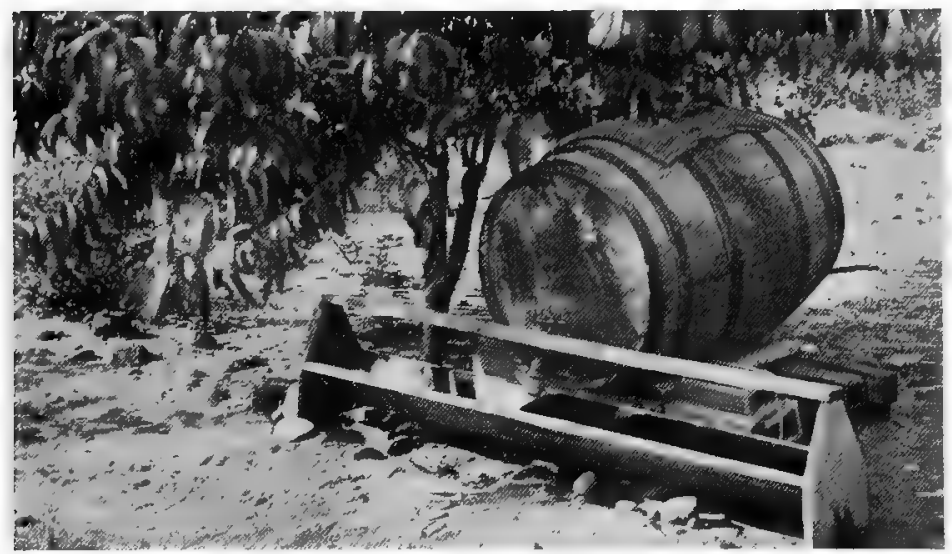

Fra. 136.-A water-tight barrel placed in a shady place on the range will insure a constant supply of fresh cool water. The barrel should be filled at least every other day.

Growing pullets should not be excessively forced. Such forcing usually results in a too early maturity, often accompanied by lack of vigor and vitality, and, if practised year after year, soon exhausts the stock. Plenty of clean, fresh water must be given. Water quenches the thirst, and also performs many functions connected with digestion and assimilation. In the summer, when the weather is dry and hot, the water supply should be closely looked after to make sure that it is accessible and plentiful (Fig. 136).

Rations for Growing Poultry.-As a rule, the composition of rations for growing poultry is very similar to that of the 
rations fed during the brooding period. An effort should be made to keep down the cost. Owing to the small size of the brooder chicks, finely ground, expensive grains are necessary; but as the chicks grow older and larger, coarser and cheaper grains may be substituted. As soon as the chicks go on range, they should get the same dry mash ration that was fed during the latter part of the brooding period. This mash should be fed in large homemade hoppers, built to hold two or three hundred pounds. They can be located a short distance apart about the range. The advantage of these large mashes and of a constant feed supply, is that the chicks thus balance their own rations, and get a diet which more nearly meets their individual requirements. The grain used to supplement the dry mashes should be of simple composition, and inexpensive to purchase. Only common feeds grown in the locality need be selected. The following is a suitable grain ration for growing poultry:

Kind of Feed

Whole wheat

Cracked corn
Amount

50 pounds

50 pounds

Total............... 100 pounds

The above ration should be scattered by hand broadcast over the range morning and night, but only so much that the youngsters will eat it up clean in one-half to three-quarters of an hour. If too much is fed, it will be found lying around on the ground and spoiling. This is an expensive as well as a dangerous way of feeding.

The birds should be anxious for the feed before the time arrives (Fig. 137). In order to keep them evenly distributed in their own colony, it is well when feeding the grain to start each day at a different point of the range. If the feeder begins at the same place cach time, the chicks will be apt to congregate there, and many will not return to their own houses, but will crowd into those nearest at hand. If the rations recommended are used, and the birds provided with 
free range, the feed necessary to mature a cockerel or pullet to five months of age will cost from thirty to forty cents.

Feeding Just Before Maturity.--After the chicks have completed the growing period, or are approaching maturity, their ultimate maturity can be quite materially affected by the feeding. If they are not maturing fast enough, or not in just the proper condition, they can be forced in slight degree by the addition of nitrogen to their feeds. Doubling the meat scrap in the mash will bring about the desired results.

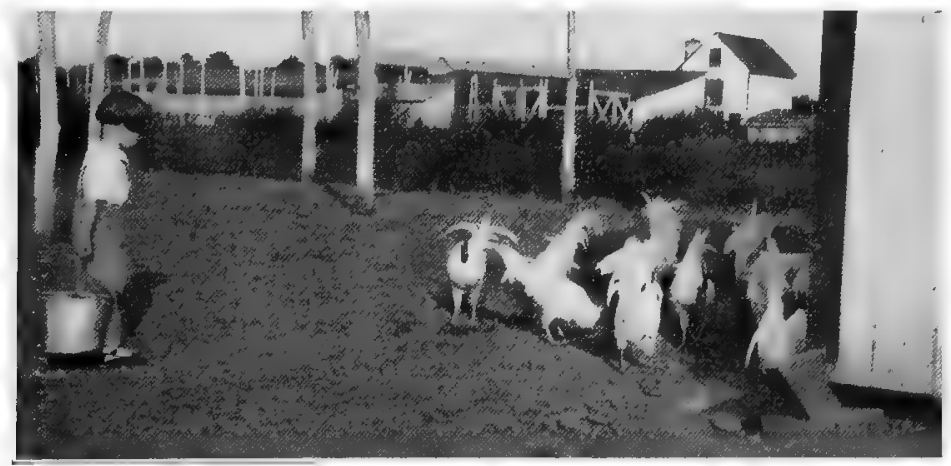

Fra. 137.-Feeding White Leghorn cockerels their scratch grain ration.

If, on the other hand, they seem to be maturing too fast, the combs and wattles reddening up too rapidly, growth and maturity can be slightly retarded by withholding some of the more concentrated nutrients.

Successful feeding calls for knowledge and skill. These can only be secured by study and personal observation of the results obtained by feeding.

\section{LABORATORY EXERCISES}

Exercise No.62.-The Unabsorbed Yolk.-Dissect a day old chick and another one four days old. Note the size of the yolk in each case. How is the presence of this yolk accounted for? How does its presence necessitate limited early feeding? 
Exercrse No. 63.-Mixing Chick Rations.-Secure small quantities of the feed materials required for the specified chick rations. Have the class mix the rations in the proportions called for. Be sure to get the ingredients well mixed. Note especially the size of the grains and the consistency of the rations after mixing.

Exercise No. 64.-Feeding Young Chicks.-After the rations are mixed, feed them to the chicks which have been hatched as called for in some of the previous exercises. If no chicks are hatched at the school, allow one or more members of the class to try the method of feeding which is specified and report to the class at frequent intervals.

\section{THOUGHT QUESTIONS}

1. For what three different objects are poultry fed?

2. Into what two groups can feeding for growth be divided?

3. What is the special object to be attained in feeding during the brooding period?

4. What is the special object desired from feeding during the growing period?

5. Enumerate the principles involved when feeding brooder chicks.

b. Why should chicks be fed sparingly during the first few hours after hatching?

7. Why is frequent feeding with young chicks desirable?

8. What is the relation between hunger and exercise in young chicks?

9. What is the function of grit in chick feeding?

10. Outline in detail a simple but efficient method of feeding brooder chicks.

11. Give a good scratch ration for brooder chicks.

12. Give a good dry mash mixture for young chicks in the brooder.

13. What is the average cost of feeding a young chick to eight weeks of age?

14. Enumerate the principles involved in feeding chicks during the growing period.

15. Why is a constant feed supply so essential during this period?

16. What are the advantages of free range feeding?

17. What is the effect of forcing for an early maturity?

18. Outline a good method of feeding birds during the so-called growing period.

19. Give a good grain ration to be used on the range during the summer.

20. What is the average cost of growing a pullet or cockerel to maturity on the range?

21. What special methods may be used to feed the birds just before they reach maturity?

22. How can a poultry keeper become an efficient feeder? 


\section{CHAPTER XXV}

\section{FEEDING FOR EGG PRODUCTION}

In feeding for egg production two definite objects must be kept in view. The first of these is maintenance. By maintenance is meant the feed necessary to build up the bird's body. The processes of digestion and production constantly wear away the tissues of the body, and a certain amount of feed material is necessary to repair this waste. The bird's body contains over 55 per cent of water, over 20 per cent of protein or nitrogenous material, nearly 20 per cent of fat, and about 4 per cent of ash. These are the materials which are constantly broken down or consumed by the processes of life, and these materials must be provided in the feed if the bird is to produce many eggs (Fig. 138).

The second object in feeding for egg production is to provide the necessary material to form the egg. If egg

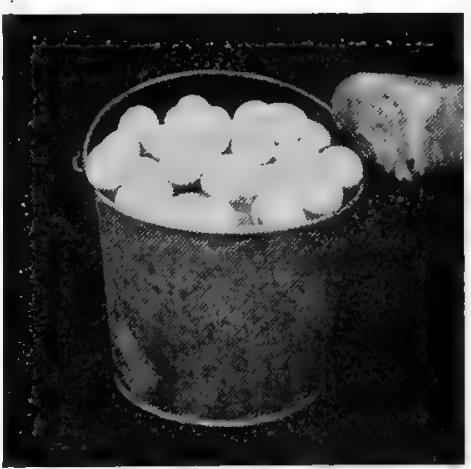

FIg. 138.-The primary object in feeding for egg production is to fill the egg pail claily throughout the year. production is to be satisfactory, these nutrients must be fed in excess of the amount needed merely to maintain the body. The bird has great powers of self-preservation, and its feed will first be utilized to maintain its own body before many eggs are produced. The whole egg contains about 65 per cent of water, over 13 per cent of protein or nitrogenous material, and about 10 per cent of fat, in addition to the shell, which constitutes about 12 per cent 
of the whole egg. The shell is almost wholly composed of mineral matter, a large proportion of which is carbonate of lime. From these figures we see that if the bird is to be properly maintained to yield a goodly egg production, the ration fed must contain a large amount of protein, water, and ash.

\section{EGG PRODUCTION A DRAIN ON THE VITALITY}

In order to produce an abundance of eggs, much raw material must be consumed to be transformed into the egg. A bird must be strong and have considerable vitality to bear this strain; weak hens frequently break down and succumb. In the average hen weighing from three to five pounds, which produces in a year twelve dozen eggs, the egg producing organs must be working all the time in order to transform the large mass of feed material into eggs.

The Record of the Belle of New Jersey.-The following interesting figures from the record of a wonderful little White Leghorn hen would emphasize the requirements of such a bird for egg production. This little White Leghorn hen was bred purposely for egg production (Fig. 139). During her pullet year she laid 246 eggs, the total weight of which was $291 / 2$ pounds. At maturity she weighed three and eight-tenths pounds. The weight of her eggs was eight times as great as that of her body. The feed she consumed during this period weighed 118 pounds. Thus the weight of her feed was thirty times as great as that of her body. Her feed cost $\$ 1.79$. When we stop to consider the immense amount of work this little hen had to do in order to transform such a large volume of feed into eggs, we do not wonder that strength is one of the first requisites for egg production. After the cost of feed and labor and the interest were deducted, the bird yielded a profit of $\$ 4.72$. This is abnormally high production. It shows, however, what can be accomplished when conditions are right. By mating the sons of this 
A

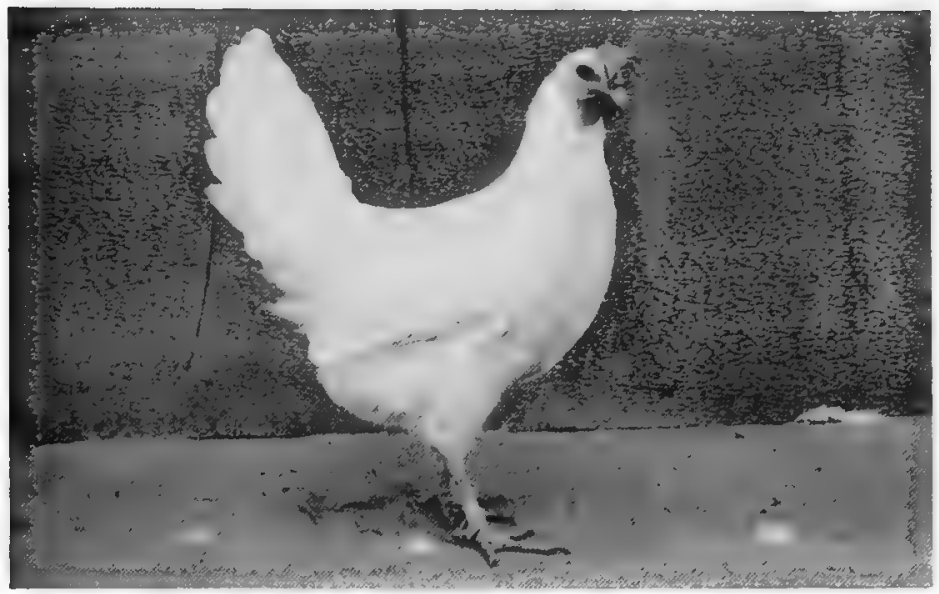

B

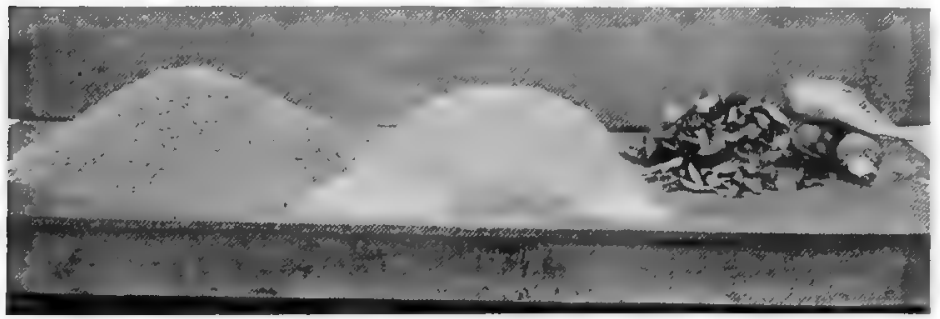

$\mathrm{C}$

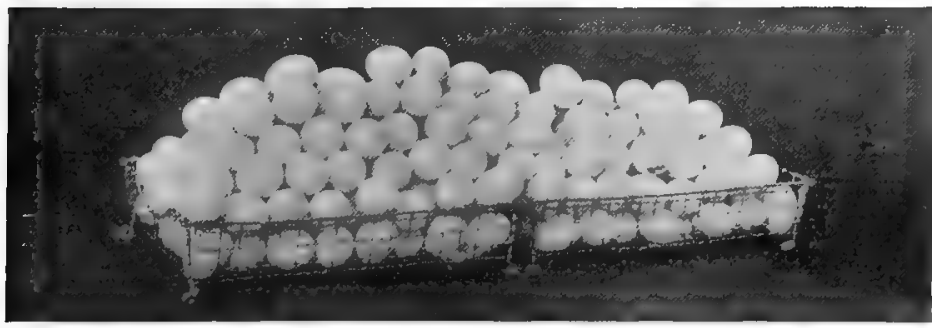

FIa. 139.-The story of Belle of Jersey in picture. $A$, Belle of Jersey as she appeared just at the close of her first year's production. $B$, The feed she ate during her twelve months of egg laying. The ration is the standard one recommended later in this chapter. $C$, The number of eggs which she produced in the 365 days, -246 , weighing $291 / 2$ pounds, or eight times her body weight. 
bird in future breeding work, her high egg producing qualities can be transmitted to future generations (Fig. 140).

PRINCIPLES INVOLVED IN FEEDING FOR EGG PRODUCTION

Health the First Requisite.-To insure success the health of the flock must be maintained. The birds must be given

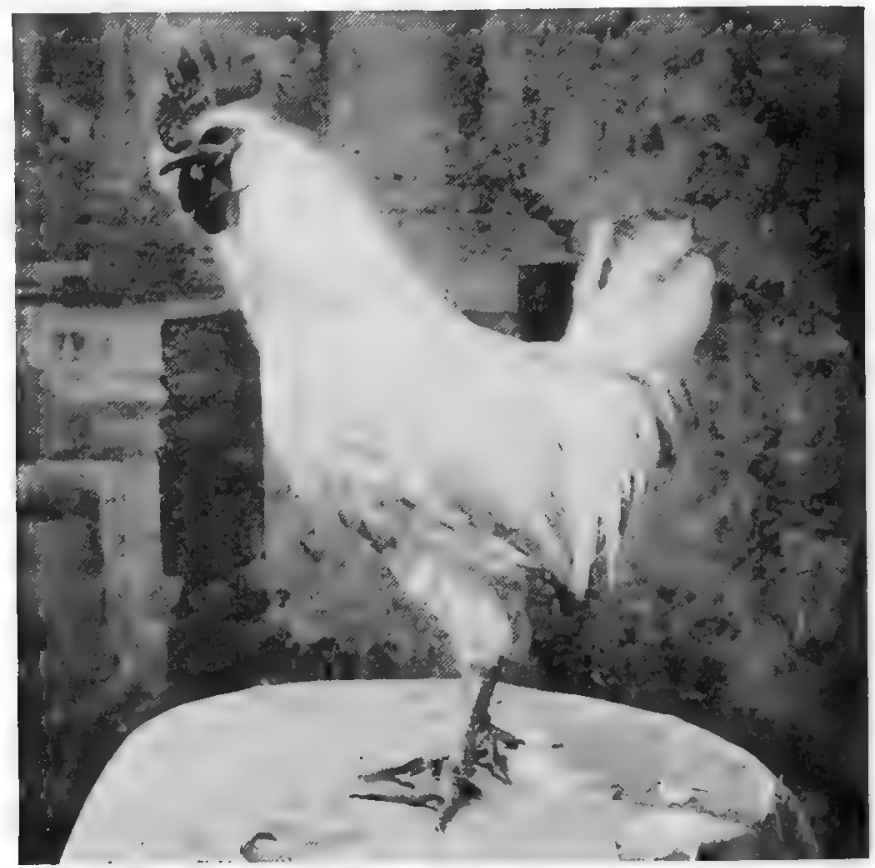

Fig. 140.-A son of Belle of Jersey. By using him as a breeder it is hoped to produce another generation of birds, many of which will be as good or better than his mother.

plenty of exercise, and nothing but clean, wholesome grains should be fed. The feeding of the grain in deep litter, and the keeping of the birds in fresh air houses, are the two main steps towards health.

Protein to be the Chief Constituent of the Laying Rations. -Experiments demonstrate that protein is the determining 
factor in rations for egg production. Protein from an animal source is far superior to that from a vegetable, which never takes the place of animal protein. For profitable egg production, birds should receive a ration which contains not less than 10, or more than 25 per cent of meat scrap.

Need of Plenty of Water.-Fresh, clean water should always be before the birds (Fig. 141), and must be supplemented by good, succulent feed, such as cabbage, sprouted oats, or mangel beets. Dry alfalfa and clover are not suc-

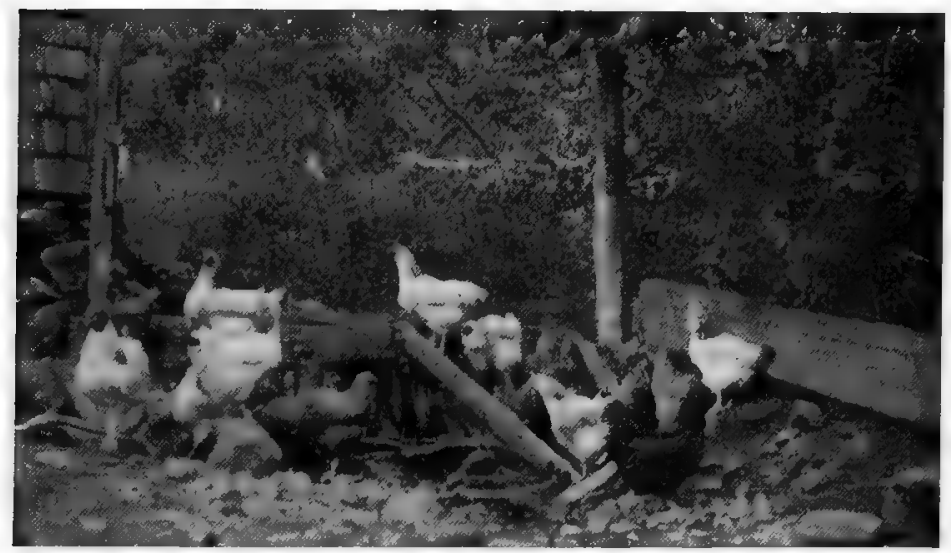

FIG. 141.-A small brook runs through the corner of this poultry yard, making an abundant supply of fresh water available even on the hottest days, and this without any labor on the part of the one attending the birds.

culent. A large amount of water is necessary owing to the high water content demanded by both the bird's body and the egg (Fig. 142).

Birds' Relish for Grain.-Birds naturally love grain and seeds. In their wild state, much of their feed consists of weeds and wild herbs. Their digestive system is so constructed as to consume and digest large amounts of hard grain and seeds. In their rations the grain supplied should form one-half to two-thirds of the total bulk of feed, the balance being dry mash. 
Sour Skim Milk.-Sour skim milk is a valuable addition to the ration. The souring of milk generates lactic acid, which

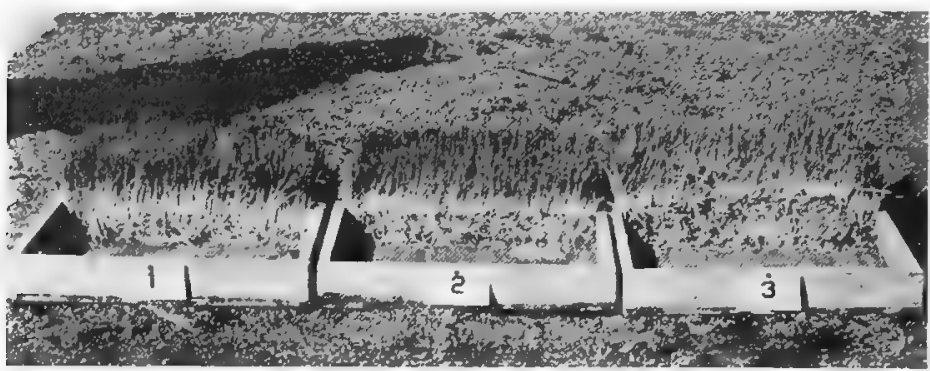

Fig. 142.-Sprouted oats form one of the best green feeds for poultry. They make the best growth when sprouted at a depth of one inch, as shown in tray No. 1 . When sprouted deeper they mold and do not make as many sprouts.

is a great aid to digestion, and is also beneficial because it kills injurious bacteria which may find entrance to the digestive

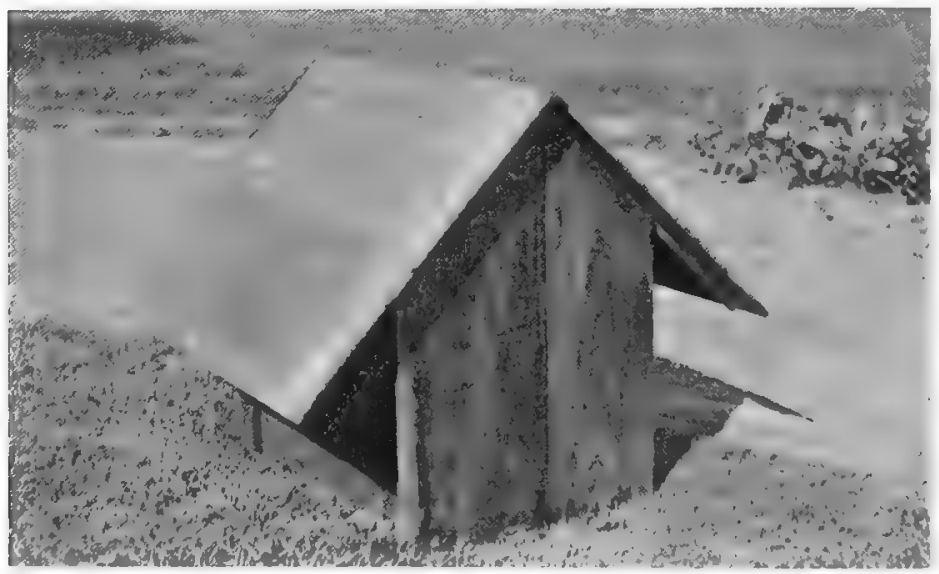

Fig. 143.-A small dry mash hopper which is designed for the feeding of dry mash to laying hens. The projecting roof makes it possible to use this hopper out of doors.

tract. Sour milk also furnishes a considerable amount of protein nutrient. Experiments show that birds lay remarkably well and produce eggs at a profit if fed on sour skim milk. 
Dry Mash Economical.-Dry mash is an excellent feed for it is fed in large hoppers, and is constantly accessible to the birds (Fig. 143). Thus they regulate their feed consumption according to their own bodily requirements. Highly concentrated protein feeds can be given in the mash. Feed nutrients from such sources are more economical than those obtained from grain.

Necessity of Ash.--Large quantities of ash must be given in the laying rations in order to form the egg shells. Oyster shells furnish such ash. They can be ground very fine, and kept in the hoppers all the time.

Necessity of Grit.-Grit has a definite use in the ration. It finds its way immediately into the gizzard, where it lodges, and helps to grind the feed into small particles, which can be readily digested. These principles of feeding should be thoroughly understood if the laying flock is to be successfully fed.

\section{A PERFECT RATION FOR LAYING HENS}

In the following are given the New Jersey state dry mash, and supplemental rations designed for the perfect feeding of laying hens throughout the winter. Such modifications as may be necessary for summer feeding and for different breeds are also described:

Mixture No. 1. Dry Mash

\begin{tabular}{|c|c|c|c|}
\hline Kind of Feed & Amount by Weight & Amount by Measure & Cost \\
\hline Wheat bran. & 200 pounds & 380 quarts & $\$ 3.20$ \\
\hline Wheat middling & 200 pounds & 240 quarts & 3.50 \\
\hline Ground oats... & 100 pounds & 100 quarts & 1.65 \\
\hline Corn meal. & 100 pounds & 95 quarts & 1.65 \\
\hline Gluten feed. & 100 pounds & 80 quarts & 1.70 \\
\hline Alfalfa. . & 100 pounds & 200 quarts & 1.60 \\
\hline Meat scrap. & 200 pounds & 176 quarts & 5.50 \\
\hline Total. & . 1,000 pounds & 1,271 quarts & $\$ 18.80$ \\
\hline
\end{tabular}

The average cost per 100 pounds is $\$ 1.88$.

This mash should be kept before the birds all the time in large self-feeding hoppers. In the fall during the molting 
season, it is well to substitute oil meal for the gluten meal in the same proportion; this will hasten the growth of feathers. As soon as the birds get on green grass range the alfalfa can be gradually omitted and the meat scrap reduced in amount. The extent to which this mash can be cut during the summer depends upon the character and amount of range allowed the birds.

The mash is compounded especially for Leghorns. When heavier breeds are kept, such as Plymouth Rocks or Wyandottes, especially yearling or two-year-old hens, if they have a tendency to put on an excess of fat the best policy is to restrict their allowance of mash, by opening the hopper during the afternoon only, thus compelling the birds to work during the morning for the cracked grain fed in the litter at the morning feeding. The following modification of the above mash will prove very economical for summer feeding when the hens have considerable range and plenty of growing green feed.

Mixture No. 1. Summer Dry Mash

\begin{tabular}{|c|c|c|}
\hline Amount by Weight & Amount by Measure & Cost \\
\hline Wheat bran. & 380 quarts & $\$ 3.20$ \\
\hline Wheat middlings. . . & 120 quarts & 1.75 \\
\hline Gluten feed........ & 40 quarts & .85 \\
\hline Ground oats....... & 100 quarts & 1.65 \\
\hline Meat scrap........ & 21 quarts & .75 \\
\hline 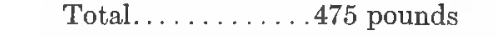 & quarts & \\
\hline
\end{tabular}

The average cost per 100 pounds is $\$ 1.70$.

As a ration to supplement the dry mash, the following may be given: A scratching ration of whole grain in deep litter, every morning, both winter and summer, at nine o'clock. The primary object, aside from its nutritive value, is to induce the birds to take plenty of exercise. About five pounds of this ration to 100 birds can be fed on the floor of the house, or under some shelter where the litter is dry, and where there is protection from cold winds (Fig. 144). The scratching ration is made up as follows: 
Mixture No. 2. Scratching Ration

Kind of Feed

Wheat.............100 pounds

Oats............ 100 pounds

Total........200 pounds

Average cost per 100 pounds is $\$ 2.06$.

Amount by Measure

53 quarts

98 quarts

151 quarts
Cost

$\$ 2.20$

1.93

$\$ 4.13$

At four to five o'clock in the afternoon, according to the season, a night ration composed of whole and cracked grains is fed at the rate of 10 pounds to 100 birds.

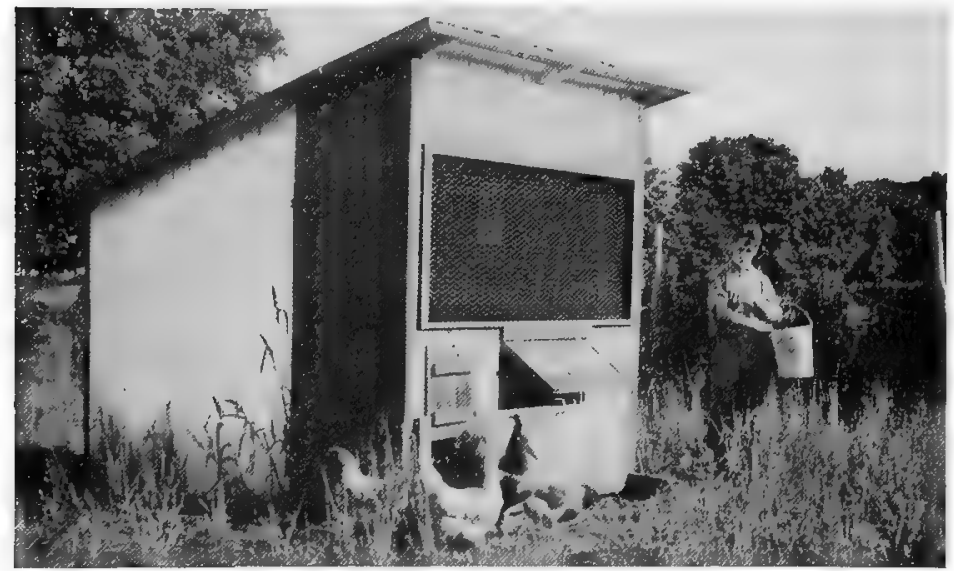

Fro. 144,-Feeding the morning scratch ration to bis pen of Buff Orpingtons. A close interest in the habits of the birds and careful attention to their feeding will be rewarded by an increased egg production.

Mixture No. 3. Night Ration

Kind of Feed Amount by Weight Cracked corn........200 pounds Wheat............... 100 pounds

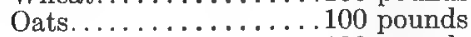
Buckwheat..............100 pounds

'Total..........500 pounds rhe cost per 100 pounds is $\$ 1.80$.
Amount by Measure 120 quarts 53 quarts 98 quarts 66 quarts

337 quarts
Cost $\$ 3.20$

2.20

1.93

2.00

$\$ 9.33$

It will be noted that this night ration, as outlined, supplies materials to keep the bird's body warm during the night. It is designed for Leghorns. When feeding heavier breeds, it 
is advisable to eliminate one-half of the cracked corn and all of the buckwheat (Fig. 145). During the summer a night ration of equal parts of corn, wheat, and oats will be ample for the needs of the Leghorns. A good rule to follow in feeding night rations is to give a little more than the birds will eat so that there will be some left for them to work for in the morning.

One advantage of dry mash feeding as stated is that the birds in large measure balance their own rations accord-

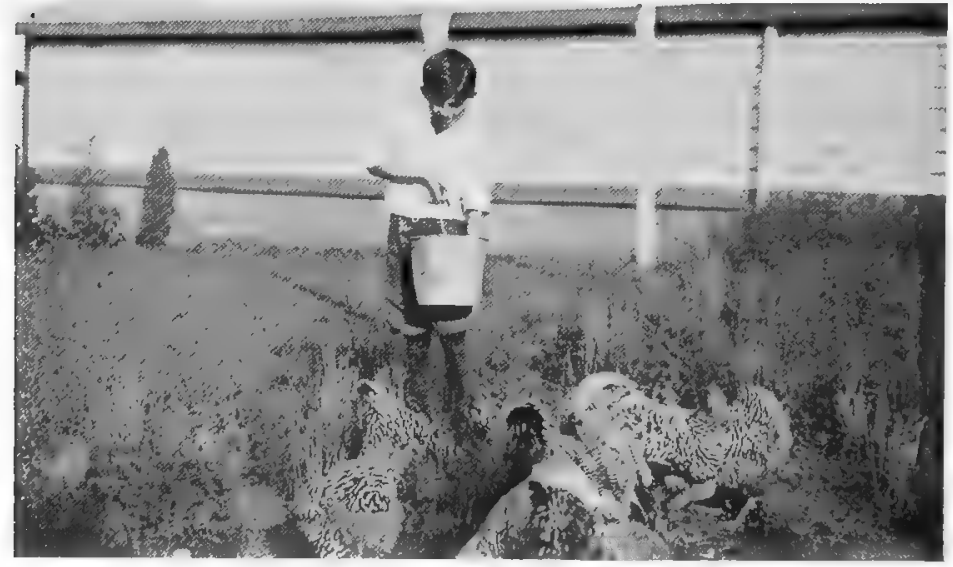

Fig. 145.-The interest which this young man shows in his birds is written all over his features and is shown by the gentleness of his birds. These Barred Plymouth Rocks are being fed their evening grain ration.

ing to their particular tastes and requirements. Some succulent material in addition to the grain rations is necessary for the best results, and sprouted oats or mangel beets are to be preferred.

In conclusion it might be said that there is no such thing as a best ration. Feeds to use and methods of fecding will vary with location, season, and breed of fowl. The best practice is to give a concentrated, well-balanecd dry mash, and keep it before the birds all of the time. This can be 
supplemented by feeding cracked grain rations twice a day in deep litters; those recommended above can be used to begin with. They should be carefully studied, both as to cost and efficiency, and from time to time can be modified as conditions warrant.

\section{LABORATORY EXERCISES}

Exercise No. 65.-Mixing Laying Rations.-Secure the feeds necessary to mix the three rations recommended for the complete feeding of laying hens. Have the class thoroughly mix them. The best method of mixing in large quantities is to dump all materials in a pile on a hard, smooth floor. Shovel the pile over to one side, making another pile. Do this three or four times until the mixture is complete. When each shovelful is emptied the contents should be spread over the top of the pile. When the rations are being mixed study their appearance and conditions.

EXercise No. 66.-Feeding Laying Hens.-Using the rations mixed above, allow one or more flocks of layers to be fed the same for a given time (three months). It is best to feed a small flock owned by the school. If not possible a student's flock will answer. The class can visit same occasionally and reports can be given. Complete records of amount and cost of feed consumed should be kept. The daily egg production and the selling price of eggs should be recorded. After the period is over or at the end of each week or month, the class can figure out the profit above feed consumed and other facts of interest to poultry keepers.

\section{THOUGHT QUESTIONS}

1. What are the two definite objects in view when feeding for egg production?

2. What is meant by feeding for maintenance?

3 . Give the average composition of the bird's body.

4. For which purpose does the bird use the feed consumed, maintenance or production?

5. Give the average composition of the egg.

6 . Why is egg production a drain on vitality?

7. Give figures showing the record of Belle of Jersey's production. 
8. In what way can this production of Belle of Jersey be handed down to her progeny?

9. Enumerate the principles involved in feeding for egg production.

10. How does the feeding practice affect health?

11. What is the most important feed nutrient in feeding for eggs?

12. What are the ways in which plenty of water can be supplied?

13. What should be the proportion of the grain to mash feed?

14. What are the advantages of sour skim milk as a feed for eggs?

15. Enumerate the advantages of dry mash feeding.

16. Discuss the need of ash in the laying rations.

17. What definite object does grit perform?

18. Outline a complete method of feeding for egg production.

19. Give the composition of a complete dry mash suitable for feeding for egg production.

20. Give a grain ration suitable to supplement the dry mash. Both morning and night.

21. How does the morning grain feed differ from that given at night?

22 . Is there a best ration for all conditions?

23. Give the composition of any rations which you know of which are giving success. 


\section{CHAPTER XXVI}

\section{FEEDING FOR FLESH}

Feeding for flesh means getting the birds ready for market. They must be plump all over, that is, well covered with flesh, which should consist of both lean meat and fat (Fig. 146). Get them into the best condition for cooking and eating. Fat is especially desirable in birds, since it permits them to be thoroughly cooked without becoming excessively dry. Many kinds of birds are used for food, and there are various methods of conditioning them for market. In this chapter we shall discuss in a general way a few of the prevailing customs.

\section{THREE CLASSES OF BIRDS TO BE FED}

All poultry conditioned for market can be grouped into one of three classes: broilers, roasting chickens, and fowls. Broilers constitute a rather large class, and are birds specially prepared for broiling. They are usually small, being sold when from 10 to 15 weeks old. Cockerels are largely disposed of in this way; sometimes pullets, also, but rarely, as they are in too great demand for laying. The object in getting broilers ready for market is to bring them quickly to marketable size, since every week they are kept adds to the cost of production, and increased cost reduces the profits.

Roasting chickens include cockerels which are approaching maturity, capons, and sometimes pullets (Fig. 147). The object in getting roasting chickens into condition is to have them of large size, yet with tender meat. "Fowls" is a trade name applied to old hens, which, when they have passed their usefulness for egg production, are disposed of for meat. Fowls constitute the poorest quality of poultry 
meat, but are in considerable demand by people in moderate circumstances. They are chiefly used for fricassees, or for meat pies. Each of the above mentioned group of birds requires a different mode of feeding and different handling.

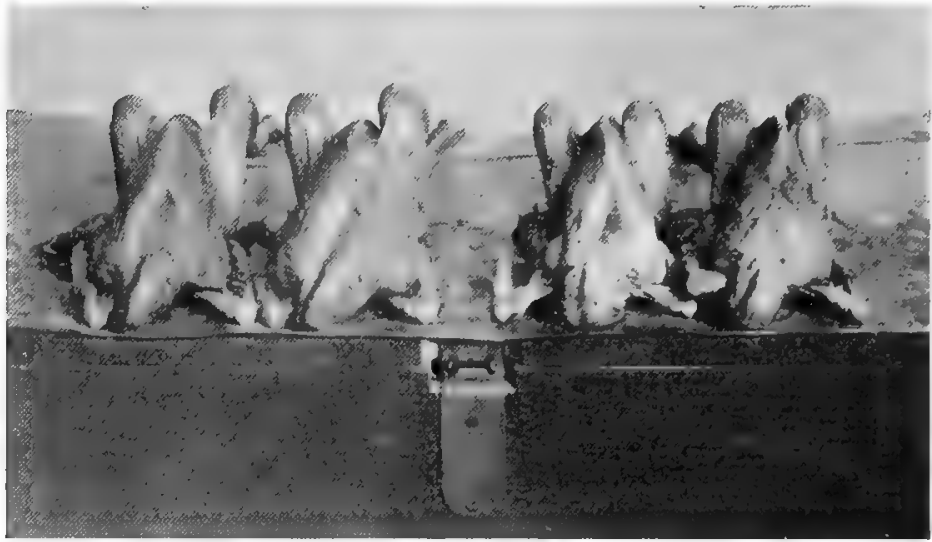

Fig. 146.-Two pairs of broilers. Those on the left are plump, full breasted and properly finished. Those on the right have not been properly fed and are thin and narrow breasted. A plump carcass is necessary if the bird is to be the best for eating.

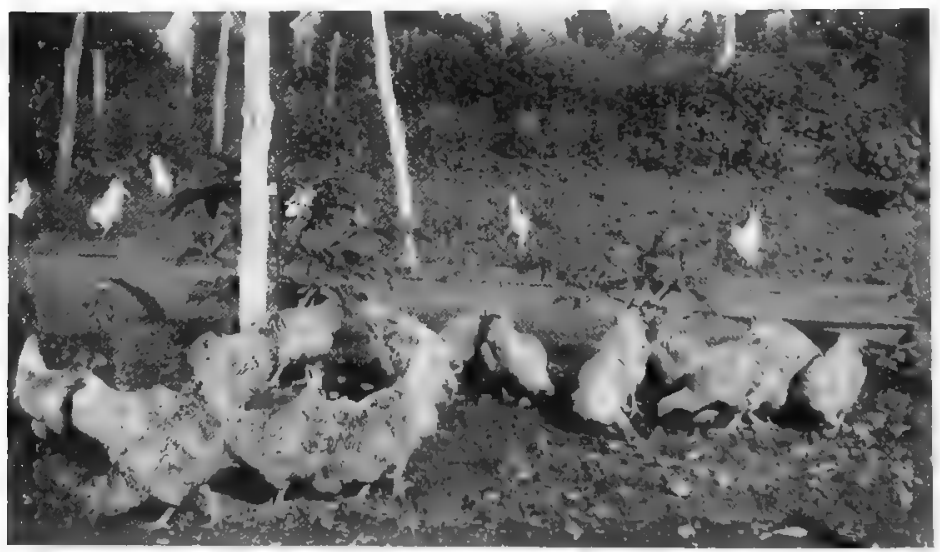

Frg. 147.-A flock of roaster chickeng about ready for market. 


\section{PRINCIPLES INVOLVED IN FEEDING FOR FLESH}

Feeding for flesh, as the term implies, is essentially a fattening process. There are a few definite principles which, if followed, will put considerable fat on the birds in a short time.

Restriction of Exercise.-The first principle in feeding for flesh is to keep the birds somewhat closely confined either in special coops or small yards. This confinement prevents them from roaming, henc' less feed is required for heat and energy. At the same time more of the feed they consume is stored up in their bodies as a reserve feed supply, and this reserve takes the form of fatty tissue.

\section{Rations Should Be Rich in Carbohydrates and Fat.-} Carbohydrates and fat are the two feed nutrients especially utilized in the formation of surplus body fat. Hence rations for fattening should be rather rich in carbohydrates and fat, as compared with nitrogenous feed elements; that is, the rations should be wide.

Plenty of Protein Needed.-In fattening birds, it is not only desirable that they should put on fat in order to be in the best condition, but they must be plump, and the whole body well covered with flesh or lean meat. Protein is necessary to form this flesh; hence the fattening ration should contain some nutritious and easily digested form of nitrogenous material. Meat scrap and granulated bone are usually the best.

Moist Feeding.-Fattening by means of well moistened feed has become very popular. First, because no excessive exercise on the part of the birds is necessary to consume it. Second, the birds relish it and usually eat more if a ration is served in this way. Third, a moist ration is more easily digested because in a fine and soluble condition.

Plenty of Grit.-Plenty of sharp grit hastens the grinding of the feed material, and also grinds it finer, which makes 
it much more easily digested. Birds confined to a small coop or yard are often deprived of all natural sources of grit, and it must then be provided in the fattening ration.

Maintenance of a Good Appetite.-If the birds are to be made to grow fast, they must keep up a good appetite. Too much feed will often result in getting them off their feed, and birds once off their feed while in the fattening yard rarely make any satisfactory gain. The best way to insure a good appetite is to allow them to become hungry and anxious for feed for a short time before each feeding. These are the fundamental principles in feeding for increase in weight, and they should be borne in mind and carried out during all fattening processes.

\section{METHODS OF FATTENING}

Three methods are commonly employed in fattening poultry: the flock method, crate fattening, and cramming. They will now be briefly discussed.

Pen or Flock Fattening.-Flock fattening is a term used to describe the fattening of a large number of birds for fleshy growth, usually in the finishing of broilers and fowls, and with very little labor. The birds are kept in large flocks, in small yards, and exercise restricted (Fig. 148). They are thus easily confined and fed, and they grow and put on flesh rapidly. Fowls are usually fit for market without any fattening process. If not, they can be fattened for about two weeks, the whole flock being restricted to a small area. Two rations are generally used in feeding flocks for fleshy growth, one a mash ration, which can be fed either wet or dry. Whole or cracked corn is usually combined with the mash, since corn, either whole or cracked, constitutes the main grain feed. This grain is especially high in carbohydrates, and valuable for that reason.

Finishing Ration for Broilers.-Often it is desirable to finish young chicks for two or three weeks before killing and 
marketing them as broilers, and this should be done right in the brooder pens where they were reared. The object is to make them a little plumper and heavier in a short time, and the following ration is excellent for this purpose. It should be mixed with skim milk and fed in a crumbly state, not sloppy.

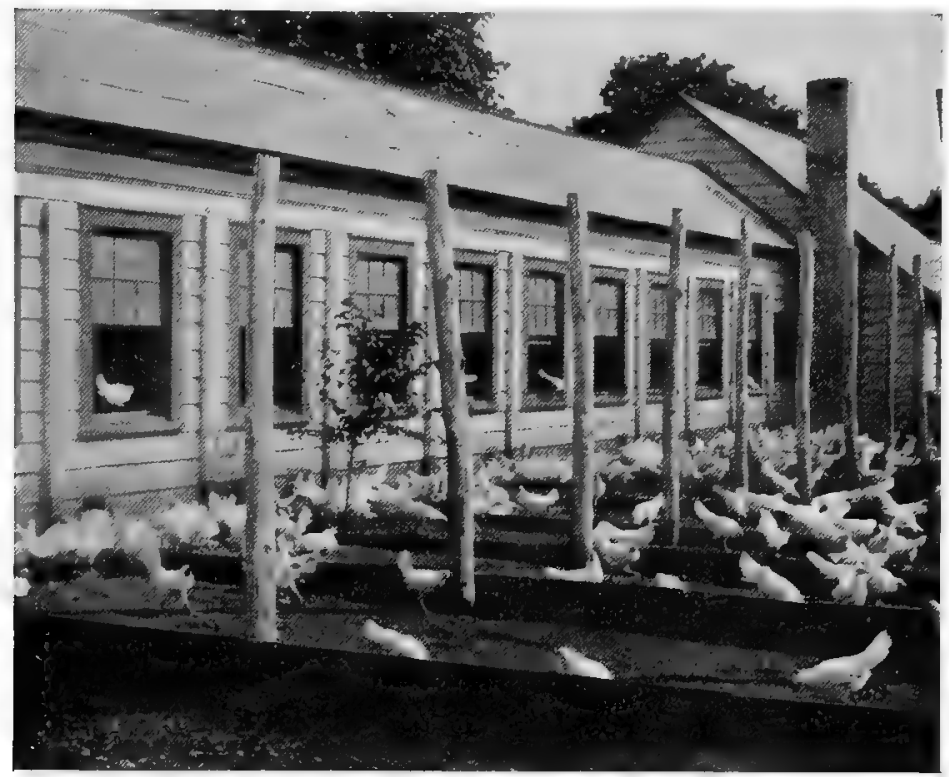

Frg. 148.-Broilers being finished on a commercial scale. The birds are confined to these small yards and fed the rations here recommended.

\section{Broiler Mash}

Kind of Feed

Corn meal...................... 25 pounds

Ground oats.................... 25 pounds

Beef scrap..................... 15 pounds

Granulated bone............... 10 pounds

Wheat middlings............... 25 pounds

Total................ 100 pounds

Moisten with skim milk and feed in a trough. Be sure the feeding troughs are kept clean, and that the mash is 
not mixed too wet or sloppy. Supplement this with a ration of equal parts cracked corn and wheat.

Rations for Fattening Fowls.-Fowls can very easily and quickly be fattened if kept in close yards in flocks from 10 to 25. They should be given a cracked grain ration of equal parts of whole corn and wheat, three times a day. This can be scattered over the bare ground, where they will eat it up quickly. Broilers and fowls should not be especially fed for more than two weeks, as they will reach their maximum weight in about 12 to 14 days, and after this will

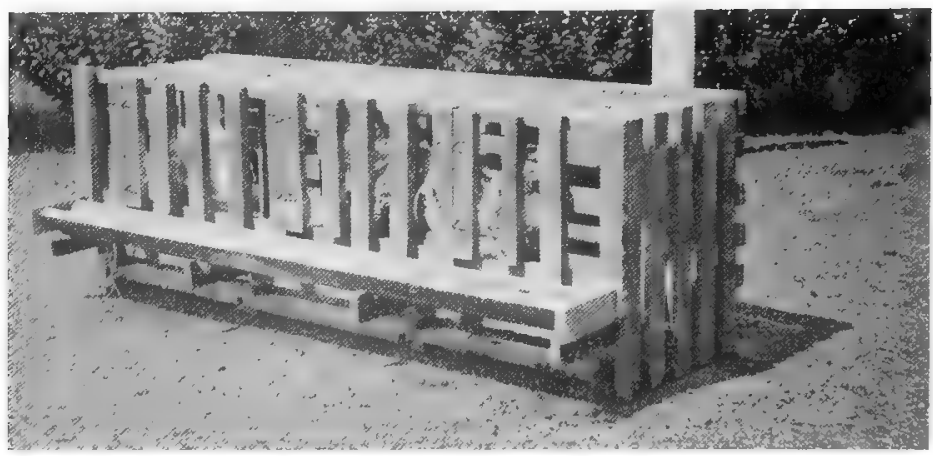

FIG. 149.-Cockerels being fattened in a homemade fattening crate. The trough along the front is for the feeding of very moist mashes. No water is given during the feeding period.

begin to lose. Special care must be exercised to keep the yards in clean and sanitary condition.

Crate fattening (Fig. 149) is a mode of bringing roasting chickens into prime condition for market. The custom is to confine the birds in specially constructed coops or crates, which are light, portable, and easily cleaned. The standard fattening crate is about righteen by twenty-four inches square, and fourteen inches high, and will hold from four to six chickens. These crates usually have movable floors to facilitate cleaning. The bird in poor condition will gain much more rapidly in wright than the one which 
was vigorous when put in the crate. The ration most used is a mash, fed moist in a trough. There are usually three or four feedings a day, according to the appetite of the birds; as a rule the rations contain a good deul of corn meal, oats, and meat. The birds shoukl not be kept in the crate longer than three weeks. They will obtain their maximum weight in from eighteen to twenty-one days, and after this time are apt to lose slightly, owing to the close confinement and want of appetite.

Crate Fattening Ration.- The following ration has given wonderful results in crate fattening. It should be mixed as moist as possible with skim milk; if none of this is at hand, water will answer the same purpose. It is best fed in pans or water-tight troughs. No water should be given to the birds during the fattening or finishing period, as the mash is moist enough to supply all that is necessary.

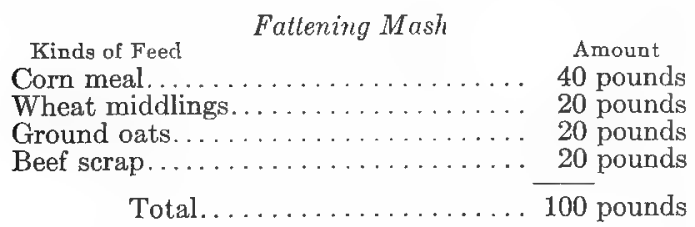

Where wet mashes are given, clean feeding is most essential. What remains in the feeding vessel is apt to become sour, and affect the digestive system unfavorably.

No mash should be left in the troughs between feeding times. When the birds are not eating it is well to darken the room to keep them quiet.

Cramming.-Cramming, as the term implies, is forced or artificial feeding. Feed is forced into the birds' crop either by hand or by a specially constructed apparatus. Cramming is not much practised in the United States, but has met with marked success in England.

The ration recommended for crate fattening can also be used for cramming. All success in artificial feeding depends 
upon the experience and judgment of the feeder. The birds can be easily injured. It is also easy to get them off their feed by lack of judgment as to the amount of feed given them. The most practical method of putting an average flock into good condition is by pen or flock feeding. If this does not produce enough flesh, they can be finished off for two or three weeks in the crate.

Commercial Fattening.-Some of the best poultry raised in America are fattened for market in the large fattening establishments of the Central West. The birds are lowgrade stock picked up on farms, especially in the South, and shipped by the carload to fattening establishments. Two or three weeks of forced feeding put the majority of them into prime condition. When fat enough they are dressed and shipped by cold storage to the centers of consumption, New York City and Philadelphia being the heaviest receiving points. The poultryman with only a few birds to sell will find it to his advantage to fatten them up. Plump birds are in greater demand, and bring a higher price, and have a finer flavor, than poor ones, to say nothing of their appearance.

\section{LABORATORY EXERCISE}

Exercise No. 67.-A Comparison of Flock and Crate Fattening.-Secure ten nearly mature cockerels. Divide them into two flocks. Allow one flock considerable yard room. Confine the other flock in a very small area. A box or crate will suffice. Feed both flocks according to the method suggested for crate fattening. Weigh the flocks at the beginning of the feeding period and each day for four weeks. Determine the efficiency of close confinement vs. some range. At what time was the greatest gain in weight made? Keep a record of the feed consumed and determine the efficiency of the fattening process. Poor birds will show a greater gain than fat ones. 


\section{THOUGHT QUESTIONS}

1. What is meant by feeding for flesh?

2. Why is considerable fat desired on market poultry?

3. Into what three classes may all birds which are being fed for market be placed?

4. Discuss the broiler group.

5. What is included in the group called roasting chickens?

6. What is meant by the trade name "fowls"?

7. Enumerate the principles involved when feeding for flesh growth.

8. Why is it necessary to restrict exercise?

9. Why should a flesh producing ration be relatively high in carbohydrates and fat?

10. What forms of concentrated protein feed can best be used in feeding for flesh?

11. Why is a moist mash more fattening than a dry mash?

12. Why is plenty of grit especially necessary in feeding for flesh?

13. Are birds which are being forced apt to get off their feed or lose their appetite?

14. What three methods of fattening are in use?

15. Define the meaning of the term "pen or flock fattening."

16. What methods of feeding are usually followed in flock fattening?

17. Give a good broiler finishing ration.

18. Discuss the fattening of fowls.

19. What is crate fattening?

20. Give in detail a good crate fattening ration.

21 . What is meant by the process of cramming?

22 . Tell what you know about commercial fattening on a large scale. 


\title{
PART V \\ POULTRY PRODUCTS
}

\author{
C'HAPTER XXVII
}

\section{VARIETY OF PRODUCTS}

POULTRY keeping affords a variety of products, the number being probably greater than in any other branch of agriculture. These products may be of two kinds: Perishable and partially perishable. Dressed poultry is of a highly perishable nature and must be shipped well iced or in cold storage. Eggs and live birds are less perishable in nature, and can be shipped considerable distance without material injury, which can not be said of milk and butter, the most important of dairy products. The demand for poultry products is constantly increasing, especially for table eggs and dressed poultry. This growing demand is probably due to the increasingly high price of beef and pork; hence eggs are more and more used to take the place of meat.

Utility and Fancy Products.-We frequently hear the terms "utility" and "fancy" applied to poultry. The term "utility" means poultry bred exclusively for food. "Fancy" means birds sold either for breeding purposes or for fancy feathers. To-day there is much closer co-operation between these two lines of poultry production than ever before, while there is also a growing demand for birds with high utility value. Utility, in this sense, means the ability to yield a product which is in steady demand for consumption as human food. The poultry keeper more and more appreciates the fact, that to be profitable, his flock must yield utility products :L well as be valuable for exhibition. More attention is now 
being paid to pure bred poultry; therefore, it is to be hoped that all true utility poultrymen will aim to have their birds well bred, vigorous, and of a standard type.

\section{POULTRY PRODUCTS}

All poultry products yielded by the average flock, which can be sold to bring in revenue, can be grouped into three general classes. First, products sold for food; second, products for breeding purposes or the reproduction of other birds; third, miscellaneous products, commonly called byproducts. In the following discussion poultry products will be divided into these three groups, and briefly discussed.

\section{FOOD PRODUCTS}

Poultry products which can be used for food are of two varieties, eggs and meat.

Table Eggs. - Table eggs constitute the bulk of all poultry products, being produced by every flock in America. The profits resulting therefrom depend upon the outlay necessary to secure the products. There is a great demand for table eggs, especially in large cities, and they must be of uniform quality, as regards freshness. Some highly specialized markets demand eggs which are uniform as to shell, while retail markets call especially for eggs uniform in shape, size, and general appearance (Fig. 150). Eggs are in demand at all seasons; in the winter we find the biggest demand in cities,

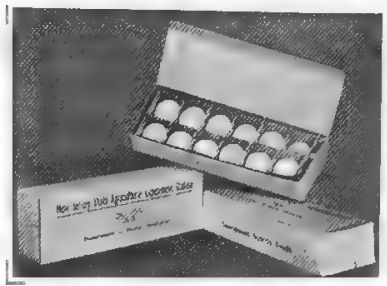

Fig. 150.-Table eggs of good quality packed in cartons. This method of packing is especially adapted to a retail trade or where the eggs are sold direet to the consumer.

in summer at seashore and other summer resorts. The demand is so constant that it does not materially affect their cost, the supply being the factor which controls the price. During the months when hens produce but few 
eggs, the price is high. In summer and even more so in the early spring when hens are producing heavily, eggs are cheap. Prices vary continually during the year, ranging from twenty-three to sixty cents. In wholesale markets, an average price of from thirty to thirty-five cents per dozen should be realized.

Eggs are divided into three classes, fresh, held, and storage. Fresh eggs are those which have been carefully handled, and are shipped immediately after laying to the point of distribution. Held eggs are those which have been held by the farmer or poultryman for some time after being laid. The incentive for holding them is the belief that prices will go up, and that more money can be gotten for them. Held eggs are usually of inferior quality, and the air cell is apt to be large, due to evaporation. They do not bring as high a market price as fresh eggs. Storage eggs are those which have been in cold storage, the temperature being kept at a low point by artificial refrigeration. Such eggs, if properly packed, and not kept longer than six to eight months, are good when taken out. It costs on an average from six to sixteen cents to produce one dozen eggs. This varies, of course, considerably, with seasons, being high in winter, and low in summer. It also varies with the breed kept, and the age of the layers. Pullets produce eggs more cheaply than hens. Leghorns produce more cheaply than heavier breeds. The amount of production will vary with season and breed. Different flocks of hens may average from 120 to 150 eggs, but in order to attain this average hens must be good layers in cold, winter weather. The profit to be realized from commercial egg production varies somewhat with the breed and size of the flock kept. Birds in good health, producing the amount specified, should yield a profit of from $\$ 1.00$ to $\$ 2.50$ per year. Commercial egg production is a profitable branch of poultry keeping, but more attention might be paid to this source of income with the averinge flock. 
Market Poultry.-Poultry designed for the table may be classified into three groups: Broilers, roasting chickens, and fowls. The demand for these three different classes depends largely upon the means of the customer. In buying broilers and roasters, quality is what the high prices are paid for. With fowls, quantity is the object desired by the consumer, hence lower prices prevail.

Broilers.-Broilers are young chickens that are usually sold when from ten to fifteen weeks old. To bring the best prices, they must have been quickly grown and must be

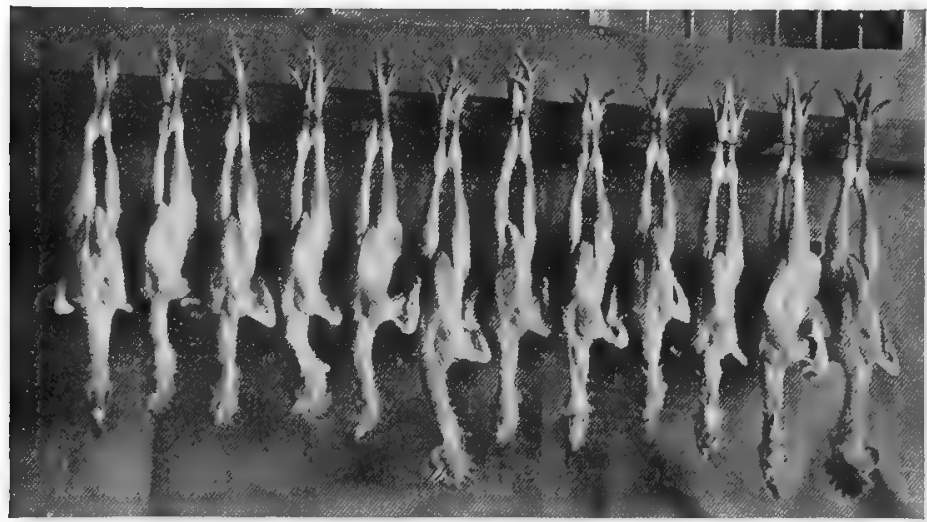

FIG. 151. - White Leghorn broilers plucked and ready for delivery. These birds are twelve weeks old, weigh about two pounds each, and are called medium broilers.

plump (Fig. 151). Three types are called for by the trade: Small, medium, and large. Small broilers weigh about one and one-half pounds, and large ones sometimes two and onehalf pounds apiece. Broilers, especially the small type, are frequently sold by the pair. They are demanded by highclass hotels and restaurants, and by well-to-do families. There is not much meat on them, but they are considered rather a delicacy.

There are two seasons for broilers: First, the special or artificial season, which is during the winter and early spring. 
The poultryman must prepare in advance for this trade. He must hatch the chicks in the fall and winter, and have them ready for market in January, February, and March. The natural season for broilers comes in the months of May, June, and July, when the surplus cockerels which result from the hatching of pullets for layers, reach the broiler age.

Most of the broilers sold are raised as a side line to egg production. There are a few special broiler farms about the country, but, as a rule, they are not financially a success. It costs from twenty to thirty cents to produce a broiler; this includes the egg and the fecd. Prices vary considerably during the special broiler season in the winter, and there is a noticeable drop in price about the first of June, when the natural supply floods the market. The largest profits are realized from broilers if they can be made marketable before the natural supply reaches the market.

Roasting Chickens. - The term "roasting chickens" applies both to pullets and cockerels sold for roasting, and usually marketed when from eight to ten months old. The idea is to market them just before they reach maturity. There are two market types, the small and large roaster. The small roaster ranges in weight from four to five pounds, the large from six to eight (Fig. 152). The natural roasting season is in the fall and winter, and the heaviest demand usually comes in the holiday seasons of Thanksgiving and Christmas. Roasters bring a price of from twenty-four to thirty cents a pound, and they can be made very profitable if grown on free range.

There are three types of roasting chickens: Cockerels, pullets, and capons. Cockerels are generally produced as a byproduct to egg farming, and are marketed for roasting during August, September, and October. In a fow sections they are produced purposely to ater to the roasting trade, and then they undergo a fattening process to put them in prime condition for market. Pullets are rarcly sold for roasters except 
when bred on special roaster farms, to be sold as roasters to the large fattening establishments in the central part of the country. The highest priced roasting chicken is known as the milk and corn fed pullet, a plump but immature bird, which, by a special method of fattening, is put into prime condition for eating. Capons possess many advantages over the cockerel. They can be produced much more cheaply; they grow to a larger size, the quality of the meat is much better, and they bring a higher price (Fig. 153). The price for a cockerel roaster averages about 26 cents, and for a capon roaster about 34 cents. The demand is steady and

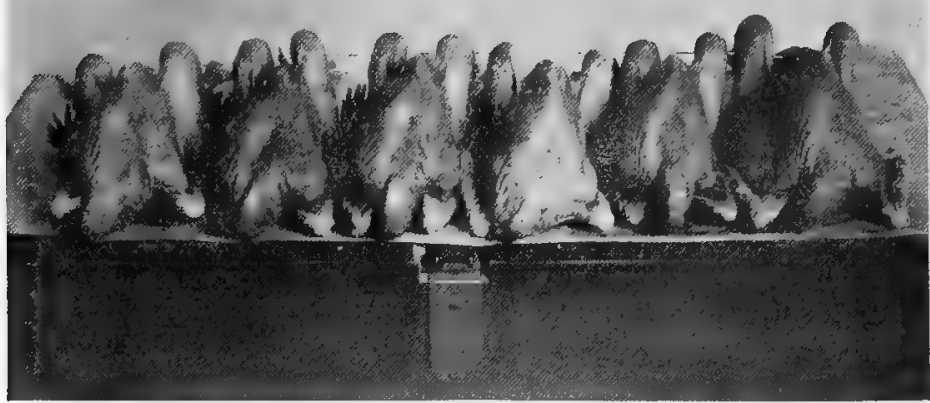

FIG. 152.-Six small roasters, weighing four pounds each. Note the plumpness, which is necessary if they are to be in demand for eating.

constantly increasing, and the time is coming when a poultryman, to realize the largest profits from his male birds, must resort to caponizing.

Fowls.-Fowls are old hens: They are usually marketed after their pullet or second year in the laying pen; but they bring a fair price in the market at any season of the year. They are especially in demand in the large markets in the late summer and early fall, and the immense Jewish trade materially affects prices during the Jewish holidays. Fowls are often bought and sold alive, but market poultry will usually bring the highest prices when shipped dressed. 


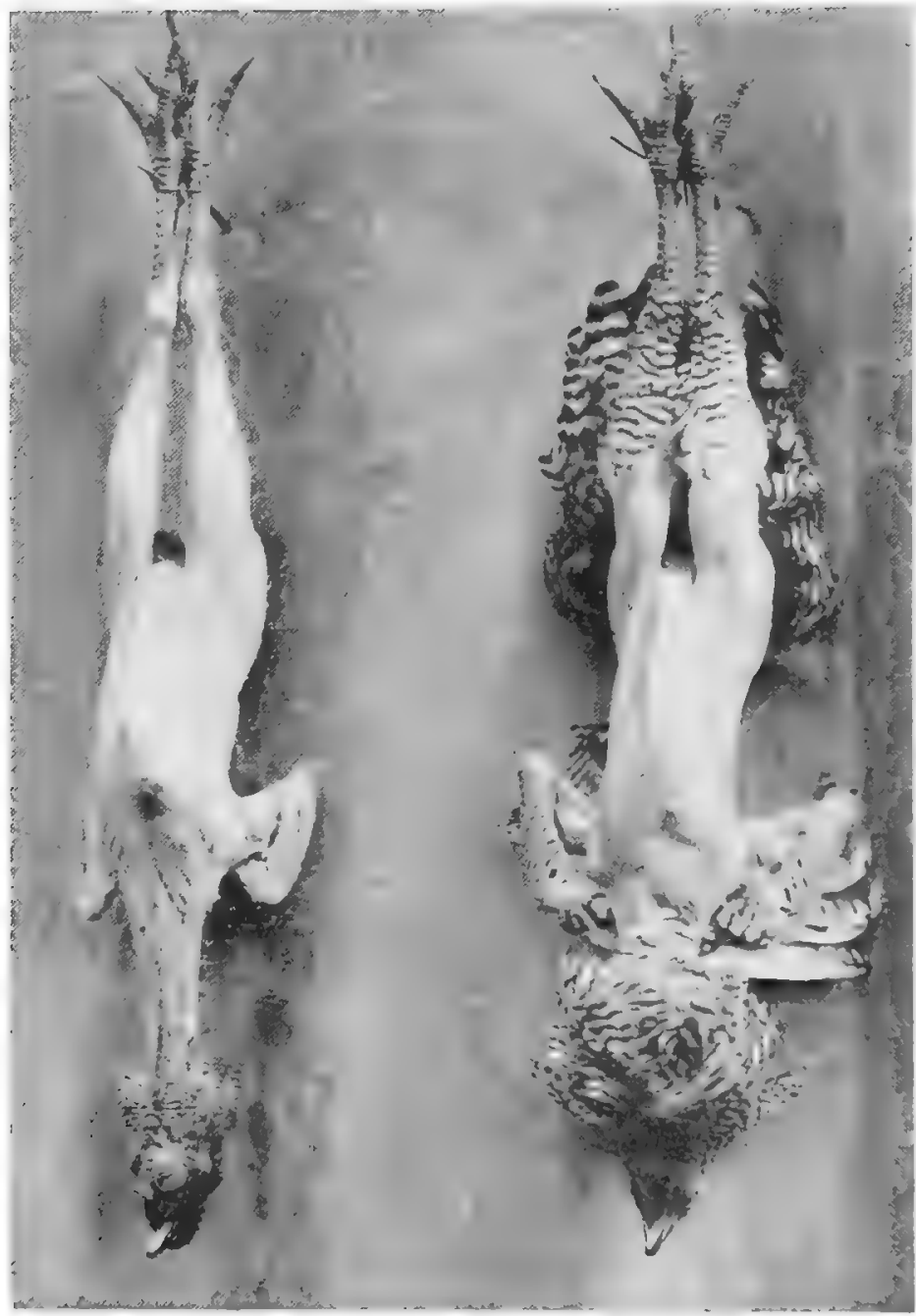

Fra. 153.-A Barred Plymouth Rock cockerel and capon. The capon is shown with the neck, wing and thigh feathers unplueked. This rapon wrighs one pound more than the ruckerel at the same uge. The capon makes the best market poultry. 


\section{PRODUCTION OF POULTRY FOR BREEDING PURPOSES OR REPRODUCTION}

Eggs and birds sold for breeding bring relatively higher prices than when sold for food. Abnormally high prices are not always certain, and prevail for only exceedingly good birds. The aim of the poultry kecper should be to combine in his birds both good breeding qualities and points of utility. In addition to the products mentioned above considerable revenue can be brought in by the sale of hatching eggs, of baby chicks, of males and females for breeding, and of pullets for laying.

Hatching Eggs.-During the months of March, April, and May, the demand for utility hatching eggs is very good. Prices range from $\$ 5.00$ to $\$ 10.00$ per 100 . Much higher prices are received for eggs in small quantity if produced by hens of exceptionally fine quality. The possibilities in selling hatching eggs are great, especially on a commercial egg farm. Good birds can be kept, and properly mated. All eggs from such hens that are sold for hatching bring about double the price they would if sold for food, and this increased revenue is all profit.

Baby Chicks.-There is a great demand for baby chicks, and it reaches its height in April, May, and June. The chicks are hatched in large numbers at commercial plants, and shipped immediately after hatching. If properly packed they can be sent considerable distances without injury. Baby chicks of good quality stock usually bring from $\$ 10.00$ to $\$ 20.00$ dollars per 100 . The profits of the baby chick business are excellent, if one has good facilities for hatching them.

Birds for Breeding.-Strong and vigorous adult birds for breeding can usually be disposed of in large numbers during the winter and early spring, and bring a good price; this ranges from $\$ 3.00$ to $\$ 10.00$ apiece. They often bring more than this, but in order to do so must be of exceptionally fine quality (Fig. 154). The selling of breeding birds can not be developed to any great extent on commercial poultry farms. 
Pullets for Layers.- The demand for pullets, fully grown, to be used in the laying flock is usually greatest in August and September, and prices range from $\$ 1.00$ to $\$ 2.00$ apiece. Such birds can be grown at a cost of from 60 to 85 cents; if free range is available, they will net the poultryman considerable profit.

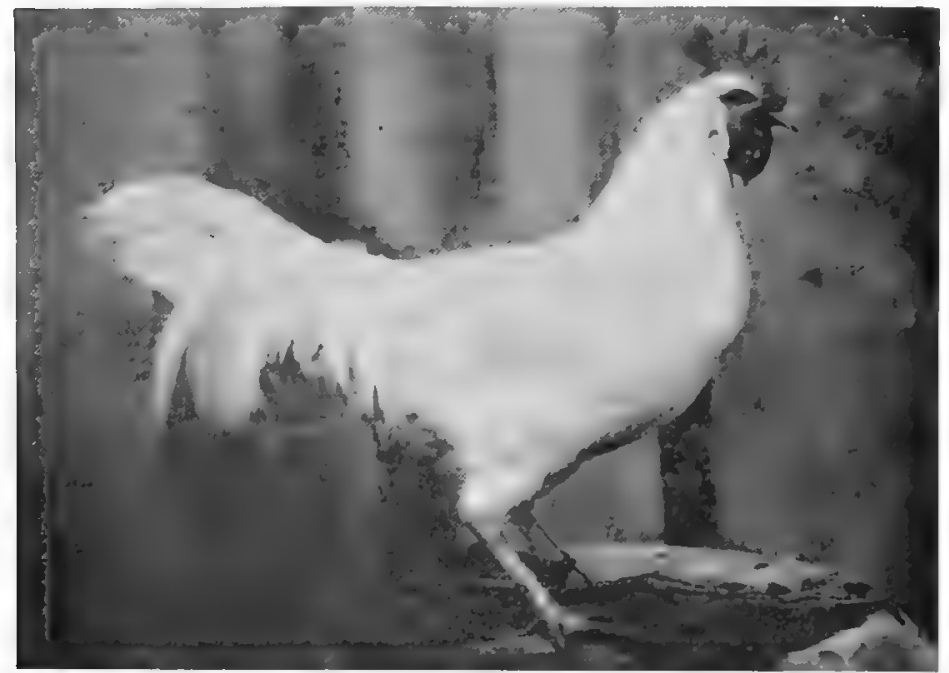

Fia. 154.-An ideal bird to be used or sold for breeding. Note especially the full breast and aigns of high vitality.

\section{BY-PRODUCTS}

There are two by-products of the poultry yard that are worthy of care. These are feathers and poultry manure. The feathers are considered quite a marketable product, if many hirds are dressed, as they can be sold for 20 to 40 cents a pound. If not produced in large enough quantities for market they can be utilized in making pillows, etc., at home. When the fenthers are to be saved the hirds should be plucked dry, the fenthers then spread out and thoroughly aired before they are bagged up. 
Poultry manure for fertilizing purposes should be kept in a dry place, and well mixed with gypsum or dry loam. A flock of 100 birds will produce in a year between 500 and 600 pounds (Fig. 155). The product is highly fertile, and well adapted for use in the home garden. If there is considerable quantity, it can be sold for from $\$ 3.00$ to $\$ 4.00$ a ton.

\section{LABORATORY EXERCISES}

Exercise No. 68.-Fresh and Held Eggs.-Take one dozen fresh eggs and place on a shelf in the schoolroom and leave there for five or six weeks. At the expiration of this time

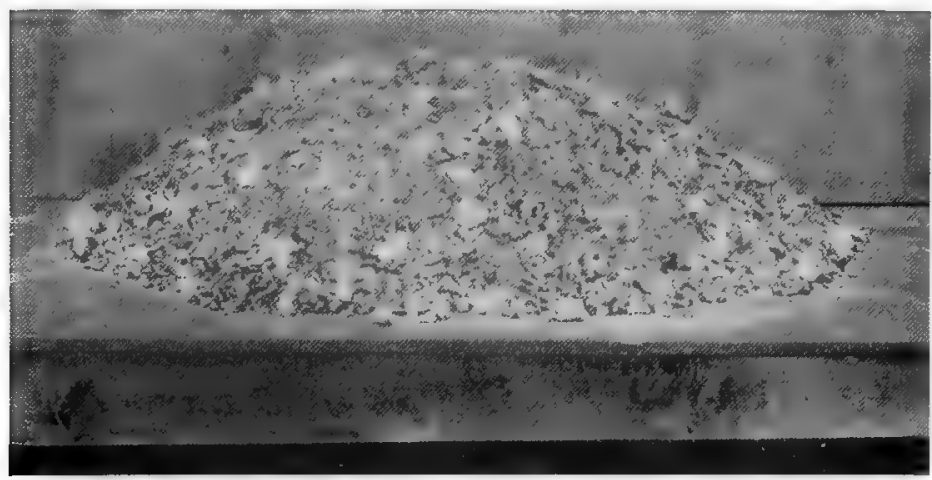

FIG. 155.-The amount of droppings voided by one ben in a year. The average is estimated at from fifty to sixty pounds, only a small portion of which can be collected and saved.

secure one dozen strictly fresh eggs. Compare the held and fresh eggs as regards the following points: Flavor, raw and cooked, size of air cell, shell lustre, hardness or toughness of yolk sac when the egg is broken and allowed to run into a dish. Why is the air cell larger in the held egg?

Exercise No. 69.-Weight of Eggs.-Have the pupils bring to class a dozen eggs each from as many flocks as possible. Weigh each dozen eggs and have determined the average weight per egg. If eggs can be secured from different breeds the comparison will be all the more interesting. 
Exercise No. 70.-Weight of Broilers.-Weigh a number of chickens about ten to sixteen weeks of age. Determine the different classes into which they would fall if shipped to market at that time. Examine the condition of plumpness and compactness. Do these factors appear to be one of breed, or care and feeding, or both?

Exercise No.71.-Curing Feathers.-When birds are plucked as called for in a later exercise on killing and picking, save the feathers, being careful to keep them clean. Dry and cure them as described. When cured a pillow or other useful article may be made for the schoolroom. Weigh the feathers before and after curing. Determine the weight of feathers obtained from each bird.

\section{THOUGHT QUESTIONS}

1. How does the variety of poultry products compare with those from other lines of agriculture?

2. Poultry raising may be for what two general purposes?

3. What about the demand for poultry products?

4. What is meant by utility and fancy poultry products?

5. Which type of product is of most importance?

6. Into what three groups can all marketable poultry products be divided?

7. Discuss fully table eggs as a poultry product.

8. What profit can usually be realized from egg production?

9. Discuss broilers as a marketable product.

10. What about market prices and profit from broilers?

11. Enumerate the important facts which treat of roasting chickens as a marketable product.

12. Enumerate the different poultry products which are sometimes sold for breeding or propagating purposes.

13. When is the natural demand for eggs for hatching?

14. What prices are generally received for hatching eggs?

15. What are the possibilities in producing baby chicks for sale as such?

16. Discuss the production and sale of breeding birds.

17. What prices can usually be obtained from the sale of mature pullets for laying?

18. What prices should be received for feathers?

19. How should feathers be prepared for market?

20. What method should be followed in order to properly preserve the poultry droppings?

Reference.-United States Farmers' Bulletin 452, Capons and Caponizing. 


\section{CHAPTER XXVIII}

\section{PREPARATION OF POULTRY PRODUCTS}

Tre demand for certain poultry products varies in different sections, and in different seasons. The market calls for certain distinct features. It should be the aim of the poultry keeper to study the markets, and cater to the specific clemand for products. It is an interesting fact that in Boston :and throughout New England the markets demand and pay ¿ premium for brown-shelled eggs. The New York markets demand and pay a premium for white-shelled eggs. In Philadelphia and its vicinity there is no discrimination as to shell. The preparation necessiary to make any poultry product meet the demand costs but little, while the increase in selling prices is often quite material. so the poultry keeper, whether he has a small or large amount of poultry produce, ought to take pride in making it look neat and attractive.

\section{SPECIAL PREPARATION OF POULTRY AND EGGS FOR MARKET}

In this chapter we wili discuss some of the details which need careful attention when preparing poultry products for market.

Eggs.-Eggs shipped to market should always be of good quality and strictly fresh. No male birds should ever be permitted with the laying flocks at any time except the breeding season in the spring. If this precaution is taken the eggs will be infertile, and these are much better than fertile eggs. They never develop into chicks. They keep longer in cold storage, do not show blood rings, and are superior from every point of view. The nests for laying hens should be kept clean, and provided with plenty of fresh litter. If eggs are laid in dirty, filthy nests some of the 
filth is apt to make them deteriorate in quality, because the filth may get inside through the pores of the shells (Fig. 156). Eggs for food should be collected regularly, and at least once a day. They should never be taken from stolen nests or the incubator, for such eggs are usually of poor quality,

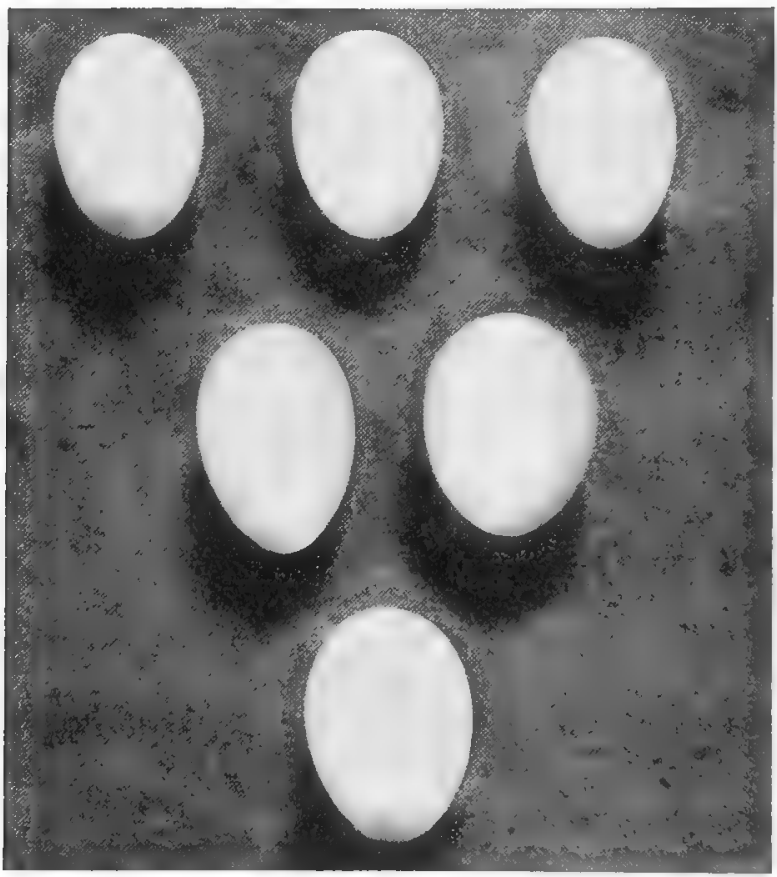

FIG. 156.-Undesirable types of eggs for market. The lower egg is clean and normal as to size and shape. The othors are dirty, thin-shelled, or cracked, Such eggs should be kept at home.

and may contain blood spots. In collecting eggs, be careful not to break the shell. A crack in the shell will allow the contents to leak out, run over other eggs, and spoil their appearance. After collection the eggs should be sorted and packed immediately. First, grade them according to the color of the shell, packing and shipping white- and brown- 
shelled eggs separately, particularly if the market pays a premium for one color over the other. To a certain extent, eggs should also be graded according to their size, putting in one box only eggs as nearly as possible of a uniform size. Exceptionally large or exceptionally small eggs should be kept for home use. If the market is high grade, it may be well to candle the eggs to make sure that none have blood spots. Blood spots may form in strictly fresh eggs, owing to injury of the oviduct during the formation of the egg. Pack the eggs in strong, durable cartons to avoid breakage. In packing

FIG. 157.

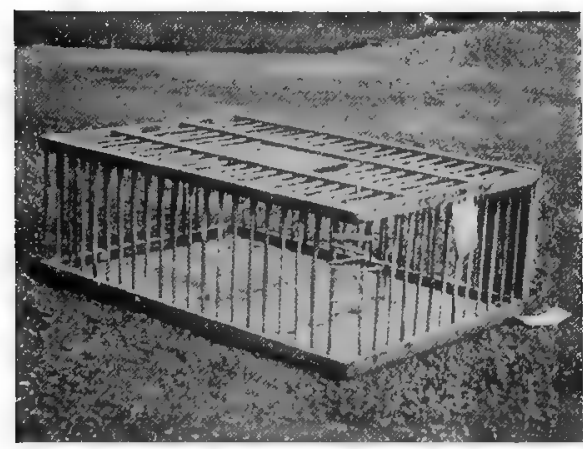

Fig. 158.

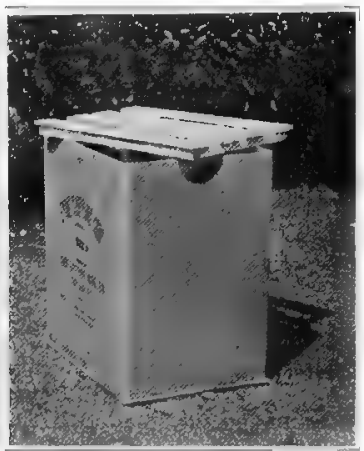

FIG. 157.-A crate used in the shipping of live poultry to market. FIG. 158.-A crate used to ship exhibition or breeding birds.

cases or crates of eggs, the top and bottom should be padded with excelsior or paper to keep the eggs from sudden jars and breaking. For retail or any other high class trade it may pay the poultryman to grade the eggs carefully and pack them in one-dozen boxes, these boxes being carefully labelled and sealed. Put up in this way eggs bring from three to six cents more per dozen than wholesale quotations.

Live Poultry.-When poultry is shipped alive it may be of two kinds. First, poultry shipped to commission merchants, ultimately reaching the butcher (Fig. 157). Second, breeding malès and females which are sold and must be 
shipped alive. Market poultry is shipped in small crates of about three by four feet, very lightly constructed and slatted. Crates for shipping exhibition birds are much heavier and more durable, the sides being usually solid, and the top slatted (Fig. 158). Solid sides protect birds from drafts, and also from any injury which might occur if they were allowed to stick their heads out of the crate. All live poultry should be shipped by express, and delivered to the express company at such a time that they can start on their journey immediately after packing. They should be provided with water and feed. Poultry shipped alive bring a smaller price per pound, but it is often the best way in which to dispose of fowls and poor quality birds.

Dressed Poultry. - The fattening of poultry has been previously discussed. The preparation of dressed poultry for market consists of three distinct operations; killing, picking and packing. Birds may be killed in one of two ways. The first, and probably the most common, is beheading, or cutting off the head, as is done on farms and by inexperienced poultry keepers. Grasp the bird firmly by the feet and wings, being sure to hold it firmly to prevent fluttering. Place the head on a chopping block, and sever it from the body by one blow with a sharp axe or hatchet (Fig. 159). The bird should be held firmly for two or three minutes until bleeding and fluttering have ceased.

The second method of killing is called sticking. This consists in severing with a sharp knife, the large artery in the back of the mouth (Fig. 160). This method is common in killing poultry for market. The bird is suspended by the feet, the head being on a line with the waist of the killer. The head is grasped in the left hand, and the knife in the right. With the point of the knife an incision is made at the back of the mouth on the left side. This severs the large artery and, if the head is held down, blecding will be profuse. 
The process is then completed by inserting the knife through the slit in the top of the mouth until it hits the brain. This punctures the lower part of the brain, and makes the bird lose control of its muscles. The feathers can then be plucked

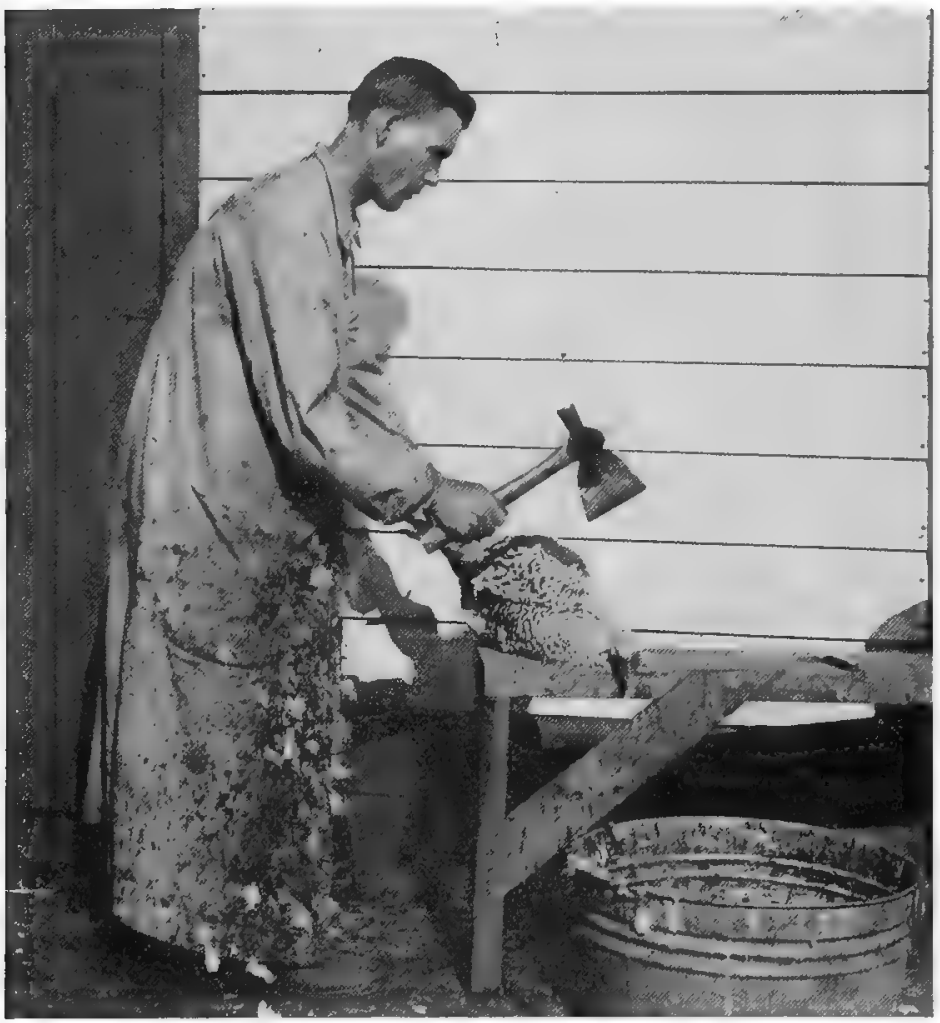

Fig. 159.-Beheading a chicken. The method of killing usually employed on farms and with small poultry floeks.

more easily. Sticking is by far the best method of killing a bird for market. If the bird is for the home table, beheading is just as satisfactory.

Picking is the process of removing the plumage from the 
A
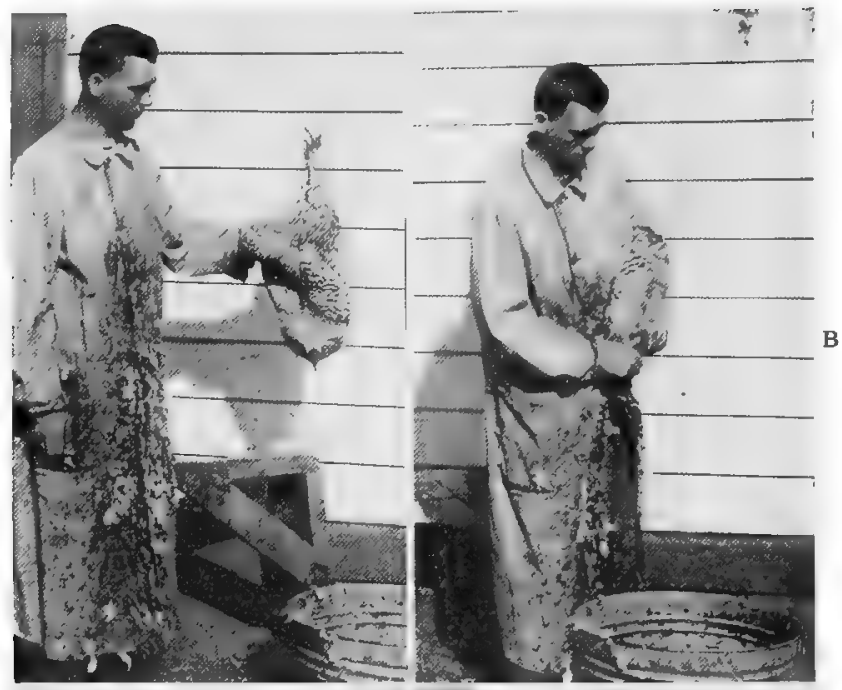

B
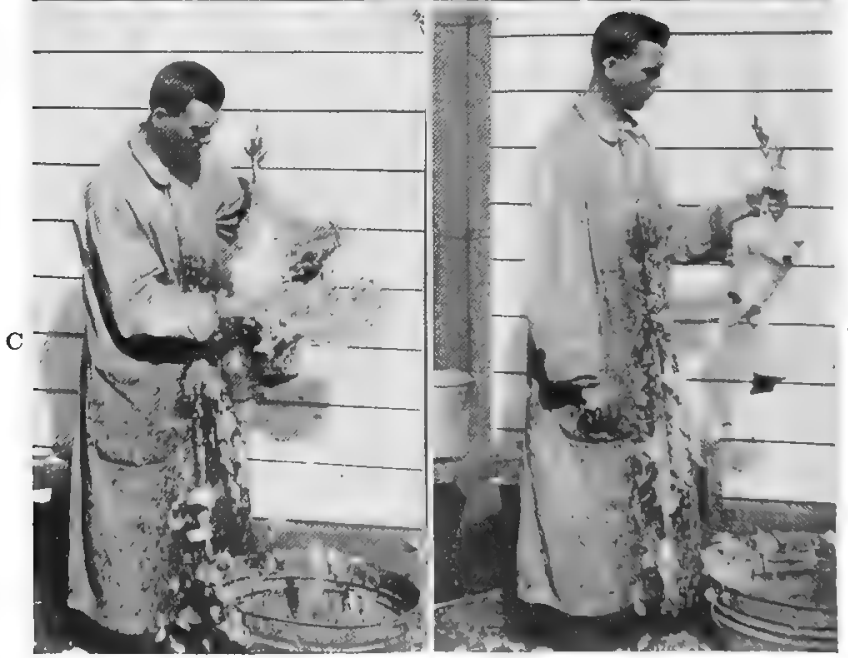

FIG. 160.-The lending operations in sticking and dry picking a bird for market. $A$, The bird suspended by the feet. The head should be on a line with the killer's waist. $B$, The operator severing the artery at the back of the mouth with a sharp knife. $C$, Immodiately after sticking, the feathers are plucked quickly and carefully. $D$, The bird completely pickod and ready for ohilling in cold water. 
bird. Two methods prevail, known as dry picking and wet picking. In dry picking the birds are plucked immediately after killing, and if properly bled the plumage can be plucked before the animal heat has left the body. Dry picking is not used extensively except where the birds are prepared for market. The method is to suspend the birds by the feet, and then remove the feathers quickly by a downward motion of the hand, grasping the feathers by the thumb and forefinger, and pulling in the direction opposite to that in which they grew. In certain parts of the birds the skin is very tender and the feathers large, and here one must be careful not to tear the skin. These spots are usually plucked first while the feathers pull easy. Among the tender places which might be mentioned are the sides of the breast, the inner joint of the wing, the thighs, and the neck.

The second method of picking is commonly called scalding. Immediately after the bird is killed immerse it in water, heated to just below the boiling point. Dip it in the water two or three times so that it is thoroughly saturated, clear to the skin. The hot water makes the feathers come out easily. As soon as the bird is scalded the feathers are rapidly plucked, pulling out a good many at a time. Scalding is usually done when birds are beheaded, and is a very satisfactory way of picking for home use. But scalding poultry for market is not a good practice; it spoils the appearance of the carcass, and prevents it from keeping well. Scalded poultry, too, does not bring as high a price as the dry picked, even though of the same quality.

After the birds have been picked they should be immediately immersed in cool water and left an hour or more (Fig. 161). This takes the animal heat out of the body, and makes them plump. When taken out of the water, wash the feet and shanks to remove any dirt, and the head and mouth parts to free them from any blood stains. Poultry can be shipped to market in boxes or barrels, but in either case 
should be packed in ice. The best way is to pack the birds very tight, layer upon layer, with a considerable quantity of cracked ice placed between each layer. The amount of ice used will depend upon the season. Birds are usually packed on the side, as this makes them fit into the receptacle more closely and neatly. When shipped long distances they are usually dry packed, and shipped in cold storage or re-

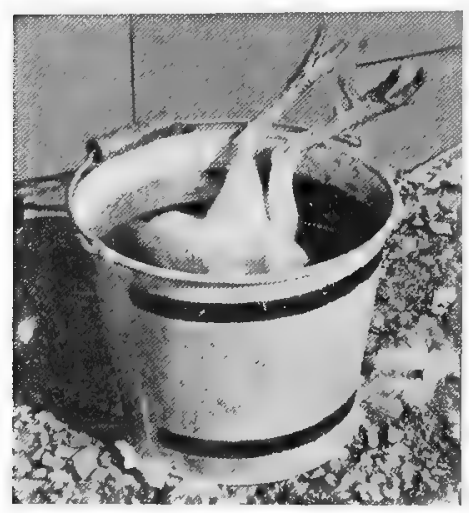

FIG. 161.-The plucked carcass is cooled by immersing in cold water for at least one hour immediately after picking. frigerator cars. Dressed poultry shipped only short distances to market should always be sent by express.

Hatching Eggs. - The great essential in the hatching egg is high fertility; this means good, vigorous germs which will hatch into strong chicks. In shipping eggs for hatching the poultryman should aim to give satisfaction. Eggs must be what they are represented to be. Hatching eggs should always be selected with special regard to uniformity in shape, size and color. Only those with uniformly hard and smooth shells should be sold, and they should be very carefully packed. In small quantities they can be wrapped in excelsior, and shipped in corrugated pasteboard boxes with separate compartments (Fig.162). Large quantities may be wrapped in excelsior and packed in large, thirty-dozen cases. Hatching eggs are often shipped in market baskets, the eggs being packed in pasteboard fillers, and the entire basket lined with excelsior. It should be plainly labelled so as to receive careful handling. All eggs for hatching should be shipped by express.

Baby Chicks.-The trade in baby chicks has developed a special container in which to ship them, and the best time 


\section{PREPARATION OF POULTRY PRODUCTS 291}

to ship them is immediately after they are taken from the incubator. At this age they have still within their bodies the absorbed yolk, which will supply them with food for a considerable time. If they are allowed to remain in the incubator or brooder for two or three days, and are then shipped, there is apt to be a heavy mortality. Corrugated pasteboard boxes, especially for shipping chicks, can be procured. They are divided into two small compartments

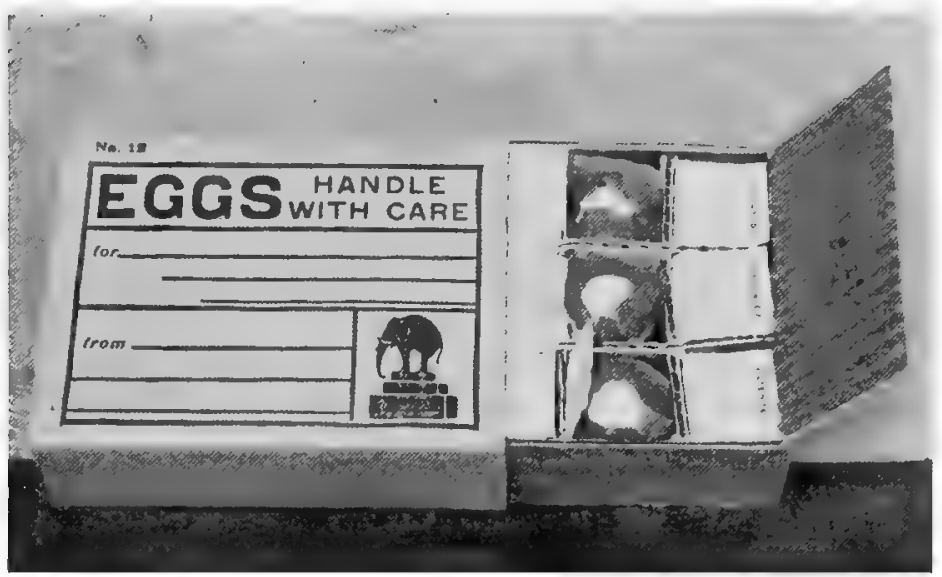

Frg. 162.-Fifteen hatching eggs packed in a corrugated pasteboard box for shipment by parcels post. Note how each egg is wrapped in felt and then inserted in a separate compartment protected by many layers of packing material.

and are well ventilated. In these 25 to 100 chicks can be safely shipped. Baby chicks should always be plainly labelled, so as to insure careful handling and quick delivery.

In conclusion, it may be said that two principles are fundamental, and should be borne in mind when preparing poultry for the trade. The first of these is that quality means higher prices, the satisfaction of customers, and business in the future. The second is that the poultry keeper should try in every way possible to meet the market demand for the particular product which he has for sale (Fig.163). 


\section{LABORATORY EXERCISES}

Exercise No. 72.-Grading and Packing Market Eggs.Have each member of the class bring to school fresh eggs in any number desired. Secure one or more shipping crates, depending upon the number of eggs to be brought. Go over the eggs carefully before the class, grade them according to instructions in the text. Candle them, letting each student handle his own eggs before the candle. The room may be

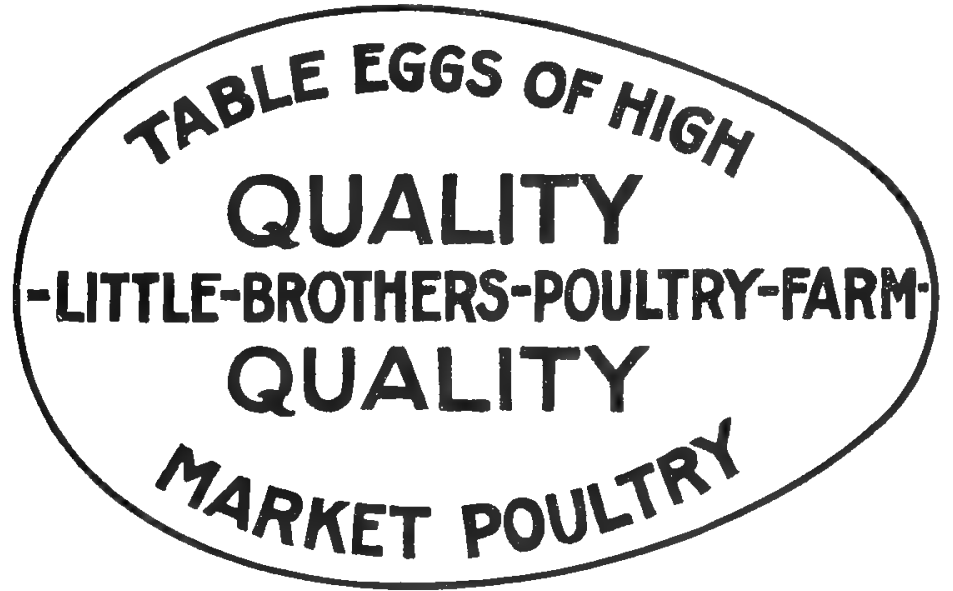

Fra. 163.-A neat trade mark for the young poultryman to use on his best products, which he sells retail. This will advertise bis fock and bring him customers.

darkened for this work, in which case the whole class can take part. Use the same candle used for testing incubator eggs. After grading, pack the eggs for shipment and ship to some wholesale market. When the returns are received, the amount can be divided pro rata among the pupils bringing eggs. Oftentimes an exercise of this kind will lead to some sort of co-operative marketing in the community. The school can often take a lrading part in such efforts.

Exercise No. 73.-Sticling and Dry Picking.-Demonstrate to the class the proper method to bleed, stick, and dry 
pick poultry. One or possibly a number of birds can be used. If the teacher is not qualified to do this work, a capable and willing person in the community can usually be secured. A bird may be scalded and picked at the same time to show the difference in appearance after picking.

Exercise No. 74.-Shipping Packages.-A small amount of effort will be required to secure a considerable assortment of boxes and crates such as are in common use in shipping poultry and eggs. A postal card to manufacturers stating object and asking for samples will bring all that is needed. The addresses can be secured from any poultry paper. Such a collection can be made the nucleus of a poultry exhibit or permanent museum. If room is available a special room or part of a room can be set aside for such a purpose. A few tables and shelves will meet the needs of the occasion.

\section{THOUGHT QUESTIONS}

1. What two factors affect the demand for poultry products?

2. How do the Boston, New York, and Philadelphia markets differ in their demand for eggs with different colored shells?

3 . What is the first requirement in eggs for eating?

4. Why are infertile eggs superior to fertile ones?

5. Will dirty nests affect the eggs laid in them?

6. Discuss the grading and packing of table eggs for shipment.

7. What two kinds of live poultry are shipped to market?

8. Enumerate some precautions which it is necessary to follow when shipping poultry alive.

9. What are the three operations which are necessary to prepare dressed poultry for market?

10. What are two common ways of killing poultry?

11. Describe the operation of sticking.

12. What are the two common methods of picking which usually prevail?

13. Describe in detail the process of dry picking.

14. When are birds generally scalded?

15. Describe the method of plumping.

16. How are dressed poultry generally packed for shipment?

17. What is the essential requirement of all eggs for hatching?

18. How are hatching eggs best packed for shipment?

19. Discuss the trade in baby chicks.

20. What are the two controlling factors regulating the marketing of poultry products?

Reference.-United States Farmers' Bulletin 182, Poultry as Food. 


\section{CHAPTER XXIX}

\section{DISTRIBUTION OF POULTRY PRODUCTS}

The profitable distribution of agricultural products calls for considerable business ability, and the distribution of poultry demands exceptional ability. The poultry keeper is a partner in a rather complex business enterprise. The three persons concerned in this enterprise are the producer, the distributor and the consumer, and success can be attained only by the most hearty co-operation of these three groups of people. The consumer creates the demand; the producer must meet this demand if he is to dispose of his products. The obligations of each of these three groups of persons to each other is very definite. The producer binds himself to furnish products of good quality, pledging his word to the consumer that he will provide him with a wholesome, nutritious food. The contract of the middleman, or distributor, is that he will so receive, care for, and distribute the farm products that the consumer will have an abundant supply. The middleman is under obligation to make this distribution as promised, and it is also his duty to take care of the product and preserve its good quality during the stages of distribution. The consumer demands a good product, and if he receives it in good condition it becomes his business to take care of it. This is especially true of eggs and milk, which often deteriorate seriously by being allowed to stind in warm rooms after reaching the consumer. In the last chapter we said a great deal about the producer and the methods of securing products of high quality. The next few paragraphs will deal with distribution.

Kinds of Markets.-There are two distinct kinds of markets, known as retail and wholesale, and differing quite 
materially from each other. The retail poultry market might be defined as follows: The distribution of goods through retail channels means the selling of poultry products in rather small amounts by the producer direct to the consumer. Here the middleman or distributor is not a factor. The distribution of poultry products through wholesale channels means the shipping of large quantities of poultry and eggs to commission merchants or agents. These middlemen, or agents, dispose of the goods for a commission. Products sold at wholesale are usually shipped in large quantities to the large centers of population.

Retail Markets.-Retail markets, as a rule, are supplied by the small producer, especially when a good market is near at hand. Such a market is very profitable, if the product is of fine quality. Two distinct methods prevail in private or retail trade. First, the produce is prepared for the customer by the producer himself. If eggs, they are carefully graded at home. If market poultry, it is usually dressed, drawn and delivered ready for cooking. In the second place, the producer himself usually delivers the product direct to the consumer. The advantages of retail trade might be enumerated as follows: First, the product is usually of superior quality when it reaches the consumer's hands,

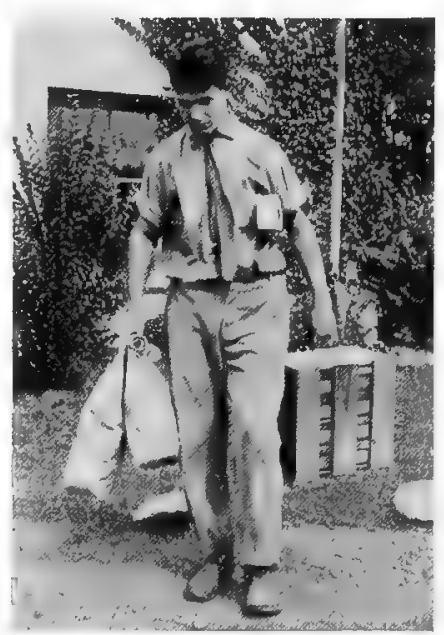

FIG. 164.-This young man is starting out to deliver eggs and poultry produced by his own flock to near-by neighbors and customers. Such a route offers great opportunities to the boy or girl wishing to keep a few birds which shall be their own.

delivery upon short notice being a decided advantage of local markets (Fig. 164). The short haul, or short time 
necessary for clelivery, prevents any deterioration, and to the consumer it means an ever-ready supply. The prices received by the producer are much higher than when products are sold at wholesale, but the cost of getting the products to market is much greater. One disadvantage of the local distribution of poultry and eggs is the excessive amount of labor required.

Wholesale Markets.-On large poultry farms where great quantities of poultry and eggs must be disposed of, the products are generally shipped to wholesale markets, and this is the best course if there are no markets near the point of production.

Much of the poultry and eggs shipped to the thickly populated cities along the Atlantic Coast come to the ccnsumer from the middle West, through wholesale channels, and in cold storage cars. Where large quantities of fresh eggs and poultry are shipped to wholesale markets from near-byr points, they are usually disposed of immediately, without being put in storage. These are the best products that the markets afford, and they bring the highest prices. As a rule, the commission merchant grades all products which pass through his hands; he invariably grades his eggs. All eggs handled by commission merchants in New York City are candled before they are sold. The adrantage of a wholesale market is that it enables one to dispose of an exceedingly large stock. The bulk of goods sold at wholesale is inferior in quality to that sold at retail. There is sometimes considerable loss in eggs sold at wholesale, owing to negligence or mismanagement on the part of the producer. Eggs are often held too long before the time of shipping; and when produced from small flocks and sent to large cities, they usually pass through four or five handlings, which makes them deteriorate. For example, eggs produced by small flocks on small farms in the central part of the United States, go through the following hands before thicy reach the con- 


\section{DISTRIBUTION OF POULTRY PRODUCTS 297}

sumer: The poultryman sclls them to egg collectors. The collector may or may not sell them to small country stores. The country stores sell them to the agents of commission merchants who travel about through small towns gathering eggs for carload shipments. The car is loaded and shipped to New York, or other points, by fast freight. These cars are kept at a low temperature by artificial refrigeration, or by ice. On reaching New York the commission merchant grades them carefully, and sells them to a jobber. The jobber

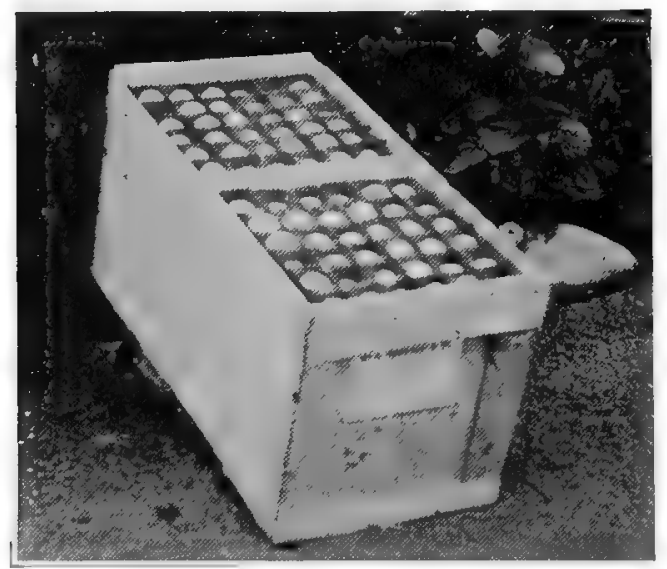

Frg. 165.-A standard, thirty-dozen egg case used for the shipping of eggs to wholesale markets. These cases are light but very durable.

in turn sells them to retail stores. The retail stores distribute them to the consumer. Of course, this long-drawn-out mode of distribution means a loss in quality and higher prices to the consumer (Fig. 165).

How to Improve Market Conditions.-A great deal has been said concerning the improvement of market conditions. The small poultry producer should try to develop a local trade. Where a number of small producers live within a certain radius of a market, they can co-operate and sell their eggs together. The larger quantity will make the price 
more uniform, and secure recognition from the purchaser. A very good way to dispose of eggs is to ship them to retail stores, which pay a good price for them; this method eliminates one or two handlings. The appointment of special agents to distribute eggs or to act as selling agent is possible if several who produce a moderate amount of poultry can co-operate. These agents may sometimes be friends or relatives. One or more cases of eggs, shipped each week to an agent of this lind in the city, can usually be disposed of without any trouble, at a good figure (Fig. 166). In an effort to market eggs more systematically, egg circles have been established in Canada and in the central part of the United States. The method of operating these egg circles is simple. Fifteen to twenty farmers band together, and elect one of their members collector. He collects the eggs from each member, grades, packs, and ships them. For this work he receives a compensation, based on the number of dozen he handles. More recently, attempts to improve market conditions have resulted in the establishment of co-operative market asso('iations. These are rather large undertakings, and to be successful, require the co-operation of many big poultry farms. The only way in which the small poultryman can benefit from them is for him to join one after it is well established.

Shipping Methods.-Poultry and eggs, being more or less perishable, should be shipped with all dispatch, and, as a rule, express is the most profitable mode of shipping. Where products are shipped to great distances, and cold storage methods must be depended upon, fast freight is the hest. Where cggs are to be shipped only a short distance, and ther is regular freight service, this is cheaper. The trolley express, running as it does, through rural and semirural communities, is often used by the poultryman for short haul distribution. The automobile also can be profitably utilized to develop a retril trade, for the small auto truck can cover a good many miles, and it brings the producer 
nearer to the city and to the seashore resorts. Small quantities can often be sent by messenger or friends.

In conclusion, the producer must realize that he is only one of the parties to a contract; that is, he must first raise

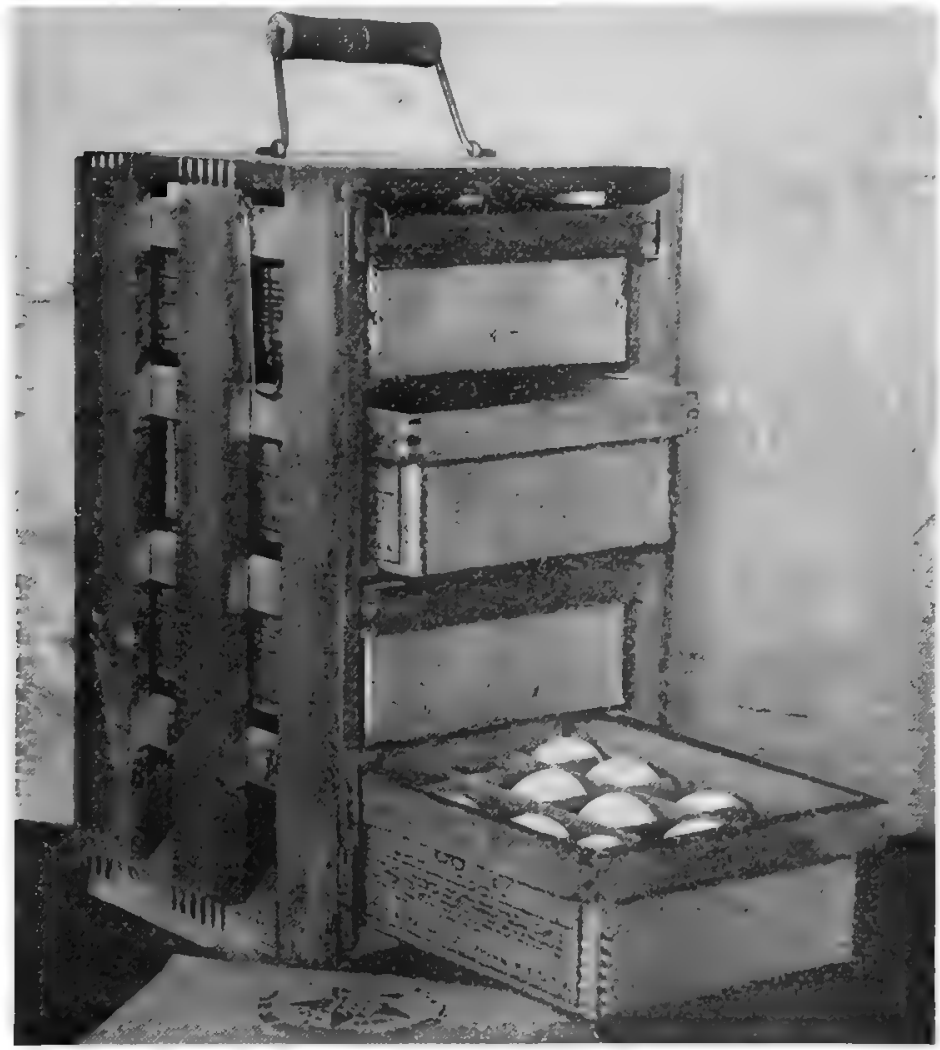

Frc. 166.-Small quantities of eggs can be shipped once a week to special customers in a carrier of this type with no breakage and at small expense. Such a carrier can also be used to deliver eggs on the retail route.

good products, and then, if he wishes to reap the largest profits, he must market them in the easiest, quickest, most inexpensive, and efficient way. 


\section{LABORATORY EXERCISES}

Exercise No. 75.--A Study of Markets and Prices.Secure regularly a copy of an agricultural paper or journal which gives market quotations for poultry products. Have the class tabulate each week the prevailing prices at the leading markets for the different classes of poultry products. Such a table if studied carefully will point out many interesting facts as regards demand and supply, seasonable variations, and prices.

Exercise No. 76.-Marketing Trip.-A trip to some local market or receiving station where much poultry are handled will be of considerable interest to the class. The co-operation of the one in charge will result in much valuable information being divulged which will clear up many of the little-understood phases of the central wholesale market scheme. Methods of handling and the distribution of eggs should be especially studied.

\section{THOUGHT QUESTIONS}

1. Explain the business partnership which is present in the distribution of poultry products.

2. Enumerate the two distinct kinds of markets.

3. Retail markets are best used by what type of producer?

4. Discuss prices and cost of marketing to retail trade.

5. What two distinct types of retail marketing are common?

6. What are the possibilities of the wholesale trade?

7. Outline the course which western eggs take in reaching eastern markets.

8. How can small producers co-operate to get better marketing conditions?

9. What method is used in establishing and operating egg circles?

10. What are the possibilities of co-operative marketing associations?

11. Discuss the express as a means of shipping poultry products.

12. When may freight be used for shipping poultry products?

13. What are the possibilities of the auto truck?

14. What fact must the producer realize in order to secure the most for his products?

15. What method of marketing poultry products is in general use in your section?

References.-United States Farmers' Bulletins: 62, Marketing Farm Produce; 375, Care of Food in the Home; 594, Shipping Eggs by Parcels Post. 


\section{PART VI \\ HEALTH, DISEASE AND ENEMIES}

\section{CHAPTER XXX}

\section{SANITATION}

IN the rearing of all animals, good health is the first requisite for proper development, and it is particularly true of poultry. If we would ward off disease, and bring the birds to the highest state of productivity, we must first of all provide them with suitable environment and then make every effort to keep their surroundings clean and sanitary. Cleanliness is the arch enemy of disease, hence we must leave no spot where disease germs can breed and be a menace to health. Let the watchword of the poultryman be "clean and sanitary environment."

\section{SANITARY MANAGEMENT}

Cleanliness in every branch of the work must be the rule. The poultryman should first try to secure strong, healthy birds. The second requisite is to have clean houses for the birds. The third is to keep the yards and ranges sweet and clean. A fourth is the providing of clean, wholesome feed. Proper attention to these four requisites constitutes sanitary management, and will help to keep the birds healthy.

Healthy Birds. - Two other things tend to promote good health in the birds. The first is the natural bodily strength which is commonly called vigor, and is an inheritance from strong, healthy parent stock in the breeding pen. Birds of vigorous constitutions are better able to resist disease. The second thing is to keep the birds from contracting disease. Common diseases, like roup and canker, if once allowed a 
foothold in the flock, will cauric production almost entirely to cease. The prevalence of any disease in the flock will so reduce the vitality and vigor of the bircls and usually so impair their productive powers that they will never be profitable as layers. Some diseases are inherited from parents; white diarrhœa is a good example of this. If chicks are hatched from eggs laid by hens with this disease, the infection is sure to be transmitted. Healthy birds, free from disease, are the first requisite if we desire perfectly sanitary conditions in the poultry flock.

Clean Homes.-The poultry house is the home of the birds, and special pains should be taken to make it as comfortable as possible to live in. In the summer the birds are out of doors most of the time, and the house is not then so easily contaminated, but can be kept clean a longer time without special effort on the part of the poultryman. In winter the birds, as a rule, are closely confined, rarely getting out of doors, and all of the droppings accumulate in the litter or elsewhere in the interior of the house. The number of birds per square foot of floor space will matericlly affect conditions. Generally spealking, from five to six square feet of floor space is an ample allowance. When birds are kept at the rate of three square feet per bird, the necessity of sanitary precaution is just redoubled. Three steps are necessary to keep the poultry house clean; to take proper care of the droppings, to keep the litter in good condition, and to give the house a thorough cleaning whenever it is needed.

Care of the Droppings.--Every poultry house should have, under the perches, a dropping board or specially constructed pit. If a pit is used, moss or some other material must be put within it to absorb the moisture from the droppings, but the dropping brard is better, being more sanitary. Finely ground gypsum or sifted coal ashes make a good absorbent if spread over the board to a depth of one-fourth 
or one-half of an inch. Either of these will destroy offensive odors and also absorb moisture. Whatever the type of dropping board the droppings must be frequently removed. The rule is to remove them daily, but on some commercial plants twice a week is considered often enough ( $F$ ig. 167). They must be removed whenever they become offensive. The bad odor is due to lack of material which will absorb the moisture. When removed from the poultry house, droppings should be stored in sheds or barrels with waterproof covers (Fig.168). Properly taken care of, they make a valuable fertilizer.

Care of the Litter.-The litter in the poultry houses serves as a carpet, and its condition materially affects the welfare of the birds.

The litter should be from six to eight inches deep, rather coarse, and dry, and it must be kept clean. Old litter should be removed and replaced with new whenever

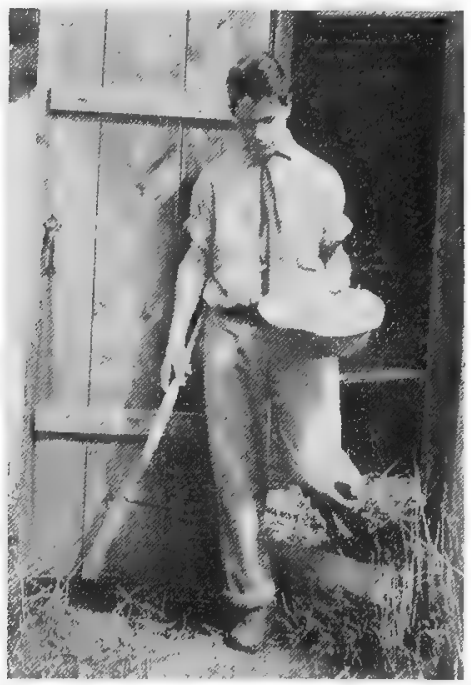

Fig. 167.-Removing the droppings in order to keep the house clean and sweet. $A$ hoe and pan is the best equipment to use for the purpose.

it becomes finely ground, or full of droppings. A good plan is to begin in the fall after a general cleaning, and scatter three or four inches of fresh, coarse litter on the floor (Fig. 169). Frequently add more, until it is from six to eight inches deep. When the litter becomes finely ground, the coarse material can be pushed back, and the fine swept up and removed. Damp, dirty litter is very detrimental to the health of the birds.

General Cleaning.-The poultry house should be thoroughly cleaned at least twice a year, preferably in the spring 
and fall. The first thing to do is to remove all fixtures, and put them out where they will get the sun and air. Next remove all the litter and accessories from the interior of the house. The glass windows should be washed clean, and the muslin one beaten with a light stick to remove all dust. The walls, ceiling, and floor should be swept clean, after which the whole interior of the house should be sprayed with a disinfectant. A good formula for this purpose is the New Jersey Disinfecting solution, which is composed of five quarts of rock lime, slaked to about the consistency of

A

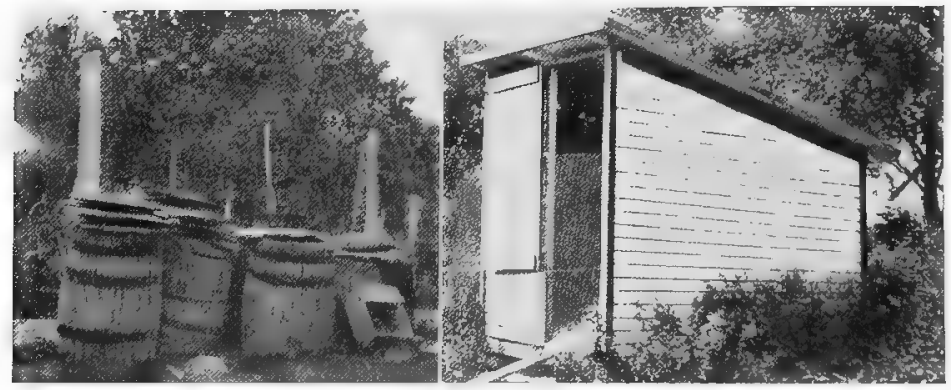

Fia. 168. - The manure collected from the poultry house should be carefully preserved to be used as a fertilizer. A, Barrels with covers made from barrel staves will be excellent if the supply is not too large. $B$, Where many birds are kept it is the best practice to have a specially constructed shed or small house in which to store the droppings until time to use them in the spring.

cream, to which is added one quart of kerosene, and one pint of any good coal tar preparation. The whole mixture should be agitated thoroughly to reduce it to an emulsion, after which it can be applied to the interior of the house by using a force pump with a spray nozzle. This constitutes very quick and thorough disinfection. By using a common spray, this method accomplishes the following results: It puts on a thick, well distributed coat of whitewash. The kerosene rids the house of all vermin. The disinfectant kills any disease germs lurking within, and also acts as a deodorant (Fig. 170). After disinfection, all fixtures should be brought in and at- 
tached to their proper places, the floor provided with litter, and the house is ready for the birds. If a house is cleaned while the birds are using it, spray it early in the morning so that it will be thoroughly dry before they go to perch at night. The window should be kept clean and the muslin shade well dusted.

Clean and Sanitary Yards. - Poultry yards are easily contaminated, especially if the house is not built on a proper

Frg. 169.

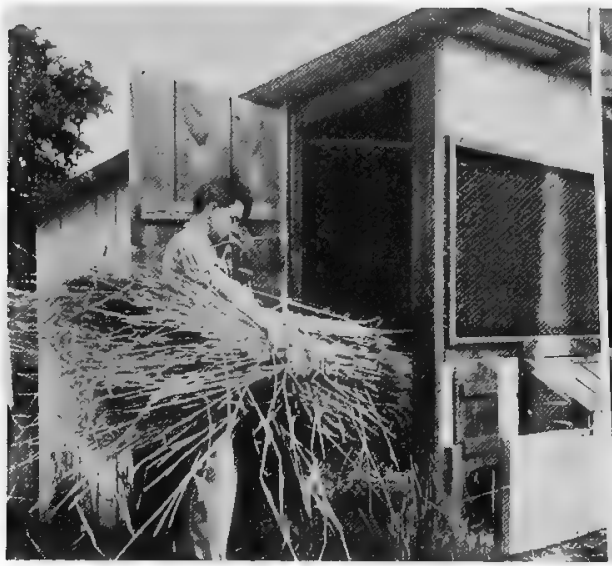

FIg. 170.

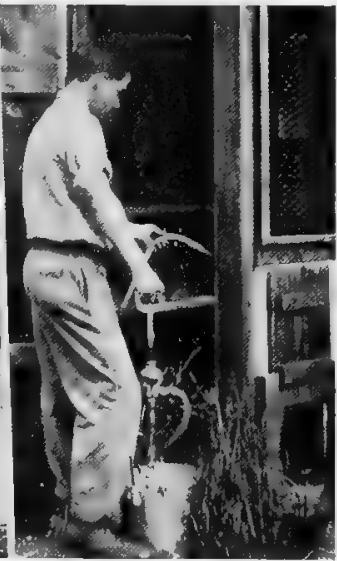

FIa. 169.-Carrying fresh clean litter to his flock in order to make their house more sanitary and healthy and also to provide a place for them to take exercise.

Fia. 170. Spraying the interior of the house with a complete disinfecting solution. The solution is placed in a pail and the pump throws the solution in the form of a mist over walls and all fixtures.

slant, or the yards are not on fairly sloping land. The drainage should flow away from the house, the soil be porous and open. The condition of the yards will depend largely upon their size. If the birds have considerable free range, the area is generally pretty clean. Intensive yards are usually small, with a large number of birds running on them. They quickly become contaminated and special efforts must be made to keep them clean. With large free runs, the only precaution necessary is to plow an acre around the poultry 
house, especially in the front of it. This should be limed before plowing, and then seeded at least once a year. Intensive yards should be limed, plowed, and seeded three or four times a year. Conditions are much improved by covering the runs in the winter with a green cover crop. A suitable crop rotation is outlined in Chapter XXIII.

Clean Feed.-The feeding of clean, wholesome feed is the first step in hygienic management. Moldy or diseased grain should never be given. Such feed may be cheap, but it is not economical. The feed provided, especially meat scrap, should be free from anything poisonous. Feeds of high quality are really the most economical, but less attention should be given to cheapness, and more to efficiency. Sloppy feeds and wet mashes are unwholesome. If used, special care must be exercised to keep the troughs and vessels clean. In feeding milk to poultry the same precaution must be taken. Sour milk is a good feed, but if it stands too long in the pans it becomes unwholesome. When grain is fed to the birds, do not allow it to accumulate in the litter, to be soiled and wasted. The supply should be only what is needed. Grain or mash left in the yards will only become moldy or sour, and be injurious to the birds.

The providing of fresh, clean water is very important. Water vessels should be rinsed out frequently, and washed with a disinfectant at least once a month.

The poultry keeper should have all of the tools and equipment necessary to properly clean the poultry plant. For even a small flock of birds, he needs a garden hoe, a stiff broom, a rake, a three-tined pitchfork, and a small spray pump. When not in use, they should be cleaned and carefully put away until wanted again.

\section{LABORATORY EXERCISES}

Exercise No. 77.-Cleaning the Poultry House.-Allow the class to perform all of the operations described as essen- 
tials in the renovation and cleaning of the poultry house. If possible the school poultry house should be the one cleaned. If not, the house of some student living nearby can be used.

Exercise No.78.-Mixing a Disinfecting Solution.--Secure the materials necessary to prepare the New Jersey Disinfecting Solution. Prepare the sameaccording to instructions and after the poultry house is cleaned, apply the solution thoroughly with a pump. If same is not available, a brush will answer.

Exercise No.79. - Cleansing the Poultry Yard.-Find a bare, dirty, foul poultry yard on some of the pupil's home farms. Lime the soil, have the yard plowed and harrow in a thick seeding of oats. Such work as this about the community not only acts as instruction to the pupils taking the poultry course, but it also acts as an object lesson to the whole community and makes the school a center of agricultural interest.

\section{THOUGHT QUESTIONS}

1. What is the first requisite in the management of all animals?

2. What is the most important factor in management towards keeping the flock healthy?

3. Enumerate four factors which must be attended to in order to insure clean management.

4. Name two things which will insure healthy birds.

5. Why is vigor important?

6. Discuss the keeping of birds free from disease.

7. How does the number of birds kept in a given house affect the condition of their environment?

8. Discuss in detail the proper care of the droppings.

9. What is the object of litter in the poultry house?

10. How would you describe litter which was in ideal condition for the health of the birds?

11. How often is it necessary to make a general cleaning of the interior of the poultry house?

12. Give the composition and method of applying the New Jersey Disinfecting Solution.

13. Enumerate the different operations which are necessary to perform in making a general cleaning of the house.

14. Describe the location of the ideal poultry yard.

15. How should a poultry yard be managed to keep it sweet and clean?

16. What conditions of feed should be avoided in a clean feeding practice?

17. What is the effect of moldy or sour feeds?

18. How should the water vessels be cared for to induce cleanliness?

19. What small tools are necessary to properly care for a small flock of poultry? 


\section{CHAPTER XXXI}

\section{COMMON POULTRY DISEASES}

Poultry are attacked by various diseases, several of which are highly contagious. Some affect individuals only, and are not readily transmitted from one member of the flock to another. The majority are caused by unsuitable environment. Disease can, in large measure, be prevented by careful attention to two factors: First, by securing healthy birds of strong vitality, which offer considerable resistance to disease. Second, by giving them suitable environment. Vigorous birds in sanitary quarters are almost immune to any kind of infection.

There is always danger of disease appearing, but a careful lookout for symptoms will usually check it before it has made much headway. At the first signs of disease all of the birds should be carefully inspected to determine how prevalent it is; and if at all dangerous, and there is a possibility of its spreading, all of the birds affected should be isolated (Fig. 171). The poultryman may not know the character or nature of the disease, but he can study it by isolating the birds, and comparing their symptoms with descriptions found in a good text-book on the subject. When he is sure of the nature of the malady, he should take immediate steps to prevent its further spread by instituting curative treatment. The medicinal treatment of poultry is generally very expensive, and unsatisfactory. It is much better to create conditions in which discase germs will not develop than to attempt to cure discase due to unhealthful conditions. The object of this chapter is to dcal, in a very elementary way, with a few of the common and simple diseases of poultry, and the student should supplement this by referring to a comprehensive text-book on the subject. 


\section{CLASSIFICATIONS OF DISEASES}

Common poultry diseases are of two distinct kinds, those which respond to flock treatment, and those which may be treated individually. By far the greater number of diseases which attack birds fall into the former group. A recognition of the cause of the trouble, and stringent measures to stamp it out are the only sure preventives.

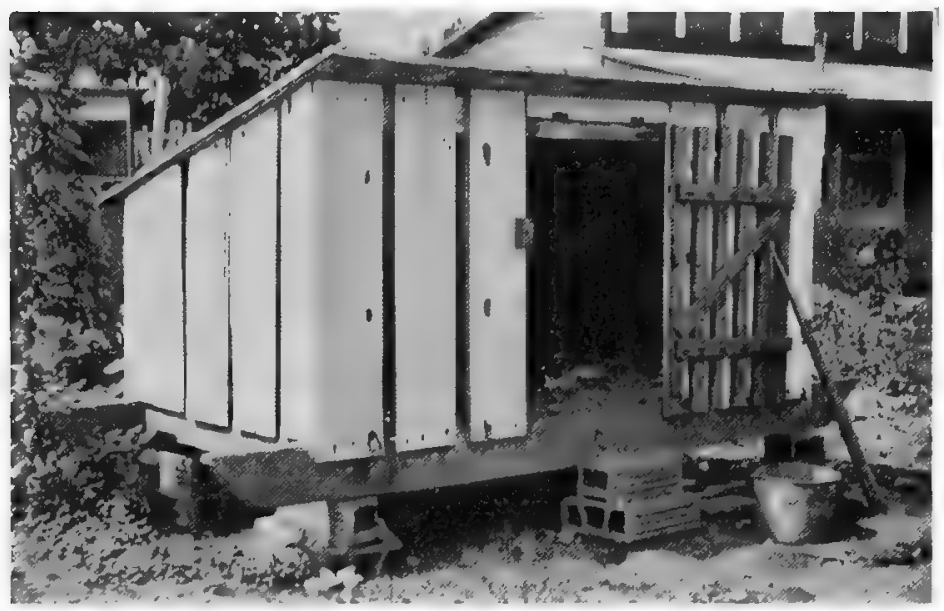

Fra. 171.-An isolation coop or fresh-gir hospital, used to separate sick or ailing birds from the rest of the flock.

Flock Diseases.-Flock diseases are those which can be treated by administering remedies to all of the birds in a flock. They are of two kinds, but the most common are those caused by improper feeding. In the same class may be grouped those due to damp or poorly ventilated houses. Roup and canker are familiar types of disease due to improper environment. In the various diseases caused by germs, infection is often from outside sources. Here there is little danger, if proper precautions are taken to keep up the strength of the home flock. 


\section{DESCRIPTION OF SOME COMMON DISEASES OF POULTRY}

Following this are a few of the ordinary poultry diseases. The amateur poultryman should understand their nature and be familiar with their appearance. He should also know how to prevent and cure them.

Roup, Chicken Pox, and Canker.-These three terms are used to describe a common disease of the skin, which attacks the mucous membrane of the mouth and nose, and the skin of the face and comb. In whichever form it appears, it is probably due to the same organism. Chicken pox first manifests itself by the formation of little vesicles, or pocks on the skin around the face, and also on the comb and wattles. Sometimes they form on the eyelids, which become so swollen that the eye is entirely closed. The effect of the disease is to lower the bird's vitality, and decrease its productiveness. If the infection is severe, it may permanently injure the bird, affecting particularly the eyelid. The organism which causes the trouble is a small parasite which, when it begins to develop, multiplies very rapidly. Chicken pox is especially prevalent during wet, damp weather in early spring, and the best preventative is to keep the birds dry, their houses well ventilated, and to look after their health in every other respect. If only a few sores appear, they can be treated individually by washing them with a two or three per cent solution of carbolic acid. The scab or crust, which forms on the surface of the sore, should be removed, so that the disinfectant may penetrate into the roots of the pock. If the whole flock is affected, a common mode of treatment is to disinfect the air above the perches when they go to roost at night by spraying with a two per cent solution of carbolic acid or any other good disinfectant. This purifying of the atmosphere will prevent the multiplication of germs in the affected parts, and at least tend to check the spread of the disease: If taken in time, and properly handled, chicken pox is easily cured. 
Roup is an infectious disease; which generally attacks the mucous membrane lining the nose, and the orbit of the eye. The affected parts become red, and, as the disease develops, are distended, owing to the formation of pus. When the disease is fully developed in the orbit, the pus pushes the eye forward, and makes it bulge. Birds of poor vitality are especially liable to roup in the winter and spring, damp weather and poorly ventilated houses leading to its development. Roup is transmitted from bird to bird largely through the drinking water. The germs from the affected birds drop into the water, and thus get on the body of well birds that come to drink from the same vessels. The best mode of prevention is to put in the drinking water a small amount of copper sulfate, potassium permanganate, or kerosene to kill the germs. Birds attacked with roup should be isolated, and the affected parts of the body thoroughly washed with a five per cent solution of creolin or peroxide of hydrogen. Roup may be cured; but it is dangerous to put birds back into the laying pens before they have entirely recovered.

Canker is somewhat similar to roup in its appearance and is believed to be caused by the same organisms. Yellowish-white spots appear on the inside of the mouth and throat. Close inspection shows that they are formed of a hard, cheesy material. Its effect on the birds is almost wholly to suspend production, and greatly to lower the vitality. It is caused by keeping the birds in damp, poorly ventilated quarters in which the germs rapidly multiply. Canker may be treated by scraping off the white deposit, and washing the parts with a 50 to 100 per cent solution of creolin or hydrogen peroxide. Observation shows, however, that relief is rarely permanent. When such birds are treated, and put back into the laying flock, there is danger of carrying the infection over from one season to another. Roup and canker are usually found closely associated one with another. 
If not given ideal environment, late hatched or low vitality pullets are apt to be more or less affected.

Liver Affections.-Liver affections, as the name implies, covers a number of abnormal conditions of the liver. Cases often appear where the liver is much enlarged. Others where it becomes hard, and still others where it is spotted, and apparently attacked by some disease germ. Most of these abnormalities of the liver are due to faulty feeding. Excessive amounts of fat or of carbohydrates in the feed with limited exercise will produce enlargement of the liver. It affects the birds in various ways, but the most common symptom is listlessness, or stupor, the comb loses its bright red color, and takes on a yellow tinge, the head and eyes lose their brightness, and become dull and yellowish. If the conditions are not remedied, many of the birds may die. When birds show symptoms similar to these outlined, it is well to scrutinize the feeding methods. If the liver disorders are caused by improper feeding, many of the flock will show the same symptoms. Corn and other starchy fecds should be cut down, and the bird affected compelled to take more exercise. They should be given plenty of green succulent material, and considerable meat.

Indigestion and Diarrhoea.-Indigestion is found quite frequently in flocks which are forced, especially if they are fed large wet mashes. Advanced cases have profuse diarrhoea and whenever this is observed, the ration should be studied and the fault corrected. Plentiful exercise will do more to cure the condition than anything else. Small amounts of Epsom salts in the drinking water will cleanse the gut and hasten recovery.

Prolapsus.-Prolapsus is very common in poultry in the spring of the year. It is caused by heavy egg production. In this condition some part of the reproductive organs is extruded from the body. The best treatment is to reduce the meat scrap in the ration, and get the birds out on ex- 
tended range. If not checked, it leads to cannibalism. The birds get the odor of, and a taste for blood, and are apt to kill each other, in considerable numbers. It is more common with the Leghorns than with any other breed.

Bumble Foot.-Birds are often noticed to walk lame. Upon close examination, one or both feet will be found to be swollen, and a corn or other growth developing on the sole of the foot. The condition is due to the perches being too high, which compels the birds to jump a considerable distance to reach the floor. The hard growth can be cut out with a hard knife, the wound washed with a solution of creolin, and the pus or core removed. The foot should then be thoroughly disinfected, and the bird put in a clean cage until the wound heals.

Frozen Combs.-In passing, it may be well to mention the possibility of frozen combs and their effect upon the health and productivity of the birds. During long spells of damp weather in the late winter, the freezing of combs, especially with the male birds, is common. It is sure to lower the vitality and stamina of the birds, and means low fertility in hatching eggs. Frozen combs also mean weak germs, and even if the eggs are incubated, there are many deaths in the shell. The combs or face parts of females are rarely frozen. Dry cold is not dangerous; but if a damp, humid atmosphere is followed by a drop to low temperature, the birds must be specially protected by closing the muslin curtain, or shade, in the front of the house, yet giving them plenty of ventilation to carry off the moisture exhaled by them at night. Frozen combs should be immediately bathed with cold water, until all of the frost is out, and they have returned to their normal appearance. They should be anointed with carbolated vaseline twice daily until the scab is entirely healed. Males whose combs or wattles have been frozen should never be used for breeding, until at least four weeks after they return to normal condition (Fig. 172). 
Infectious Diseases.-There are two diseases which it is well to mention since they are very highly contagious and if they attack a flock of poultry they will carry off many birds, and cause the total failure of the enterprise. These diseases are tuberculosis and fowl cholera. Tuberculosis is caused by the bacillus tuberculosis, the same organism which produces the disease in cattle and other animals. The disease affects the lungs, liver, and intestines. Birds are especially prone to tuberculosis, if large flocks are crowded into stuffy quarters. Fresh air and sunlight are the best

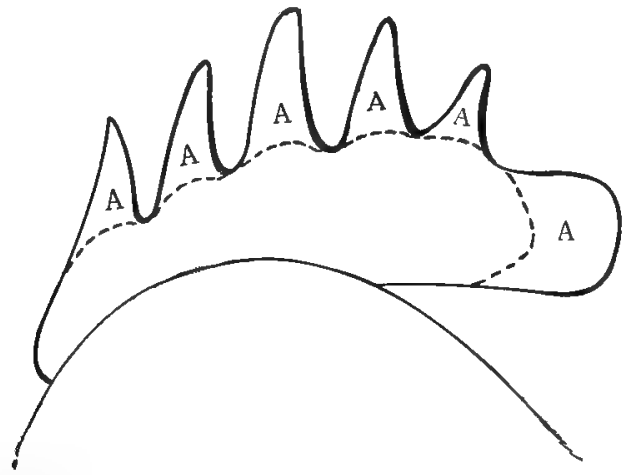

Fig. 172. When a male bird's comb is severely frozen the points will usually be killed and will later drop off. The points marked $A$ are those which are frequently lost by freezing.

preventives. The disease causes rapid loss of flesh, and all birds whose breasts look thin and emaciated should be examined after death for sore spots on the lungs, white spots on the liver and small nodules on the outside of the liver. If any of these symptoms are found, it is absolutely certain that the bird is suffering foom tuberculosis, and all birds affected should be culled out, killed, and their carcasses burned. It is probably wise to sacrifice the entire flock and start again. Before beginning again, the entire area where the birds have run should be thoroughly disinfected, and any faults in the construction of the houses corrected. 
Cholera is the most to be dreaded of all poultry diseases. In its action, it is quite similar to human cholera, and its spread through a flock is most rapid. It affects chiefly the alimentary tract, particularly the intestines. The most common symptoms are a quiet listlessness, and the inclination of the birds to go off into corners by themselves. They appear to lose the use of their legs, the comb and head parts become purplish in color, and in advanced stages, there is a profuse greenish diarrhoea. Birds affected rarely live more than three days from the time they show the first symptoms. These two diseases, though not especially common, call for more than passing mention, because their prevalence in a flock will ruin the possibilities of any poultry farm. Let it here be emphasized that to have healthy birds, we must give them clean quarters and keep up their vitality.

\section{LABORATORY EXERCISES}

Exercise No. 80.-Chicken Pox, Roup, and Canker.-Try and secure in the community cases of these three conditions so that they may be presented to the class during the lesson. By having the actual disease before them the appearance and place of infection may be readily appreciated and similar cases which they may have at home may be determined. Each pupil may relate experiences which he has had at home with such forms of disease. If several cases appear, a visit from the teacher or the entire class may be of benefit in checking the trouble by recommending preventive measures.

Exercise No. 81.--Potassium Permanganate Solution.Prepare a stock or saturated solution of potassium permanganate. This is done by placing about a quart of water in a glass or china dish (not a metal or galvanized pail). Place in this enough of the crystals of potassium permanganate so that they will not all dissolve. After they have stood for some time the solution should be poured into a glass bottle 
which can be tightly corked. Each day when the drinking vessel is filled with fresh water, a small amount of the solution should be poured into same until the water is colored light blue.

Exercise No. 82.-Diagnosis.-Whenever a bird dies from among the school flock or from one of the pupil's flocks it may be brought to school and opened, and the trouble located. Such study of the internal structure of birds will result in a closer interest and a better understanding of the organs even if the exact disease can not in all cases be determined.

\section{THOUGHT QUESTIONS}

1. What is the cause of most of the common poultry diseases?

2. Attention to what two factors will largely result in the elimination of most of the common diseases?

3. As soon as signs of disease are noted what should the poultry keeper immediately do?

4. Is doctoring poultry generally satisfactory?

5. Into what two groups can all common poultry diseases be divided?

6. Diseases which can be treated as a flock can be divided into what two groups according to causes?

7. Describe the appearance of chicken pox.

8. What is the effect of chicken pox upon the health of the bird affected?

9. How can chicken pox be treated?

10. Discuss the appearance of roup.

11. Outline a method of treating birds affected with roup.

12. Where is canker located?

13. How can canker best be treated?

14. Describe the appearance of the liver when diseased.

15. What are some of the common causes of liver troubles?

16. What are the common causes of indigestion and diarrhoea?

17. What may prolapsus lead to?

18. How can cannibalism be checked?

19. How would you treat a bird affected with bumble foot?

20. What conditions make possible frozen combs?

21. What is the effect of frozen combs on the vitality of the bird so affected?

22. Describe the appearance of a bird affected with tuberculosis.

23. How would you know that a bird was affected with fowl cholera?

References.- United States Farmers' Bulletins: 473, Tuberculosis; 530, Important Poultry Diseases. 


\section{CHAPTER XXXII}

\section{PARASITES AND ENEMIES OF POULTRY}

ANIMALs which live on other animals and obtain their nourishment from them are called parasites. Many small animals live on birds. These poultry parasites may be grouped in two different classes, internal and external. Internal parasites are those which infest the intestinal tract. External parasites consist of lice and many other minute animals which inhabit the skin and feathers of the bird. Their effect is very detrimental; if present in large numbers, the vitality of the birds is lowered, and they generally become unproductive. Therefore, if the poultry flock is to yield a profit, the birds must be protected from the ravages of these little parasites.

\section{INTERNAL PARASITES}

Internal parasites are more rarely found in the average flock than external, and are less dangerous. Internal parasites are commonly called intestinal worms; they are of two

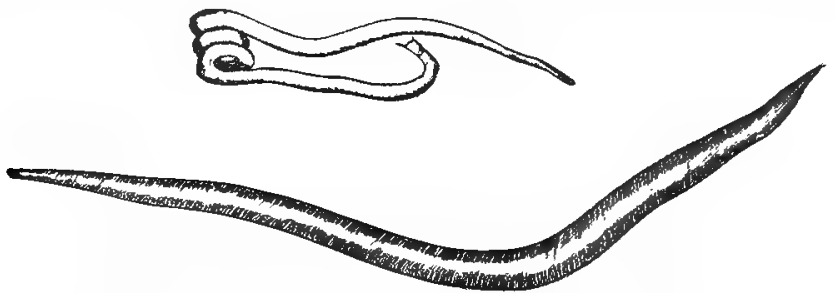

FIG. 173. - The round worm; an internal parasite of fowls.

kinds, round and tape worms. The round worm is white, about one and one-half inches in length, and of quite small diameter (Fig. 173). The tape worm is often two or three feet in length. The presence of either of these parasites will usually retard both growth and egg production, as the para- 
sites take their nourishment from the feed which the bird eats. They also attach themselves to the walls of the intestines, and suck nourishment from the blood and the digested feed material. Every precaution should be taken to keep a flock free from these parasites, for if once present, they are apt to spread until all of the birds are affected. Birds which die should be cut open, and the intestinal tract examined to see if there are any worms. If present, steps should immediately be taken to rid the whole flock of them. The best way is to give the birds a purgative, such as Epsom salts or castor oil, withholding feed from them until two or three doses of the medicine have been given, when the worms will usually be discharged.

\section{EXTERNAL PARASITES}

The most common group of animals which feed on live birds are the external parasites. These live wholly on the outside of the body. Some get their nourishment by sucking the blood, others feed on the skin or the quills of the feathers, others consume the waste products thrown off from the body. These are most numerous in warm weather, and multiply very rapidly in unsanitary quarters. There are four common types of external parasites with which every poultry keeper should be familiar: lice, red mites, depluming mites, and scaly leg mites.

Body lice (Fig. 174) are numerous on all full grown poultry. They are yellow in color, and about the size of the head of a pin, most of them are long and slender. In adult birds body lice are usually found in the fluff and the hind part of the body, especially about the vent and sometimes under the wings. They subsist on the skin, particularly the scales of dead skin which peel off. Body lice stay on the birds all the time, never leaving the body, and their presence is very irritating. There are three methods for getting rid of them. The first and simplest is to provide a dust box 
in the poultry house (see Chapter XVIII, page 195). If this box is kept full of dry powdered dirt, the birds will largely rid themselves of lice. When very numerous and the birds do not seem to get rid of them by dusting in sand wallows, sprinkle each bird individually with a good lice powder, dusting it well into the quill. A good method is to get a preparation of blue ointment, and rub a little of it into the fluff at the base of the feathers, and also thoroughly into the skin. If birds seem to be a little out of condition and not doing well, they should be examined for body lice.

Red mites (Fig. 175) are minute insects. When empty they are of yellow color, when filled up with blood, bright

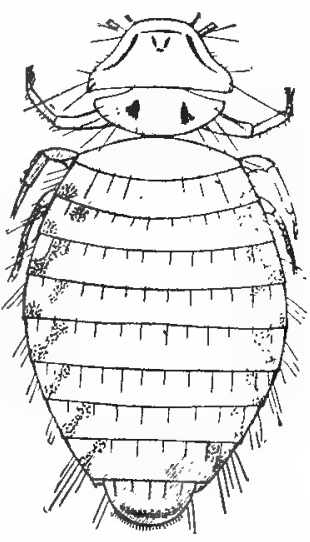

FIG. 174.-Enlarged sketch of a body louse. red. Red mites migrate during the night, from hiding places

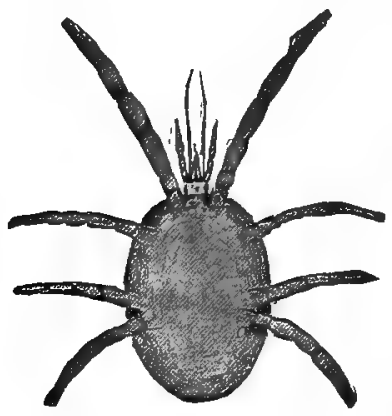

Fig. 175.-Enlarged sketch of a red mite, showing the shape of the body. in the house, to the bird's body to suck its blood, then return to their cracks and crevices around the dropping boards, where they remain during the day. They sap the vitality of the birds. Mites are much easier to kill than lice because they can be attacked in their hiding places. A 5 per cent solution of carbolic acid, or kerosene, full strength, if applied directly to the wood work, will usually kill the mites. If nests and fixtures are portable, this will facilitate the extermination of mites.

Depluming Mites.-The depluming mite is much more rare but, when present in large numbers, does considerable 
damage. These mites live on the quills of the feathers, and are most numerous just at the point where the quills leave the body. On the birds affected there will be areas where the feathers are either thin or entirely wanting. Close examination will reveal that they have not been pulled out, but broken off, and the edges are frayed. The damage which these mites do is most detrimental to the appearance of the birds. The best way to get rid of them is to anoint the birds affected with carbolated vaseline, especially the parts where the mites seem to be at work. The vaseline should contain at least two to three per cent of carbolic acid.

Scaly Leg Mites.-The scaly leg mite is one of the smallest of the true poultry mites. These mites infest the shanks of the bird, and, as they burrow underneath in their process of development, they throw out a calcareous substance, yellowish in color. As they multiply this deposit rapidly increases, and forms scales which, if allowed to develop, will entirely cover the outside of the leg. The deposit is especially harmful because it sometimes makes the legs misshapen and unsightly. The birds, too, are likely to become lame and useless. If no steps are taken to kill them, these mites rapidly multiply. Birds with scaly legs should have individual treatment. The affected leg should be soaked in lukewarm water, for five or ten minutes, until the scales become soft, when the white deposit should be scraped off with a very dull knife, until the legs bleed slightly. The shank should then be anointed with carbolated vaseline. If this is done two or three times, a complete cure will be effected. In scraping the legs, be careful not to go so deep as to mar them permanently.

\section{ENEMIES OF POULTRY}

The enemies of poultry are many, and include both predatory animals and birds. The following are a few of the most common ones for which to be on the lookout: 


\section{PARASITES AND ENEMIES OF POULTRY 321}

Rats.-Rats abound in old buildings, earth or wooden floors attracting them, while trash or refuse lying about forms for them an ideal breeding place. In the spring and summer they do considerable damage to poultry, by carrying off young chicks and growing pullets. A rat does not kill the chickens for the sake of eating them immediately; but if a rat once gets into a brooder full of chicks he kills them all on the spot before he attempts to carry any away. A family of rats will usually devour considerable poultry feed. Dry mash hoppers are most attractive to them, but these should be so constructed that they can be closed at night. It is much better to build a poultry plant so that there can be no danger from rats rather than to combat them constantly with poisons. If all summer poultry houses were elevated on posts, or on brick or stone piers, an attractive breeding place for rats would be eliminated. Permanent poultry houses should be constructed on a concrete foundation with a concrete floor, which is practically rat proof, and a good dog trained to catch rats is the best agent to keep them out of the plant.

Weasels, Minks, and Skunks.-Weasels and minks, if numerous, do considerable damage by carrying off growing, and even adult birds. The best way to prevent these depredations is to keep the house fairly near the dwelling house, where they can be frequently seen by the poultry keeper. Skunks delight in eating eggs. It is very common for them to break up a hen which has stolen her nest in order to eat the eggs under her. A gun is the best thing to use to get rid of minks and weasels. Skunks can be trapped if their hiding places can be found.

Hawks and Crows.-There are two kinds of hawks. chicken hawks and hen hawks. Chicken hawks are small, and prey upon young chicks, not more than a few months old. Hen hawks, as the name implies, are much larger, are vicious by nature, and do not hesitate to carry off and kill 
adult birds. Crows will kill many chicks if they are out on the range. The best way to get rid of either crows or hawks is to use a shotgun. Sometimes they can be caught in steel traps fastened to tall poles in the center of the plant. If a hawk or crow is killed, it should be hung up somewhere in the plant, as the sight of a dead bird will drive the others away.

Theft.-Small and large poultry keepers alike are compelled to protect themselves from thieves. There are always plenty of unscrupulous persons who do not hesitate to steal poultry. Therefore, fasten the poultry house door securely with a padlock, and keep a well trained dog to insure protection.

\section{LABORATORY EXERCISES}

EXERCise No. 83.-Secure a few small glass vials about two inches long and one-half an inch in diameter. Fill these half full with a fifty per cent alcohol solution. Catch one or more old hens and search about the body fluff for body lice. When found they may be placed in the alcohol, a large number in each bottle. The bottle should be labelled stating when and where the parasites were secured. Later, after the alcohol has killed the insects, they may be examined by the class with the aid of a small lens.

Exercise No. 84.-A Study of Red Mites.-Red mites may be secured in the same kind of a vial as described in Exercise No. 83. When searching for the mites the most likely place to find them is in cracks and crevices under the perches. Where perches are attached to the wall is the best place to search. After the specimens for study have been secured the remaining lot should be covered with kerosene. In a few hours a return visit will show the miss to be dead, if the kerosene was thoroughly applied.

Exercise No. 85.-Treating Scaly Legs.- Secure a bird affected with scaly leg mite. Carefully treat the same as described in the text. This work will occupy but a few 
minutes during the class hour. It should be done in the presence of the class so that they may take notes on the work done and the efficiency of the process.

Exercise No. 86.-Combating Poultry Enemies.-The class can take part in a general discussion, each one telling of ways and means used at his own home to protect the young chicks and older birds from the ravages of the enemies described in the text. There is rarely a farm which is free from such animals.

\section{THOUGHT QUESTIONS}

1. What is a parasite?

2. What is the difference between external and internal parasites?

3 . What is the effect of parasites upon the health of the flock?

4. What are internal parasites commonly called?

5. Tell what you can about the round worms of poultry.

6. How can worms be eradicated?

7. How do external parasites get their nourishment?

8. Describe the appearance of body lice.

9. How can poultry be kept free from body lice?

10. What is the appearance of red mites?

11. Describe the habits of red mites.

12. How can red mites be successfully combated?

13. How can you tell when the flock is affected by depluming mites?

14. How would you proceed to eradicate depluming mites?

15. What is the appearance of a bird affected with scaly leg mites?

16. Describe the best method of ridding birds of scaly leg mites.

17. What is meant by poultry enemies?

18. What damage do rats do to poultry?

19. How can a poultry plant best be protected from the ravages of rats?

20. Tell what you can about the damage which may be done by weasels, minks, and skunks.

21. How do hawks and crows destroy poultry?

22. How can you best protect a plant from theft?

References.-United States Farmers' Bulletins: 369, How to Destroy Rats; 444, Remedies and Preventatives against Mosquitoes. 


\section{PAR'T VII}

\section{MANAGEMENT}

\section{CHAPTER XXXIII}

\section{THE POULTRY INDUSTRY}

Poultry keeping, as an industry, is one of the greatest branches of American agriculture, and is recognized as such by the Federal Government. Every ten years the United States Census Bureau makes a careful study of poultry conditions in the United States. The last census, taken in 1910, shows that there were in the United States 295,000,000 birds, the great majority of which were domestic fowls. Ducks and geese were also found in considerable numbers. The value of these birds was about $\$ 155,000,000.00$, the average value of a bird being figured at about fifty cents. On 87 per cent of our farms poultry is raised to some extent. On comparison with the census of 1900, these figures show the increase in poultry is 17 per cent during the last ten years. The value of the birds is greater, birds bred to-day being much finer and bringing a higher price than those bred years ago. In the year 1909 the United States produced almost $1,600,000,000$ dozens of eggs, which were valued at $\$ 200,000,000.00$. This was an increase in the last ten years of more than ten per cent in the amount of eggs produced, while the value of the eggs increased more thim 100 per cent. These figures show that poultry products are of great economic value in providing the American people with food. They also show that the price paid for poultry products is rising much more rapidly than the prices of feed which produces the eggs. This is an important point, als it indicates 
richer profits in the business. The great bulk of poultry and eggs in the United States is produced in the central part (Fig. 176). The ten leading States, based on the value of the poultry raised therein, are as follows: Iowa, Missouri, Illinois, Ohio, New York, Indiana, Pennsylvania, Kansas, Michigan and Texas. These ten states raise within their borders nearly 60 per cent of all the poultry in the United States.

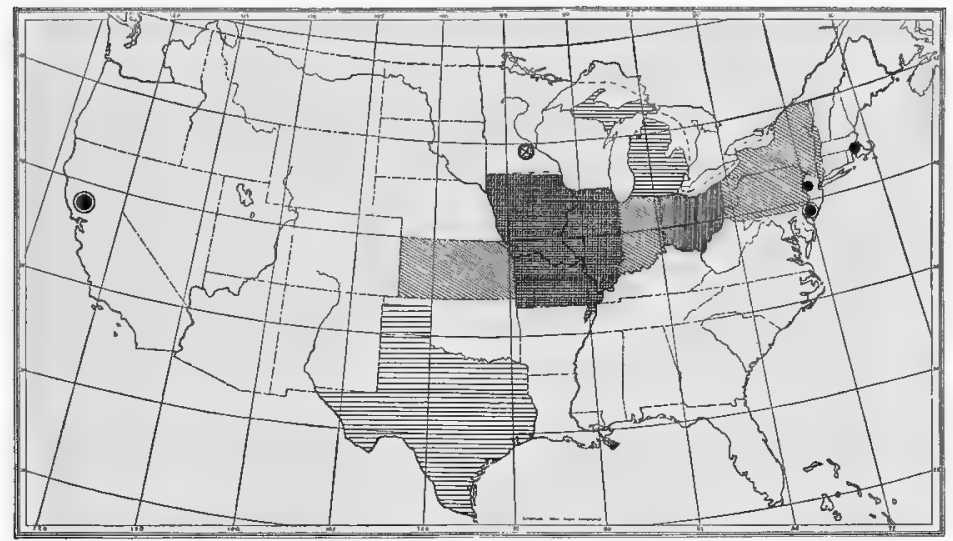

FIG. 176.-Map of the United States showing the distribution and location of the leading poultry producing centers.

\section{LEADING CENTERS OF POULTRY PRODUCTION}

We have in the United States a number of interesting and important centers; interesting, because they have made a specialty of some poultry product of fine quality, and these products have made the places famous. These points of special production can be divided into two classes: First, those devoted to egg production; second, those devoted to meat production.

Eggs. - The ten states previously mentioned constitute the greatest egg producing section in the world. In these central states eggs are produced by small flocks on farms. The birds are often considered merely as a side issue, and are 
neglected (Fig. 177). There is no egg production during the winter months, but their maximum is obtained during the months of March, April, and May. Most of the eggs produced are shipped to the East, especially to New York and Philadelphia, and go through a good many hands before reaching the consumer. These eggs are not of as good quality as those produced near the Eastern markets. Owing to the low cost of grain, poultry in this section has been made to net considerable profit, with but little attention. In the

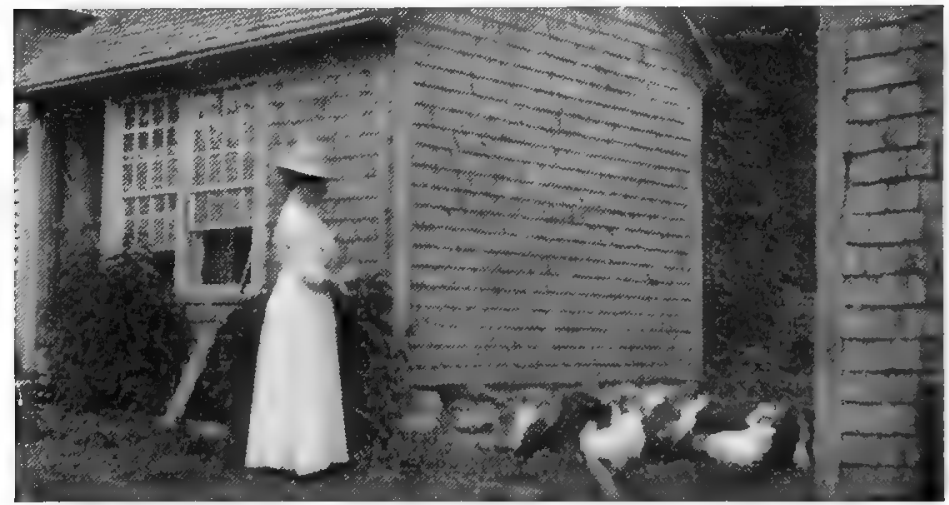

FIG. 177. - In most cases farm flocks are largely cared for by the women of the family. They are looked upon by the men as side lines, not worth bothering with. Young folks can, and do in many cases, raise such flocks by careful attention, from non-producing to very profitable business.

future, however, more systematic and business-like methods must prevail. The central part of the United States furnishes the great supply of eggs demanded by both Atlantic and Pacific coasts.

In Sonora County, California, lies an intensive egg producing district. It centers around Petaluma, and is commoniy called the Petaluma district. In this district large poultry farms are common, the White Leghorn breed predominating, and the poultry being kept to supply high class eggs to the Pacific markets. The poultry farmers in this district are specialists. Most of them do little incubating, 
but buy baby chicks from special hatching establishments. Birds are kept in flocks and given considerable range. The Petaluma district produces eggs of exceptionally fine quality which bring a high price.

In Vineland, in southern New Jersey, is another intensive egg producing plant. Here flocks of from 500 to 1000 birds are kept, and extremely intensive artificial methods prevail. Most of the poultrymen do their own hatching and rearing, and care for the chicks themselves. White Leghorns prevail here as in California. The primary object is to produce strictly fresh, white eggs for the New York markets. The Vineland district is known to be one of the most intensive specialty egg producing sections in the United States.

Meat District.-The great mass of poultry produced for food comes as a by-product from general poultry farms. There are, however, two special districts concerning which the poultryman should be informed. These are the capon district of New Jersey, and the roaster district of Massachusetts. Burlington County in New Jersey is primarily devoted to grain raising. After the grain is harvested, the birds are allowed to forage in the fields and in this way some high quality poultry is produced. It finds a ready market in Philadelphia at phenomenally high prices. The roaster district in Massachusetts covers a small area near Hanover; here are a number of small plants which do nothing but hatch chickens and rear them to be sold for meat. The Brahma is the prevailing breed kept. These birds grow to a great size and are of fine quality at maturity.

Poultry farms in America are of two kinds: First, there are the intensive small farms, which cover only a small area, but do a large business; second, and these are many, the extensive poultry plants, which are scattered over a large area. Along the Atlantic and Pacific coasts, the intensive system of poultry keeping is the most common. On cheap land far from market, the extensive type prevails. 


\section{EXPORTS AND IMPORTS}

The United States produces somewhat more poultry and eggs than it needs for its own use, and this surplus finds its way into Canada. Owing to the perishable nature of poultry and eggs, no efforts have been made to export them to Europe and Asia. So far, the United States has seldom needed to import poultry products, owing to the abundant supply at home. But at the present time, the high prices of poultry

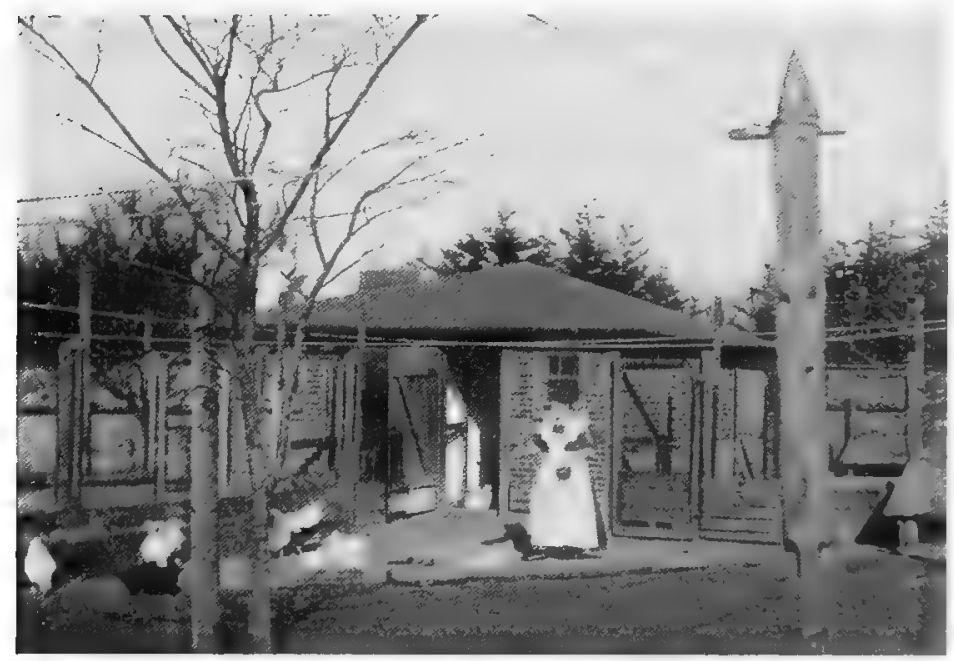

Fra. 178.-A typical Danish poultry house and flock. The houses are usually built of brick and the women of the family take the most care of the flock. Denmark is noted for the excellent quality of its poultry products. Co-operative marketing has been an important factor in the development of the poultry industry in Denmark.

and eggs and an apparent scarcity at certain seasons have led to a consideration of the possibility of importing foreign eggs. Eggs shipped to the United States from Europe arrive in good condition (Fig. 178). The experiment is being made of bringing eggs from China, but this ments with opposition, and it is doubtful if it will succeed. Cold-storage spice on shipboard is very expensive. 


\section{PRESENT CONDITIONS OF OUR POULTRY INDUSTRY}

There are a few interesting facts in connection with the American poultry industry which should here be mentioned. The first is that each year more and more attention is being paid to utility features, and less and less to the so-called pure exhibition value of birds. Success on a poultry farm depends on the poultryman's ability to secure a product for human food.

The second important fact is the development of a socalled co-operative system along educational and marketing lines, with the idea of buying cheaper and selling at a higher price. This also will result in larger profits (Fig. 179).

An increased interest on the part of the public is noticeable. The population in general has become more interested in the domestic hen and her possibilities.

Poultry exhibitions of a utilitarian nature are becoming very common. These include the exhibition of both eggs and dressed and live poultry. Prizes are offered in accordance with trade standards, not artistic standards. These exhibitions will have a marked affect upon the successful development of commercial poultry culture, for they awaken interest and suggest new methods of management.

The egg laying contest has come to stay. A good type of this is the Boys' and Girls' Poultry Raising and Egg Laying Contest, which is being rapidly developed.

On the whole, the poultry industry offers to the boys and girls of America an exceptional opportunity to study nature and animal life, and to the farm lad a life work which for healthfulness, for the pleasure it affords, and for its financial possibilities has no equal.

\section{LABORATORY EXERCISE}

Exercise No. 87.- Locating the Centers of Poultry Production.-Secure an outline map of the United States, or have the class prepare such a map. The former method will 


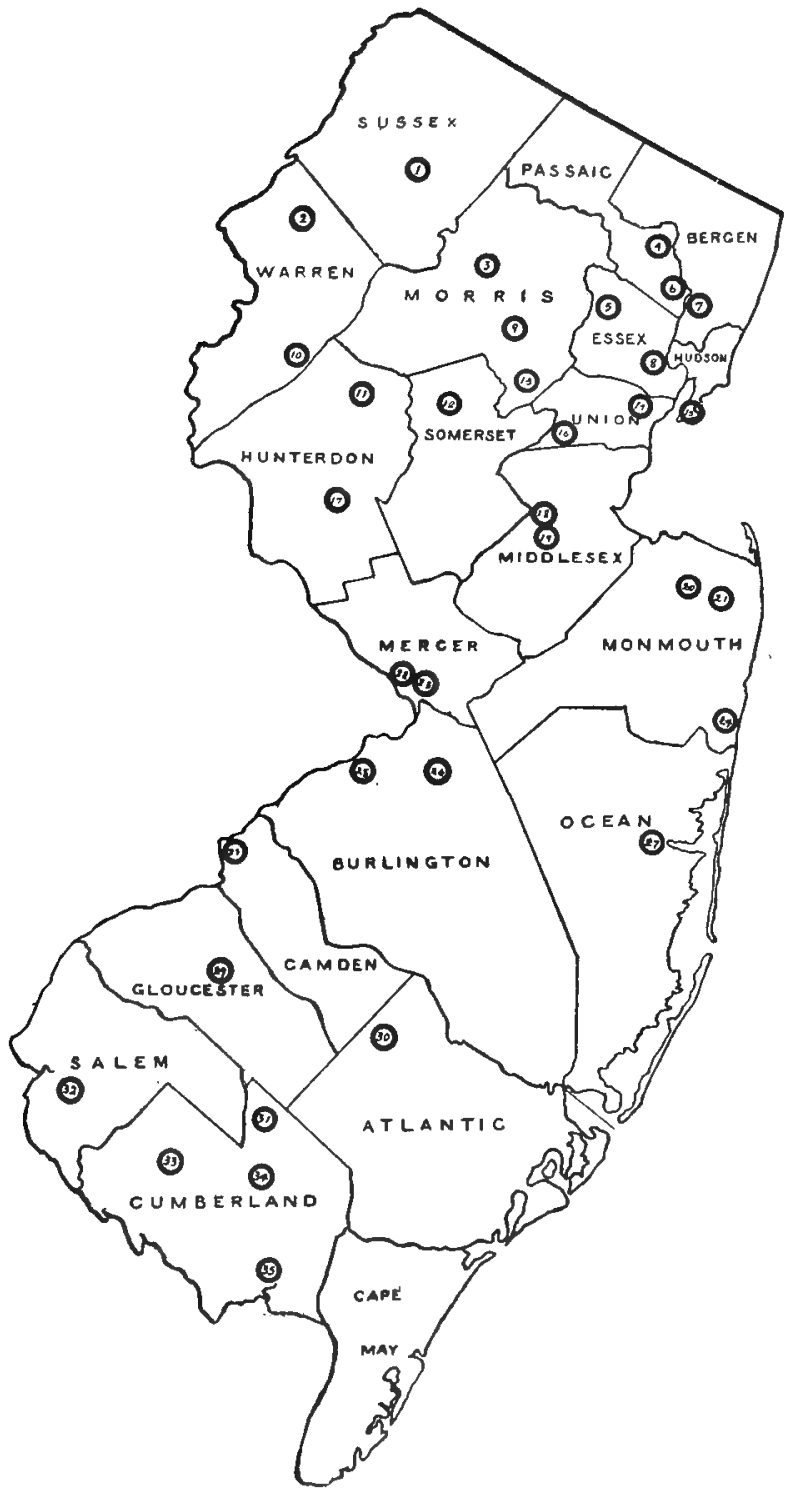

FIG. 179. -New Jersey has 35 county and local poultry associations for educational and co-operative purposes, $-a$ total membership of over 4000 . 
make the neatest work. From the text have the locations mentioned filled in with different colored crayons or other distinctive marks. A key to such a map can be made and thus the places mentioned as special poultry centers will be fixed in mind. Such a map will make a fine addition to the museum.

\section{THOUGHT QUESTIONS}

1. How does poultry keeping compare with other branches of general agriculture?

2. How many birds of our domestie breeds of poultry were there in the United States in 1910?

3. What was the total value of these birds?

4. What increase does this show over that of 1900 ?

5. What was the amount and value of eggs produced in the United States in 1909 ?

6. In what section of the United States are the great masses of poultry and eggs produced?

7. Tell what you know about the great egg producing section in central United States.

8. Describe the intensive egg producing section in Sonora, California.

9. What are the peculiar characteristics of the Vineland District in Southern Jersey?

10. Why is Burlington County in New Jersey especially suited to the production of large sized roasting chickens?

11. Tell what you can about the roaster district near Hanover, Massachusetts.

12. Into what two general classes can most poultry farms be grouped?

13. Discuss the exportation and importation of poultry and eggs.

14. Why is more and more attention being paid to the utility possibilities of poultry?

15. Why are poultrymen becoming greatly interested in co-operative efforts?

16. What is the cause of the general public becoming so seriously interested in poultry keeping?

17. What are some of the advantages of a poultry exhibition?

18. What is to be the future of the egg laying contests? 


\section{CHAPTER XXXIV}

\section{THE BUSINESS OF POULTRY FARMING}

AGRICULTURe is as much a business as any manufacturing or trade occupation, and if poultry raising is to succeed, it should be conducted on the same principles as any other business enterprise. This means that the poultryman should always know just what his flock is doing. The best results can be obtained only when records are kept of all individual hens and of the total produce. These records should show the actual cost of operation, also the income or money received. Financial success in poultry keeping depends, not alone on the abundant production of poultry and eggs, but on the ability to secure these products at the lowest cost. Once produced, the profits of the business depend upon the ability of the poultryman to dispose of his products at the greatest advance over the cost of production.

\section{RECORDS}

The keeping of simple yet accurate accounts is the foundation of business success. Such records should serve as a guide in future seasons. They indicate to the poultryman in what ways he was successful and in what unsuccessful. By carefully referring to his records he can each year improve on the preceding one, and can duplicate the conditions which proved satisfactory in previous years. The keeping of records prevents any guesswork. A small diary, with a page allotted to each clity, filled out regularly and carefully, serves as a complete and interesting record of all operations on the plant during the time it is kept. Make the records as simple as possible, and have them handy. A little book of a size that will fit in the pocket is probably the best for small flocks. Large sheets and index cards are not necessary unless 
many birds are kept. The book should contain the following information: Egg yield; this record should be so kept that it will show at a glance the egg production for every day in the year, and the number of hens in the flock

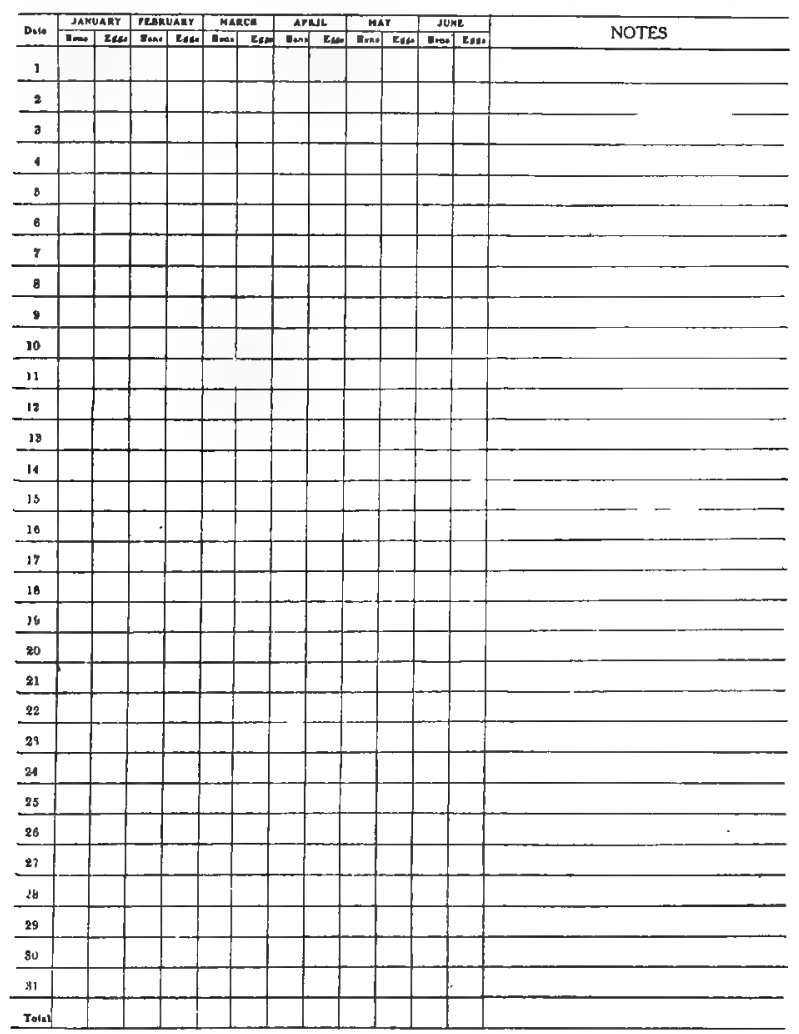

FIG. 180.-An egg record for six months.

(Fig. 180). There should also be a record of the amount and cost of feed consumed. It is usually best to keep the different rations separate, noting down the mash ration as one and the grain ration as another. This will be simpler 
than to put down every day the amount of each that is fed. Given the egg yield and the cost of feed consumed, it becomes merely a matter of mathematics to figure out the profit which the birds are bringing in above the feed consumed. A record should also be kept of the cases of sickness among the birds, and the number of deaths. This should not only show the number dead, and the number of birds that have been sick, but should briefly describe the ailments with a statement as to the probable cause, and the treatment given. If any treatment has been especially beneficial, this should be stated. Hatching should be fully recorded, together with any methods which gave exceptionally good results. Whenever eggs have been set, either under a hen or in an incubator, the poultry keeper should be able to tell at the finish of the hatch what results he has secured. The following facts are important: The number of eggs set, the breed, the number of infertile eggs, the number of dead chicks, and, lastly, the number of vigorous chicks hatched. From these entries the efficiency of the hatching process can be determined, and expressed in percentages. A record should be kept, too, of the results in the brooder house, stating the number of chicks placed in the same, and the feed given. If artificially brooded, the temperature of the hover should be frequently taken and recorded. After the chicks have been put on range, note should be made of the amount of feed consumed and the mortality. These accounts are simple, yet are essential to a perfect understanding of the details of management. Many poultry enterprises have failed because the business was losing money in one or two minor ways.

\section{MONEY TRANSACTIONS}

A careful account should be kept of all money transactions. These accounts may be very simple, but they should show where every penny goes and where rrery penny comes from. By knowing the exact amount of money re- 
quired to finance the flock for a year, the poultryman can plan in advance the work which is to bring in the money.

A Simple Form of Accounts.-A simple and satisfactory way of keeping accounts is known as single entry. The account book, or ledger, is ruled into two columns, one known as the debit, and the other known as the credit column. The sale of products, for which money is received, is entered in the credit. All supplies purchased for which money is paid out are entered in the debit column. Each of these two columns should be added, and the difference between their sums will show the amount of profit or loss. A modification of this method, in quite common use, is called the column system. The debit and credit sides of the book are again subdivided into columns; for example, incoming money can be ruled off into spaces for money received for eggs, for meat, and for live poultry. Outgoing money can be separately entered under feed, labor, etc. On adding up each side, the totals will tell at a glance in which branch there has been the heaviest expenditure, and what product has yielded the highest revenue. Such an account book should be balanced at least once a month, and can be done oftener if desired. The method is simple, but it shows the poultry keeper at any time exactly how his flock is paying.

\section{THE COLUMN SYSTEM OF KEEPING ACCOUNTS} INCOMING MONEY OR PRODUCTS SOLD

\begin{tabular}{|c|c|c|c|c|}
\hline Date & To Whom & Eggs & Meat & Live Poultry \\
\hline April & & & \multirow{5}{*}{$\begin{array}{r}10 \text { lbs. roaster } \\
\text { @ } 25, \$ 2.50 \\
\ldots \ldots \ldots \ldots\end{array}$} & \multirow{5}{*}{$\begin{array}{l}1 \text { cockerel } \\
\text { (a) } \$ 1.00\end{array}$} \\
\hline 10 & John Smith...... & 5 doz.@30 & & \\
\hline 18 & & $\ldots \ldots \ldots$ & & \\
\hline 21 & & & & \\
\hline 23 & $\begin{array}{r}\text { Mrs. Miles. . . . . } \\
\text { Total. . . . . }\end{array}$ & 1 doz.@32 & & \\
\hline
\end{tabular}


OUTGOING MONEY OR SUPPLIES PURCHASED

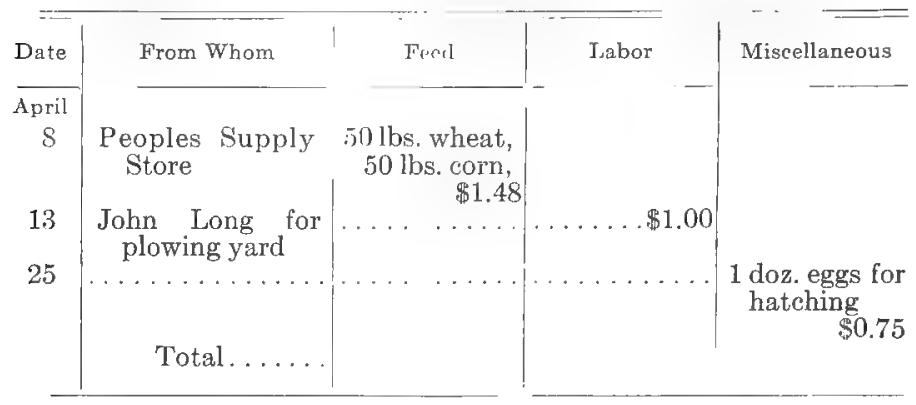

NoтE.-Two sheets similar to the above can be ruled for each month in the year. One sheet each month to be used for incoming money and the other for outgoing money. They can be made long enough to accommodate the number of transactions for the month. At the end of the year these sheets can be bound together to make a permanent record.

\section{SECURING BUSINESS}

As a rule, it is unnecessary for the small poultry keeper to advertise in order to dispose of his products, yet he should thoroughly understand the possibilities and advantages of advertising. Large business enterprises owe their success chiefly to the fact that the public became acquainted with the character of their production. The poultry keeper may start with only five to ten birds; as his plant grows, and productions increase, it may be well for him to do a little advertising in order to secure higher selling prices. In commercial poultry raising, extensive advertising is profitable only when there is a heavy stock on hand and the product is particularly valuable. Advertising of exhibition poultry pays well, but to advertise mirket poultry for sale is rarely profitable.

\section{WAYS OF ADVERTISING}

There are various ways of ulvertining, but most of them are expensive. With a small flock, an advertisement in the local newspapers is usually sulficient. Sometimes it may be worth while to advertise in prominent nowspapers or period- 
icals, but the poultryman should be cautious about this kind of advertising until he finds that it pays. Moreover, there are other ways of reaching the public. Taking pride in the quality of his products is one, and making both plant and products show off well, is another. One customer served to his satisfaction, is certain to bring others; and a neat, well-appointed plant with sanitary house and yards and an attractive flock of pure bred birds, is a sure sign of progress, and always indicates good management and thrift on the part of the owner (Fig. 181).

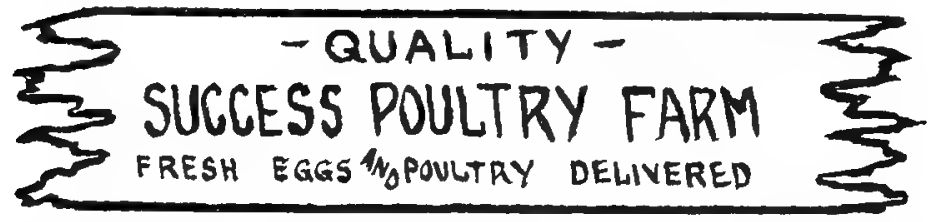

FIG. 181.-A small, neat sign located at the entrance to the yard or farm makes a very desirable type of advertising, especially in the suburb of a city or village where it is desirable to build up a retail route.

\section{BUSINESS PRINCIPLES}

The following business principles can well be applied to the management of a flock of chickens, for unless the business is conducted in accordance with these principles, it will yield neither satisfaction nor profit to the poultryman. A practical knowledge of ordinary business methods is the first requisite to success. Next, the poultryman must so manage his flock as to secure the highest degree of production. He must have the fullest knowledge of everything pertaining to the care of the birds, and also of all methods that will improve the character of production. Keen foresight in distributing his products at the proper season will also materially increase his revenues.

The importance of keeping simple, yet accurate records of all the operations that turned out well must be borne in mind, since these records should be the poultry keeper's 
guide in his future work. The keeping of exact accounts of all monetary transactions can not be too strongly urged.

Wastefulness in any of the operations about the plant is poor policy, and must be guarded against. Save the pennies, and dollars will be saved. Lastly, the poultryman should make it a point always to be courteous and considerate in his business dealings. A pleasant manner will not only win customers, but will make friends of all those with whom he comes in contact, while humane and gentle treatment of his birds will make friends of them as well.

\section{LABORATORY EXERCISES}

Exercise No. 88.-Making Poultry Records.-On uniform-sized paper have the class work out neat and concise forms suitable to record the data which one might wish to keep concerning the following work: An incubator record; a brooder record; a laying or egg record; a mortality record.

Exercise No. 89.-A Simple Account Sheet.-Plan, on a sheet of paper, suitable headings for a column system of keeping account of money transactions. Such a sheet can be made in the form of a book and the pupil can be encouraged to keep a record of his home flock on such a form.

Exercise No. 90.-Writing an Advertisement.-Write a suitable advertisement for strictly fresh table eggs for sale to retail trade. Same to be in the form of a business card. The size to be two by four inches. Neatness and facts are the two things to be given special consideration.

\section{THOUGHT QUESTIONS}

1. Is poultry keeping a business?

2. Upon what two factors is financial success in poultry keeping dependent?

3. What is the foundation for business success?

4. Enumerate some of the advantages of record keeping.

5. Describe two ways of keeping records.

6. The record kept should show what facts?

7. What should be the first aim in kecping poultry accounts? 
8. What is the great advantage to be realized by keeping an accurate record of all financial transactions?

9. Describe a simple method of keeping accounts.

10. How often should financial accounts be balanced?

11. Discuss the needs and possibilities of advertising.

12. Enumerate a few inexpensive ways of advertising a small poultry business.

13. What can you say about the desirability of advertising in papers and periodicals?

14. Mention some business principle which must apply in the poultry business if the poultry keeper is to succeed.

15. Have you ever kept any records or fiaancial accounts?

References.- Inited States Farmers' Bulletins: 287, Poultry Management; 355, A Successful Poultry and Dairy Farm; 511, Farm Bookkeeping; 528, Hints to Poultry Raisers; 572, A System of Farm Cost Accounting. 


\section{PART VIII}

\section{APPENDIX}

\section{REFERENCE BOOKS}

EActr school in which poultry is taught should have in the library reference bulletins and books on poultry keeping. The publications of the federal department of agriculture at Washington, D.C., can be secured for the asking. Poultry bulletins, reports and circulars can be secured for library purposes from State Colleges which are specially prominent in the poultry work. A letter explaining the material desired, and its use, if sent to the following State Colleges, will be productive of much valuable reference material.

Rhode Island, Massachusetts, Connecticut, New York, New Jersey, Missouri, Wisconsin, Ohio, Indiana, Michigan, and West Virginia. For the addresses of the above institutions see list of Agricultural Colleges on page 342.

The following standard poultry books should be in the library. Their use by the pupils should be encouraged by the teacher.

\section{Berds}

Birds in Their Relation to Man-Weed and Dearborn, J. B. Lippincott Company, Philadelphia.

Nature Study Birds-Chester A. Reed, Chas. I. Reed, Worcester, Mass.

Bird Guide (Water Birds) - Chister A. Reed, Chas. K. Reed, Worcester, Mass.

Bird Guide (Land Birds) - Chester A. Recd, Chas. K. Reed, Worcester, Mass.

American Standard of Perfection- Lmerican Poultry Lssociation.

Perfected Poultry of America- If Grew and Hou'ard, Howard Pub. Co., Washington, D. C.

Domestic Birds-John H. Robinson, Ginn and Co., N. Y. 340 


\section{Breeding}

Animal Breeding-Thomas Shaw, Orange Judd Co., N. Y.

Principles of Breeding-Eugene Davenport, Ginn and Co., N. Y.

\section{Housing}

Poultry Architecture-George B. Fiske, Orange Judd and Co., N. Y. Poultry Houses and Fixtures-Compilation American Poultry Pub. Co., Buffalo, N. Y.

Farm Buildings-Compilation, Saunders Pub. Co., Chicago, Ill.

\section{Feeding}

Poultry Feeding and Fattening-Geo. B. Fiske, Orange Judd and Co, N. Y.

The Feeding of Animals-W. H. Jordan, Macmillan Co., N. Y.

Feeds and Feeding-W. A. Henry, Pub. by Author, Madison, Wis.

\section{Diseases}

Diseases of Poultry-D. E. Salmon, Geo. Howard Co., Washington, D. C.

Poultry Diseases-B. F, Kaupp, American Journal of Veterinary Medicine, Chicago, Ill.

\section{Miscellaneous}

The following books cover the whole subject of poultry in a general way:

Productive Poultry Husbandry-Harry R. Lewis, J. B. Lippincott Company, Philadelphia.

Progressive Poultry Culture-A. A. Brigham, Torch Press, Cedar Rapids, Iowa.

Principles and Practice of Poultry Culture-John H. Robinson, Ginn and Co., N. Y.

Poultry Craft-John H. Robinson, Farm Poultry Pub. Co., Boston, Mass.

How to Keep Hens for Profit-C. S. Valentine, Macmillan Co., N. Y. 


\section{LOCATION OF COLLEGES}

Addresses of Colleges, Experiment Stations, etc. These devote more or less time to the study of poultry problems. Most of them publish much valuable material showing the results of their findings, in the form of bulletins and circulars. These can in most cases be secured by writing for them.

Alabama-Experiment Station: Auburn.

Tuskegee Station: Tuskegee.

Arizona-Experiment Station: Tucson.

Arkansas-Experiment Station: Fayetteville.

California-State College: Berkeley.

Canada-Ontario Agricultural College: Guelph.

Colorado-Experiment Station: Fort Collins.

Connecticut-Agricultural College: Storrs.

Delaware-Experiment Station: Newark.

Georgia-Experiment Station: Athens.

Illinois-Experiment Station: Urbana.

Indiana-Perdue University: Lafayette.

Iowa-Agricultural College: Ames.

Kansas-Agricultural College: Manhattan.

Department of Agriculture: Topeka.

Kentucky-Experiment Station: Lexington.

Louisiana-Experiment Station: Baton Rouge.

Maine-Agricultural College: Orono.

Department of Agriculture: Augusta.

Maryland-Agricultural College: College Park.

Massachusetts-Agricultural College: Amherst.

Board of Agriculture: Boston.

Michigan-Agricultural College: East Lansing.

Minnesota-University of Minnesota: St. Paul.

Mississippi--Agricultural College: Agricullural College.

Missouri-Experiment Station: Columbia.

Poultry Station: Mountain Grove.

Montana-Experiment Station: Bozeman.

Nebraska-Experiment Station: Lincoln.

Nevada-Experiment Station: Rcno.

New Jersey-Agricultural College: New Brunswich.

New South Wales-Department of Igriculture: Tictorin.

New York-Cornell station: Ilhuru. 
New Zealand-Department of Agriculture: Wellington.

North Carolina-Department of Agriculture: Raleigh.

College Station: West Raleigh.

North Dakota-Experiment Station: Agricultural College.

Ohio-Agricultural College: Columbus.

Experiment Station: Wooster.

Oklahoma-Experiment Station: Stillwater.

Oregon-Agricultural College: Corvallis.

Pennsylvania-Agricultural College: State College.

Department of Agriculture: Harrisburg.

Rhode Island-Agricultural College: Kingston

South Carolina-Experiment Station: Clemson College.

South Dakota-Agricultural College: Brookings.

Tennessee-Knapp School of Country Life, at Peabody College for Teachers: Nashuille.

United States Department of Agriculture-Washington, D. C.

Utah-Experiment Station: Logan.

Virginia-Experiment Station: Blacksburg.

Washington-Experiment'Station: Pullman.

West Virginia-Experiment Station: Morgantown.

Wisconsin-Agricultural College: Madison.

\section{PLAN AND RULES FOR BOYS' AND GIRLS' POULTRY CONTESTS}

\section{PLAN}

EACH student enrolling in the contest is to set twenty-five eggs from a standard breed of fowls under two hens. The following are some of the more popular breeds of fowls: Plymouth Rocks, Rhode Island Reds, Wyandottes, Orpingtons, Langshans, Brahmas and Leghorns. The contestant must advise with the teacher in regard to the breed selected. The pupil is to hatch same, rear them to maturity, write essays and show the products at the fall poultry show or agricultural fair.

The poultry raising contest of one year is to be followed the next year by an egg laying contest.

Where possible, it is recommended that groups of boys and girls form regular organizations and call them "Boys' 
and Girls' Poultry Clubs." The nature of the organization can be similar to that outlined on page two of Farmers' Bulletin 562.

\section{RULES FOR POULTRY RAISING CONTEST}

(1) Any boy or girl wishing to enter the contest must make proper entry on blanks provided for the purpose, the same being properly filled out and filed with the supervising principal or teacher in charge, before the work is started. This entry will aid in properly following up each contestant and will be necessary to properly make the awards in the fall. Each contestant will file an affidavit, previous to making the awards, stating that the birds are his and that they came from the original twenty-five eggs set and that he or she has performed all the work personally.

(2) The supervising principal or teacher shall be the one to whom the student shall apply for registration blank and from whom detailed instructions shall be taken. Any student regularly enrolled in the schools of - County between the ages of ten and sixteen years is eligible to enter.

(3) Twenty-five eggs from any standard breed shall be hatched under two hens. The eggs must be set prior to May 10th and as much earlier than this date as possible.

(4) A record must be kept of the following facts: Number of eggs set, breed, weight of eggs when set, infertile eggs and dead germs when tested on both the seventh and fourteenth days of incubation, number of vigorous chicks hatched, weight of chicks hatched, percentage of vigorous chicks hatched to total eggs set. (For management of sitting hen and manner of testing the eggs see Farmers' Bulletin, No. 562 , pages 8 and 9 .)

(5) The chicks hatched should be brooded under hens and fed and cared for according to instructions given in the previous pages of this book. 
(6) Keep records of amount and cost of feed fed and notes as to the general management and care of the hens and chicks during the growing period. These records must be kept in a neat and orderly manner on special blanks which will be provided, as they will be considered when making the awards.

(7) Carefully weigh and record the total weight of the flock of chicks weekly, up to and including the twelfth week. From the twelfth week on keep a weekly record of the individual weight of each bird, leg bands being used to identify the individuals.

(8) Write an essay covering the manner of setting the hen, the management of the chicks, their feed and care, and also including the general results of the work. The subject of the essay should be, "My Poultry Flock," and should consist of from 200 to 300 words.

(9) In the fall each contestant is requested to exhibit some of his birds at the county agricultural and poultry exhibition or fair, these exhibits to compete for the prizes specified in section eleven of these rules.

(10) Seventy-five dollars in prize money will be divided among the school districts which are contesting, three prizes being awarded to each district.

These cash prizes will be awarded on the following basis:

Appearance and neatness of the poultry equipment.. 25 per cent Methods of care and management........... 25 per cent Efficiency of the work accomplished........... 40 per cent

Grade giving the records and special essay....... 10 per cent

Total. ..................... $\overline{100}$ per cent

Judges are to be as follows: A representative of the County Poultry Association, a representative of the State Experiment Station, the county superintendent, the supervising principal or principals of the district.

(11) At the annual fall poultry and agricultural exhibi- 
tion, the following prizes will be awarded to pupils entering birds raised in this contest as follows:

For best cockerel hatched and reared by the contestant:

First prize........ $\$ 3.00$

Second prize.... 1.50

For best pullet hatched and reared by the contestant:

First prize. . . . . $\$ 3.00$

Second prize..... 1.50

For the greatest number of birds raised by the contestant from the original twenty-five eggs set. Both number and quality to count:

First prize. . . . . $\$ 4.00$

Second prize. .... 2.00

(12) It shall be the duty of the judges in co-operation with the supervising principal or principals to pick from among the winners in the various districts the best poultry keeper for the county. The winner is to receive a ten dollar gold piece.

\section{EGG LAYING CONTEST FOR THE FOLLOWING YEAR}

The pullets hatched and reared during the previous poultry raising contest can be entered in an egg laying contest to be outlined and conducted during the following year, the idea being to conduct each year two contests; one elementary, and to consist of hatching and rearing, and the other advaneed and to consist of the management of adult birds for egg production.

It should be the idea to give this movement all of the publicity possible through the press and all other means.

Each county poultry association or other agricultural society should assume the responsibility of securing the one hundred dollars designated for prize money, and should stand back of the effort with their moral and financial support. The funds for prize money should be solicited from interested parties in the county. Banks, newspapers, prominent business houses, etc., will always be glad to aid such a worthy cause. 


\title{
BLANKS TO USE FOR POULTRY RAISING CONTEST
}

The following is a common form of application blank:

\section{Middlesex County Poultry Raising Contest.}

\author{
For School Boys and Girls
}

\section{ENTRY APPLICATION}

I. residing at. . . . . . . . . . . . . and a regular pupil in District. . . . . . . . . .... School No.........., hereby respectfully apply to enter the Boys' and Girls' Poultry Raising Contest of Middlesex County. I will carefully follow all rules and regulations applying to same.

I will set 25 eggs from the . . . . . . . . . . . breed.

Approved.

Supervising Principal.

Dated this............. day of . . . . . . . . . . 191..

Noтe-Application to be filed with Supervising Principal.

New Jersey, ss:

being duly sworn according to law, on ...... oath saith that the attached records are the results which have been attained from following the rules and regulations of the Poultry Raising Contest of Middlesex County. The adult birds herein described are............., and that they came from the original 25 eggs set and that all of the work has been performed by............. personally.

Sworn and subscribed the. day of. A.D. 1914, before me.

(This oath to be taken at close of Contest)

The records to be kept can be made much more simple or more complicated than this form, depending upon the age and capability of the pupils enrolling (see page 348 ). 


\section{OFFICIAL RECORD CARD FOR A POULTRY RAISING CONTEST}

Name.

District.

Breed of Fowl to be Used.

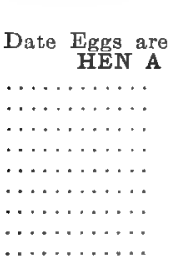

\section{Address.}

Principal in Charge

\section{BROODING \\ Mortality

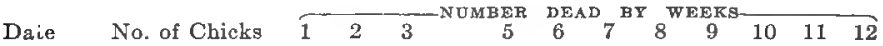

INCUBATION

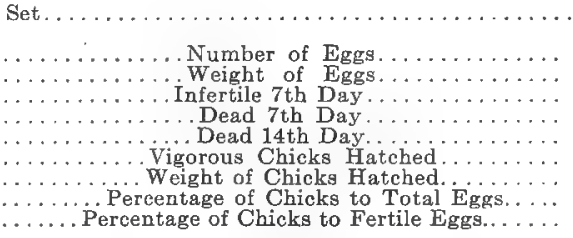

\section{HEN B} WEIGHTS

Number of Chicks........

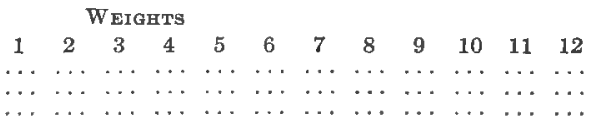

FEED FED

Total Weight....

Amount by Weight.

$\begin{array}{llllllllllll}1 & 2 & 3 & 4 & 5 & 6 & 7 & 8 & 9 & 10 & 11 & 12\end{array}$

Total Cost.

Feed Fed at Different Trmes (Designate by Week)

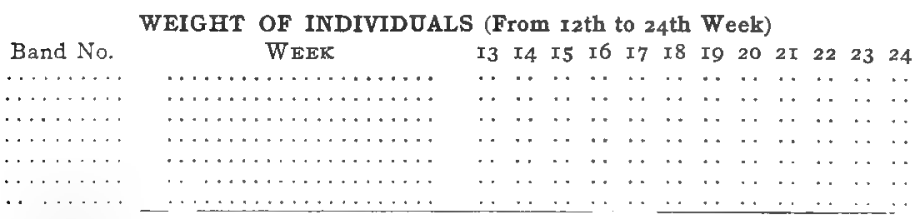

Name.

Address.

\section{TOTAL RESULTS}

No. of Birds at Six Months

No. of Females.

Average Weight of Females

No. of Males

Average Weight of Males.

Cost of Setting Eggs.

Cost of Feed

Total Expenses

Average Cost of Birds at Six Months .

Market Value of Adults Reared.

Profit or Loss above Feed and Cost of Ëgrg 


\section{SCORE CARDS}

THe following score cards will be found useful in determining the good and bad points of birds, both live and dressed, and also of market eggs.

\section{SCORE CARD FOR STANDARD BRED BIRDS}

\section{CLASS NO. II-ASIATIC BREEDS}

Date

Entry No. ........ Coop No.

Band No. ..........

Owner

Breed

Estimated Weight

Corrected Weight

Student's Name.

Section

SCALE OF POINTS

\begin{tabular}{|c|c|c|c|c|c|c|c|}
\hline \multicolumn{3}{|c|}{ Perfection } & & \multicolumn{2}{|c|}{$\begin{array}{l}\text { Student's } \\
\text { Estimate }\end{array}$} & \multirow{2}{*}{\multicolumn{2}{|c|}{ Corrected }} \\
\hline Shape & |Color| & Total & & Shape & Color & & \\
\hline $\begin{array}{l}4 \\
4 \\
4 \\
4 \\
5 \\
5\end{array}$ & $\begin{array}{l}6 \\
4 \\
5 \\
5 \\
5 \\
3\end{array}$ & $\begin{array}{r}8 \\
6 \\
5 \\
6 \\
8 \\
5 \\
10 \\
8 \\
9 \\
9 \\
10 \\
8 \\
8\end{array}$ & 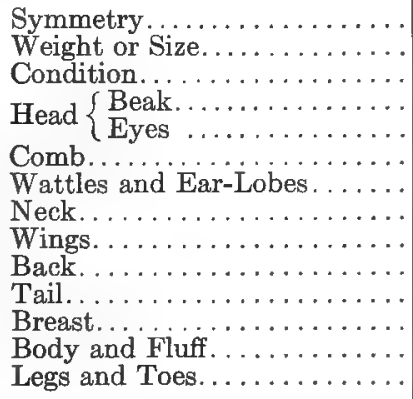 & & & & \\
\hline
\end{tabular}

TOTAL

100

TOTAL CUTS

Score.

Instructor

NoTE.-For detailed instructions as to the use of this score card see the American Standard of Perfection. 


\section{UTILITY SCORE CARD FOR LIVE POULTRY}

\section{Commercial Egg Production the Primary Object}

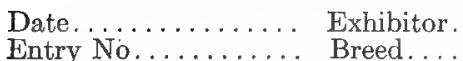

\section{DESCRIPTION}

Age.

Counts Cuts

General Appearance

Form, compact and symmetrical, with no undue development in any part, as excessive fat growth, abnormal leg development, or extra long neck........

Quality, texture of comb fine, skin and flesh soft but not fat, skin mellow and not too thick. Body plump and skin tight, not loose and flabby..............

Temperament, vigorous constitution, active, not lazy. A nervous, energetic temperament is associated with

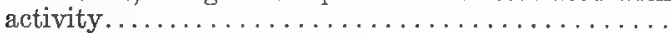

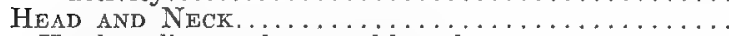

Head medium to large and broad...............

Eyes full and prominent; bright, showing vigor......

Comb and Wattles medium to large in size, and bright red in color. Comb firmly fastened to the head. Comb of single-comb White Leghorn large......... .

Neck medium in length with full hackle............. BODY

Hindquarters greatly developed, with heaviest part of the body carried back of the hock joint. Y-shaped when viewed from side, top, and front............

Breast moderately full and wide.

Back wide and long, showing great depth from centre of back to point of keel.

Fluff abundant, fine, and lying close to the body......

Tail carried rather high and well spread............

Feathers soft and held close to the body...........

Wings held well up and carried close to the body.....

Lay bones soft, pliable, and wide-spread; low-producing fernales and all females during seasons of low production show these bones much contracted and hardened. .............................

Legs.

Legs straight, wide-spread, especially at and above the

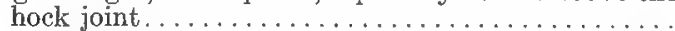

Length medium to short; long legs - giving the bird a stilted appearance - are usually associated with lack of vitality and low production

Color of yellow, bluish-black, or flesh, depending upon breed characteristics, yellow to have the preference. .

Shanks free from feathers. 


\section{SCORE CARD FOR DRESSED POULTRY}

Date.

Exhibitor.

Entry No.

Breed... . . .

Age

Average Weight.

Market type.

\section{DESCRIPTION}

Any sign of poor health or diseased condition is a disqualification. Lack of vigor is a serious defect.

Counts Cuts

Condition

Weight, perfection being the highest weight allowable in a given class... . . . . . . . . . . . . . . . . . . .

Plumpness, a full plump development in all parts,

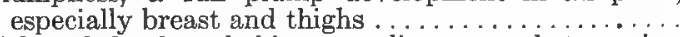

Color of shank and skin, according to market requirements: yellow, white, and blue usually preferred in the order named............................. 10

Killing and Dressing.

Manner of sticking, or bleeding. Perfection is in the throat. For beheading cut five points. For exposed bleeding cut three points........................ scalding cut three to ten points, depending upon

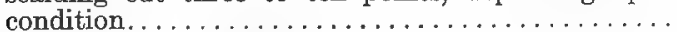

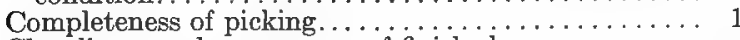

Cleanliness and appearance of finished carcass.......

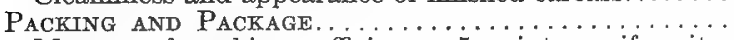

Manner of packing-efficiency, 5 points; uniformity, 5 points.

Package, neat, substantial, and attractive...............

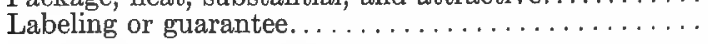

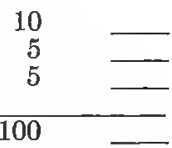

Total.

100

Final score........ Judge. 


\section{SCORE CARD FOR MARKET EGGS}

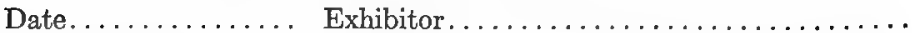

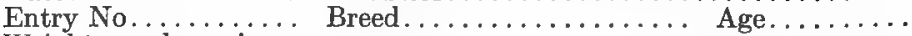

Weight per dozen in ounces.

\section{DESCRIPTION}

Counts Cuts

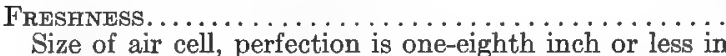
depth. Cut five points for each additional eighth

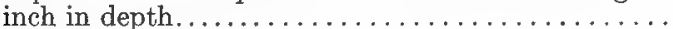

Natural shell lustre, lack of same due to washing or age

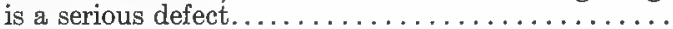

WEIGHT.

Weight of total sample, perfection is 27 ounces or more per dozen. Cut one point per dozen for each ounce under weight. Overweight is not a defect........

Uniformity of sample, all eggs making up a given sample should be of the same weight...........

CoLor

Color of total sample, pure white or brown is perfect. Creamy or tinted white eggs, a defect. Dark brown eggs have the preference over light brown.........

Uniformity of sample, all eggs in sample should be of same tint. Cut one point for each egg varying in color from average color of sample...............

SHAPE

Egg shape, the ratio of the large to the small diameter is about one to one and one-fifth; this varies slightly with different breeds.

Uniformity of sample, cut one point for each egg varying from the average shape of all eggs in a given sample

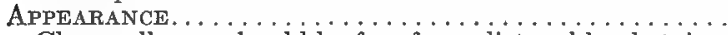

Clean, all eggs should be free from dirt or blood stains; cut one-half point for each egg so stained.........

Not cracked or broken, cut one point for each cracked egg in sample. More than five eracked eggs or any egg broken so that the contents leak disqualifies the sample.

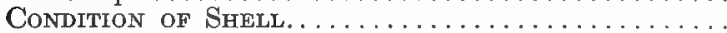

Smoothness of shell, cut one-half point for each rough shelled egg.

Hardness of shell, thin-shelled eggs which break easily and do not offer desirable shipping possibilities are defective.

PACKAGE

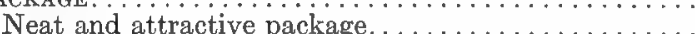

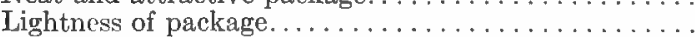

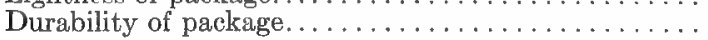

Total 


\section{GLOSSARY OF PARTS OF A BIRD}

Сомв: A fleshy growth lying on top of the bird's head.

BEAK: The horny outer portion of the upper and lower jaw. It is used to seize the food.

FACE: The bare skin around the eye just back of the beak.

EAr-Lobes: Fleshy growth hanging just below the ear.

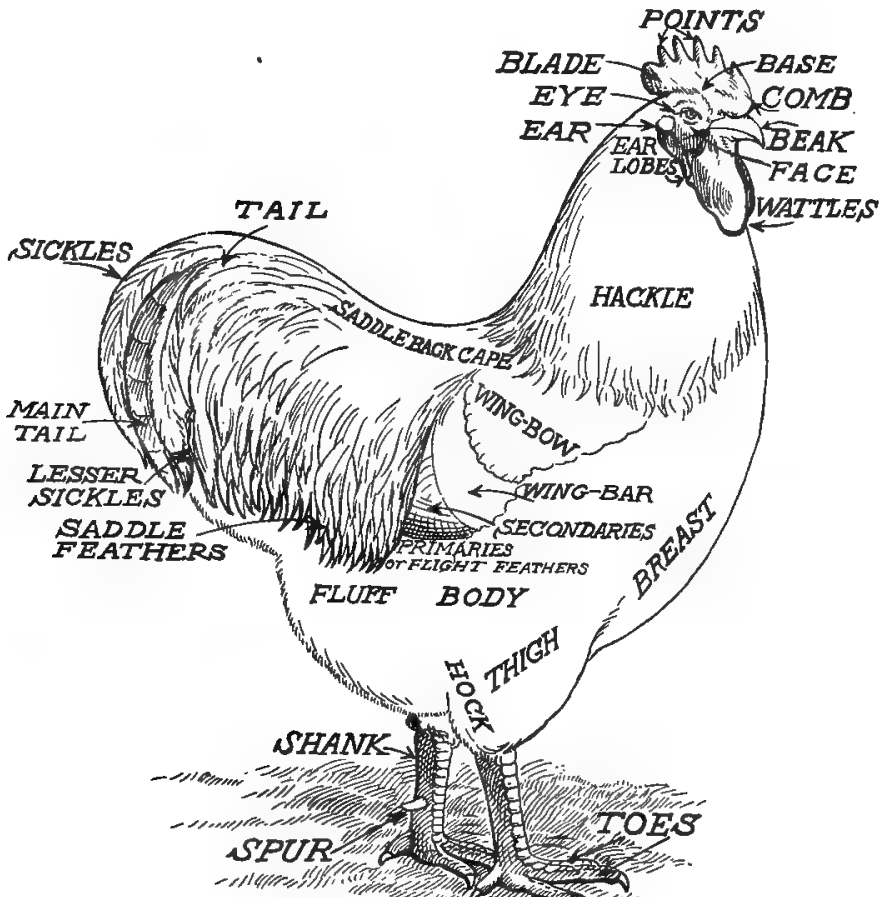

CLAW W

Note. - In the female the cushion takes the place of the saddle of the male and the sickle feathers are absent. (Farmers' Bulletin No. 562, by Harry ir. Lamon.)

WATtLas: Large fleshy growths, one on each side, hanging just below the base of the beak.

HACKLE: The neck feathers; usually full and flowing.

BACK: The top part of the body lying between the tail and hackle feathers.

SADDLE: The rear part of the back, lying at the base of the tail. 
Saddle Feathers: Long narrow flowing feathers which cover the base of the tail. They start from the saddle.

TAIL: The long, wide and coarse feathers at the rear of the body. The outer ones are usually curved and are called the sickle feathers. The under ones are straight and heavy and are what give the tail its form. They are called the main tail feathers.

Wing: The forearms or appendages, they lie one on each side of the body just below the back.

WING Bow: The front part of the wing.

Flight Feathers: The large straight heavy feathers lying at the rear part of the wing when it is folded. The upper ones are called the secondaries while the under ones are called the primaries.

Breist: The full rounded front part of the body.

FLUFF: The fine fluffy feathers at the back part of the body below the tail.

Bony: The portion of the body below the wings and breast and between the legs.

ThIgH: The upper visible portion of the leg; it is always covered with feathers.

SHANK: The scaly portion of the leg just below the thigh. It is sometimes clean and with some breeds it is covered with feathers.

SPUR: A sharp horny growth protruding from the rear part of the shank just above the hind toe.

Toes: The appendages extending from the bottom part of the leg. They are usually four in number, three in front and one at the rear. In two breeds there are five toes present. 


\section{THE COMPOSITION AND DIGESTIBILITY OF COM= MON FEED STUFFS}

\section{Digestible Nutrients in 100 Pounds}

\begin{tabular}{|c|c|c|c|c|}
\hline Kind of food & Dry Matter & Protein & $\begin{array}{c}\text { Carbohy- } \\
\text { drates }\end{array}$ & Fat \\
\hline Alfalfa, green. . . . . . . . . . . & 20.00 & 4.00 & 7.00 & .60 \\
\hline 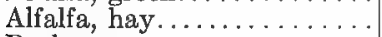 & 89.00 & 14.00 & 37.00 & 2.00 \\
\hline Barley, green............. & 28.00 & 2.00 & 10.00 & .00 \\
\hline Barley meal. ............. & 93.00 & 11.00 & 66.00 & 2.00 \\
\hline 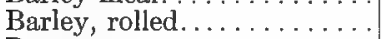 & 90.00 & 9.00 & 60.00 & 2.00 \\
\hline Beans. ................ & 87.00 & 17.00 & 49.00 & 1.00 \\
\hline Blood, dried............. & 90.00 & 72.00 & 6.00 & 1.00 \\
\hline Bone, dry.............. & 92.00 & 28.00 & .00 & 3.00 \\
\hline Bran, rice. . & 89.00 & 10.00 & 42.00 & 10.00 \\
\hline Bran, wheat.............. & 88.00 & 11.00 & 42.00 & 2.00 \\
\hline Brewers' grains, dry......... & 92.00 & 16.00 & 37.00 & 5.00 \\
\hline Brewers' grains, wet........ & 24.00 & 4.00 & 9.00 & 1.00 \\
\hline Butter milk. .............. & 10.00 & 4.00 & 4.00 & .00 \\
\hline Cheese, cottage. .......... & 28.00 & 21.00 & 4.00 & 1.00 \\
\hline Clover, green............ & 23.00 & 3.00 & 9.00 & .00 \\
\hline Corn, cracked........... & 89.00 & 8.00 & 63.00 & 4.00 \\
\hline Cracklings........... & 94.00 & 43.00 & .00 & 46.00 \\
\hline Feed flour..... & 88.00 & 9.00 & 67.00 & 1.00 \\
\hline Kale, green........... . & 15.00 & 3.00 & 10.00 & .00 \\
\hline Lettuce, green. . . . . . . . & 5.00 & 1.00 & 3.00 & .00 \\
\hline Meal, corn .... & 88.00 & 6.00 & 66.00 & 3.00 \\
\hline Meal, cottonseed............ & 90.00 & 41.00 & 15.00 & 11.00 \\
\hline Meal, gluten........... & 92.00 & 26.00 & 43.00 & 14.00 \\
\hline Meal, linseed oil........... & 89.00 & 26.00 & 38.00 & 7.00 \\
\hline Meal, soy bean............ & 90.00 & 40.00 & 23.00 & 7.00 \\
\hline 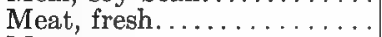 & 26.00 & 20.00 & .00 & 3.00 \\
\hline Meat scrap.... & 94.00 & 54.00 & 7.00 & 3.00 \\
\hline Milk, dried... . & 89.00 & 51.00 & 16.00 & 1.00 \\
\hline Milk, skim. . . . & 9.00 & 3.00 & 5.00 & .00 \\
\hline Millet. . & 92.00 & 20.00 & 35.00 & 4.00 \\
\hline Mixed feed. . & 89.00 & 10.00 & 47.00 & 3.00 \\
\hline Oats........ & 89.00 & 9.00 & 47.00 & 4.00 \\
\hline Peas......... & 90.00 & 19.00 & 51.00 & .00 \\
\hline Rice.... & 88.00 & 5.00 & 68.00 & .00 \\
\hline Wheat middlings. . . . . . . . . & 88.00 & 12.00 & 53.00 & 4.00 \\
\hline Wheat plump............ & 89.00 & 9.00 & 61.00 & 1.00 \\
\hline Wheat shrunken . . . . . . . . & 92.00 & 13.00 & 57.00 & 2.00 \\
\hline
\end{tabular}




\section{FEEDING STANDARDS FOR POULTRY}

Requirements for Maintenance

\begin{tabular}{|c|c|c|c|c|c|}
\hline & Protein & Fat & $\begin{array}{l}\text { Carbo- } \\
\text { hydrates }\end{array}$ & $A_{s i s h}$ & T.D.M. \\
\hline $\begin{array}{l}\text { Mature hen: } \\
5 \text { to } 7 \text { pounds......... }\end{array}$ & .40 & .20 & 2.00 & .10 & 2.7 \\
\hline & .50 & .30 & 2.95 & .15 & 3.9 \\
\hline 9 to 12 pounds... & .30 & .20 & 1.74 & .06 & 2.3 \\
\hline
\end{tabular}

REQUIREMENTS FOR LAYING

\begin{tabular}{l|r|r|r|r|r}
\hline Laying hen: & & & & & \\
5 to 8 pounds................. & .65 & .20 & 2.25 & .20 & 3.3 \\
3 to 5 pounds.............. & 1.00 & .35 & 3.75 & .30 & 5.4 \\
\hline
\end{tabular}

Requirements FOR Growth

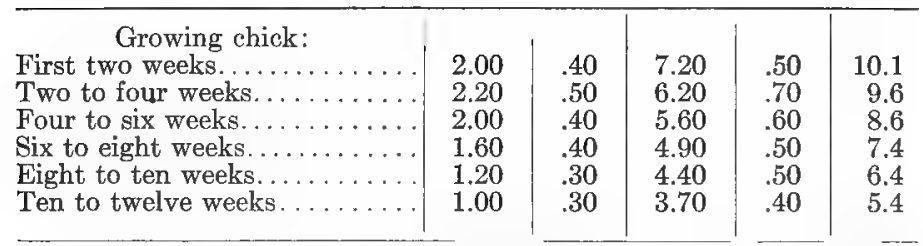

The above feeding standards are by William P. Wheeler, New York Agricultural Experiment Station, Geneva, N. Y. 


\section{WEIGHT AND VOLUME OF COMMON FEEDING STUFFS}

\begin{tabular}{|c|c|c|}
\hline Feed & 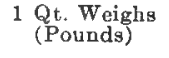 & $\begin{array}{l}1 \text { lb. Measures } \\
\text { (Quarts) }\end{array}$ \\
\hline Barley meal. & 1.1 & 0.9 \\
\hline$\ldots \ldots \ldots \ldots \ldots \ldots$ & 1.5 & 0.7 \\
\hline$\ldots \ldots \ldots \ldots \ldots$ & 2.0 & 0.5 \\
\hline Brewers' dried grains. . . . . . . . . . . . . & 0.6 & 1.7 \\
\hline 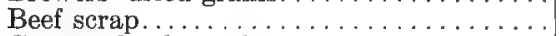 & 1.3 & 0.8 \\
\hline Corn and cob meal. . . . . . . . . ....... & 1.4 & 0.7 \\
\hline 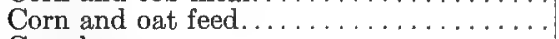 & 0.7 & 1.4 \\
\hline 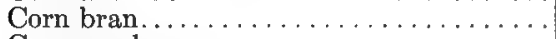 & 0.5 & 2.0 \\
\hline 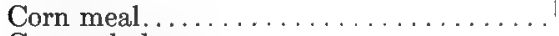 & 1.5 & 0.7 \\
\hline Corn, whole. . . . . & 1.7 & 0.6 \\
\hline Cottonseed meal. . . . . . . . & 1.5 & 0.7 \\
\hline Distillers' dried grain. . . . . . . . . . . . . & $0.5-0.7$ & $1.0-1.4$ \\
\hline Germ oil meal . .................. & 1.4 & 0.7 \\
\hline 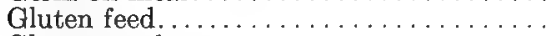 & 1.3 & 0.8 \\
\hline 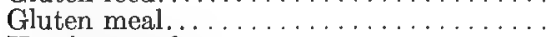 & 1.7 & 0.6 \\
\hline 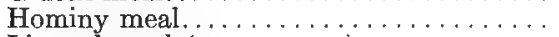 & 1.1 & 0.9 \\
\hline Linseed meal (new process) ............ & 0.9 & 1.1 \\
\hline Linseed meal (old process).............. & 1.1 & 0.9 \\
\hline Malt sprouts. . . . . . . $\ldots \ldots \ldots \ldots$ & 0.6 & 1.7 \\
\hline Mixed feed, bran and middlings........ & 0.6 & 1.7 \\
\hline 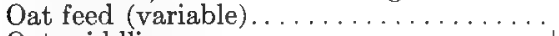 & 0.8 & 1.3 \\
\hline Oat middlings................... & 1.5 & 0.7 \\
\hline 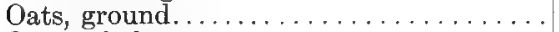 & 0.7 & 1.4 \\
\hline 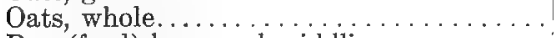 & 1.0 & 1.0 \\
\hline Rye (feed) bran and middlings.......... & 1.3 & 0.8 \\
\hline 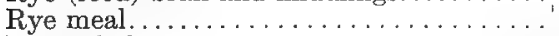 & 1.5 & 0.7 \\
\hline 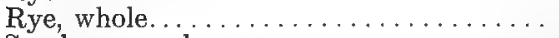 & 1.6 & 0.6 \\
\hline Soy bean meal. & 1.3 & 0.8 \\
\hline Wheat bran.... & 0.5 & 2.0 \\
\hline Wheat, ground. . . . . . & 1.7 & 0.6 \\
\hline Wheat middlings (flour). . & 1.2 & 0.8 \\
\hline Wheat middlings. . . . . . . & 0.8 & 1.3 \\
\hline Wheat, whole.... & 1.9 & 0.5 \\
\hline
\end{tabular}




\section{FACTS A POULTRY KEEPER SHOULD KNOW}

ONE dozen eggs for market should weigh twenty-four ounces.

A standard crate of eggs holds thirty dozen.

A standard crate of eggs should weigh fifty-one pounds.

A good hen should lay at least ten dozen eggs a year.

An average hen will consume in a year one hundred pounds of feed.

It will cost approximately one dollar and fifty cents to feed the average hen for one year. This is when all feed is purchased.

One dollar to one dollar and a half profit should be expected per bird per year. This amount is above feed, labor, interest and all expenses.

It will cost approximately twelve cents for feed to produce an average dozen eggs. This varies much with season.

It will cost approximately twenty to twenty-five cents to produce a broiler to one and a half pounds in weight.

It will cost approximately forty cents to feed a pullet from hatching time to maturity.

It will cost approximately sixty to seventy-five cents to rear a pullet to laying age.

One hundred laying hens will consume about fifteen pounds of scratch grains a day.

One hundred laying hens will consume about five to eight pounds of mash per day.

Four to five square feet of floor space should be allowed each laying hen in the poultry house.

It will cost from one dollar to one dollar and twenty cents to house each laying hen.

One nest should be allowed for every four laying hens.

Ten inches of perch room should be allowed the average bird.

When building grain bins one and one-quarter cubic feet will hold one bushel of grain. Two and one-quarter cubic feet will hold one bushel of corn on the cob. 


\section{INDEX}

Accounts, 335

Advertising, ways of, 336

Aërial birds, 23

Agricultural Colleges, addresses, 342

Alfalfa, 238

Alternating yards, 155

Ancona, 55

Andalusian, 79

Appetite, importance of, 266

Aquatic birds, 19

Artificial hatching, definition, 122

Aseel fowl, 35

Ash, in bird's body, 212

in feeds, 231

for laying hens, 257

Assimilation, definition, 218 organs of, 221

Association with poultry, 80

Atavism, 87

Aves, or birds, 15

Baijy chicks, method of shipping, 291

profits from, 279

seasons for, 279

Bantams, 79

Barley, 229

Beet pulp, 230

Beets, mangel, home-grown, 237

Beheading, method of, 286

Belle of Jersey, record of, 252

Bird, parts of, 353

Birds, aërial, 23

and animal life, 15

aquatic, 19

and bird life, 15

classification of, 19

composition of, 211

definition of, 15

description of, 16

feeding, 30

references on, 33

and success, 13

terrestrial, 22
Blood spots, 283

Bluebird's nest and eggs, 26

Bone, products of, 225

Books of reference, 340

Boys' and Girls' Poultry Clubs, 8 objects of, 10 present development of, 9 records and rules

Brahma, 62 for, 343

Bran and middlings (wheat), 227

Breed, definition, 37 selecting, 45

Breeding, definition, 84 for egg production, 88 factors'affecting, 85

laws of, 86

for meat, 90

pedigree, 91

problems of mating, 84

selling birds for, 279

for size, 90

stock, care of, 104

Breeds, classification of, 38 development of, 36 utility classification, 38

Broiler production, 276 seasons for, 275

Broilers, definition, 275 feeding of, 263

Brooder, chicks, feeding of, 243 houses, kinds of, 133

operation of, 136 points of, 133 putting chicks in, 137

Broodiness, of egg breeds, 50 of general purpose breeds, 70 of meat breeds, 61

Brooding, dangers in, 140 definition, 133

fresh air for, 140

temperature for, 138

Buckwheat, 228, 236

Buildings, arrangement of, 159 
Bumble foot, 313

Business, of poultry keeping, 332 principles of, 337 securing of, 336

By-products, 225, 280

Campine, 55

Canker, 310

Capons, 277

Carbohydrate feeds, 226

Carbohydrates, in feeds, 214 for flesh production, 265

Care of chicks, 118

Cartons for eggs, 285

Chicken pox, 310

Chicks, care of, after hatching, 118 development of, 108

feeding young, 138

protection from lice, 119

putting in the brooder, 137

rations for, 244

weaning, 120,140

Cholera, 315

Choosing a poultry farm, 151

Circulation, 153

City lot poultry house, 207

Class, definition of, 37

Classification of birds, 19

Clean feed, 306 houses, 302 yards, 305

Cleaning, method of, 303 old houses, 171

Cloaca, 99

Clubs, Boys' and 'Girls', 8

Cochin, 64

Colony brooder, 134 house material for, 146 plans for, 147 houses for young chicks, 145

Column system of keeping records, 335

Commercial fattening, 270 value, 82

Communication, 152

Community centers, schools as, 11

Composition, of bird's body, 211 of feeds, 213

Consumer, 294

Cooking eggs, 100

Cooling, eggs in incubator, 128 plucked poultry, 289
Corn, home-grown, 226, 234

Corner stones for success, 12

Cornish fowl, 66

Correlation, 87

Cottonseed meal, 226

Cramming, 269

Crate fattening, 268

Crop rotations for yards, 156

Crops, for green feed, 238

necessary to the poultryman, 239

Cross-bred birds, definition, 42

Crows, 321

Depluming mites, 319

Development of chick, 108

Diarrhœa, 312

Diary, 332

Digestible nutrients in feeds, 355

Digestion, definition, 218 work of, 219

Digestive organs, 221 tract, 219

Diseases, 308 classification of, 309 of the liver, 312

Disinfection, methods of, 304

Disposition, of egg breeds, 49 of general purpose breeds, 69 of meat breeds, 59

Distribution of poultry products, 294

Distributor, 294

Domestic fowl, 34

Dorking, 74

Drainage, 152

Dressed poultry, 286 score card, 351

Dropping boards, 173 platform, 189

Droppings, care of, 302

Dry fodders, 236

mash, for laying hens, 257

picking, 289

Dryness in poultry houses, 163

Ducks, 20

Dust boxes, 195

Dwarf Essex rape, 239

Economy, in housing, 167

in remodelling, 171

Egg breeds, 39, 48 
Egg breeds, broodiness in, 50

disposition, 49

feeding of, 51

hardiness, 50

maturity of, 50

production from, 51

size and appearance, 48 varieties, 51

function of, 94

production, effect on vitality, 252

feeding for, 88,251

profit from, 274

record, 333

score card, 352

Egg shape, 52

structure of, 94

Eggs as food, 99

classes of, 274

collection for hatching, 104

cooking of, 100

evaporation in, 95

formation of, 97

for market, 283

misshapen, 99

placing in incubator, 127

where produced in the United

States, 325

for the table, 273

testing of, 116

Elevation of fixtures, 188

Enemies, 317

Environment, factors of, 162

Exercise, feeding for flesh, 265

Exhibition, 77

Exports of poultry, 328

External parasites, 318

Facts for the poultry keeper, 358 Fancy, definition, 272

Farm classification of birds, 39

Fat, in bird's body, 212 in feeds, 215

Fattening commercially, 270

Fatty feeds, 230

Feathers, 17

parts of, 18

returns from sale of, 280

Feed, clean, 306 composition of, 213

for meat breeds, 61

stuffs, composition of, 355
Feed and success, 13

Feeds, animal, 235

classification of, 224

home-grown, 234

for poultry, 224

vegetable, 224

weight and volume, 357

Feeding, brooder chicks, 243

egg breeds, 51

chicks, 138

cost of feeding chicks, 245

for egg production, 251, 254

for flesh, objects, 263 principles, 265

general purpose breeds, 71

for growth, 242 principles, 246

at maturity, 249

standards, 356

young chicks, 148

Fence, ideal construction, 158

Fertility, 103

Fixtures, requirements of, 188

Flesh, feeding for, 263

Flicker's nest and eggs, 26

Flock diseases, 309

Floor, construction of, 182 remodelling, 172 space for birds, 166

Fowls, 277 domestic, 34

number in the United States, 324

Free range for young birds, 143

Fresh air for brooders, 140

houses for young chicks, 145

Frozen comb, 313

Gable roof house, 208

Gallus bankiva, 35

Gates, 158

Geese and swans, 20

General purpose breeds, 41 broodiness of, 70 disposition, 69

feeding, 71

hardiness, 70

maturity, 69

production from, 71

size, 68 
General utility breeds, definition, 68 varieties, 72

Gizzard, 219

Glossary of the parts of a bird, 353

Gluten meal, 226

Grain feeds, 234

for laying hens, 255

Grasses and green erops, 238

Green feed for young birds, 143 method of providing, 238

Grit for laying hens, 257

Grosbeak, Rose-breasted, at nest, 27

Growing chicks, feeding, 148

pullets, early care of, 142 rations for, 247

Growth, feeding for, 242

\section{Hamburg, 78}

Hardiness, of egg breeds, 50 of general purpose breeds, 70 of meat breeds, 61

Hatching, 109

eggs, 103

collection of, 104

importance of fertility, 290

prices of, 279

production of, 103

saving, 105

seasons of demand, 279

selection of, 106

shipping, 290

history of artificial, 122

and rearing, 94

Hawks, 321 records, 117,129

picture of young, 28

Healthy birds, how to secure, 301

Hen, points for sitter, 112

Hens' nests, 113

Heredity, 86

Herons, 22

Heron's nest and eggs, 23

Home-grown feed, 234

Hoppers, 193

Houdan, 56

House, material for, 179

small flock, 177

types, city lot poultry house, 207
House types, gable roof house, 209

long breeding house, 205 multiple unit house, 202 scratching shed house, 208

small-flock colony house, 201

Houses, area for birds, 166

cheapness, 167

development of types, 198

dryness in, 163

ideal plan, 167

interior furnishings, 188

location of, 151

materials for, 200

modern type, 199

principles of design, 162

protection from rats, 166

requirements of, 162

simplicity of, 167

temperature in, 166

types of, 198

Humidity in incubators, 127

Humming bird's nest and eggs, 25

Importance of poultry, 328

Incubation, care at hatching, 129

cooling eggs, 128

dangers of, 129

testing eggs, 128

Incubator, 122

care of, 126

care of lamp, 126

heat control, 127

humidity in, 127

place for, 124

placing eggs, 127

records, 129

requirements for, 124

Indigestion, 312

Infectious diseases, 314

Information, miscellaneous, about poultry, 358

Inspection trips, 8

Instruction, advice to teachers, 5 coördination with other subjects, 6

demand for, 1

methods of, 7

schedule, 3

in schools and colleges, 2 
Instruction, systematic, 2

Intensive brooding, 135

Internal parasites, 317

Investment, in the United States, 324

Killing poultry, 286

Langshan, 64

Laying, dry mash, 257

Leghorns, 51

Lice, 318

ridding of, 119

Linseed meal, 226

Litter, 195

care of, 303

Live poultry for market, 285

Liver diseases, 312

Location of houses, the problem, 151

ideal, for poultry houses, 155

Long breeding house, 205

Lumber terms defined, 179

Malay fowl, 35

Management of young stock, 148

Mangel beets, 237

Manure, as a salable product, 281

Market conditions, improvement of, 297

egg, score card, 352

eggs, quality, 283

poultry, kinds of, 275 shipping, 286

Marketing poultry, principles of, 291

Markets, 151

kinds of, 294

Materials for houses, 200

Mating defined, 84

Matings, importance of, 88

Maturity, of egg breeds, 50 of general purpose breeds, 69 of meat breeds, 59

Meat breeds, 41,58 broodiness of, 61 definition of, 58 disposition of, 59 feed for, 61 hardiness of, 61 maturity, 59 production from, 61
Meat breeds, size of, 58 varieties of, 62

feeds, 224

production, breeding for, 90 centers of, 327

products, composition, 225

scrap, 225

shape, 60

Mill-products, composition, 226

Minks, 321

Minorca, 53

Miscellaneous breeds, definition, 77

Mites, 319

Money transactions, 335

Mother hen, uses of, 112

Moulting, 17

Mouth, 219

Multiple unit house, 202

Nest for sitters, 113

Nests, 173, 191 homemade, for birds, 29 making, 114

Night rations for layers, 259

Nuthatch, 28

Nutrients, definition, 218

Nutrition, definition, 218 organs of, 221

Oats, 228,236

Organization, 331 in teaching, 8

Oriole's nest, 25

Orpington, 74

Ovary, 97

Oviduct, 98

Oyster shell, 231.

Parasites, 317

Partnership in poultry keeping, 294

Pedigree, 91

Pelicans, brown, 21

Pen fattening, 266

Perches, 173, 189

Picking, methods of, 287

Pigeons, 22

Plates, erection of, 183

Pleasure from poultry, 79

Plymouth Rocks, 72

Polish, 77

Portability of fixtures, 188 
Posts, erection of, 182

Potatoes, 230

Poultry, classification, 36 definition of, 36

distribution in the United States, 324

farm, choosing same, 15

feeds, 224

house, building, 177

industry, 324

for market, 275

keeper and success, 12

Poultry keeping, advantages of, 1 as a business, 332

Preparing the production, 283

Prepotency, 87

Principles, of business, 337 of house design, 162

Production, from egg breeds, 51 factors affecting, 14

from general purpose breeds, 71

from meat breeds, 61

Product, preparation of, 283 variety of, 271

Prolapsus, 312

Protein, in the body, 212

feeds, 224

in feeds, 213

in laying rations, 255

when feeding for flesh, 265

Pullets, as a salable product, 280

Pure bred birds, definition, 43 breeds, value of, 44

Quail and grouse, 22

nest and eggs, 23

Rafters, ways to construet, 181

Rat-proof houses, 166

Rats, 321

Rations, for baby chicks, 139

for chicks, 244

for crate fattening, 269

for fattening fowls, 268

for finishing broilers, 266

for growing poultry, 247

for laying hens, 257

requirements of, 356

for young chicks, 148

Rearing, object of, 142

Records, 332
Records, Boys' and Girls' Poultry Clubs, 346 of incubation, 129

Reference books, 340

Remodelling of house, 170,175

Reproduction, 19

Retail markets, 295

Rhode Island Reds, 73

Roasters, kinds of, 276

Roasting chicken, definition, 276 feeding of, 263

Roof, construction of, 185 repairing, 172

Roofs, types, 199

Root crops, home-grown, 237

Rotation of crops for yards, 156

Round worms, 317

Roup, 310

Runners, construction of, 181

Sanitation, 301

Scalding, 289

Scaly leg mites, 320

Schedule of instruction, 3

Score cards, 349

Scratch rations for layers, 259

Scratching shed house, 208

Selection of hatching eggs, 106

Shade for young chicks, 144

Shipping, dressed poultry, 290

market eggs, 285

methods of, 298

Simplicity in house, 167

Sitters, management of, 115

Sitting the hen, 114

Size, of egg breeds, 48

of general purpose breeds, 68 of meat breeds, 58

Skunks, 321

Slope, 153

Small-flock colony laying house, 201

house, 177

Sonora County, California, 326

Sour milk, as a feed, 256

S.oy bean meal, 226

Sparrows, nest and eggs, 25

Special matings, importance of, 88

Sports, 87

Standard classification, of breeds, 38

defined, 39 
Standard classification, score card, 349

Standards for feeding, 356

Starting poultry keeping, 43

Sticking, method of, 286

Stock, for foundation, 44 securing first, 44

Studding, erection of, 184

Success, foundation for, 12

Succulence, source of, 232

Sunlight in houses, 164

Surroundings and success, 13

Swallow, Barn, and nests, 26

Tree, and nesting stump, 26

Table eggs, 273

Tape-worm, 317

Temperature for brooder, 138 of houses, 166

in incubator, 125

Terms of lumber defined, 179

Terns, Royal, on nesting site, 20

Terrestrial birds, 22

Testing eggs, 116

Theft, 322

$$
\text { in incubator, } 128
$$

Thrush's, nest and eggs, 25

Transportation, 152

Trap nests, 192

Tuberculosis, 314

Turkeys, Bronze, 24

White Holland, 24

Turning eggs in the incubator, 128

Type, definition, 37

Unique features, 81

Utility classification, 38
Utility classification, definition, 39,272 score card, 350

Variation, 86

Varieties, development of, 36

Variety, definition, 37

Vegetation, 154

Ventilation in houses, 164

Ventilators for houses, 165

Vineland, New Jersey, egg center, 327

Volume of feeds, 357

Walls, erection of, 184 repairing, 172

Warbler, Hooded, nest, etc.,27

Water, 193 in body, 213

in feeds, 213,231

in laying rations, 255

Weaning chicks, 120,140

Weasels, 321

Weight of feeds, 357

Wheat, 227 home-grown, 235

Wholesale markets, 296

Wire for fences, 158

Wyandottes, 74

Yards, alternating, 155 clean, 305 crop rotation for, 156 location of, 151 where to use, 155

Young stock, care at maturity, 149 management of, 148 






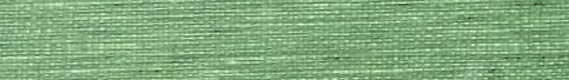

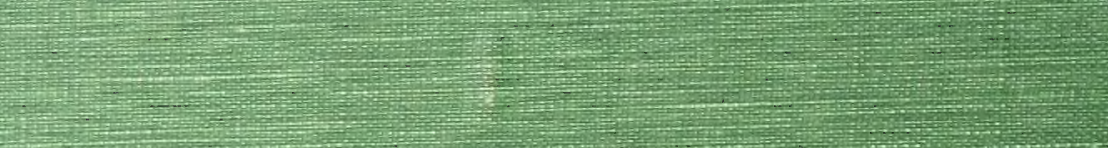

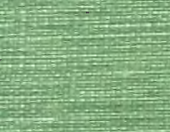

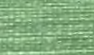

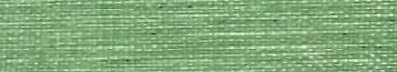

$\cos ^{x^{2}}$

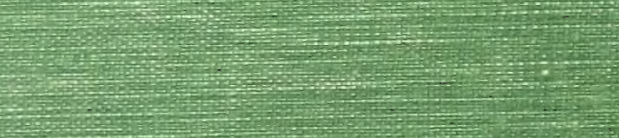

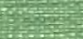

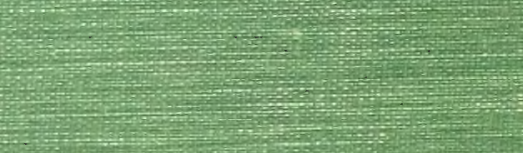

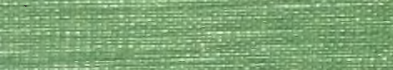

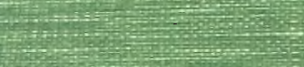

Hing

(1)

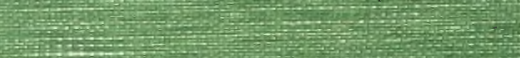

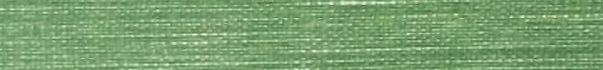

